\title{
PROBCON-HDW: A Probability and Consequence System of Codes for Long-Term Analysis of Hanford Defense Wastes
}

M. G. Piepho

T. H. Nguyen

December 1988

Prepared for the U.S. Department of Energy under Contract DE-AC06-76RLO 1830

Pacific Northwest Laboratory Operated for the U.S. Department of Energy by Battelle Memorial Institute 


\title{
DISCLAIMER
}

This report was prepared as an account of work sponsored by an agency of the United States Government. Neither the United States Government nor any agency thereof, nor Battelle Memorial Institute, nor any or the r employees, makes any warranty, expressed or implied, or assumes any legal liability or responsibility for the accuracy, completeness, or usefulness of any information, apparatus, product, or process disclosed, or represents that its use would not infringe privately owned rights. Reference herein to any specific commercial product, process, or service by trade name, trademark, manufacturer, or otherwise doe:s not necessarily constitute or imply its endorsement, recommendation, or favoring by the United States Covernment or any agency thereof, or Battelle Memorial Institute. The views and opinions of authors expressed herein do not necessarily siate or reflect those of the United States Government or any agency thereof.

\author{
PACIFIC NORTHWEST LABORATORY \\ operated by \\ BATTELLE MEMORIAL INSTITUTE \\ for the \\ UNITED STATES DEPARTMENT OF IENERGY \\ under Contract DE-ACO6-76RLO 1830
}

\begin{tabular}{|c|c|}
\hline \multicolumn{2}{|c|}{ Printed in the United States of America } \\
\hline \multicolumn{2}{|c|}{ Avalable from } \\
\hline \multicolumn{2}{|c|}{ National Iechnical Iniormation Service } \\
\hline \multicolumn{2}{|c|}{ United States Departmenl of Commerce } \\
\hline \multicolumn{2}{|c|}{5285 Port Roval Koad } \\
\hline \multicolumn{2}{|c|}{ Springfield, Virginia 2216.1} \\
\hline \multicolumn{2}{|c|}{ NTIS Price Codes } \\
\hline \multicolumn{2}{|c|}{ Microfiche A01 } \\
\hline \multicolumn{2}{|c|}{ Printed Copy } \\
\hline & Price \\
\hline Pages & Codes \\
\hline $001-025$ & $\mathrm{~A} 02$ \\
\hline $026-050$ & A03 \\
\hline $051-075$ & $\mathrm{~A} 04$ \\
\hline $076-100$ & A0s \\
\hline $107-125$ & $A 06$ \\
\hline $726-150$ & $\mathrm{~A} \theta 7$ \\
\hline $151-175$ & $\mathrm{~A} 08$ \\
\hline $176-200$ & $A 09$ \\
\hline 201.225 & A10 \\
\hline $226-250$ & A11 \\
\hline $251-275$ & $\mathrm{~A} 12$ \\
\hline $276-300$ & $\mathrm{~A}+3$ \\
\hline
\end{tabular}


PNL -6656

UC -70

PROBCON-HDW: A PROBABILITY

AND CONSEQUENCE SYSTEM OF

CODES FOR LONG-TERM ANALYSIS

OF HANFORD DEFENSE WASTES

M. G. Piepho

T. H. Nguyen

December 1988

Prepared for

the U.S. Department of Energy

under Contract DE-AC06-76RL0 1830

Pacific Nor thwest Laboratory

Richland, Washington 99352 


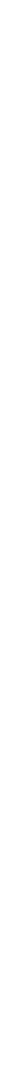

. . 


\section{ABSTRACT}

The PROBCON-HDW (PROBability and CONsequence analysis for Hanford defense waste) computer code system calculates the long-term cumulative releases of radionuclides from the Hanford defense wastes (HDW) to the accessible environment and compares the releases to environmental release limits as defined in 40 CFR 191. PROBCON-HOW takes into account the variability of input parameter values used in models to calculate HDW release and transport in the vadose zone to the accessible environment (taken here as groundwater). A human intrusion scenario, which consists of drilling boreholes into the waste beneath the waste sites and bringing waste to the surface, is also included in PROBCON-HDW. PROBCON-HDW also includes the capability to combine the cumulative releases according to various long-term $(10,000$ year) scenarios into a composite risk curve or complementary cumulative distribution function (CCDF). The system structure of the PROBCON-HOW codes, the mathematical models in PROBCON-HDW, the input files, the input formats, the command files, and the graphical output results of several HDW release scenarios are described in the report. 
.

in 


\section{SUMMARY}

The PROBCON-HDW system of computer codes was written to perform a probability and consequence analysis of the Hanford defense waste (HDW) disposal alternatives' performances over the long tem of 10,000 years as part of the Hanford Defense Waste Environmental Impact Statement (HDW-EIS 1987). The PROBCON-HDW code system consists of six computer programs: PROBCON, CMCCDF, COMHUM, PRAPLT, WBCCDF, and WBPLOT. Each program is described in this document. All programs were developed in FORTRAN on a Digital Equipment Corporation VAX $11 / 780$ computer. The PROBCON-HDW system is an analysis tool that permits quantitative comparison of the potential long-term impacts of the HDW relative to release limits as defined by the U.S. Environmental Protection Agency (EPA) 40 CFR 191.13 standard.

PROBCON-HDW uses the Monte Carlo approach, in which key model parameters are sampled from probability density functions and the deterministic perfornance assessment models are run once for each set of parameter values sampled. Since no confirmed basis is available for the values of such key parameters as retardation coefficients for nuclide transport in soils and protective barrier parameters, it is necessary to assume such values in order to perform the analysis called for in 40 CFR 191.13. Until more experimental data are available, the calculations performed by PROBCON-HDW are useful for illustration of the relative features of each disposal alternative. However, the calculational results from PROBCON-HDW are not intended to be used to demonstrate compliance, or lack thereof, with the EPA standard.

The HDW disposal alternatives that can be analyzed by PROBCON-HDW consist of the in-place stabilization and disposal alternative (waste is disposed of near surface), the geologic alternative (high-level waste is removed for disposal in a geologic repository, and low-activity waste residuals are disposed of near surface), and the reference alternative (a combination of the previous two alternatives in that some waste is removed for disposal and some waste is disposed of near surface). The Tong-term performances of the disposal alternatives can also be compared to the performance of the no disposal action alternative (continued storage). 
PROBCON-HDW Calculates the EPA release limits for each radionuclide. The limits are based on the limits shown in Table I of 40 CFR 191, the number of metric tons of heavy metal represented in waste, and the fuel burnup. PROBCON-HDW further determines two sets of release limits. One set (total release limits) is based on the total waste activity; the other set (partitioned release limits) is based on the remaining amount of radionuclide inventory that is disposed of near surface. The amount of radionuclide activity that potentially reaches the accessible environment is then calculated by PROBCON-HDW for each radionuclide and is divided by the appropriate release limit to form a release ratio. The release ratios for all radionuclides included in PROBCON-HDW's data base are summed to form the consequence measure for comparative analyses. Since a Monte Carlo approach is used in PROBCONHDW, a distribution of summed release ratios is obtained for each scenario.

The default release scenarios include two different distributions of recharge values to the groundwater: one distribution each for a current climate and a much wetter climate. The default scenarios also include protective barrier failures and drilling intrusions. The barrier failures are assumed to occur 500 years after disposal.

Two major release mechanisms are modeled in PROBCON-HDW. One is the leaching of the waste source followed by transport to the groundwater. The other is an intrusive mechanism, drilling, by which the radioactive materials are brought to the surface. Five leaching mechanisms are included:

- adsorption-controlled release

- solubility-controlled release

- dissolution-controlled release (linear release)

- diffusion-controlled release

- hybrid releases (combinations of the above).

The type of release is governed principally by physical and chemical characteristics of the waste form.

The PROBCON-HDW results are summarized as a complementary cumulative distribution function (CCOF) of the release-ratio consequences. Sample CCDFs are shown in Section 3.3. 


\section{ACKNOWLEDGMENTS}

The authors received a great deal of assistance from a number of individuals at the Pacific Northwest Laboratory. The authors would like to acknowledge Clarence Oster for doing much of the original coding, Iral Nelson for providing the initial support and enthusiasm for getting the programs started and finished, and Phil Bramson for providing the support to get the PROBCON-HDW system documented. THe authors are also appreciative of the effort provided by Nancy Waugh and Lori Nelson in typing and preparing the final documentation. 


\section{CONTENTS}

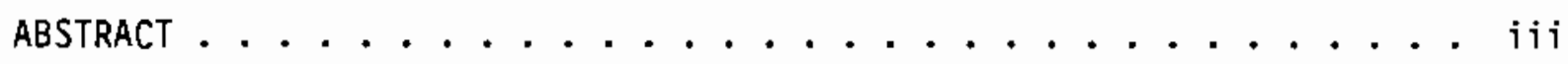
SUMMARY .............................. v

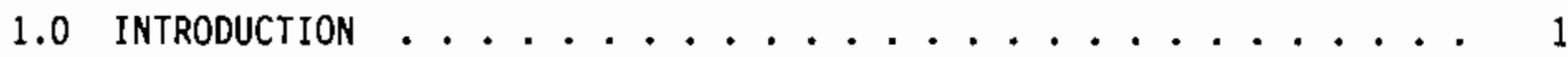

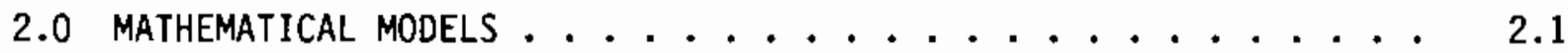

2.1 PROBABILITY RISK ANALYSIS METHODOLOGY . . . . . . . . . 2.1

2.2 LONG-TERM NATURAL RELEASE MEChaniSMS . . . . . . . . . 2.4

2.2.1 Dissolution-Controlled Release . . . . . . . 2.4

2.2.2 Solubility-Controlled Release . . . . . . . . 2.5

2.2.3 Adsorption-Controlled Release . . . . . . . . 2.7

2.2.4 Diffusion-Controlled Release . . . . . . . 2.8

2.2.5 Combination Releases . . . . . . . . . . 2.9

2.3 HUMAN INTRUSION RELEASE MEChANISMS . . . . . . . . . . . 2.10

3.0 DESCRIPTION OF SYSTEM AND COMPUTER CODES . . . . . . . . . 3.1

3.1 SYSTEM OF COMPUTER CODES . . . . . . . . . . . . . . . 3.1

3.1.1 PROBCON Code ........................ 3.1

3.1 .2 COMHUM Code .................. 3.1

3.1.3 CMCCDF Code ................. 3.3

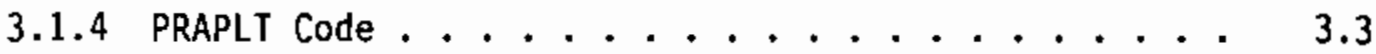

3.1 .5 W8CCDF Code ................. 3.3

3.1.6 WBPLOT Code . . . . . . . . . . . . . 3.3

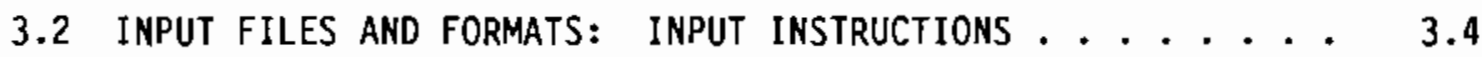

3.2.1 PROBCON Input ................ 3.4

3.2.2 CMCCDF Input ................ 3.19 
3.2 .3 COMHUM Input . . . . . . . . . . 3.20

3.2 .4 PRAPLT InPut ................... 3.20

3.2 .5 W8CCDF Input .............. 3.21

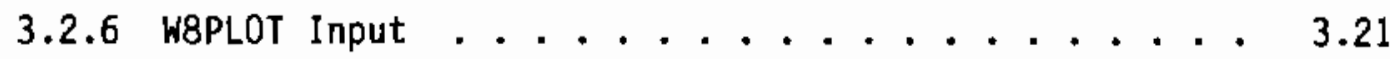

3.3 OUTPUT FILES . . . . . . . . . . . . . . 3.22

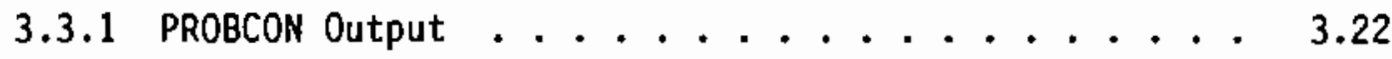

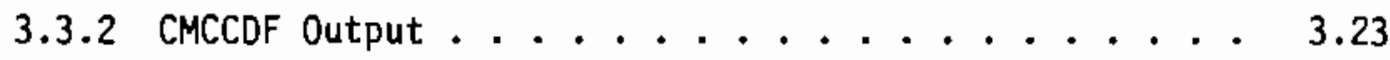

3.3 .3 COMHUM Output . . . . . . . . . . 3.23

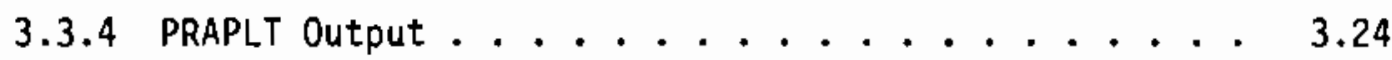

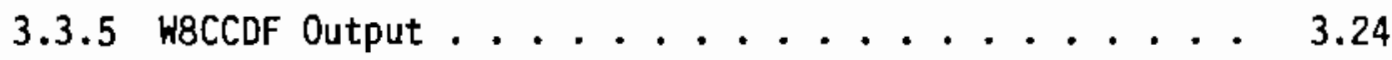

3.3 .6 WBPLOT Output . . . . . . . . . . 3.24

3.4 COMMAND FILES FOR CODE EXECUTION . . . . . . . . 3.24

3.4.1 PROBCON Command File ................ 3.24

3.4 .2 CMCCDF Command File................ 3.27

3.4 .3 COMhUM Conmand File . . . . . . . . . 3.28

3.4.4 PRAPLT Conmand File . . . . . . . . . 3.28

3.4 .5 W8CCDF Command File . . . . . . . . . 3.28

3.4 .6 W8PLOT Command File . . . . . . . . . 3.29

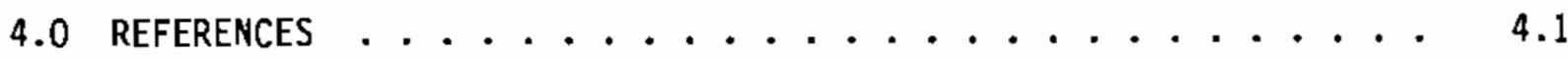

APPENDIX A - ENVIRONMENTAL RELEASE LIMITS (40 CFR 191) . . . . . A.1

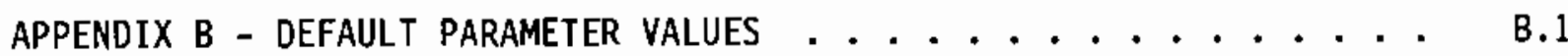

APPENDIX $C$ - PROBCON CODE LISTING .............. c.1

APPENDIX D - CMCCDF CODE LISTING . . . . . . . . . D.1

APPENDIX E - COMHUM CODE LISTING . . . . . . . . . . E. 1

APPENDIX F - PRAPLT CODE LISTING . . . . . . . . . . F.I 
APPENDIX G - WBCCDF CODE LISTING . . . . . . . . . . . G.I
APPENDIX H - WBPLOT CODE LISTING . . . . . . . . . . H.I

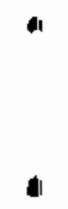

. 


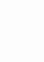

i.

'

$-$ 


\section{FIGURES}

2.1 Natural Release Simulation Model in PROBCON-HDW for Calculating Probabilities and Consequences . . . . . . . . . . . . 2.2

2.2 Probabilistic Scenario Event Tree . . . . . . . . . . 2.3

2.3 Drywell Storage Facility Canister Area for Borehole Model . . . . 2.16

3.1 PROBCON-HDW System . . . . . . . . . . . . . . 3.2

3.2 Assumed Probability Density Function of the $K_{d}$ Values for Plutonium in Single-Shell and Double-Shell Tank Waste . . . . 3.25

3.3 Release-Ratio Curves for Alternatives for the Scenario of Current Climate, No Barrier Failure, and 400-Year Intrusion . . 3.25

3.4 Preliminary Composite CCDFs for All Alternatives Based on All Scenarios for Wastes Disposed of Near Surface (DOE 1987) . . . .

\section{TABLES}

2.1 Annual Probabilities of Boreholes in Waste Categories and WasteClass Surface Areas . . . . . . . . . . . . . . . 2.14

3.1 Indices for Nuclides . . . . . . . . . . . . . 3.8

3.2 Indices for Waste Disposal Alternatives . . . . . . . . 3.8

3.3 Indices for Waste Categories . . . . . . . . . . . . 3.9

3.4 Option Card Summary . . . . . . . . . . . . . 3.18

A.1 Fractions of Existing and Future Radionuclide Inventories Disposed of Near Surface for Geologic Disposal and Reference Alternatives ...................... A.4

A.2 40 CFR 191 TabTe 1 Values and Partioned Release Limits (Equation A.1) for Each Radionuclide Disposed of Near Surface for Each Alternat ive ................ A.5

B.1 Total Radionuclide Inventories . . . . . . . . . . . B.1

B.2 Summary of Probability Density Functions and Corresponding Parameters 
1.

- 
PROBCON-HDW: A PROBABILITY AND CONSEQUENCE SYSTEM OF CODES

FOR LONG-TERM ANALYSIS OF HANFORD DEFENSE WASTES

\subsection{INTRODUCTION}

The PROBCON-HDW system of codes was developed at Pacific Northwest Laboratory (a) for use in the Hanford defense waste environmental impact statement, or HDW-EIS (DOE 1987). PROBCON-HDW was motivated by the 40 CFR 191.13 standard (EPA 1985). This standard requires not only a consequence analysis, but also a probabilistic analysis. The consequence defined by the standard is the sum of ratios of each radionuclide's release from the waste disposal site to the accessible environment during the 10,000 years after disposal over each radionuclide's release limits. The release limit is the allowed amount of activity that can be released to the accessible environment during the 10,000 years after disposal. The consequence $C$ is defined as

$$
C=Q_{1} / R L_{1}+Q_{2} / R L_{2}+Q_{3} / R L_{3}+\ldots+Q_{N} / R L_{N}
$$

where $\quad C=$ the release-ratio consequence

$$
\begin{aligned}
Q_{n}= & \text { the quantity of the } n \text {th nuclide released to the accessible } \\
& \text { environment over the } 10,000 \text { year time period following disposal } \\
R L_{n}= & \text { release limit for the } n \text {th radionuclide (EPA 1985) } \\
n= & \text { radionuclide index and has integer values from } 1 \text { to } N \\
N= & \text { the total number of radionuclides considered in analysis. }
\end{aligned}
$$

The release limit for each radionuclide is based on the values in Table 1 of

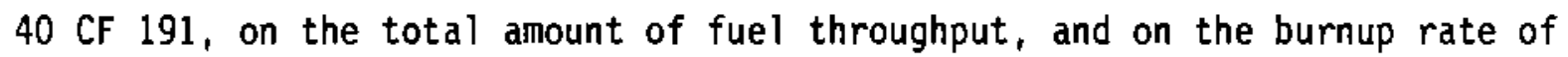
the fuel. The basis of the release limit derivations for each alternative of Hanford defense waste is described in Appendix $A$ of this report.

(a) Operated by Battelle Memorial Institute for the U.S. Department of Energy under Contract DE-ACO6-76RLO 1830. 
The 40 CFR 191.13 standard states that the probability (P) of the releaseratio consequence $(C)$ in excess of $1(C>1)$ should be less than 0.1 , as shown in Equation (1.2):

$$
P(C>1)<0.1
$$

In other words, the 90th percentile value of C's distribution should not exceed 1. In addition, the standard requires that the probability of the releaseratio consequence in excess of $10(C>10)$ should be less than 0.001 , as shown below:

$$
P(C>10)<0.001
$$

In other words, the 99.9 th percentile value of C's distribution should not be greater than 10 .

The PROBCON-HDW system is operational on a DEC VAX 11/780 computer with the VMS operating system. PROBCON-HDW was written for the performance assessment of the Hanford defense wastes, but could be easily modified for other nearsurface waste disposal systems that require a probability and consequence analysis.

The mathematical models used in PROBCON-HDW for risk analysis and the releases to the accessible environment (both natural and human intrusion releases) are described in Section 2.0, Mathematical Models. The computer codes in the PROBCON-HDW system are described in Section 3.0, which includes a system flow chart, a listing of the input and output files, the input description for the main user input file, and examples of run command files. Section 3.3 contains example graphical output of PROBCON-HDW. Appendix A describes the derivation of the release limit values for each alternative. Appendix B summarizes the parameter values used in the HDW-EIS (DOE 1987); these parameter values are the default values used in PROBCON-HDW. The listings of the computer programs in the PROBCON-HDW system are shown in the Appendices C through $\mathrm{H}$. 


\subsection{MATHEMATICAL MODELS}

The mathematical models used in PROBCON-HDW are described in this section. The probabilistic risk analysis methodology used by PROBCON-HDW is described first, to set the stage for the mathematical models of release mechanisms that follow. The risk analysis method acts as an integrator and ties everything together.

\subsection{PROBABILITY RISK ANALYSIS METHODOLOGY}

The PROBCON-HDW system utilizes a probabilistic risk analysis (PRA) method that is based on a scenario analysis defined by event trees. A chain of events along each branch of an event tree defines the scenario that is represented by that branch. A Monte Carlo simulation of each scenario's consequences is performed; i.e., the parameters with uncertainty associated with their values are sampled many times, and a range of consequences is calculated (see Figure 2.1), where one consequence value is obtained for each set of sampled parameter values. The range of consequence values is shown graphically, with the consequence values represented along the $x$-axis and the complementary cumulative distribution function (CCDF) of the consequence values represented along the $y$-axis.

The CCDF of a consequence value is the probability that a consequence is greater than or equal to the consequence value. The CCDF curve is sometimes called the "risk curve." Since the consequences calculated by PROBCON-HOW are defined as the ratio of calculated releases to the accessible environment to the amount of release allowed by 4D CFR 191 (i.e., as release ratios), the CCDF curve is referred to here as the release-ratio curve or, more simply, the release curve.

A release curve is calculated for each branch or scenario on the scenario event tree. As an example, Figure 2.2 shows an event tree representing eight scenarios; these scenarios were assumed in the HDW-EIS (DOE 1987) and they are used to illustrate the capabilities of PROBCON-HDW. After a release curve is calculated for each scenario, all of the curves are summed, with the probability of each scenario used to weight each scenario as shown in Equation (2.1): 


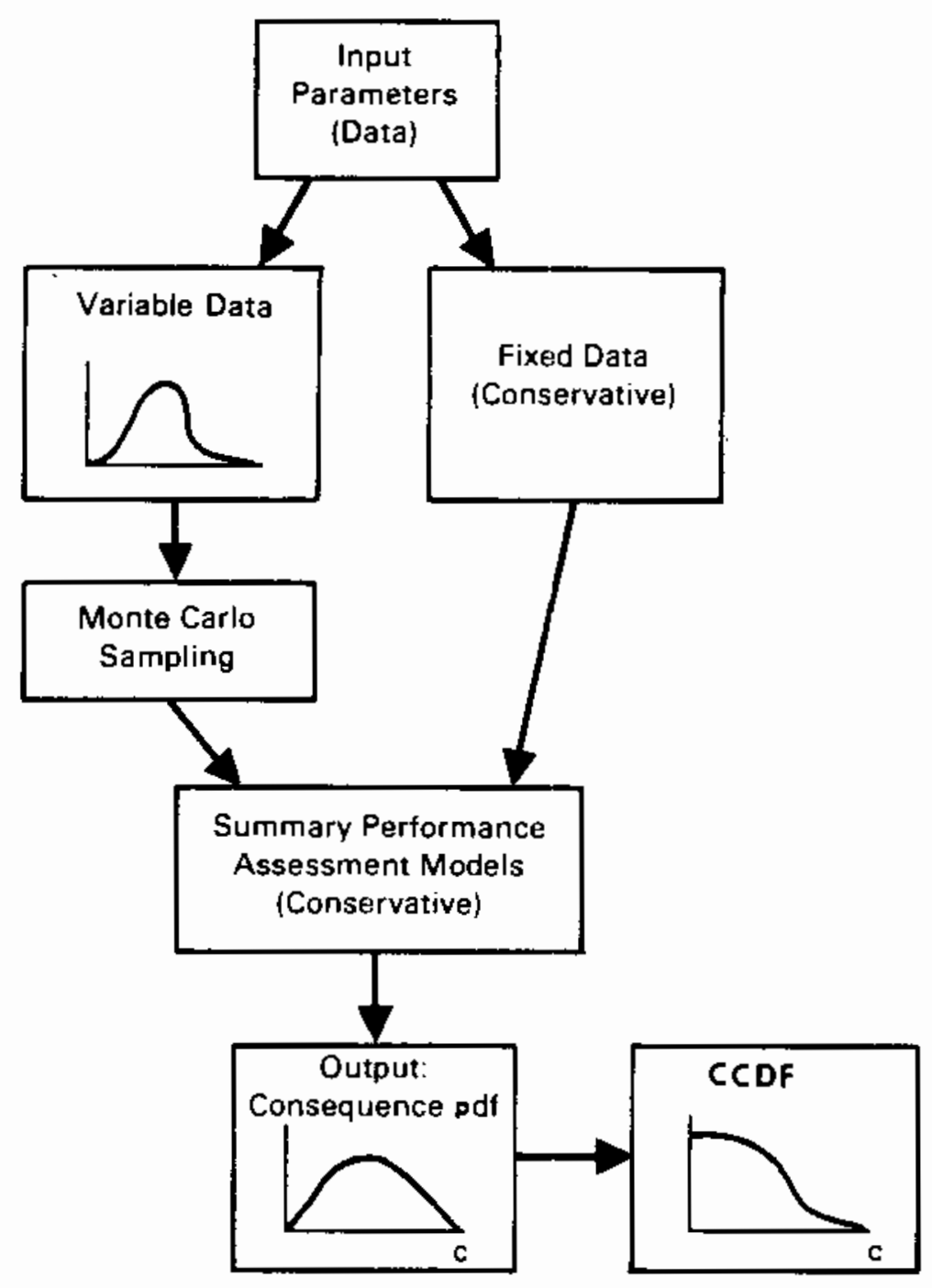

FIGURE 2.1. Natural Release Simulation Model in PROBCON-HDW for Calculating Probabilities and Consequences (DOE 1987)

$$
\text { Composite } \operatorname{CCDF}(C)=\sum_{j} P\left(S_{j}\right) \cdot \operatorname{CCDF}\left(C \mid S_{j}\right)
$$

where $\operatorname{CCDF}\left(C \mid S_{j}\right)$ is the release curve or CCDF for scenario $S_{j}$ ( $j$ is the scenario index), and $P\left(S_{j}\right)$ is the probability of the scenario occurring over a defined time period (in this case, 10,000 years). Of course, by probability theory the sum of scenario probabilities must equal 1.0 as shown in Equation (2.2). 


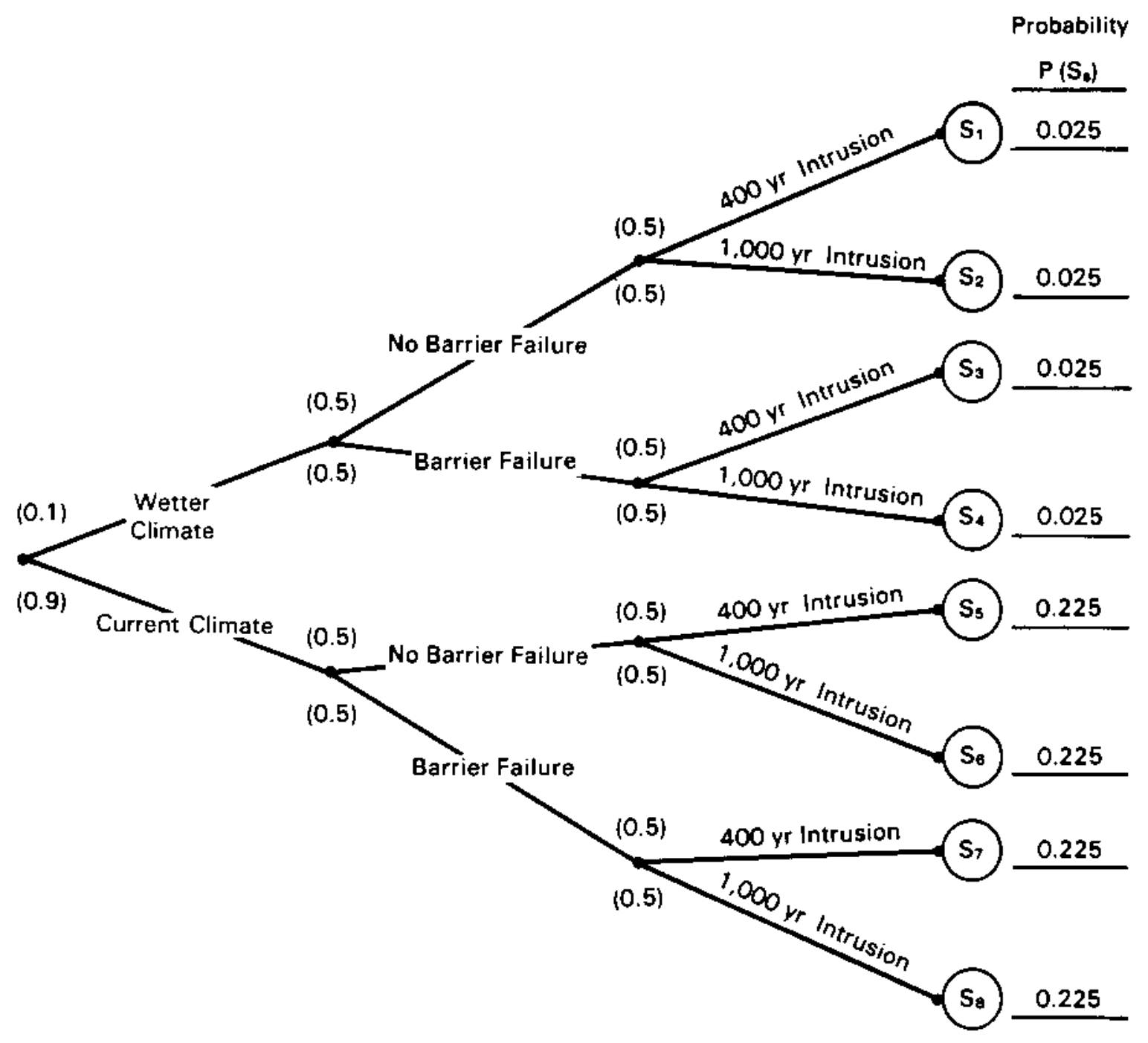

FIGURE 2.2. Probabilistic Scenario Event Tree (DOE 1987)

$$
\sum_{j} P\left(S_{j}\right)=1.0
$$

In the PROBCON-HDW system, the scenario probabilities can be varied. In fact, since there is a chance of no release (i.e., 100\% containment), the scenarios that are included in the release analys is do not require their probabilities 
to add to 1.0. In other words, Equation (2.2) includes all the release scenarios and the scenario with no release.

\subsection{LONG-TERM NATURAL RELEASE MECHANISMS}

The natural release mechanisms in the PROBCON code include the following types: 1) dissolution-controlled release, 2) solubility-controlled release, 3) adsorption-controlled release, 4) diffusion-controlled release, and 5) a combination of the above releases. Each waste form is assigned only one release mechanism except when the scenario includes a barrier failure for a fraction of the waste form. In that case, the fraction with barrier failure may have a different release model than the fraction without a barrier failure. For example, for intact barriers, the diffusion-controlled release would apply; however, for the portion where a barrier admitted water, the release may be controlled by dissolution, solubility, or adsorption.

\subsubsection{Dissolution-Controlled Release}

The dissolution-controlled release process (linear-release model) is used for calculating the release of radionuclides from existing and future grout waste for postulated protective barrier failures that result in infiltration of water. The linear release model assumes that infiltrating water directly contacts the waste form, becomes saturated with the dissolving chemicals and radionuclides in the waste, and carries the entire solution downward. The activity in curies of nuclide $n$ reaching the groundwater per year, $Q_{n}{ }^{\prime}$, is given for grout by the following equation (DOE 1987, Appendix P):

$$
\begin{gathered}
Q_{n}^{\prime}=Q_{0 n} \cdot\left[\exp \left(-\lambda_{n} \cdot t\right] / T_{L}\right. \\
\text { for } T_{I}<t<T_{F}
\end{gathered}
$$

where $\lambda_{n}=$ the radioactive decay constant, $0.693 /$ half-life, $\mathrm{yr}^{-1}$, of the ntr radionuclide

$$
Q_{0 n}=\text { the initial inventory of nuclide } \mathrm{n}, \mathrm{Ci}
$$


$T_{I}=$ minimum of $T_{n}+T_{H}$ and 10,000 years = initial arrival time of radionuclide $n$ to groundwater; 10,000 yrs is the time period of interest

$T_{F}=$ minimum of $T_{n}+T_{H}+T_{L}$ and 10,000 years (for grout, 10,000 years is always the minimum) = final arrival time

$T_{H}=$ the holdup time before leaching starts (taken as 505 years from the year 1995 for barrier failure cases)

$T_{n}=$ the nuclide travel time from waste site to groundwater, year

$T_{L}=$ the time required to dissolve (leach) all of the radionuclides from the waste form, year $(14,000$ years is used for grout waste) .

Integrating the release rate [Equation (2.3)] over time from the initial radionuclide arrival time at the groundwater, $T_{I}$, to the time of final radionuclide arrival, $T_{F}$, yields the following expression for the activity in curies of nuclide $n$ accumulated in the groundwater under the waste sites over the next 10,000 years:

$Q_{n}($ Dissolution $\left.)=Q_{0 n} \cdot \exp \left(-\lambda_{n} \cdot T_{I}\right) \cdot\left[1-\exp \left(-\lambda_{n} \cdot T_{D}\right)\right] / T_{L} \cdot \lambda_{n}\right)$

where $T_{D}=T_{F}-T_{I}$. If $T_{D}=0$, then $Q_{n}=0$. Equation (2.4) is used for onty the grout waste for scenarios with a barrier failure.

\subsubsection{Solubility-Controlled Release}

The solubility-controlled release model is used here to model the radionuclide release from the single-shell tank waste and the double-shell tank waste residuals to the groundwater. The solubility-controlled release assumes that the solute (radionuclide) concentration remains constant (except for radionuclide decay) in the waste form. The activity in curies of radionuclide $n$ reaching the groundwater per year, $Q_{n}^{\prime}$, at time $t$, for the solubility-controlled release is given by

$$
Q_{n}^{\prime}=A_{w} \cdot q \cdot C_{n} \cdot C_{v} \cdot \exp \left(-\lambda_{n} \cdot t\right)
$$




$$
\text { for } \mathrm{T}_{\mathrm{I}}<\mathrm{t}<\mathrm{T}_{\mathrm{F}}
$$

where $A_{W}=$ surface area of waste for waste class $W, \mathbf{k m}^{2}$

$q=$ annual recharge infiltrating waste and reaching groundwater, $\mathrm{cm} / \mathrm{yr}$

$C_{n}=$ fixed maximum concentration of radionuclide $n$ in tank waste, $\mu C i / L$

$C_{v}=$ units conversion factor $=10\left(10\right.$ liters $\left.=1 \mathrm{~m}^{2} \mathrm{~cm}\right), \mathrm{L} / \mathrm{m}^{2} \mathrm{~cm}$;

$\lambda_{n}=$ radioactive decay constant, $1 / y r$

$T_{I}=$ initial arrival time to groundwater = minimum of $T_{n}+T_{H}$ and 10,000 years

$T_{n}=$ nth radionuclide travel time from waste site to groundwater, yr

$T_{H}=$ holdup time before leaching starts [taken as 505 years for barrier failure (the year 2500), and 155 years for no barrier (the year 2150)]

$T_{F}=$ minimum of $T_{I}+T_{R}$ and 10,000 years = final arrival time to groundwater

$T_{R}=$ time duration of solubility-controlled release, year, and is given by

$$
T_{R}=\ln \left[Q_{O n} \cdot \lambda_{n} \cdot \exp \left(-\lambda_{n} \cdot T_{H}\right) /\left(A_{W} q C_{n} C_{v}\right)+1\right] / \lambda_{n}
$$

where $\ln$ is the natural logarithm (see Appendix P of DOE 1987).

Integrating the arrival rate of radionuclide $n$ to the groundwater [Equation (2.5)] over time, from the initial arrival time, $T_{I}$, to the final arrival time, $T_{F}$, yields the following integrated release to the groundwater:

$$
\begin{gathered}
Q_{n} \text { (solubility) }=A_{W} \cdot q \cdot C_{n} \cdot C_{v} \cdot \exp \left(-\lambda_{n} \cdot T_{I}\right) \\
\cdot\left\{1-\exp \left[-\lambda_{n} \cdot\left(T_{F}-T_{I}\right)\right]\right\} / \lambda_{n}
\end{gathered}
$$


If $T_{I}=T_{F}$, then $Q_{n}=0$.

\subsubsection{Adsorption-Controlled Release}

An adsorption-controlled release model is used here to model the radionuclide release from the double-shell tank wastes for the no action alternative. The adsorption-controlled release assumes that infiltrating water comes into contact with the waste form and carries the solute (radionuclides) downward. The concentration of the solute varies with time, even if the radioactive decay is negligible. The adsorption-controlled release model, which is most appropriate for the liquid waste form, was used under the no action alternative for double-shell tank wastes, which are primarily liquids. The activity in curies of radionuclide $n$ reaching the groundwater per year, $Q_{n}^{\prime}$ ' for the adsorption-controlled release is given by

$$
\begin{aligned}
& Q_{n}^{\prime}=\lambda_{\operatorname{Ln}} \cdot Q_{O n} \cdot \exp \left[-\lambda_{n} \cdot t-\lambda_{L n} \cdot\left(t-T_{H}-T_{n}\right)\right] \\
& \quad \text { for } T_{I}<t<10,000
\end{aligned}
$$

where $\lambda_{L n}=$ leach rate parameter, $1 / y r,\left[q \cdot C_{L} /\left(R_{\Pi} \cdot \theta \cdot h\right)\right]$, of nuclide $n$ $q=$ annual recharge infiltrating waste and reaching groundwater, $\mathrm{cm} / \mathrm{yr}$$$
C_{L}=\text { unit conversion factor }=0.01, \mathrm{~m} / \mathrm{cm}
$$

$R_{n}=$ retardation factor for radionuclide $n$ [see Equation (S.6) of DOE 1987]

$\theta=$ soil moisture content fraction $(0.078$ for the wetter climate, 0.064 for the current climate)

$\mathrm{h}=$ effective waste class thickness (taken as $64 \mathrm{~m}$ for double-shell tank waste (no-action alternative only) and $1 \mathrm{~m}$ for double-shel1 tank residuals (see Table P.24 of DOE 1987)

$T_{1}=$ initial arrival time of radionuclide $n$ to groundwater $=$ minimum of $T_{H}+T_{n}$ (holdup time plus nuclide travel time) and 10,000 years 


$$
\begin{aligned}
T_{H}= & \text { holdup time before leaching starts (taken as } 155 \text { years from } 1995 \\
& \text { for no barrier cases) } \\
T_{n}= & \text { nth radionuclide's trave } 1 \text { time to groundwater, years. }
\end{aligned}
$$

Integrating Equation (2.8) from the initial arrival time, $T_{I}$, to the final arrival time of 10,000 years yields the following accumulated release:

$$
\begin{aligned}
& Q_{n} \text { (adsorption) }=\lambda_{L n} \cdot Q_{0 n} \cdot \exp \left(-\lambda_{n} \cdot T_{I}\right) \cdot\left\{1-\exp \left[-\left(\lambda_{n}+\lambda_{L n}\right)\right.\right. \\
& \left.\left.\cdot\left(10,000-T_{I}\right)\right]\right\} /\left(\lambda_{n}+\lambda_{L n}\right)
\end{aligned}
$$

If $T_{I}=10,000$, then $Q_{n}=0$.

\subsubsection{Diffusion-Controlled Release}

The analys is here sumanarizes the diffusion model results presented in Appendix $P$ of DOE 1987. The simplified model includes only the most transportable radionuclides, ${ }^{14} \mathrm{C},{ }^{99} \mathrm{Tc},{ }^{129} \mathrm{I}$, and ${ }^{238_{\mathrm{U}}}$ (each was given a zero $\mathrm{K}_{\mathrm{d}}$ value for analysis of movement under the barrier for the diffusion model). These are the only radionuclides calculated to diffuse to the barrier's edge in less than 10,000 years.

In the simplified diffusion model a fraction of the waste, $F$, is assumed to diffuse out at a constant rate (if radioactive decay is ignored) over a time period, T. This period starts from the time that the diffusion of nuclides at the barrier's edge is non-zero, which is about 4,800 years (for zero $K_{d}$ ) after the year 2150 , and ends when the diffusion of nuclides is zero [see Appendix P, $T_{0}$ defined after Equation (P.24) is approximately 4,800 years and is equal to $T$ here (DOE 1987)]. In summary, the rate at which the most transportable radionuclides reach the groundwater (radioactive decay is included) at time $t$, is:

$$
Q_{n}^{\prime}=F \cdot Q_{0 n} \cdot \exp \left(-\lambda_{n} \cdot t\right) / T
$$




$$
\text { for } T_{I}<t<10,000
$$

where $T_{I}=T_{n}+T_{H}+4,800$ years and the exponential function is the radioactive decay term.

The fraction $F$ is 0.03 and time period $T$ is 6,000 years for the tank waste (single-shell tank, double-shell tank, future double-shell tank). The fraction and time period for grout waste were equal to 0.05 and 19,000 years, respectively. These values are based on the results of the more sophisticated diffusion release analysis in Appendix $P$ of DOE (1987). Equation (2.10) is integrated from $T_{I}$ years (the initial arrival time of radionuclides to the groundwater) to 10,000 years.

$$
\begin{aligned}
& Q_{n} \text { (diffusion) }=F \cdot Q_{0 n} \cdot \exp \left(-\lambda_{n} \cdot T_{I}\right) \cdot \\
& \left\{1-\exp \left[-\lambda_{n} \cdot\left(10,000-T_{I}\right)\right]\right\} /\left(T \cdot \lambda_{n}\right)
\end{aligned}
$$

\subsubsection{Combination Releases}

For the scenarios with postulated barrier failures (for the three disposa] alternatives), a combination of two release models is required because the barrier failure is modeled to affect only a fraction, $F_{L^{\prime}}$ of the waste class. This fraction, $F_{L}$, of waste requires a non-diffusive or leaching release model, and the complementary part of this waste, $1-F_{L}$, requires the diffusion-release model. $F_{L}$ is a random variable assumed to have a log-normal distribution (see Table B.2 of this report).

The two releases are modeled by dividing the waste classes into two parts, one part with fraction $F_{L}$, described by the leaching-release models, and the other with fraction $1-F_{L}$, described by the diffusion-release model. Such a model ignores any interaction or coupling of the two parts, which would require a much more complicated model. The simple combined release model described here should be considered as a first-order approximation to more complicated combination releases. The combined integrated release from the waste to the groundwater for radionuclide $n$ for the barrier failure scenarios is 
$Q_{n}$ (tank waste) $=F_{L} \cdot Q_{n}($ solubility $)+\left(1-F_{L}\right) \cdot Q_{n}($ tank diffusion $)$

for the tank waste classes with a barrier [see Equations (2.7) and (2.11)], and

$$
Q_{n} \text { (grout) }=F_{L} \cdot Q_{n} \text { (dissolution) }+\left(1-F_{L}\right) \cdot Q_{n} \text { (grout diffusion) }
$$

for the grout waste classes with a barrier [see Equations (2.4) and (2.11)]. For the scenarios with no barrier failure, $F_{L}$ is set to 0 and only diffusion occurs.

For the no disposal action alternative, the integrated release to the groundwater is just $Q_{n}$ (adsorption), Equation (2.9), for double-shell tank wastes, and $Q_{n}$ (solubility), Equation (2.7), for the single-shell tank waste.

The radionuclides in waste categories other than tank and grout wastes contribute almost nothing to the integrated releases over 10,000 years. The travel times to groundwater for the radionuclides in other waste categories are longer than 10,000 years or the activities in curies of the radionuclides are significantly smaller than the nuclide activities in tank and grout wastes. Hence, release models for the nuclides in other categories (i.e., other than tank and grout wastes) are not included in PROBCON-HDW.

\subsection{HUMAN INTRUSION RELEASE MECHANISMS}

Representative human intrusion events include borehole drilling and excavation. The marker system is assumed to prevent any systematic intrusion, excavation, or habitation. If the mitigating effect of the marker system is assumed (Appendix M of DOE 1987), then the probability of a major excavation occurring over the waste over the next 10,000 years is less than 0.0001 . The 40 CFR 191 guidelines do not require inclusion of events with probabilities less than $10^{-4}$ over 10,000 years; hence, major excavation was not included in the probabilistic analysis capability of the PROBCON code. 
The borehole event, however is considered representative of the more probable human intrusion events and is cited in the 40 CFR 191 standard. PROBCON-HDW uses the Poisson distribution as the probability distribution for boreholes. Other distributions could have been chosen, but the Poisson distribution was initially tried. Since the intrusion consequences or releases are extremely small relative to the leaching releases, the initial intrusion model was never changed.

The Poisson distribution is well suited for calculating the probability of an event occurring randomly within a period of $m$ years if the annual probability(a) of the event, $p$, is known. The probability of $i$ events, $P(i)$, occurring over $m$ years is

$$
P(i)=\exp (-L) \cdot L^{i} / i !
$$

where $L=m \cdot p(m=9,900$ years here $)$

$p=$ the annual probability of a borehole intercepting a waste category

$i=$ the number of boreholes drilled in m years.

The probability of more than $i$ events occurring over time period $m$ is

$$
P(j>i)=\sum_{j=i+1}^{\infty} \exp (-L) \cdot L^{j} / j !
$$

where $\mathrm{j}=$ the number of boreholes drilled in $\mathrm{m}$ years.

Equation (2.14) was used to calculate the probability of $0,1,2$, and so on boreholes for each waste category. Equation (2.15) was used to determine how many boreholes should be included in the analysis. The maximum number of boreholes included in the PROBCON-HDW analysis is the value of $i$ for which $P(j>i)$ is less than 0.0001 . This maximum number is the 99.99 percentile value of the number of boreholes expected to occur over $m$ years.

(a) "Annual probability" as used here is the probability per year that a borehole will intercept a given waste class. 
The annual probability for each waste class is derived by multiplying an annual borehole frequency per square kilometer (obtained from literature) by the surface area occupied by each waste class. Annual drilling frequencies per unit area vary from $0.0002 / \mathrm{km}^{2} / \mathrm{yr}$ to $0.012 / \mathrm{km}^{2} / \mathrm{yr}$ as given in Little (1980); a value of $0.01 / \mathrm{km}^{2} / \mathrm{yr}$ is chosen for the default value in PROBCON-HOW. This number is more than three times higher (more conservative) than the number recommended in EPA standard 40 CFR 191. Estimates of annual frequencies or annual probabilities for borehole drilling on each of the waste classes are calculated and given in Table 2.1. These annual frequencies are used with the Poisson distribution to generate 10,000-year probabilities in PROBCON-HOW.

Even though the drilling borehole is not expected to be random but somewhat clustered in time, the random-based Poisson distribution should be adequate here. The Poisson distribution is adequate partly because the clustering effects from the past are included in the annual borehole probabilities (Table 2.1). Furthermore, a large number of boreholes result during the long time period of 10,000 years, which tends to make the Poisson distribution a conservative choice. After the various numbers of boreholes that could intercept each waste category over the next 10,000 years is determined, the simplified model assumes that all the boreholes occur in one year. The year of drilling is an input parameter; 400 and 1,000 years after disposal were the values used in the HDW-EIS (DOE 1987). Since the model assumes that all the boreholes occur in one year, this is extreme clustering in time and certainly not random. Furthermore, if only the rather early years $(400$ and 1,000$)$ of the 10,000-year period are chosen as the drilling years, then the mitigating effects of radioactive decay are minimized in these early years and the results are conservative in this sense.

The source terms (inventories) per borehole were calculated for each waste class listed in Table 2.1 by dividing the waste class inventory (for each alternative) per radionuclide by the surface area of that class, and then multiplying this result (an inventory areal density) by the area of a $30-\mathrm{cm}-\mathrm{diameter}$ borehole, $7 \times 10^{-8} \mathrm{~km}^{2}\left(0.07 \mathrm{~m}^{2}\right)$. The resulting product is the initial inventory per borehole for each radionuclide in each waste class or category for each disposal alternative. The following equation was used for calculating the 
yth percentile value of the accumulated release of radionuclide $n$ from waste category $W$ to the land surface due to drilling:

$$
Q_{n}\left[I_{W}(y)\right]=\left[Q_{I n} \cdot \exp \left(-\lambda_{n} \cdot T_{D R I L L}\right) / A_{W}\right] \cdot A_{B H} \cdot I_{W}(y)
$$

where $\quad Q_{\text {In }}=$ initial inventory $(C i)$ of radionuclide $n$ in waste category $W_{i}$ $W=1$ to 11 (see Table 2.1)

$\mathrm{T}_{\text {DRILL }}=$ time of drilling (year) after the year 1995; $\mathrm{T}_{\text {DRILL }}$ has three values in this study: 155 years, 455 years, and 1,055 years(a)

$A_{W}=$ surface area of waste class $W\left(\mathrm{~km}^{2}\right)$ (see Table 2.1)

$A_{B H}=$ area of borehole $\left(\mathrm{km}^{2}\right)=7 \times 10^{-8} \mathrm{~km}^{2}$

$I_{W}(y)=$ the yth percentile value of the number of boreholes in waste category $W$ where $0<y \leq 99.99$.

$I_{W}(y)$ must satisfy the following relationship with the probabilities for $i$ boreholes in waste class $W, P(i)$, (Equation 2.14):

$$
\sum_{i=0}^{I_{W}(y)-1} P(i)<0.01 y \leq \sum_{i=0}^{I_{W}(y)} P(i)
$$

which says that the yth percentile value of the number of boreholes in waste category $w, I_{w}(y)$, is the first integer number which causes the sum of probabilities for each borehole to exceed the probability value $0.01 y$. The 0.01 factor converts percentile values into probability values.

The yth percentile value of the release-ratio consequence (summed release ratios) for waste category $W$ for each alternative $A$ (each alternative has $a$ different set of waste categories) due to drilling boreholes is given by

(a) The 55 years included in the drilling time is the time between the reference inventory year (1995) and the year of disposal (2050), and accounts for radioactive decay during that period. 
IABLE 2.1. Annual Probabilities of Boreholes in Waste Categories and WasteClass Surface Areas

\begin{tabular}{|c|c|c|c|}
\hline $\begin{array}{l}\text { Waste } \\
\text { Index, } \\
W \\
\end{array}$ & Waste Class/Category & $\begin{array}{c}\text { Annual } \\
\text { Probability, } \\
\text { intrusions/yr }\end{array}$ & $\begin{array}{l}\text { Surface Area, } \\
\text { AW, } \mathrm{km}^{2}\end{array}$ \\
\hline 1 & Single-shell tanks & $5.5 \times 10^{-4}$ & 0.055 \\
\hline 2 & Double-shell tanks & $5.8 \times 10^{-5}$ & 0.0058 \\
\hline $3 a$ & $\begin{array}{l}\text { Grout of existing waste } \\
\text { (ISD and reference) }\end{array}$ & $5.8 \times 10^{-4}$ & 0.058 \\
\hline $3 b$ & $\begin{array}{l}\text { Grout of existing waste } \\
\text { (geologic) }\end{array}$ & $2.5 \times 10^{-3}$ & 0.25 \\
\hline 4 & $\begin{array}{l}\text { Future double-shell } \\
\text { tanks }\end{array}$ & $5.8 \times 10^{-5}$ & 0.0058 \\
\hline 5 & Grout of future waste & $3.3 \times 10^{-4}$ & 0.033 \\
\hline 6 & $\operatorname{DWSF}(\mathrm{a}) /{ }^{90} \mathrm{Sr}$ canisters & $1.0 \times 10^{-6}$ & 0.00010 \\
\hline $7 a$ & $\begin{array}{l}\text { DWSF } /{ }^{137} \mathrm{Cs} \text { canisters } \\
\text { (in-place stabilization } \\
\text { and disposal) }\end{array}$ & $2.4 \times 10^{-6}$ & 0.00024 \\
\hline $7 b$ & $\begin{array}{l}\text { DWSF } /{ }^{137} \text { Cs canisters } \\
\text { (no disposal action) }\end{array}$ & $1.3 \times 10^{-6}$ & 0.00013 \\
\hline 8 & TRU-contaminated soil & $1.2 \times 10^{-4}$ & 0.012 \\
\hline 9 & Pre-1970 buried TRU & $7.5 \times 10^{-4}$ & 0.075 \\
\hline 10 & Retrievable TRU & $2.5 \times 10^{-4}$ & 0.025 \\
\hline 11 & Future TRU & $1.7 \times 10^{-4}$ & 0.017 \\
\hline
\end{tabular}

(a) Drywell storage facility. 


$$
C_{W}(y)=\sum_{n} Q_{n}\left[I_{W}(y)\right] / R L_{n, A}
$$

The yth percentile value of the release-ratio consequence for all waste categories is calculated by

$$
C(y)=\sum_{W} C_{W}(y)
$$

Equation (2.19) assumes that the yth percentile consequence value of each waste class can simply be added to obtain the total consequence value at the yth percentile. This total distribution of consequence values, Equation (2.19), is not the same as the total distribution found by adding Poisson distributions. In general, the yth percentile value of the distribution of the sum of random variables is not equal to the sum of the yth percentile value of the distribution of each random variable. The distribution defined by Equation (2.19) is conservative in the sense that $C(y)$ is greater than or equal to the yth percentile value of the distribution found from the sum of random variables. The drilling model in PROBCON-HDW is only approximate, which is, however, sufficient for purposes such as comparison of waste disposal alternatives. Furthemore, the releases from the drilling model were found to be very much smaller than the releases from the leaching models; thus, refinements to the drilling model were not necessary.

The complementary cumulative distribution function of the yth percentile consequence value, $\operatorname{CCDF}[C(y)]$, is defined by

$$
\operatorname{CCDF}[C(y)]=1.0-0.01 y
$$

Since the consequences due to drilling are discrete [depending on the integer number of boreholes in Equation (2.16)], the corresponding CCDF will be a step function indicating the discrete nature of the borehole model.

Special note should to be made of Equation (2.16) and the drywell storage facility (DWSF) waste category $(W=6,7 a, 7 b)$ of strontium and cesium 
canisters. This is the only waste class/category that has a target waste area smaller than the borehole area. Each canister is about $6 \mathrm{~cm}$ in diameter, and the borehole is assumed to have a 30-cm diameter. Hence, a larger area for the canisters was calculated, with the use of Figure 2.3 for use in Equation (2.16) and for finding the annual probabilities of a borehole intrusion of a canister (Table 2.1). The calculated canister area for the drilling model, $3.4 \times 10^{-7} \mathrm{~km}^{2}$, is based on a $33-\mathrm{cm}$ radius. If a borehole intercepts anywhere within this 33-cm-radius circle, as shown in Figure 2.3, then the canister is at least grazed by the borehole and, for conservativism, is assumed to release all its inventory to the accessible environment. That is, the borehole area, $A_{B H_{-}^{\prime}}$ is set to $3.4 \times 10^{-7} \mathrm{~km}^{2}\left(0.34 \mathrm{~m}^{2}\right)$ for the DWSF canisters instead of $7 \times$ $10^{-8} \mathrm{~km}^{2}\left(0.07 \mathrm{~m}^{2}\right)$. The area for the DWSF canisters, $A_{W}$, in Table 2.1 is the calculated larger area, $A_{B H}$ (Figure 2.3), multiplied by the number of canisters. For all other waste categories, the area of the borehole is negligible compared to the target waste area; hence, the borehole area is not included in the other waste class/category areas.

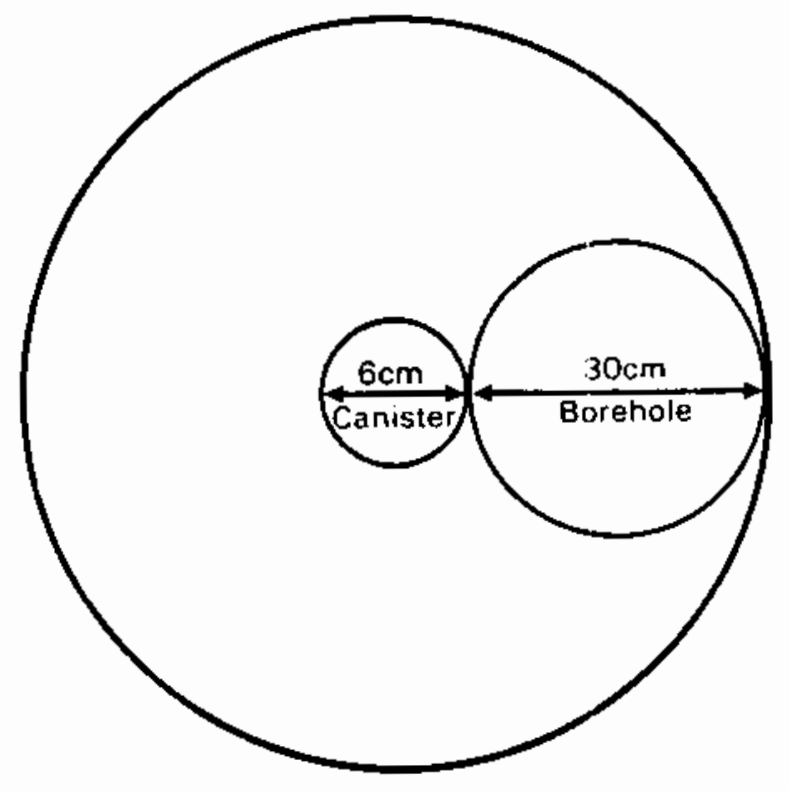

FIGURE 2.3. Drywell Storage Facility Canister Area for Borehole Model (DOE 1987) 


\subsection{DESCRIPTION OF SYSTEM AND COMPUTER CODES}

This section describes the different components of the PROBCON-HDW system, which includes the computer codes, the input files, and the output files. The user input instructions for the key input that is essential to meaningful simulations are also included.

\subsection{SYSTEM OF COMPUTER CODES}

The PROBCON-HDW code system contains six different computer codes: 1) PROBCON, 2) CMCCDF, 3) COMHUM, 4) PRAPLT, 5) WBCCDF, and 6) WBPLOT. The complete PROBCON-HOW system of codes, their interfaces, and their files are shown in Figure 3.1.

\section{1 .1 PROBCON Code}

The PROBCON code (PROBability and CONsequence analysis), which contains the natural (leaching) release models and human intrusion model, is the main code of the system. The mathematical models used in this code were described in Section 2.0; the input instructions are included in Section 3.2. The PROBCON code runs in two modes, the natural (leaching) release mode and the human intrusion release mode. The release modes cannot be exercised simultaneously, nor can more than one waste alternative be run or simulated at the same time; i.e., PROBCON is run once for each waste disposal alternative simulation for each set of scenario conditions and assumptions.

Because of the potentially large number of PROBCON runs, the user is advised to develop a bookkeeping system for tracking the many input and output files that result. Many of the output files of PROBCON are used as input files for the post-processing codes and plotting codes. The bookkeeping system that was used for the HDW-EIS simulations is described in Sections 3.2 and 3.3. A listing of the PROBCON code is displayed in Appendix C.

\section{1 .2 COMHUM Code}

COMHUM (COMbines HUMan intrusion CCDFs) is a post-processing code that combines the CCDFs from human intrusion for each waste class and writes 


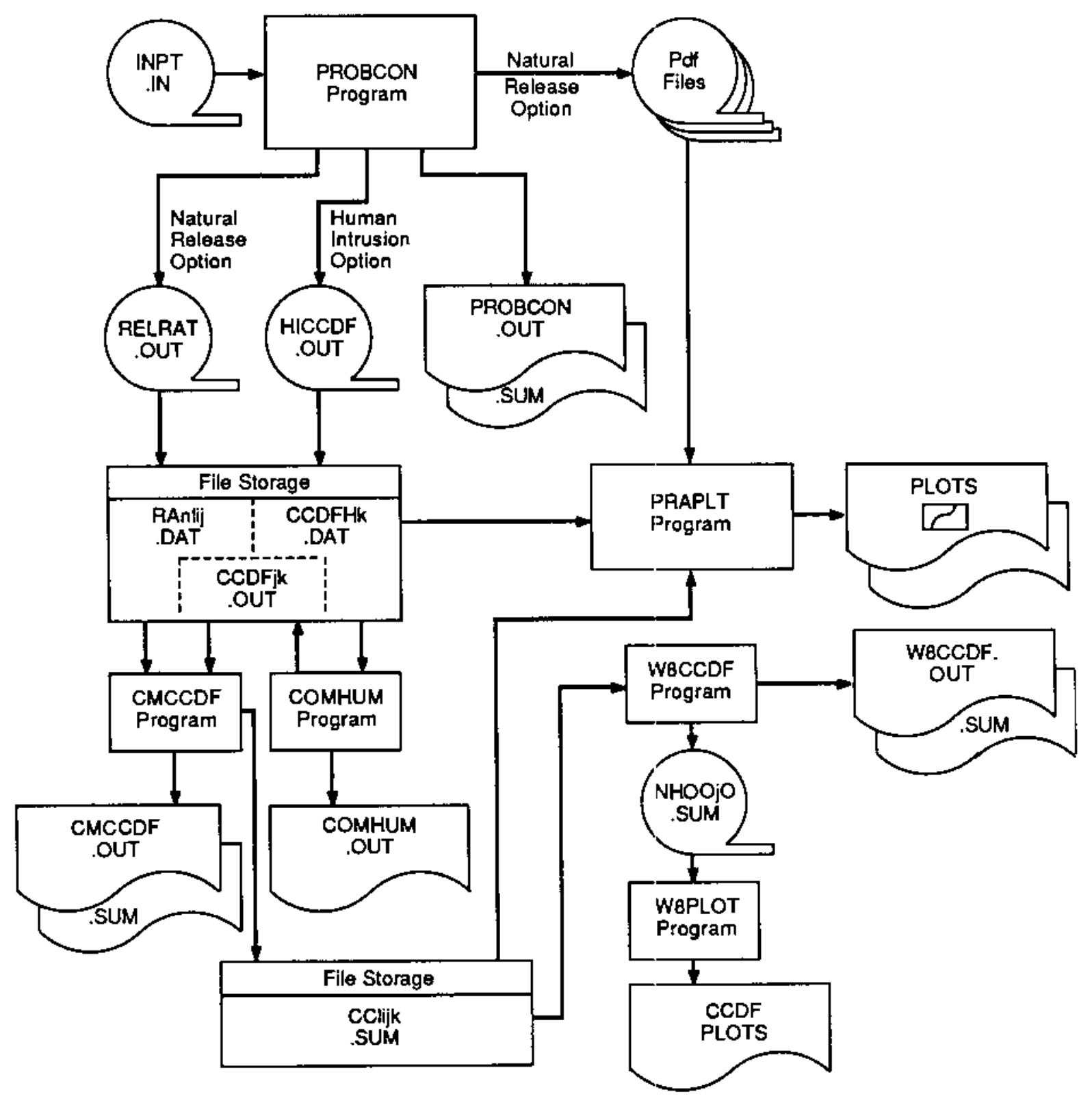

FIGURE 3.1. PROBCON-HDW System

the human intrusion CCDF for each waste alternative to a file that can be used for further processing. The additional processing consists of plotting and/or combining the human intrusion CCDFs with the natural release CCDFs. The COMHUM code listing is displayed in Appendix $D$. 


\subsubsection{CMCCDF Code}

CMCCDF (CoMbine human intrusion and natural release CCDFs) combines the human intrusion CCDF (CCDFjk.DAT file, $j=$ waste alternative index, k=human intrusion date index) with the natural release CCOF (RAneij.DAT file, $n=m o d e l$ or simulation index, $\ell=$ barrier failure indicator, $i=c l i m a t e$ index, and $j=$ waste alternative index); these indices are described further in Section 3.2. The output data file from CMCCDF is the CCnijk. SUM file, which contains the total CCDF for a given scenario (described by indices $k, l$, and $j$ ) and for a given waste alternative (denoted by index $j$ ). The CCnijk.SUM file is processed by the plotting program PRAPLT. The CMCCDF code listing is displayed in Appendix E.

\section{1 .4 PRAPLT Code}

PRAPLT is the main plotting program in the PROBCON-HDW system. PRAPLT plots the CCDF files (natural release only, human intrusion only, or combined), and/or the probability density functions (PDFs) of the water recharge parameter, the radionuclide distribution coefficients, and waste area fraction or percentage affected by barrier failure. The PRAPLT code listing is displayed in Appendix F.

\subsubsection{WBCCDF Code}

The WBCCDF (Weight 8 CCDFs) code calculates the combined or weighted CCDF from the CCDF of each scenario and an estimated probability of each scenario's occurrence over the next 10,000 years. In other words, WBCCDF combines all the scenario CCDFs (eight were used for the HDW-EIS; see Figure 2.2) according to Equation (2.1) in order to get the composite CCDF for each waste alternative. The composite CCDF data is on output file W8CCDF.SUM. The W8CCDF code listing is displayed in Appendix G.

\section{1 .6 W8PLOT Code}

The W8PLOT (Weight 8 PLOTS) code plots the composite CCDFs, one for each alternative. This code is essentially the PRAPLT code except for seven extra lines of coding, which fix the scale of the $x$-axis of the composite CCDF plots. The W8PLOT code listing is displayed in Appendix $H$. 


\subsection{INPUT FILES AND FORMATS: INPUT INSTRUCTIONS}

The main user input (internal file name INPT.IN) for the PROBCON-HDW system is read by the PROBCON program. The other programs primarily read the output files generated by PROBCON or other programs in the PROBCON-HDW system. The user input for the PROBCON program is described in detail in the next subsection. Although the internal file name for this input is INPT.IN, the file name that is used for storage purposes must be more descriptive since a separate input file is needed for each scenario and for each alternative with natural long-term releases. As shown in Figure 3.1, the file name convention that was used in the HDW-EIS for file storage contains five descriptive indices:

1. $i=c l i m a t e ~ i n d e x_{1}=1$ for current climate, $=3$ for wetter climate

2. $j=$ disposal alternative index, see Table 3.2 for values and definitions

3. $k=$ time of human intrusion index, $=1$ for 100 years after disposal, $=2$ for 400 years after disposal, $=3$ for 1000 years after disposal

4. $\ell=$ barrier failure index, $=2$ for no barrier failure, $=3$ for barrier faiture in the year 2500 A.D. (One, 1, was not used as index value.)

5. $n=$ simulation index, $=1$ for models described in this report, can equal any other number for different models that are tried out. This last index was useful during the model development phase when changes were made to the models.

Each user of PROBCON-HDW can choose an index scheme for keeping track of the potentially large number of files generated by the system.

\subsubsection{PROBCON Input}

The PROBCON program contains all necessary inodel data for a "defautt" run (a standard run). Default data values can be altered as desired via input to the program. Only a title card with some trailing options is necessary to run PROBCON with the default data values.

Input to the PROBCON program must be done through an input file called INPT.IN, which is created in the same directory as PROBCON. The input file must be named INPT.IN, and the construction of such a file requires knowledge 
of the "option cards" or "option records," which are described below. For filing purposes, descriptive file names should be used. Before the time of PROBCON execution, each of these input files must be assigned or copied to local file name INPT.IN. An example of a file-naming convention is described in Section 3.4.

To run PROBCON, an INPT. IN file containing at least the "TITL>" option card (explained below) is required, since a title and certain mode selections are necessary for a run.

\subsubsection{INPT. IN File Format}

The INPT.IN file should consist of a list of option records, commented with the $" \star \star \star \star * \|$ option (explained below) and separated by any number of blank records as desired for easier reading. The first option record should have option card "TITL," since this option specifies necessary information for the PROBCON program.

The following is a complete list of the allowable option cards:

$\begin{array}{ll}\star \star \star \star & \text { CINV } \\ \text { AINV> } & \text { DLYT> } \\ \text { AISO> } & \text { HINT> } \\ \text { AKDV } & \text { ISON } \\ \text { AREA> } & \text { NATR> } \\ \text { BARR> } & \text { RCHG } \\ \text { BFRD> } & \text { TITL> } \\ \text { CAWF> } & \end{array}$

All option cards should constitute the first five positions of the ir associated records. The ">" is a mandatory entry on the option cards except for the comment card.

The data values following most option cards can be entered in a free format just as for list-directed input/output. However, the data values must be separated by commas, and the last data value must not be followed by a comma. 


\subsubsection{Option Cards and Option Record Formats}

The construction of an INPT.IN file is made simple and logical through the use of option records, each one consisting of an option card and data values, which are entered in an almost free format. Each option card is associated with the changing of specific data values from their defaut values nomally used by PROBCON. Default values can be obtained by running the PROBCON program with no changes specified in the INPT.IN file (only the "TITL $>$ " card shouTd be used) and then inspecting the PROBCON.OUT file, which includes formatted outputs of all data values used by PROBCON. The following INPT.IN file with four card images is recommended for this purpose:

***INPT.IN file for showing default values in PROBCON.OUT

TITL $>$ NAT. REL: IPSD ALT., WET CLIMATE,W/BAR.FAIL 005 YRS N

2,2

Al1 the option cards, the associated data values, and the required format are described next.

\section{$" \star \star \star \star ":[$ comment]}

This option reserves the associated record for comments. It follows the same restriction as all other option cards in that it must occupy the first (in this case, four) positions of a record. Thus, whole lines must be reserved for commenting; one particular line cannot be used for both record-changing information and a comment.

\section{"AINV": [Add INVentory values]}

The inventory values for an additional nuclide may be added to the existing collection via this option. Since a large amount of data is involved here [44 (4 alternatives times 11 waste categories) inventory values per addec nuclide], the format for this option has some special features. The precise format is as follows:

AINS isonum

arg11, arg12, arg13, arg14, arg15, arg16, arg17, arg18, arg19, arg1a, arglb 
arg21, $\arg 22, \arg 23, \arg 24, \arg 25, \arg 26, \arg 27, \arg 28, \arg 29, \arg 2 a, \arg 2 b$ arg31, arg32, arg33, arg34, arg35, arg36, $\arg 37, \arg 38, \arg 39, \arg 3 a, \arg 3 b$ $\arg 41, \arg 42, \arg 43, \arg 44, \arg 45, \arg 46, \arg 47, \arg 48, \arg 49, \arg 4 a, \arg 4 b$ where

- isonum = index number of the nuclide to be added. "isonum" is restricted to the number imnediately following the index number for the last nuclide currently on the list of nuclides for the run (Table 3.1 gives the nuclide index numbers).

- $\operatorname{argij}=$ the inventory value in curies $(\mathrm{C} \mathrm{i}$ ) of the activity of the nuclide for the $i$ th waste disposal alternative and in the $j$ th waste category (Table 3.2 gives the disposal alternatives indices " $i=1$ to $4 "$ and Table 3.3 gives the waste category indices $" \mathrm{j}=1$ to $\left.11^{\prime \prime}\right)$.

When adding a new nuclide, "isonum" must be the number immediately following the last "isonum" used. For instance, I-129 is the last listed nuclide in the unaltered (default) data base of the PROBCON program. Since its "isonum" is "11" (see Table 3.3), the "isonum" for the next added nuclide should be "12". If "12" is not presented, PROBCON will print an error message on the screen and stop. This restriction is necessary to ensure clarity in output.

The inventory values should appear as presented above, where there is separate record for each waste disposal alternative, and there are no blank records between them. None of the values should be left blank unless the value to be stored is a zero. (Blanks are read in as " 0 " for the "AINV" option.) In addition, although commas are probably the safest to use in terms of avoiding errors, blanks may also to used as delimiters between inventory values. (NOTE: This is a special feature of "AINV>" that should not be attempted for other options that require commas as delimiters.)

\section{"AISOS": [Add ISOtope]}

When adding a nuclide, several miscellaneous parameters must also be included that normally need not be changed for already existing nuclides. 
TABLE 3.1. Indices for Nuclides

$\begin{array}{rll}\frac{\text { Index }}{1} & & \text { Nuclide } \\ & & { }^{90} \mathrm{Sr} \\ 3 & & { }^{137} \mathrm{Cs} \\ 4 & & 231_{\mathrm{Sm}} \\ 5 & & 241^{24} \mathrm{Am} \\ 6 & & 63_{\mathrm{Ni}} \\ 7 & & { }^{14} \mathrm{C} \\ 8 & & 238_{\mathrm{U}} \\ 9 & & 93_{\mathrm{Zr}} \\ 10 & & 99 \mathrm{Tc} \\ 11 & { }^{129} \mathrm{I}\end{array}$

TABLE 3.2. Indices for Waste Disposal Alternatives

\begin{tabular}{cl}
$\frac{\text { Index }}{1}$ & \multicolumn{1}{c}{ Waste Disposal Alternative } \\
2 & Geologic disposal \\
3 & Reference \\
4 & No action
\end{tabular}

This option allows the necessary inclusion of such data via the following format:

AISOS isonum, decay_constant, solubility_concentration, 40_CFR_191_value multfact1, multfact2, multfact3, multfact4

where

- isonum $=$ index number of the nuclide to be added. "isonum" is restricted to the number immediately following the index number for the last nuclide currently on the list of nuclides for the run (Table 3.1 gives the nuclide index numbers) 
TABLE 3.3. Indices for Waste Categories

$\underline{\text { Index }}$ Waste Category

$\begin{aligned} 1 & \text { Single-shell tank } \\ 2 & \text { Double-shell tank } \\ 3 & \text { Grout--existing tank waste } \\ 4 & \text { Double-shelled tank, future } \\ 5 & \text { Grout--future tank waste } \\ 6 & \text { Strontium drywell waste } \\ 7 & \text { Cesium drywell waste } \\ 8 & \text { TRU contaminated soil } \\ 9 & \text { Pre-1970 buried TRU site } \\ 10 & \text { Existing stored TRU site } \\ 11 & \text { Future TRU site }\end{aligned}$

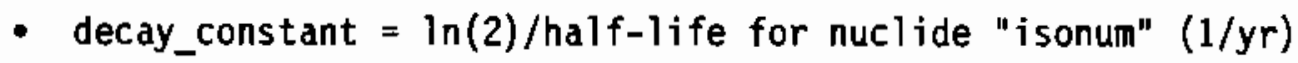

- solubility_concentration = concentration of nuclide "isonum" in single-shell tank waste - used for solubility controlled leaching model (microcuries/1iter)

- 40_CFR_191_value = release limit rates from Table 3.1 of 40 CFR 191 for radionuclide "isonum" per 1000 metric tons of heavy metal (MTHM) of fuel throughput (Ci)

- multfacti = factor for modified release limits for nuclide "isonum" and waste disposal alternative " $i "$

A11 multfact's are set to 1.0 on default.

All values must be specified for this option; a blank in a data slot will be read in as zero.

All four factors must be entered in the record immediately following the "AISO>" record; they cannot appear in the "AISOS" record, and no b] ank records may separate the two records.

When adding a new nuclide, "isonum" must be the number immediately following the last "isonum" used. For instance, ${ }^{129} 1$ is the last listed 
nuclide in the unaltered (default) data base of the PROBCON program. Since its "isonum" is "11" (see the documentation), the "isonum" for the next added nuclide should be "12". If "12" is not presented, PROBCON will print an error message on the CRT and stop. This restriction is necessary to assure clarity in output.

"AKDVS": [Alter (or Add) KD Value]

Kd distribution parameters may be altered or added for an already existing nuclide or for a new nuclide, respectively, via this option. The necessary format is as follows:

AKDV > isonum, Kd_median, Kd_variance, Kd_low, Kd_high where

- isonum $=$ index number of the nuclide involved (already existing or added)... when adding an nuclide, "isonum" is restricted to the number immediately following the index number for the last nuclide currently on the list of nuclides used for the run (Table 3.1 gives the nuclide index numbers)

- Kd_median = median of the Kd pdf for nuclide "isonum"

- Kd_variance $=$ variance of the $\mathrm{Kd}$ pdf for nuclide "isonum"

- Kd_low = minimum Kd pdf value for nuclide "isonum"

- Kd_high = maximum $\mathrm{Kd}$ pdf value for nuclide "isonum"

- $p d f=$ probability density function

Adding only the $\mathrm{Kd}_{\text {_median }}$ value and leaving the rest of the $\mathrm{Kd} \mathrm{pdf}$ information blank (but retaining the proper "AKDV" format) will suffice when a new nuclide is added. The reason for this involves difficulty (time constraints) in modifying the PROBCON code into a modular and general one. As it appears now, PROBCON will only fully account for the Kd pdfs of strontium, plutonium, americium, and uranium. The pdfs for other nuclides are not accounted for; rather, only median values are used. New nuclides are treated in a manner similar to the nuclides in the "other" category. It is quite possible to generalize the code, so that it can 
account either for the Kd distributions of all the nuclides involved or for a selected few.

\section{"AREA $>$ ": [change AREA value]}

Waste area default values may be changed using this option with the following format:

AREA $>$ waste_disposal_alternative, waste_class, area_value

where

- waste_disposal_alternative = index of the waste disposal alternative associated with the area value

- waste_class $=$ number of the waste category associated with the area waste category (Table 3.2 below gives the disposal alternatives indices $" j=1$ to $4 "$ and the waste category indices $" j=1$ to $11 "$ are shown in Table 3.3)

- area_value $=$ surface area of waste class for borehole model $\left(\mathrm{km}^{2}\right)$ and the solubility-controlled release mode 1

None of the data slots may be left blank for this option.

"BARP>": [BARRier in place? answer]

The PROBCON program assumes that a barrier is in place, unless this option is used with the following format to indicate that a barrier is not in place:

BARR>barrier_in_place? answer where

- barrier_in_place? answer $=Y$ for "yes, " $N$ for "no"

The "Y" option is usually redundant, but can be used to negate a previous "BARR> N" . 


\section{"BFRDS": [change Barrier Failure Recharge Distribution parameters]}

Functional-barrier-failure recharge and disruptive-barrier-failure recharge distribution default parameters may be altered via this option card, which requires the following format:

BFRD $>$ fbfrmn, fbfrmx, dbfrmn, dbfrmx, fdbprob where

- $f b f r m n=$ functional-barrier-failure recharge minimum $(\mathrm{cm})$

- $f b f r m x=$ functional-barrier-failure recharge maximum $(\mathrm{cm})$

- $d b f r m n=$ disruptive-barrier-failure recharge minimum $(\mathrm{cm})$

- $d b f r m x=$ disruptive-barrier-failure recharge maximum $(\mathrm{cm})$

- $f d b p r o b=$ probability of functional barrier failure

Any of the data slots may be left blank to indicate no change in the respective PROBCON default values.

\section{"CAWF>": [Change Affected Waste Fraction pdf paraneters]}

The affected waste fraction is actually the percentage of the waste inventory that is affected by the barrier failure. The assumed barrier failure will not change the recharge for $100 \%$ of the waste, but for some $x \%$ where $x$ is an uncertain parameter; the variability of $x$ (affected waste percentage) is described by this input option. The affected waste fraction pdf default parameters may be altered via this option, which requires the following format:

CAWF> awf_low, awf_high, awf_median, awf_variance

where

- awf_low = minimum value for the affected waste fraction pdf $(\%)$

- awf_high = maximum value for the affected waste fraction pdf (\%)

- awf_median = affected waste fraction pdf median $(\%)$

- awf_variance $=$ affected waste fraction pdf variance $(\%)$

Any of the data slots may be left blank to indicate no change in the respective PROBCON default values. 


\section{"CINS": [Change InVentory value]}

This option allows one to change an inventory value for an already existing nuclide. Its format is as follows:

CINV waste_disposal_alternative, isonum, waste_class, inventory_value where

- waste_disposal_alternative $=$ index of the waste disposal alternative associated with the inventory value (Table 3.2 gives the indices of the waste disposal alternatives " $i=1$ to $4 "$ ).

- isonum $=$ index number of the isotope involved (Table 3.1 gives the nuc1ide index numbers)

- waste_class = index of the waste category associated with the inventory value (Table 3.3 gives the indices for the waste categories).

- inventory_value $=$ the inventory activity of nuclide "isonum" (Ci)

None of the data slots may be left blank for this option.

\section{"DLYT>": [change DeLaY Time]}

The default diffusion time delay for an nuclide may be altered via this option, which requires the following format:

DLYT> isonum, diffusion_dly_time

where

- isonum = index number of the nuclide involved (Table 3.1 gives the nuclide index numbers)

- diffusion_dly_time = diffusion time delay associated with nuclide "isonum"; i.e., the time it takes for the initial molecules to diffuse to the outer edge of barrier where advection takes place.

None of the data slots may be left blank for this option. 
"HINT>": [change miscellaneous Human INTrusion data]

This option allows one to alter miscellaneous data values associated with the Human Intrusion PROBCON option from their PROBCON default values. The following format is required:

HINT> disposal_time, period, intrusion_time where

- disposal_time = disposal time after 1995 (years)

- period $=$ time period for drilling boreholes (about 9900 years)

- intrusion_time = assumed intrusion time after disposal (years) when all boreholes are assumed to occur - model simplification

Any of the data slots may be left blank to indicate no change in the respective PROBCON default values.

\section{"ISOND": [change ISOtope (nuclide) Name]}

When a nuclide is added to the existing list of nuclides, PROBCON should know its name so it can provide a readable output. A name may be entered via this option in the following format:

ISON isonum, nuclide_name where

- isonum $=$ index number of the nuclide to be added..."isonum" is restricted to the number. immediately following the index number for the last nuclide currently on the list of nuclides for the run (Table 3.1 gives the nuclide index numbers)

- nuclide_name = name of nuclide "isonum". This name should be a character string containing no blanks. Some of the nuclide names already stored in PROBCON do, indeed, contain spaces, e.g., Sr 90. However, any new nuclide names should not contain a space. 
"NATR": [change NATuRal release miscellaneous data]

Miscellaneous data associated with the natural release option of the PROBCON program may be altered via this option, which requires the following format:

NATR $>$ random, samples, bft, tshell, leach_time, bulk_dens, vol_mois, thick where

- random $=$ number of random numbers to be discarded prior to run

- samples = number of samples to be run

- bft $=$ number of years after 1995 to barrier failure

- tshell = steel shell tank lifetime (years)

- leach_time = leaching time parameter for non-grout; used in dissolution-controlled release model; this is the time that is required to completely dissolve waste (years)

- bulk_dens = bulk density of soil (grams per milliliter, 1.8)

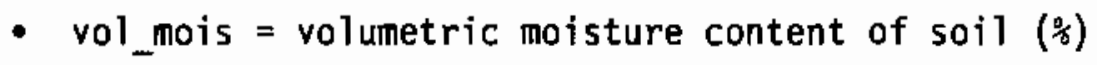

- thick = waste deposit thickness for double-shell tank liquids or residuals to be used in adsorption-controlled release model $(64 \mathrm{~m}$ was effective thickness of liquids assuming soils would soak up liquids for $64 \mathrm{~m}, 1 \mathrm{~m}$ for residuals in double shell tanks).

Any of the data slots may be left blank to indicate no change in respective PROBCON default values.

\section{"RCHQ": [change ReCHarGe pdf parameters]}

The main descriptors of the recharge pdf may be altered via this option, which requires the following format:

RCHOS rchrg_low, rchrg_high, rchrg_median, rchrg_variance where

- rchrg_low $=$ recharge pdf minimum value $(\mathrm{cm})$

- rchrg_high $=$ recharge pdf maximum value $(\mathrm{cm})$ 
- rchrg_median $==$ recharge pdf median $(\mathrm{cm})$

- rchrg_variance $=$ recharge histogram variance $\left(\mathrm{cm}^{2}\right)$

Any of the data slots may be left blank to indicate no change in the respective PROBCON default values.

"TITL": [TITLe and necessary information card]

The INPT. IN file must contain this card and the two cards that follow, since it specifies information required by the PROBCON program. The special multiple-card format appears as follows:

TITLtitle

release_type

waste_disposal_alternative, release_limits_index

where

- title $=$ the title for the run (no more than 60 characters)

- release_type $=$ either natural (enter $\mathrm{N}$ ) or human intrusion (enter H)...the letter must be entered in the very first position of the record

- waste_disposal_alternative $=$ the number associated with the waste disposal alternative for the run (Table 3.2 gives the disposal alternatives indices " $i=1$ to $4 "$ ).

- release_limits_index = the index of the waste disposal alternative from which release limit values will be taken (Table 3.2 gives the disposal alternatives indices " $i=1$ to $4 "$ ).

Normally the two fields are the same, except when the geologic alternative or reference alternative is to be run or modeled with the "total release limits" instead of the "partitioned release limits." The total release limits are the ones calculated for the in-place stabilization and disposal alternative or no action alternative and is based on the entire or total HOW fuel throughput (past and future).

The records must appear, in order and format, as in the format module above; the release type ( $\mathrm{N}$ or $\mathrm{H}$ ) must occupy the first position of the 
record immediately below that of the title, and the

"waste_disposal_alternative, release_limits_index" record must be the next record. The information for the latter record can be entered in a free format. None of the data slots may be left blank for this option. Unchanged Data Values:

For many of the options, a data value can be left unchanged by merely leaving its "slot" blank. An example is shown below for the following option record:

BFRD $\quad 1 . \quad, 9 ., 21$. After this record is processed, the functional-barrier-failure recharge minimum will be 1.0 , the functional-barrier-failure recharge maximum will remain unchanged, the disruptive-barrier-failure recharge minimum will be 9.0, and the disruptive-barrier-failure recharge maximum will be 21.0 , the functional-barrier-failure recharge minimum and probability for functional barrier failure will both retain their previous values. An option record with the format

BFRD> , ,9. ,21. ,

will bring about the same changes as the above, except the disruptivebarrier-failure recharge minimum will remain the same, in addition to the other two.

\section{Changeable Default Data Values:}

The following Table 3.4 tells which default data values are changeable and which can be added. The option cards necessary for changing and adding particular data values are also indicated. Hopefully, this table should prove convenient in changing default data values.

Adding a Nuclide:

A nuclide may be added to the existing PROBCON list if it is one which does not require special Kd distribution treatment. The reason for this involves time that is necessary to modify the PROBCON code into a general one. 
TABLE 3.4. Option Card Summary

Default Data Type Card

Affected waste fraction pdf maximum (change)

CAWF>

Affected waste fraction pdf median (change)

CAWF>

Affected waste fraction pdf minimum (change)

CAWF>

Affected waste fraction pdf variance (change)

CAWF>

Area value (change)

Barrier not in place specification

Bulk density of soil (change)

Decay constant value for an nuclide (add)

Diffusion delay time (add or change)

AREA $>$

BARR>

NATR>

AISOS

Disposal time after 1995 (change)

Disruptive-barrier-recharge pdf maximum (change)

OLYT>

HINT>

BFRD>

Disruptive-barrier-recharge pdf minimum (change)

$B F R D$

Functional-barrier-recharge pdf maximum (change)

BFRDD

functional-barrier-recharge pdf minimum (change)

BFRDS

Intrusion time after disposal (change)

HINT>

Inventory value (add)

Inventory value (change)

Kd distribution maximum for an nuclide (add or change)

Kd distribution median for an nuclide (add or change)

Kd distribution minimum for an nuclide (add or change)

Kd distribution variance for an nuclide (add or change)

AINVS

CINVS

AKDVS

AKDV $>$

AKDV

AKDV

Leaching time parameter for non-grout (change)

Factors for modified release limits (add)

NATR

AISOS

Name of a new nuclide (add)

Number of random numbers discarded prior to run (change)

Number of samples run (change)

Number of years after 1995 to barrier failure (change)

Probability of functional barrier failure (change)

Recharge pdf maximum (change)

Recharge pdf median (change)

Recharge pdf minimum (change)

Recharge pdf variance (change)

ISON>

NATR>

NATR

NATR>

BFRD>

$\mathrm{RCHG}>$

RCHG>

RCHG>

Release limit from Table 3.1 of 40 CFR 191 for a nuclide (add)

Release limits for the run

Release type for the run

Solubility limit for an nuclide (add)

Steel shell tank lifetime (change)

Time period (change)

Title for the run

Volumetric moisture content of soil (change)

Waste deposit thickness (change)

RCHG>

AISO>

TITL

TITL

AISO>

NATR>

HINT>

TITL

NATR>

NATR> 
As it appears now, PROBCON will fully account for the $\mathrm{Kd}$ pdfs of only strontium, plutonium, americium, and uranium. The pdfs for other nuclides are not accounted for; rather, only median values are used. New nuclides are treated in a manner similar to the nuclides in the "other" category. Thus, as long as a nuclide has a $K d$ distribution which is not very crucial for calculations (i.e., its median value) it can be added to the existing list without impairing results.

Several option cards must be involved when adding a nuclide. A list of the necessary options follows:

AINVS

AKDV

DLYT>

AISO>

ISON>

\section{2 .2 CMCCOF Input}

This program reads the standard input file (default file TAPES) that follows the program execution in the standard VAX.COM file (see example in next section). The input format is

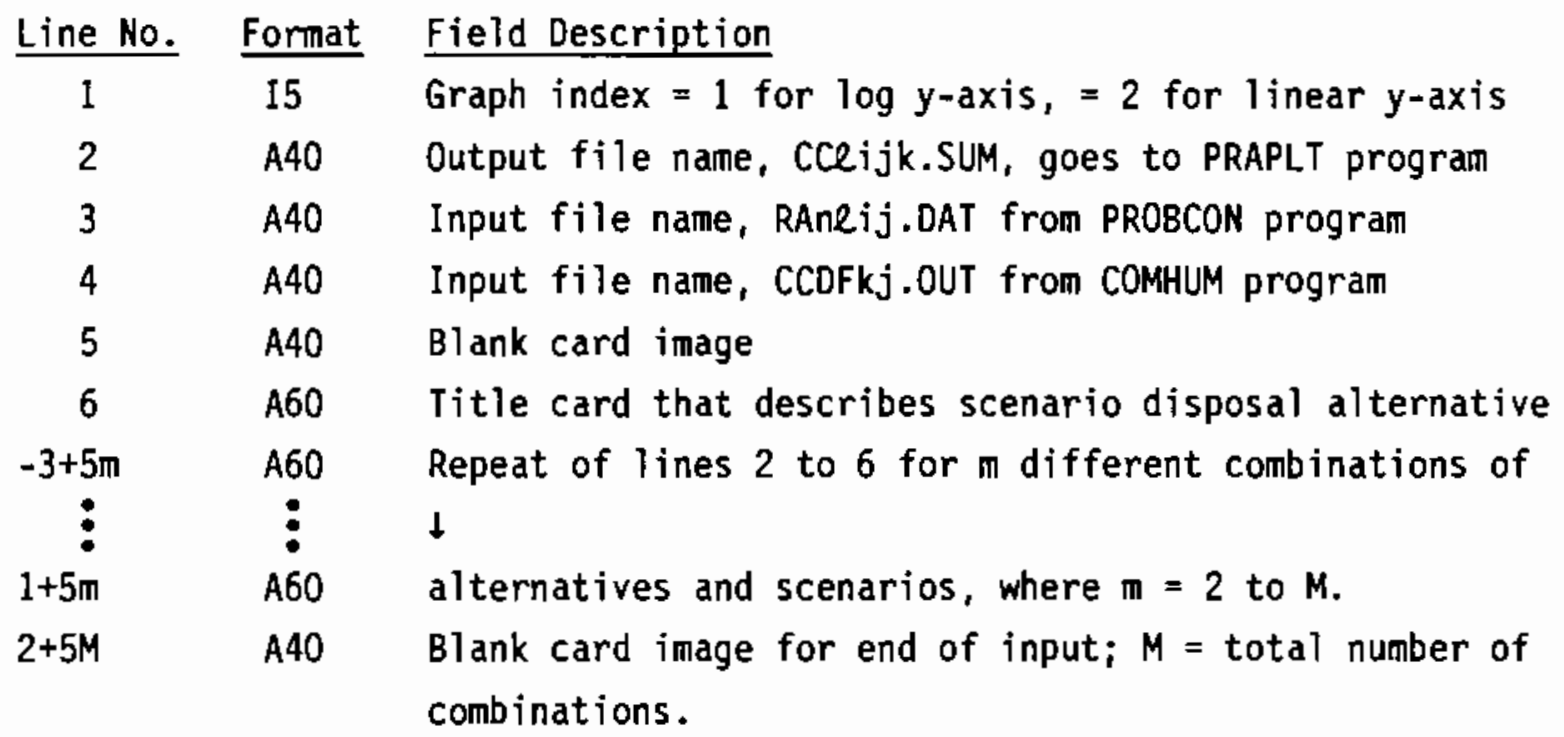

CMCCDF reads each data file RAneij.DAT, which contains the CCDF for the natural release scenario $(l, i)$ for the $j$ th waste disposal alternative. 
CMCCDF also reads each data file CCDFjk. OUT, which contains the CCDF for the human intrusion scenario $k$ (the kth date of occurrence) for the $j$ th waste disposal alternative.

\subsubsection{COMHUM Input}

\begin{tabular}{|c|c|c|}
\hline Line No. & Format & Field Description \\
\hline 1 & I5 & Graph type index, $=1$ for $\log y$-axis, $=2$ for linear $y$-axis \\
\hline 2 & $\mathrm{~A} 40$ & Input file name \\
\hline 3 & 15 & Disposal alternative index (see Table 3.2 ) \\
\hline 4 & A40 & Output file name, CCDFjk.out \\
\hline$-1+3 m$ & A40 & Repeat lines 2 to 4 for $m=2$ to $M_{1}$ where $m$ is the ordinal \\
\hline $3 m$ & I5 & $\downarrow$ \\
\hline $1+3 m$ & A40 & number of output files. \\
\hline $2+3 M$ & A40 & $\begin{array}{l}\text { Blank card image, end of input; } M=\text { total number of output } \\
\text { files. }\end{array}$ \\
\hline
\end{tabular}

COMHUM reads the data file CCDFHk. DAT which contains the CCDF due to the human intrusion scenario for the kth date of occurrence. This file contains the CCDF for each of the four waste alternatives used in the HOW-EIS.

\subsubsection{PRAPLT Input}

PRAPLT is usually run in an interactive mode where the user is prompted for input on the terminal screen.

\begin{tabular}{|c|c|c|}
\hline \multirow{2}{*}{$\frac{\text { Line No. }}{1}$} & Format & Field Description \\
\hline & I5 & Plotter inde \\
\hline & & $=1$ for CALCOMP \\
\hline & & $=2$ for $\mathrm{HP7221T}$ \\
\hline & & $=3$ for $\mathrm{HP7550 \textrm {A }}$ \\
\hline
\end{tabular}

2

3

4
A40 Input file name (blanks end the run)

A1 Correct input file? Yes or No answer.

I5 Plot type index

$=1$ for single pdf plot

$=2$ for multiple CCDF plot.

A1 Are more curves to be plotted? Yes or No answer. 
PRAPLT reads the probability density function (pdf) files which consist of the KDSR.OUT file (strontium Kd pdf), KDPU.OUT file (plutonium Kd pdf), KDAM.OUT file (americium Kd pdf), KDU.OUT file (uranium Kd pdf), AWF.OUT file (area of waste affected by barrier failure pdf), and the RECHRG.OUT file (water recharge to groundwater pdf).

PRAPLT also reads the CCDFHk.DAT data file which contains the CCDF due to the human intrusion scenario for the kth date of occurrence.

PRAPLT also reads the CCeijk.SUM data file which contains the CCDF for scenario $(R, i, k)$ for the $j$ th disposal alternative.

\subsubsection{W8CCDF Input}

\begin{tabular}{|c|c|c|}
\hline Line No. & Format & Field Description \\
\hline 1 & 15 & Graph type index $=1$ for $\log y$-axis, $=2$ for linear $y$-axis. \\
\hline 2 & A40 & Output file name, NHOOjO.sum. \\
\hline 3 & A40 & Input file name, cceijk.sum from CMCCDF program. \\
\hline 4 & E15.7 & Scenario probability (multiplier weight) for CCDF. \\
\hline $1+2 m$ & A40 & Repeat of lines 3 and 4 for $m=2$ to $M$, where \\
\hline $2+2 m$ & E15.7 & $\begin{array}{l}m=\text { the number of input files or scenarios for each } \\
\text { alternative ( } 8 \text { scenarios were in HDW-EIS). }\end{array}$ \\
\hline $3+2 M$ & $\mathrm{~A} 40$ & $\begin{array}{l}\text { Blank card image, indicating end of input files; } M= \\
\text { total number of input files or scenarios. }\end{array}$ \\
\hline $4+2 M$ & A60 & $\begin{array}{l}\text { Title for composite CCDF for a particular disposal } \\
\text { alternative. }\end{array}$ \\
\hline $5+2 M$ & A40 & Blank card image, end of run. \\
\hline
\end{tabular}

\subsubsection{WBPLOT Input}

The input file for W8PLOT is interactive and the same as PRAPLT input. W8PLOT reads the W8PLOT.SUM data file, which is the total composite CCDF of all the scenarios combined. 


\subsection{OUTPUT FILES}

The index scheme described in Section 3.2 is used in this section. Recall that $\mathbf{i}=$ climate index, $j=$ disposal alternative, $k=$ date of human intrusion, $\ell=$ barrier failure index, and $n=$ simulation index.

The reader should also refer to Figure 3.1, which shows all of the output files in the system.

\subsubsection{PROBCON Output}

The PROBCON output files for the Natural (Leaching) Release option are the following:

$$
\begin{aligned}
& \text { PROBCON.OUT } \\
& \text { PROBCON.SUM } \\
& \text { KDAM.OUT } \\
& \text { KDPU.OUT } \\
& \text { KDSR.OUT } \\
& \text { KDU.OUT } \\
& \text { AWF.OUT } \\
& \text { RECHRG.OUT } \\
& \text { RELRAT.OUT }
\end{aligned}
$$

PROBCON.OUT contains tables of all data values used by PROBCON and all. important results. It is an essential file for the user.

PROBCON.SUM is an executive summary of PROBCON.OUT.

Kd pdf plot files are made for ${ }^{90} \mathrm{Sr},{ }^{239} \mathrm{Pu},{ }^{241_{A m}}$, and ${ }^{238_{U}}$. They have a format suitable for processing by PRAPLT, the plotting program.

AWF.OUT is a plot file for the affected waste fraction distribution. Data are presented in a format suitable for processing by PRAPLT.

RECHRG.OUT is a plot file for the recharge distribution. Data is presented in a format suitable for processing by PRAPLT.

RELRAT.OUT is a standard output file for further processing by the CMCCDF code. 
When PROBCON is run using the Human Intrusion option, the following files are produced:

PROBCON.OUT

PROBCON. SUM

HICCDF.OUT .

PROBCON.OUT contains tables of all data values used by PROBCON and all important results. It is the most convenient file for review of results.

PROBCON. SUM is an executive summary of PROBCON.OUT.

HICCDF.OUT is a standard output data file for further processing by COMHUM after several files have been stored as CCDFHk.DAT where $k$ denotes the date of occurrence for the human intrusion.

\section{3 .2 CMCCDF Output}

The main output file from program CMCCDF is the data file CCeijk.SUM, which contains the CCDF for each scenario $(l, i, k)$ for the jth disposal alternative. The CCDF on this file includes release-ratio consequences from both the natural release mode and the human intrusion mode. The purpose of this data file is to provide the CCDF curve information to the plotting program PRAPLT and/or to be read by the W8CCDF program so that it can be combined with other CCDFs into the total composite CCDF for all scenarios.

Two additional output files are the document files CMCCDF.OUT and CMCCDF.SUM. File CMCCDF.SUM is an executive output file that suntarizes the CMCCDF.OUT file.

\subsubsection{COMHUM Output}

The main output file from program COMHUM is the data file CCDFjk.OUT, which contains the CCDF for the kth date of human intrusion for the jth disposal alternative. The CCDF on this file contains only the releases caused by human intrusion. The purpose of this file is to provide the human intrusion release data for the CMCCDF program, which will combine the human intrusion release data with the release data from the natural release mode. 


\subsubsection{PRAPLT Output}

The main output of program PRAPLT is plots of probability density functions and CCDFs. An example plot of a probability density function is shown in Figure 3.2, and an example plot of a CCDF or release-ratio consequence curve is shown in Figure 3.3 .

\subsubsection{W8CCDF Output}

The W8CCDF program has the output data file NHO0j0.SUM which contains the total composite CCDF of all scenarios for the jth alternative. These files are read by program W8PLOT for plotting purposes.

WBCCDF also has the standard document output files WBCCDF.OUT and W8CCDF.SUM where the *.SUM fiTe is the executive summary file and the *.OUT file is the more detailed output.

\subsubsection{W8PLOT Output}

The program WBPLOT's only output is the plot of the total composite CCDF curve for each alternative. An example plot is shown in Figure 3.4.

\subsection{COMMAND FILES FOR CODE EXECUTION}

The command files for execution of each program are stored in *.COM files on the VAX 11/780 computer. Some example command files are shown for each program except for the plotting programs, which are run interactively.

\subsubsection{PROBCON Command File}

The following command file executes the PROBCON program in the natural release mode for the scenario that includes a barrier failure ( 3 index in filename), the current $c l$ imate recharge (second 1 index in filename), for the in-place stabilization and disposal alternative ( 2 index in filename). The

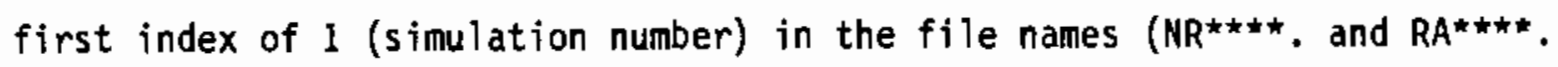
files) in the comprand file indicates that the current models (as described in this document) are used. The temporary file FOROO7 is a scratch file that contains additional information about each of the 2000 trials that is performed 


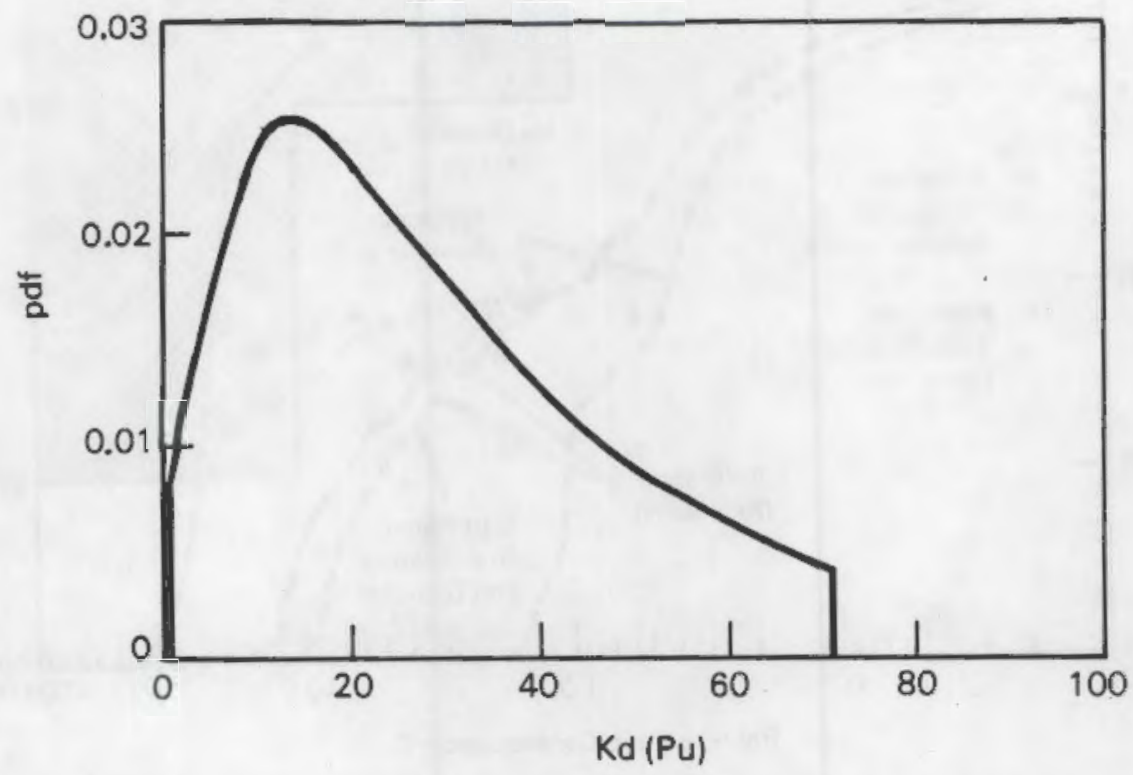

FIGURE 3.2. Assumed Probability Density Function of the $K_{d}$ Values for Plutonium in Single-Shell and Double-Shell Tank Waste (DOE 1987)

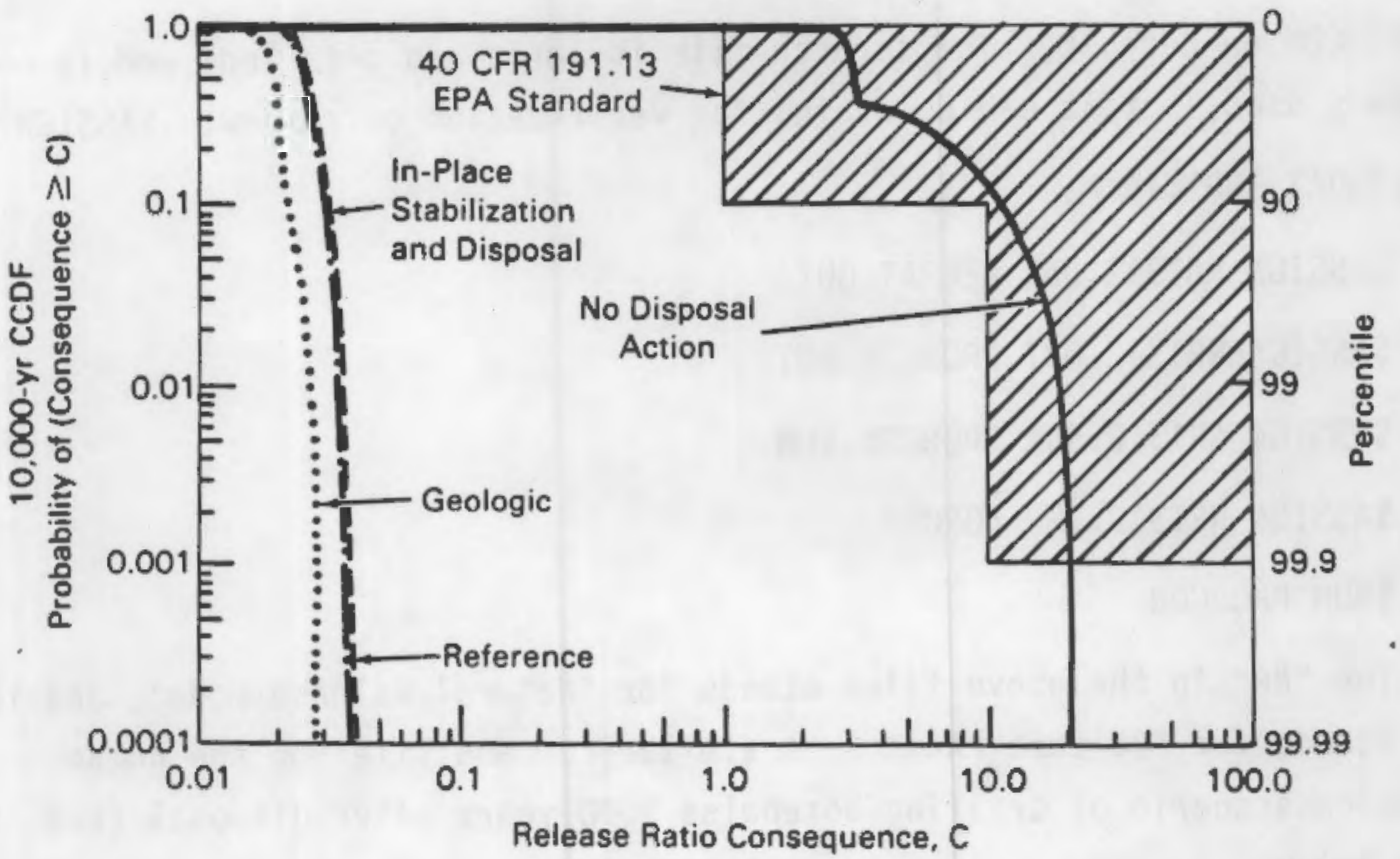

FIGURE 3.3. Release-Ratio Curves for Alternatives for the Scenario of Current Climate, No Barrier Failure, and 400-Year Intrusion (DOE 1987) 


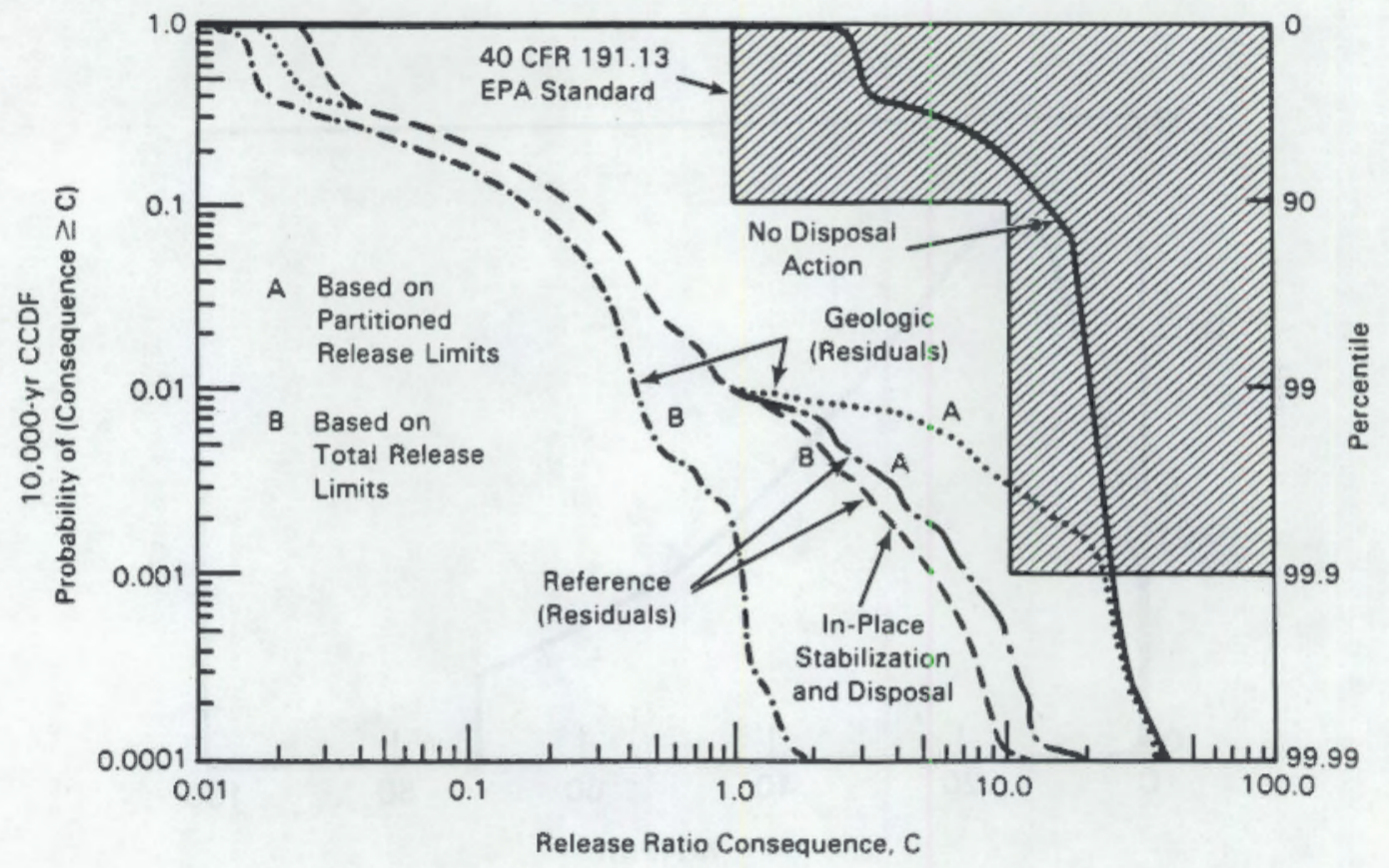

FIGURE 3.4. Preliminary Composite CCDFs for All Alternatives Based on All Scenarios for Wastes Disposed of Near Surface (DOE 1987)

in PROBCON on default. The scratch file is large and detailed, and is not commonly used, but it can be useful for verification or review. \$ASSIGN NR1312.DAT INPT.IN

\$ASSIGN RA1312.DAT RELRAT.OUT

\$ASSIGN NR1312.0UT PROBCON.OUT

\$ASSIGN NR1312.SUM PROBCON.SUM

\$ASSIGN NR1312. TMP FOR007

\$RUN PROBCON

The "NR" in the above files stands for "Natural Release mode", and the "RA" stands for "Release rAtes." A similar command file for the human intrusion scenario of drilling boreholes 1000 years after disposal $(k=3)$ is shown below.

\$ASSIGN HI3.DAT INPT. IN

\$ASSIGN HIOUT3.OUT PROBCON.OUT 
\$ASSIGN HISUM3. SUM PROBCON. SUM

SASSIGN CCDFH3.DAT HICCDF.OUT

\$RUN PROBCON

The "HI" in the above files stands for "Human Intrusion mode."

\subsubsection{CMCCDF Cormand File}

The following comband file executes the CMCCDF code, reads both the human intrusion CCDF files (one for each alternative) and the natural release files (one for each alternative) for the same scenario as above (barrier failure with current climate):

\$ASSIGN CMCCOF.SUM FOR004

SASSIGN CMCCDF.OUT FOROO6

\$RUN CMCCDF

1,

CC3113. SUM

RA1311.DAT

CCDF13.DAT
,LOG Y-AXIS

,OUTPUT FILE NAME

, INPUT FILE NAME

, INPUT FILE NAME

,END OF INPUT FILES

GE0. ALT.;CUR. CLIM. BF @2500 A.D.; BH @ 1000YR. TITLE FOR ABOVE

CC3123. SUM

RA1312.DAT

, OUTPUT FILE NAME

CCDF23.0UT

, INPUT FILE NAME

- INPUT FILE NAME

,END OF INPUT FILES

IPSD ALT.;CUR. CLIM. BF 02500 A.D.; BH @ 1000 YR. TITLE FOR ABOVE CC3133.SUM , OUTPUT FILE NAME

RA1313.DAT ,INPUT FILE NAME

CCDF33.0UT , INPUT FILE NAME ,END OF INPUT FILES

REF. ALT.;CUR. CLIM. BF 92500 A.D.; BH O1000 YR. TITLE FOR ABOVE , END OF RUN INDICATOR 


\subsubsection{COMHUM Command File}

The following command file executes the COMHUM code, reads the human intrusion CCDF for 1000 years after disposal ( $k=3)$, and creates 4 new files with the CCDF for each alternative on each file.

\$ASSIGN COMHUM.OUT FOROO6

SRUN COMHUM

1.

CCDFH3.DAT

1 ,

CCDF13.0UT

2 ,

CCDF23.0UT

3 ,

CCDF33.0UT

4,

CCDF43.0UT

0 ,
,LOG Y-AXIX

, INPUT FILE NAME

-ALTERNATIVE SELECTION

,OUTPUT FILE NAME

- ALTERNATIVE SELECTION

,OUTPUT FILE NAME

, ALTERNATIVE SELECTION

,OUTPUT FILE NAME

,ALTERNATIVE SELECTION

,OUTPUT FILE NAME

, END OF RUN INDICATOR

\subsubsection{PRAPLT Command File}

This program is run interactively. The user just needs to interactively answer the questions on the terminal screen.

\subsubsection{W8CCDF Command File}

The following command file executes program W8CCDF, reads the CCDF files for each scenario for the geologic disposal alternative, and reads the corresponding scenario probability for each scenario:

\$ASSIGN W8CCDF.SUM FORO04

\$ASSIGN WBCCDF.OUT FOROOG

\$RUN W8CCDF

1 ,

NH0010.SUM

CC2312.SUM

0.025
,LOG Y-AXIS

,OUTPUT FILE NAME

, INPUT FILE NAME-SCENARIO $(2,3,2)$

,SCENARIO PROBABILITY 
CC2313. SUM

0.025

CC3312.SUM

0.025

CC3313. SUM

0.025

CC2112.SUM

0.225

CC2113.SUM

0.225

CC3112.SUM

0.225

CC3113.SUM

0.225
, INPUT FILE NAME-SCENARIO $(2,3,3)$

,SCENARIO PROBABILITY

, INPUT FILE NAME-SCENARIO $(3,3,2)$

,SCENARIO PROBABILITY

I INPUT FILE NAME-SCENARIO $(3,3,3)$

, SCENARIO PROBABILITY

, INPUT FILE NAME-SCENARIO $(2,2,2)$

,SCENARIO PROBABILITY

, INPUT FILE NAME-SCENARIO $(2,1,3)$

,SCENARIO PROBABILITY

, INPUT FILE NAME-SCENARIO $(3,1,2)$

, SCENARIO PROBABILITY

- INPUT FILE NAME-SCENARIO $(3,1,3)$

, SCENARIO PROBABILITY

,END OF INPUT FILES INDICATOR

GEOLOGIC ALT. COMPOSITE CCDF FOR 8 SCENARIOS - TITLE FOR ABOVE ,END OF RUN INDICATOR

\subsubsection{W8PLOT Command File}

This program is run interactively. The user must answer the questions on the terminal screen. 


\subsection{REFERENCES}

Department of Energy (DOE). 1987. Final Environmental Impact Statement--

Disposal of Hanford Defense High-Level, Transuranic and Tank Wastes. DOE/EIS0113, U.S. Department of Energy, Washington, D.C.

Environmental Protection Agency (EPA). 1985. High-Level and Transuranic Radioact ive Waste--Background Information Document Final Rule. EPA 520/185-023, U.S. Environmental Protection Agency, Office of Radiation Protection Programs, Washington, D.C.

Little, A. D. 1980. Release Mechanisms. Volume D: Technical Support of Standards for High-Level Radioactive Waste Management. EPA 520/4-79-007D (PB81-106254), Office of Radiation Protection Programs, Washington, D.C. 


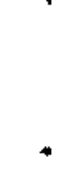




\section{APPENDIX A}

ENVIRONMENTAL RELEASE LIMITS (40 CFR 191) 
APPENDIX A

ENVIRONMENTAL RELEASE LIMITS (40 CFR 191)

The release limits used in Equation (1.1) are defined in this Appendix. Since the release limits for Hanford defense wastes depend on the disposal alternative being simulated, the disposal alternative index, $A$, will be used as a subscript; e.g.. $R L_{n}, A . R L_{n, A}$ is the release limit for the nth radionuclide in curies for waste alternative $A . N$ is the total number of radionuclides in the waste that are modeled. Eleven radionuclides were used on default in program PROBCON $(N=11)$. Their selection was based primarily on the inventory of each radionuclide divided by its release limit (i.e., the inventory-to-release-limit ratio). The radionuclides corresponding to the ten largest inventory-to-release-limit ratios were selected. The radionuclides

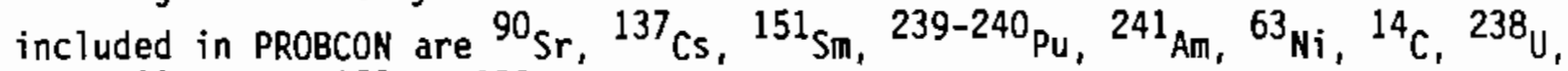
${ }^{93} \mathrm{Zr},{ }^{99} \mathrm{Tc}$, and ${ }^{129} \mathrm{I}$. ${ }^{129} \mathrm{I}$ was also included because it is highly soluble and transportable. The radionuclides that were omitted from PROBCON are not expected to contribute significantly to the release-ratio consequence over the next 10,000 years. This expectation is based on the knowledge that at least one of the following statements is true: the inventories of the remaining radionuclides are small relative to their allowed release limits; their high retardation factors cause their travel times to the groundwater to be greater that 10,000 years; or their radioactive decay half-lives are short compared to their travel times.

The release limits for the reprocessed irradiated fuel throughput used as default in PROBCON are based on approximately 94,000 metric tons of heavy metal (MTHM), before processing, represented in existing waste and 12,000 MTHM projected for future waste. Release limits (in curies) are calculated for each radionuclide from Table 1 of EPA standard 40 CFR 191 (EPA 1985), the fuel throughputs, the fuel burnup, and the amount of radionuclide inventory that is disposed of near surface on site for each disposal alternative.

For the reference and geologic disposal alternatives, the majority of the radionuclide inventories are disposed of in a geologic repository. The 
EPA release limits for the radionuclides disposed of near surface in these two alternatives are lower than for the other alternatives when the release limits are proportioned by the amount of inventory disposed of on site.

The release limit, $R_{n, A}$, for each radionuclide, $n$, for each alternative, $A$, is calculated by the following equation:

$$
R L_{n, A}=C_{n} \cdot B \cdot\left(M_{e} \cdot E_{n, A}+M_{f} \cdot F_{n, A}\right)
$$

where $\quad C_{n}=$ the release limit from Table 1 of 40 CFR 191 for each radionuclide $n$ per 1,000 MTHM of fuel throughput

$B=$ burnup correction factor $=5,000 \mathrm{MWd} / 30,000 \mathrm{MWd}=1 / 6$ (see Note 3 of 40 CFR 19I; 5000 MWd/MTHM may be used when the average burnup is below $5000 \mathrm{MWd} / \mathrm{MTHM}$ )

$$
\begin{aligned}
& \mathrm{Me}_{\mathrm{e}}=\text { number of thousand MTHM al ready processed and existing } \\
& \text { as waste at Hanford } \\
& M_{f}=\text { number of thousand MTHM projected to be processed in the } \\
& \text { future at Hanford } \\
& =12 \text {; i.e., 12,000 MTHM in future waste } \\
& E_{n, A}=\text { existing inventory of radionuclide } n \text { disposed of by } \\
& \text { alternative A divided by the total existing inventory of }
\end{aligned}
$$

$$
E_{n, A}=\frac{Q_{n, A, e}}{Q_{n, e}}
$$

$$
\text { where } \begin{aligned}
Q_{n, A},= & \text { existing inventory }(C i) \text { of radionuclide } n \text { disposed of } \\
& \text { near surface by disposal alternative } A \\
Q_{n, e}= & \text { total existing inventory }(C i) \text { of radionuclide } n \text { before } \\
& \text { disposal }
\end{aligned}
$$




$$
\begin{aligned}
& F_{n, A}=\text { total existing inventory }(C i) \text { of radionuclide } n \text { to be } \\
& F_{n, A}=\frac{Q_{n, A} f}{Q_{n, f}}
\end{aligned}
$$

Both the existing and future inventory-remaining fractions defined above are all equal to 1 for the no disposal action and the in-place stabilization and disposal alternatives. For these alternatives all radionuclide inventories remain near surface on site. Hence, these alternatives use the "total" release limits, which are not "partitioned." The radionuclide inventory fractions for the geologic disposal and reference alternatives, shown in Table A.1, are used in Equation A.1 to calculate the partitioned release limits for each radionuclide. The inventory-remaining fraction of each radionuclide is directly proportional to the partitioned release limit for each. The partitioned release limits were motivated by Note 4 of the 40 CFR 191, which states that a different release limit allocation may be used as long as the total release limit remains unchanged. The calculated release limits, as used here, for each radionuclide for each alternative are shown in Table A.2.

The burnup correction factor $(B=1 / 6)$ effectively reduces the existing fuel throughput from 94,000 MTHM to about 16,000 equivalent MTHM (eMTHM), and the future fuel throughput from 12,000 MTHM to 2,000 eMTHM (i.e., 18,000 eMTHM in total) for calculating the EPA release limits. The burnup correction factor used here is based on 5,000 MWd/MTHM, a value permitted by the EPA in Note 3 of 40 CFR 191 when the average burnup is below $5000 \mathrm{MWd} / \mathrm{MTHM}$. 
IABLE A.1. Fractions of Existing and Future Radionuclide Inventories Disposed of Near Surface for Geologic Disposal and Reference Alternatives

\begin{tabular}{|c|c|c|c|c|c|}
\hline \multirow[b]{2}{*}{$\underline{n}$} & \multirow[b]{2}{*}{ Radionuclide } & \multicolumn{2}{|c|}{ Geologic Disposal } & \multicolumn{2}{|c|}{$\begin{array}{c}\text { Reference } \\
\text { (combination } \\
\text { Disposal) }\end{array}$} \\
\hline & & $\underline{E_{n}, A=1}$ & $F_{n, A}=1$ & $\underline{E_{n}, A=2}$ & $\underline{F_{n}, A=2}$ \\
\hline 1 & ${ }^{90} \mathrm{Sr}$ & 0.029 & 0.006 & 0.53 & 0.034 \\
\hline 2 & $137 C_{5}$ & 0.010 & 0.03 & 0.29 & 0.081 \\
\hline 3 & ${ }^{151} \mathrm{Sm}$ & 0.045 & 0.006 & 0.81 & 0.031 \\
\hline 4 & $239-240 \mathrm{Pu}$ & 0.017 & 0.009 & 0.72 & 0.02 \\
\hline 5 & $241_{\text {Am }}$ & 0.029 & 0.009 & 0.72 & 0.048 \\
\hline 6 & $63 \mathrm{Ni}$ & 0.051 & 0.001 & 0.93 & 0.001 \\
\hline 7 & ${ }^{14} \mathrm{C}$ & 1.0 & 1.0 & 1.0 & 1.0 \\
\hline 8 & $238_{U}$ & 0.046 & 0.75 & 1.0 & 0.75 \\
\hline 9 & $93 z r$ & 0.053 & 0.032 & 1.0 & 0.075 \\
\hline 10 & ${ }^{99} \mathrm{TC}$ & 0.037 & 0.034 & 1.0 & 1.0 \\
\hline 11 & $129_{I}$ & 1.0 & 1.0 & 1.0 & 1.0 \\
\hline
\end{tabular}


TABLE A.2. 40 CFR 191 Table 1 Values and Partioned Release Limits (Equation A.1) for Each Radionuclide Disposed of Near Surface for Each Alternative (Ci)

\begin{tabular}{|c|c|c|c|c|c|c|}
\hline & & Table 1 & $\begin{array}{l}\text { Geologic } \\
\text { Disposal }\end{array}$ & $\begin{array}{r}\text { Reference } \\
\text { (combination } \\
\text { Disposal) } \\
\end{array}$ & $\begin{array}{l}\text { In-Place } \\
\text { Stabiliza- } \\
\text { tion and } \\
\text { Disposal }\end{array}$ & $\begin{array}{c}\text { No Disposal } \\
\text { Action } \\
\end{array}$ \\
\hline$\underline{n}$ & Radionuclide & $191 C_{\pi}$ & $\mathrm{RL}_{n}, \mathrm{~A}=1$ & $R L_{n A}=2$ & $R L_{n, A=3}$ & $\mathrm{RL} n, A=4$ \\
\hline 1 & ${ }^{90} \mathrm{Sr}$ & 1,000 & 470 & 8,300 & 18,000 & 18,000 \\
\hline 2 & ${ }^{137} \mathrm{Cs}$ & 1,000 & 210 & 4,750 & 18,000 & 18,000 \\
\hline 3 & ${ }^{151_{\text {Sm }}}$ & 1,000 & 720 & 12,500 & 18,000 & 18,000 \\
\hline 4 & $239-240_{\mathrm{Pu}}$ & 100 & 28 & 1,000 & 1,800 & 1,800 \\
\hline 5 & $241_{A \Pi}$ & 100 & 47 & 1,100 & 1,800 & 1,800 \\
\hline 6 & ${ }^{63} \mathrm{Ni}$ & 1,000 & 800 & 14,500 & 18,000 & 18,000 \\
\hline 7 & ${ }^{14} \mathrm{C}$ & 100 & 1,800 & 1,800 & 1,800 & 1,800 \\
\hline 8 & ${ }^{238} 8_{U}$ & 100 & 220 & 1,700 & 1,800 & 1,800 \\
\hline 9 & $93 z r$ & 1,000 & 900 & 15,800 & 18,000 & 18,000 \\
\hline 10 & ${ }^{99} \mathrm{Tc}$ & 10,000 & 6,500 & 180,000 & 180,000 & 180,000 \\
\hline 11 & $129_{1}$ & 100 & 1,800 & 1,800 & 1,800 & 1,800 \\
\hline
\end{tabular}

\section{REFERENCE}

Environmental Protection Agency (EPA). 1985. High-Level and Transuranic Radioactive Waste -- Background Information Document Final Rule. EPA 5201185-023, Office of Radiation Protection Programs, Washington, D.C. 

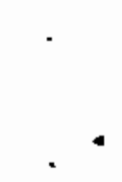
APPENDIX B

DEFAULT PARAMETER VALUES 
APPENDIX B

DEFAULT PARAMETER VALUES

The PROBCON code includes default values for all the model parameters as mentioned in the input section (Section 3.0). The parameter values consist primarily of inventory values for 11 radionuclides, transport parameter (Kd distribution coefficient) values for each radionuclide, and barrier and leaching parameter values. This appendix provides additional information on many of the default parameter values. The output file PROBCON.OUT lists all of the parameter values used for each sum. The scratch file FORO07.DAT gives actual values of key parameters used for each trial or sample (2000 samples are run on default in PROBCON).

The total radionuclide inventory values (including future waste) used on default in PROBCON are given in Table B.1.

The initial inventories of each radionuclide in each waste class for each alternative are listed in Tables P.19 through P.22 of the Hanford Defense Waste Environmental Impact Statement (DOE 1987). The inventory of ${ }^{240} \mathrm{Pu}$,

\section{TABLE B.1. Total Radionuclide Inventories}

\begin{tabular}{|c|c|c|}
\hline n & Radionuclide & Inventory, $\mathrm{Ci}$ \\
\hline 1 & ${ }^{90} \mathrm{Sr}$ & $123,000,000$ \\
\hline 2 & ${ }^{137} \mathrm{Cs}$ & $126,000,000$ \\
\hline 3 & ${ }^{151}{ }_{\text {Sm }}$ & $1,220,000$ \\
\hline 4 & $239-240 \mathrm{Pu}$ & 123,000 \\
\hline 5 & ${ }^{241_{A m}}$ & 392,000 \\
\hline 6 & ${ }^{63} \mathrm{Ni}$ & 320,000 \\
\hline 7 & ${ }^{14} \mathrm{C}$ & 5,290 \\
\hline 8 & $238_{U}$ & 580 \\
\hline 9 & ${ }^{93} \mathrm{Zr}$ & 6,380 \\
\hline 10 & ${ }^{99} \mathrm{TC}$ & 34,800 \\
\hline 11 & ${ }^{129}{ }_{I}$ & 58 \\
\hline
\end{tabular}


small in comparison to ${ }^{239} \mathrm{Pu}$, is added to that of ${ }^{239} \mathrm{Pu}$ because their transport and release properties are expected to be the same; both have long radioactive half-lives and are usually taken together for dosimetry calculations. The longer half-life of ${ }^{239} \mathrm{Pu}$ is used on default in program PROBCON.

Fixed single-valued $K_{d}$ values were used for grout waste and TRU wastes. For the single-shell and double-shell tank wastes, PROBCON uses these values for all the radionuclides except plutonium, americium, uranium, strontium, and nickel where pdfs are used. Log-normal pdfs of $k_{d}$ values are used for plutonium, americium, strontium, and nickel, and a uniform pdf was used for uranium. Adopting a range or distribution of $k_{d}$ values permits a realistic analysis that includes provision for uncertainty. The defautt minimum $K_{d}$ values in the pdfs are the $K_{d}$ values listed in Appendix $P$ of the HDW-EIS for concentrated and complexed nuclides. The maximum sampled $k_{d}$ values in the pdfs are chosen to be those for dilute noncomplexed values of soils reported by Delegard and Barney (1983). Nickel is assumed to have the same $K_{d}$ values as ${ }^{90} \mathrm{Sr}$, and ${ }^{93} \mathrm{Zr}$ is assumed to have a $K_{d}$ value of $20 \mathrm{~mL} / \mathrm{g}$. The default median $K_{d}$ values are reported in Delegard and Barney (1983) except for plutonium in the no action alternative, where a median value closer to the concentrated complexed value was used. The plutonium $k_{d}$ value is very important to the release-ratio consequence. For ${ }^{238_{U}}$, a uniform pdf of $k_{d}$ values was used for all waste classes with a low $K_{d}$ value of 0 and $h i g h K_{d}$ value of $16 \mathrm{~mL} / \mathrm{g}$. The $k_{d}$ pdfs for single-shell and double-shell tarlk waste are summarized in Table B.2.

Input parameters that are described by pdfs are shown in Table B.2 with the assumed pdfs. The bimodal uniform (two-step) pdfs for the barrier failure recharges have a probability for the functional barrier faiture of 0.95 (i.e., the area under the uniform section with the lower recharge values of the pdf is 0.95 ) and a probability of disruptive barrier failure of 0.05 (i.e., the area under the uniform section with the higher recharge values of the pdf is $0.05)$. 
TABLE B.2. Sumnary of Probability Density Functions and Corresponding Parameters

\begin{tabular}{|c|c|c|c|c|c|c|}
\hline \multicolumn{2}{|r|}{ Parameter (Unit) } & \multirow{2}{*}{$\frac{\text { pdf Type }}{\text { log-norma }}$} & \multirow{2}{*}{$\frac{\text { Median }}{1.5}$} & \multicolumn{3}{|c|}{$\begin{array}{l}\text { Parametric Values } \\
\text { Low High Deviation }\end{array}$} \\
\hline 1. & $\begin{array}{l}\text { Current } \mathrm{Cl} \text { imate Recharge } \\
(\mathrm{cm} / \mathrm{yr})\end{array}$ & & & 0 & 5 & 0.9 \\
\hline 2. & $\begin{array}{l}\text { Wetter Climate Recharge } \\
(\mathrm{cm} / \mathrm{yr})\end{array}$ & log-normal & 5.0 & 1.5 & 15 & 2.5 \\
\hline 3. & $\begin{array}{l}\text { Current } \mathrm{Cl} \text { imate Recharge } \\
\text { Under Barrier Failure } \\
\text { (cm/yr) }\end{array}$ & $\begin{array}{l}\text { bimodal }(0.95) \\
\text { uniform }(0.05)\end{array}$ & $\begin{array}{l}0.05 \\
7.5\end{array}$ & $\begin{array}{l}0 \\
5\end{array}$ & $\begin{array}{l}0.1 \\
10\end{array}$ & 1.7 \\
\hline 4. & $\begin{array}{l}\text { Wetter Climate Recharge } \\
\text { Under Barrier Failure } \\
\text { (cm/yr) }\end{array}$ & $\begin{array}{l}\text { bimodal }(0.95) \\
\text { uni form }(0.05)\end{array}$ & $\frac{0.1}{15}$ & $\begin{array}{r}0 \\
10\end{array}$ & 20.2 & 3.3 \\
\hline $5 a$. & $\begin{array}{l}\text { Plutonium } K_{d} \text { for Disposal } \\
\text { Alternatives }(\mathrm{mL} / \mathrm{g})\end{array}$ & $\log$-normal & 26.0 & 0.63 & 71 & 17.0 \\
\hline $5 b$. & $\begin{array}{l}\text { Plutonium } K_{d} \text { for No } \\
\text { Disposal Action }(m L / g)\end{array}$ & log-normal & 6.0 & 0.63 & 71 & 10.7 \\
\hline 6. & Americium $K_{d}(\mathrm{~mL} / \mathrm{g})$ & $\log$-normal & 15.5 & 5.6 & 130 & 15.0 \\
\hline 7. & Uranium $K_{d}(\mathrm{~mL} / \mathrm{g})$ & uniform & 8.0 & 0 & 16 & 4.6 \\
\hline 8. & $\begin{array}{l}\text { Strontium, Nickel } \mathrm{K}_{d} \\
(\mathrm{~mL} / \mathrm{g})\end{array}$ & log-normal & 1.5 & 0.02 & 21 & 3.0 \\
\hline & $\begin{array}{l}\text { Waste Fraction Under } \\
\text { Barrier Failure, } F_{L}\end{array}$ & $\log$-normal & 0.08 & 0 & 1.0 & 0.25 \\
\hline
\end{tabular}

\section{REFERENCES}

Delegard, C. H., and G. S. Barney. 1983. Effect of Hanford High-Level Waste Components on Sorption of Cobalt, Strontium, Neptunium, Plutonium, and Americium on Hanford Sediments. RHO-RE-ST-IP, Rockwell Hanford Operations, Richland, Washington. 
APPENDIX C

PROBCON CODE LISTING 
APPENDIX C

PROBCON CODE LISTING

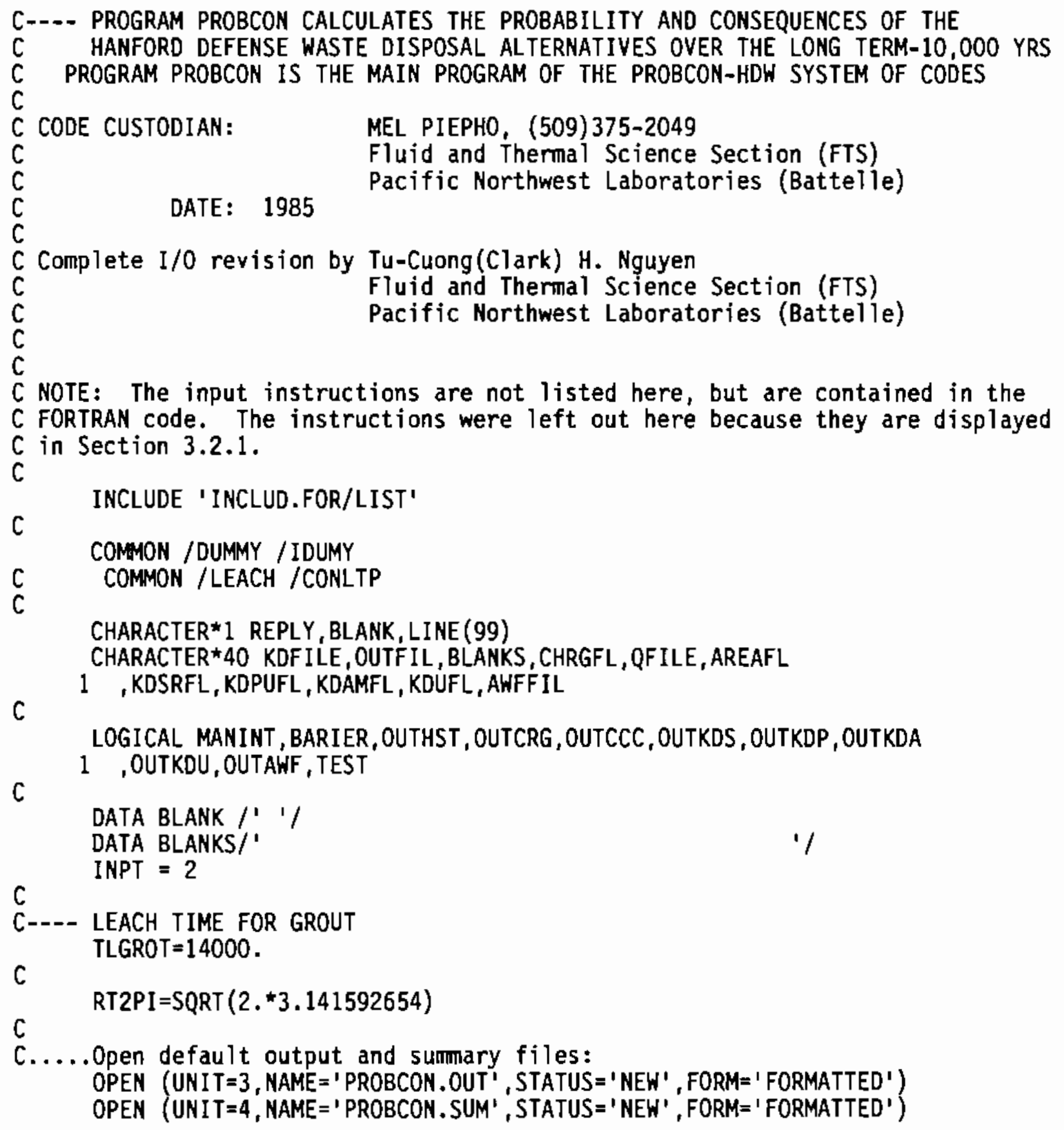


C.....Read in the title and the default data changes:

$\mathrm{C}$ CALL RDINPT(INPT)

C......Make sure that the 'TITL' card is in 'INPT.IN':

DO $3 \mathrm{I}=1,60$

IF (TITLE(I).NE.' ') GOTO 1

3 CONTINUE

PRINT *,'PROBCON: title not given in 'INPT.IN'י'

PRINT *,' use the 'TITL' ' option card!'

STOP

1 MANINT $=$ TYPE.EQ. ' $H^{\prime}$

2 FORMAT (60A1)

14 FORMAT(' OPENING ERROR ENCOUNTERED FOR FILE: 'A40)

DO 9 GALT $=1,4$

IF (GALT.EQ.1) WRITE $(3,500)$

IF (GALT.EQ.4) WRITE $(3,500)$

WRITE $(3,522)$

WRITE $(3,4)$ ALTERN (GALT)

4 FORMAT ('OALTERNATIVE: ', A35)

WRITE $(3,7)$ (NAMEWC $(\mathrm{J}), \mathrm{J}=1$, MAXWST)

1 , (IFIX(YROI (J)), J $=1$, MAXWST)

7 FORMAT(' 0 ', 39X, 'ISOTOPE INVENTORIES [Ci] BY HASTE CLASS'/

$153 X^{\prime}$ 'W W S TE CLAS S.

21 N ISOTOPE ',11(A6,3X),2X,' TOTAL N'/

$\left.316 \mathrm{X}, 11\left({ }^{\prime}\left(1,14,{ }^{\prime}\right) ', 3 \mathrm{X}\right) /\right)$

DO $9 \mathrm{~N}=1$, NSTOPE

DO $19 \mathrm{~J}=1,99$

$19 \operatorname{LINE}(\mathrm{J})=\mathrm{BLANK}$

$S U M=0$.

DO $8 \mathrm{~J}=1$, MAXWST

IF (RQ (N, J,GALT) .LE.0.) G0 T0 8 $K=9 \star(J-1)+1$

$\operatorname{ENCODE}(9,21, \operatorname{LINE}(K)) \quad R Q(N, J, G A L T)$

21 FORMAT (1PE9.2)

$S U M=S U M+R Q(N, J, G A L T)$

8 CONTINUE

WRITE $(3,10)$ N, NAME (N) , LINE, SUM, N

9 CONTINUE

10 FORMAT (I3, 2X, A6, 2X, 99A1, 1PE11.2, I4)

c

C...- CALCULATE RELEASE LIMITS

CALL CALCRL

$\mathrm{C}$
$\mathrm{C}$

32 FORMAT (4E8.0)

C

IF (MANINT) GO TO 114

C

C---- NATURAL RELEASE 


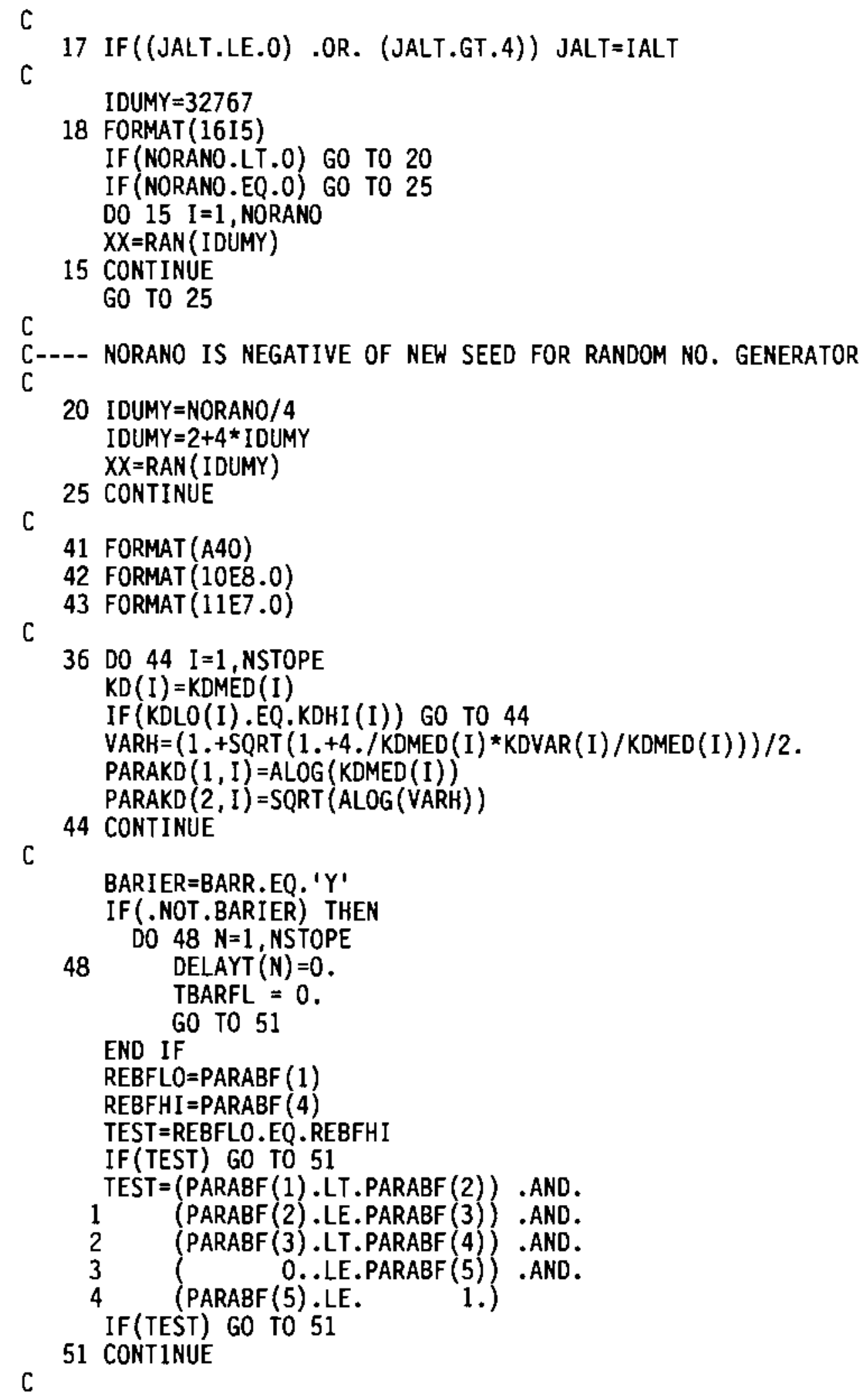




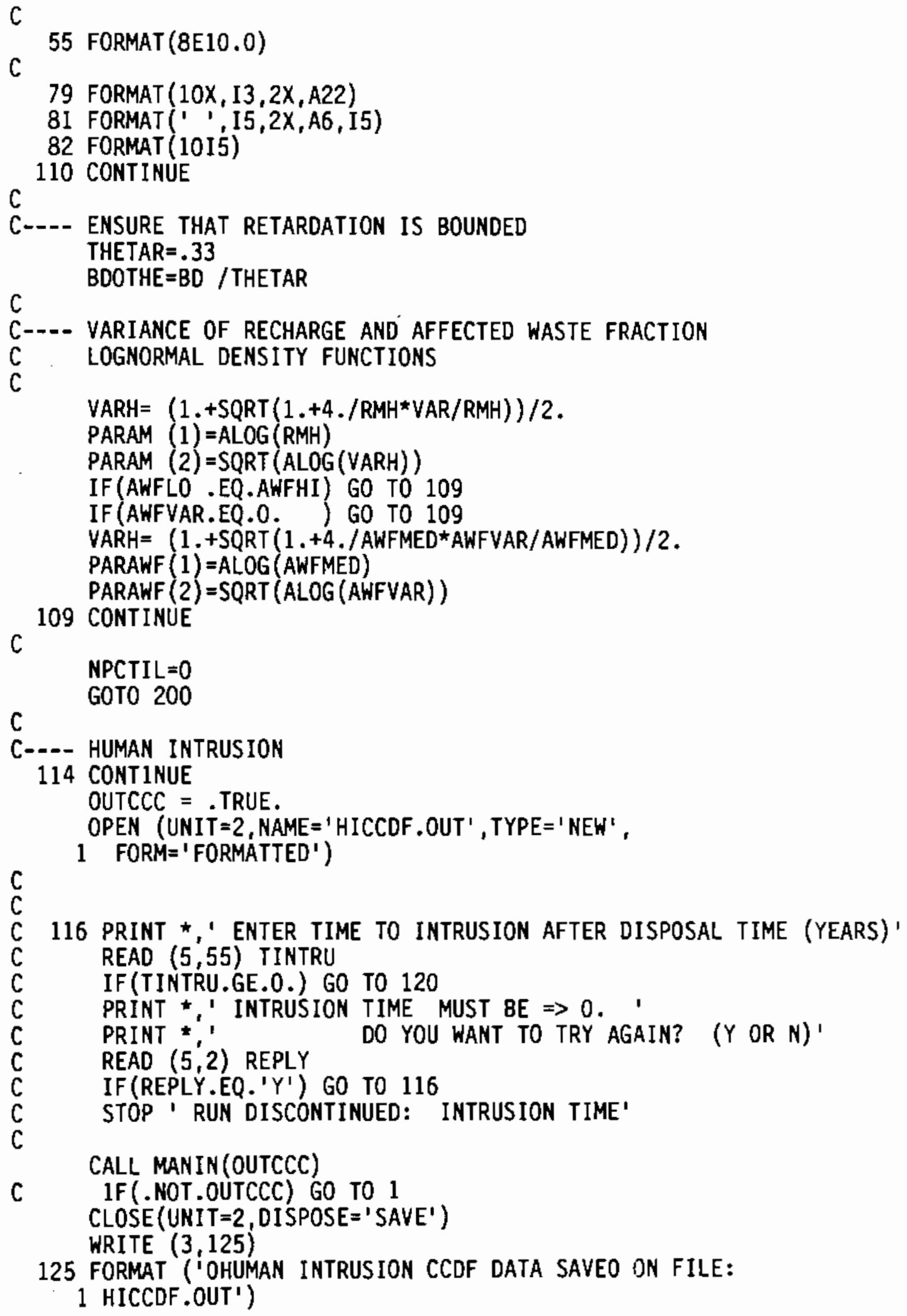




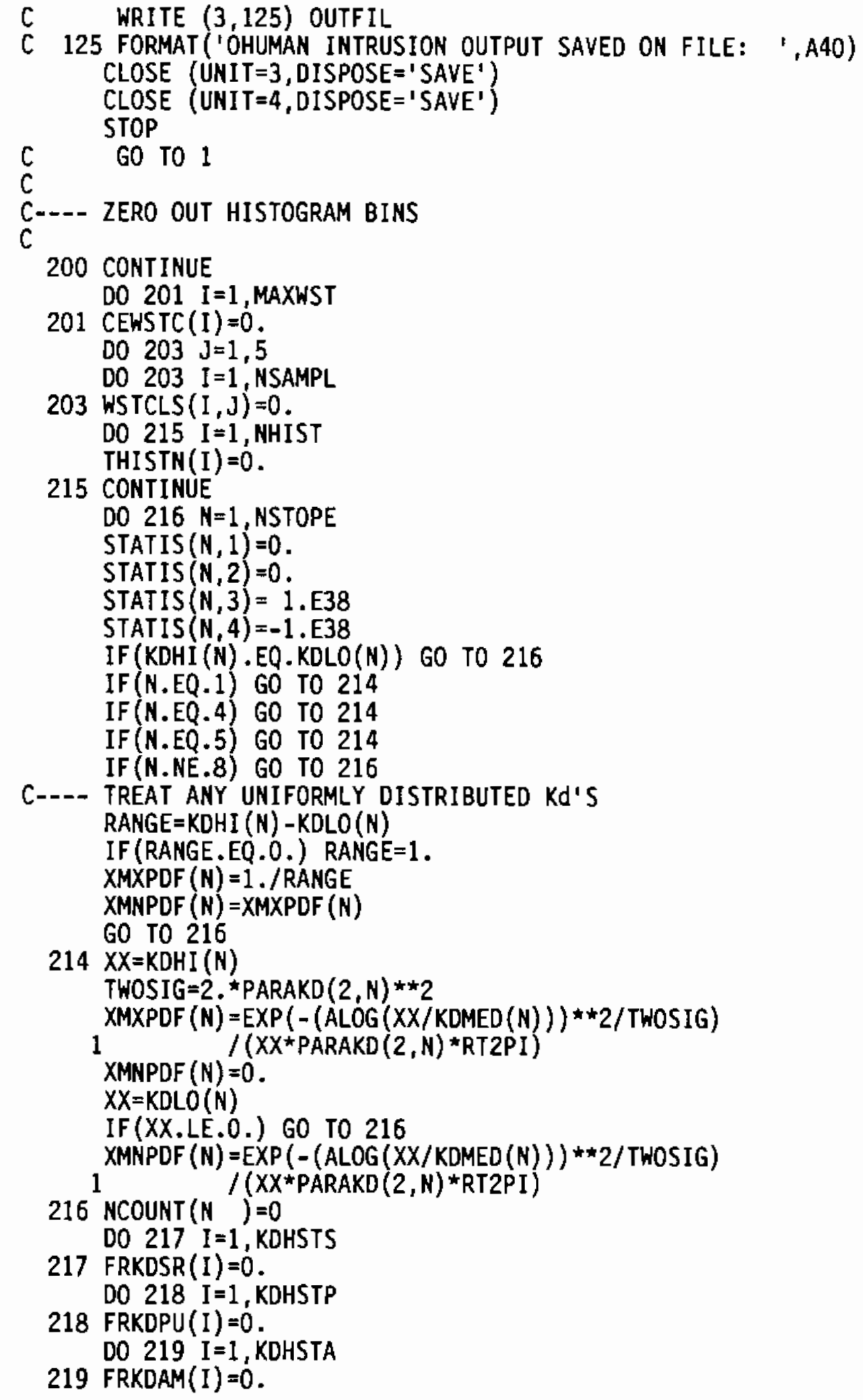




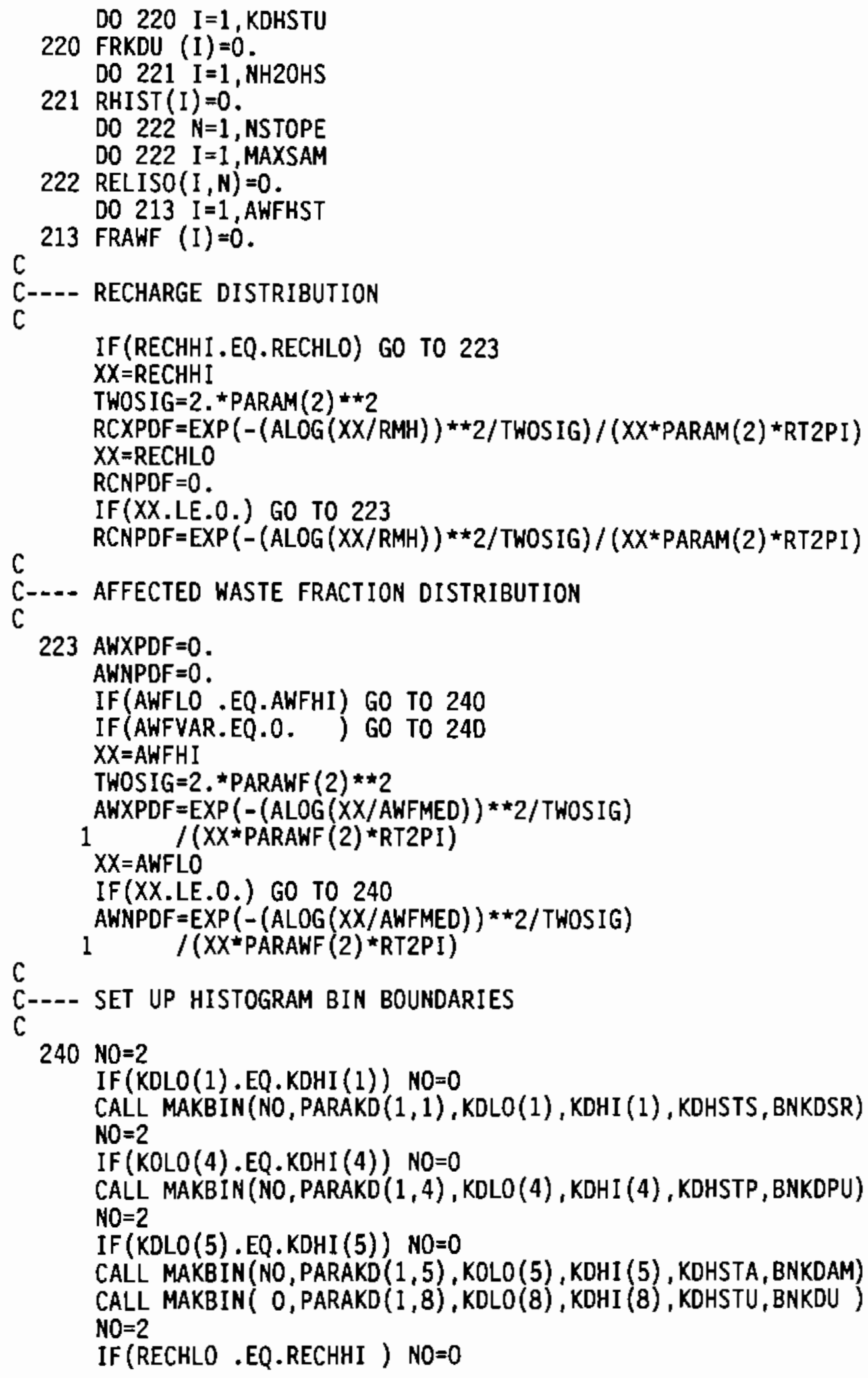




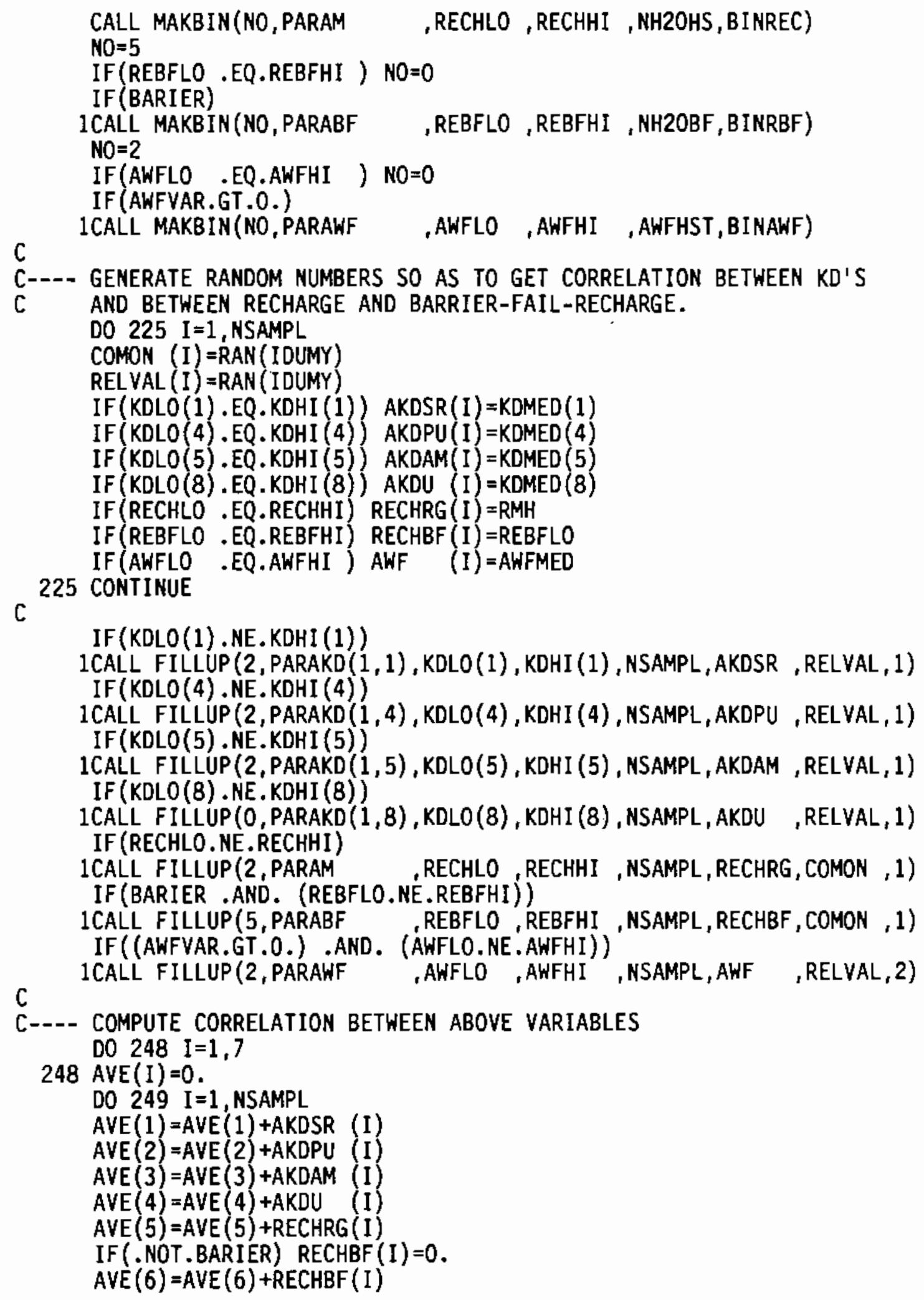


IF (AWFVAR.LE.0.) AWF(I) $=100$.

249 AVE (7) $=$ AVE $(7)+$ AWF (I)

SAMPLN=NSAMPL

DO 247 I =1,7

247 AVE (I) =AVE(I)/SAMPLN

SSQ $(1,1)=00 T P R D(A K D S R, A K D S R, N S A M P L, A V E(1), A V E(1))$

$\operatorname{SSQ}(2,1)=$ DOTPRD (AKDPU ,AKDSR ,NSAMPL, AVE (2), AVE(1))

$\operatorname{SSQ}(3,1)=$ DOTPRD (AKDAM , AKDSR ,NSAMPL, AVE (3), AVE (1))

SSQ $(4,1)=$ DOTPRD (AKDU ,AKDSR ,NSAMPL, AVE (4), AVE(1))

$\operatorname{SSQ}(5,1)=D O T P R D$ (RECHRG, AKDSR ,NSAMPL, AVE (5), AVE(1))

SSQ $(6,1)=D O T P R D(R E C H B F, A K D S R$,NSAMPL, AVE (6), AVE(1))

$\operatorname{SSQ}(7,1)=D O T P R D(A W F \quad, A K D S R$,NSAMPL, AVE $(7)$, AVE (1))

$\operatorname{SSQ}(2,2)=D O T P R D(A K D P U, A K D P U, N S A M P L, A V E(2), A V E(2))$

$\operatorname{SSQ}(3,2)=$ DOTPRD (AKDAM , AKDPU ,NSAMPL, AVE (3), AVE (2))

SSQ $(4,2)=$ DOTPRD (AKDU ,AKDPU, NSAMPL, AVE (4), AVE (2))

SSQ $(5,2)=00 T P R D$ (RECHRG, AKDPU ,NSAMPL, AVE (5), AVE (2))

SSQ $(6,2)=$ DOTPRD (RECHBF, AKDPU ,NSAMPL, AVE (6), AVE (2))

SSQ $(7,2)=D O T P R D(A W F \quad, A K D P U, N S A M P L, A V E(7), A V E(2)$ )

$\operatorname{SSQ}(3,3)=$ DOTPRD (AKDAM , AKDAM , NSAMPL, AVE (3), AVE (3))

$\operatorname{SSQ}(4,3)=$ DOTPRD (AKDU , AKDAM , NSAMPL, AVE (4), AVE (3))

$\operatorname{SSQ}(5,3)=$ DOTPRD (RECHRG, AKDAM , NSAMPL, AVE (5), AVE (3))

$\operatorname{SSQ}(6,3)=D 0 T P R D(R E C H B F, A K D A M, N S A M P L, A V E(6), A V E(3)$ )

$\operatorname{SSQ}(7,3)=$ DOTPRD (AWF ,AKDAM ,NSAMPL, AVE (7), AVE (3))

SSQ $(4,4)=$ DOTPRD (AKDU , AKDU ,NSAMPL, AVE (4), AVE (4))

$\operatorname{SSQ}(5,4)=$ DOTPRD (RECHRG, AKDU ,NSAMPL, AVE (5), AVE (4))

$\operatorname{SSQ}(6,4)=$ DOTPRD (RECHBF, AKDU ,NSAMPL, AVE (6), AVE (4))

$S S Q(7,4)=D O T P R D(A W F \quad$ AKDU ,NSAMPL, AVE (7), AVE (4))

SSQ $(5,5)=$ DOTPRD (RECHRG, RECHRG, NSAMPL, AVE (5), AVE (5))

$\operatorname{SSQ}(6,5)=D O T P R D(R E C H B F, \operatorname{RECHRG}, \operatorname{NSAMPL}, \operatorname{AVE}(6), \operatorname{AVE}(5)$ )

$\operatorname{SSQ}(7,5)=D O T P R D$ (AWF $, \operatorname{RECHRG,NSAMPL,AVE}(7), \operatorname{AVE}(5)$ )

$\operatorname{SSQ}(6,6)=$ DOTPRD (RECHBF, RECHBF, NSAMPL, AVE $(6), \operatorname{AVE}(6)$ )

$\operatorname{SSQ}(7,6)=$ DOTPRD (AWF $\quad, \operatorname{RECHBF}, \operatorname{NSAMPL}, \operatorname{AVE}(7), \operatorname{AVE}(6)$ )

SSQ $(7,7)=D O T P R D(A W F \quad, A W F \quad$,NSAMPL, AVE $(7), \operatorname{AVE}(7)$ )

DO $250 \quad I=1,7$

$\operatorname{SDN}(I)=0$.

$\operatorname{IF}(\operatorname{SSQ}(I, I), G T .0.) \quad \operatorname{SDN}(I)=\operatorname{SQRT}(\operatorname{SSQ}(I, I))$

250 CONTINUE

DO $254 \mathrm{~J}=1,7$

DO $254 \mathrm{I}=\mathrm{J}, 7$

$\operatorname{SDNIJ}=\operatorname{SDN}(\mathrm{I})$ *SDN (J)

IF(SDNIJ.GT.0.) GO T0 253

$\operatorname{SSQ}(I, J)=0$.

GO TO 254

$253 \mathrm{SSQ}(\mathrm{I}, \mathrm{J})=\mathrm{SSQ}(\mathrm{I}, \mathrm{J}) / \mathrm{SDNIJ}$

254 CONTINUE

TSUM=SQRT (SAMPLN-1.)

IF (NSAMPL.LE.1) GO T0 256

DO $255 \quad I=1,7$

$255 \operatorname{SDN}(\mathrm{I})=\operatorname{SDN}(\mathrm{I}) / \mathrm{TSUM}$

C

C.8 


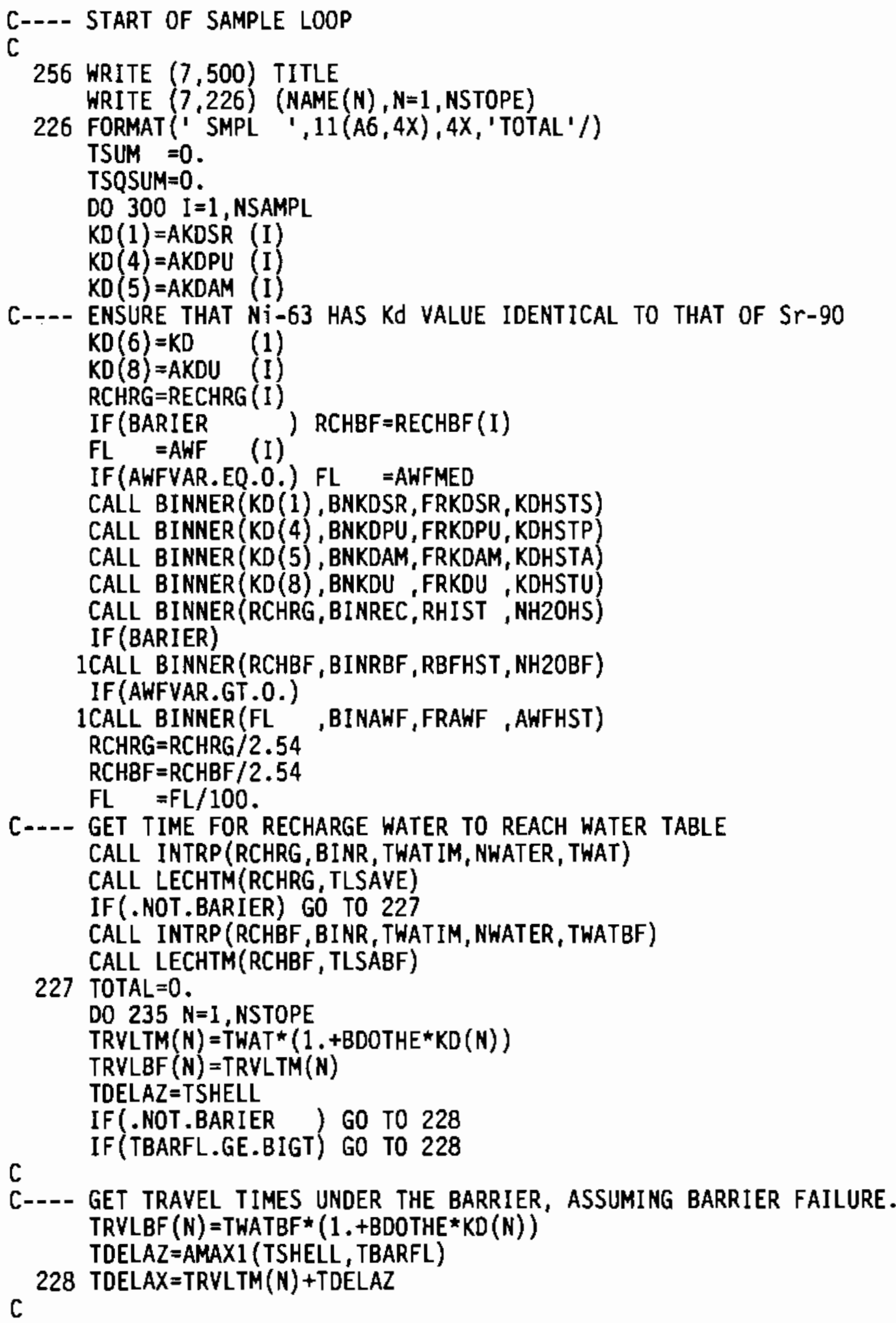


C DO $238 \mathrm{~J}=1$, MAXWST

DO $238 \mathrm{~J}=1,5$

IF (((J.EQ.3) .OR. (J.EQ.5)) .AND. (N.LE.6)) GO TO 238

IF $(R Q(N, J, I A L T)$. LE.0.) GO TO 238

RATIO $=R Q(N, J, I A L T) / R L(N, J A L T)$

CEN $=0$.

TL =TLSAVE

IF(BARIER .AND. (TBARFL,LT.BIGT)) TL=TLSABF

IF ((J.EQ.3) .OR. (J .EQ.5 )) TL=TLGROT

TDELAY=AMAX 1 (TDELAX-YROI $(\mathrm{J})+1995 ., 0$.

C

IF(.NOT.BARIER ) GO TO 224

C---- DIFFUSION RELEASE MODEL

TDELAD=TDELAY+DELAYT $(N)$

IF(TDELAD.GT.BIGT) GO TD 229

DENOM $=$ LAMDA $(N)$

EXPDK $=\operatorname{EXP}(-\mathrm{LAMDA}(\mathrm{N}) * T D E L A D)$

EXPARG $=\operatorname{LAMDA}(N) \star(B I G T-T D E L A D)$

EXPDIF $=0$ NEMEX (EXPARG)

CEN $=F R(\mathrm{~J}) / \mathrm{TP}(\mathrm{J})$ *EXPDK*EXPDIF/DENOM*RATIO

229 IF (LEACHM(J, IALT).EQ.1 ) GO TO 234

IF (TBARFL

$\mathrm{CEN}=(1,-\mathrm{FL}) \star \mathrm{CEN}$

224 TDELAY =AMAX1 (TRVLBF $(\mathrm{N})+$ TDELAZ-YROI $(\mathrm{J})+1995,0$.

IF(TDELAY .GT.BIGT) GO TO 234

CHRG =RCHRG

IF (BARIER .AND. (TBARFL.LT.BIGT)) CHRG=RCHBF

$\operatorname{IF}(\operatorname{LEACHM}(\mathrm{J}, \mathrm{IALT}) . \mathrm{GT} .2) \mathrm{GO}$ TO 230

C

C---- DISSOLUTION-CONTROLLED RELEASE MODEL (LINEAR RELEASE MODEL)

DENOM $=$ LAMDA $(N) * T L$

EXPDK $=\operatorname{EXP}(-\operatorname{LAMDA}(\mathrm{N}) \star T D E L A Y)$

EXPARG $=$ LAMDA $(N)$ * AMIN1 (BIGT, TDELAY +TL) - TDELAY $)$

EXPDIF $=$ ONEMEX (EXPARG)

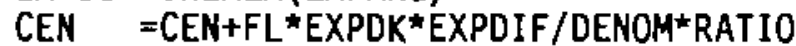

C

GO TO 234

C

$230 \operatorname{IF}(\operatorname{LEACHM}(\mathrm{J}, \mathrm{IALT}) . \mathrm{GT} .3)$ GO TO 233

C--.- SOLUBILITY-CONTROLLED RELEASE MODEL

IF ((TDELAZ+TRVLBF $(N))$.GE.BIGT) GO TO 234

AREA $=H I G A(J, I A L T)$

BASE $=$ CHRG*AREA*0.0254*CSOL $(N) * 1000$.

CI $=R Q(N, J, I A L T) * \operatorname{EXP}(-\operatorname{LAMDA}(N) * T D E L A Z)$

TRLEAS $=10 .{ }^{\star} B I G T$

IF (BASE.NE.0.) TRLEAS=ALOG (CI *LAMDA (N)/BASE+1 .)/LAMDA(N)

TUPPER $=$ TRLEAS

IF ((TRLEAS+ (TRVLBF (N)+TDELAZ)) . GE.BIGT)

1

$\operatorname{EXPDK}=\operatorname{EXP}(-\operatorname{LAMOA}(\mathrm{N}) \star \operatorname{TRVLBF}(\mathrm{N}))$ 


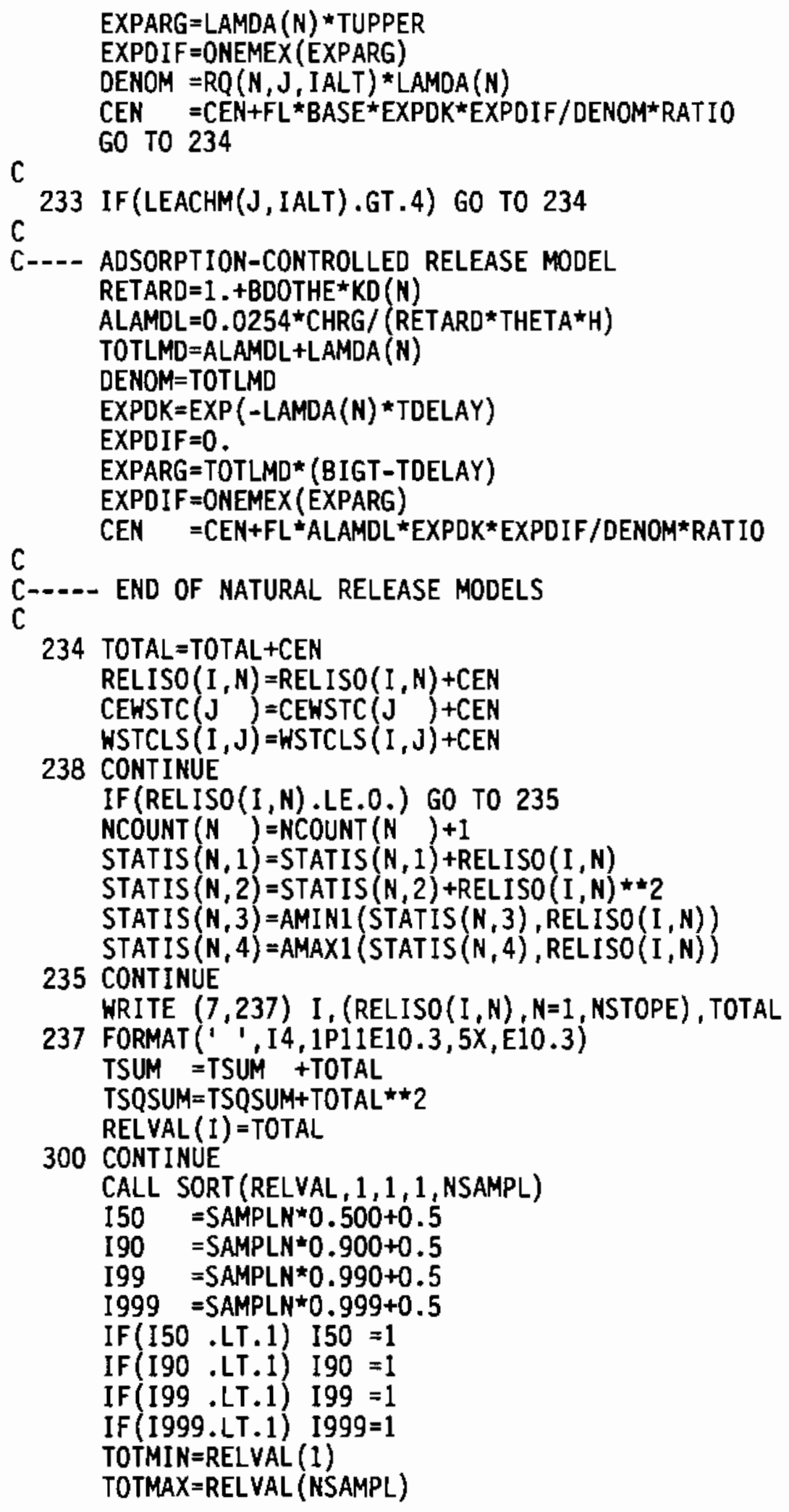




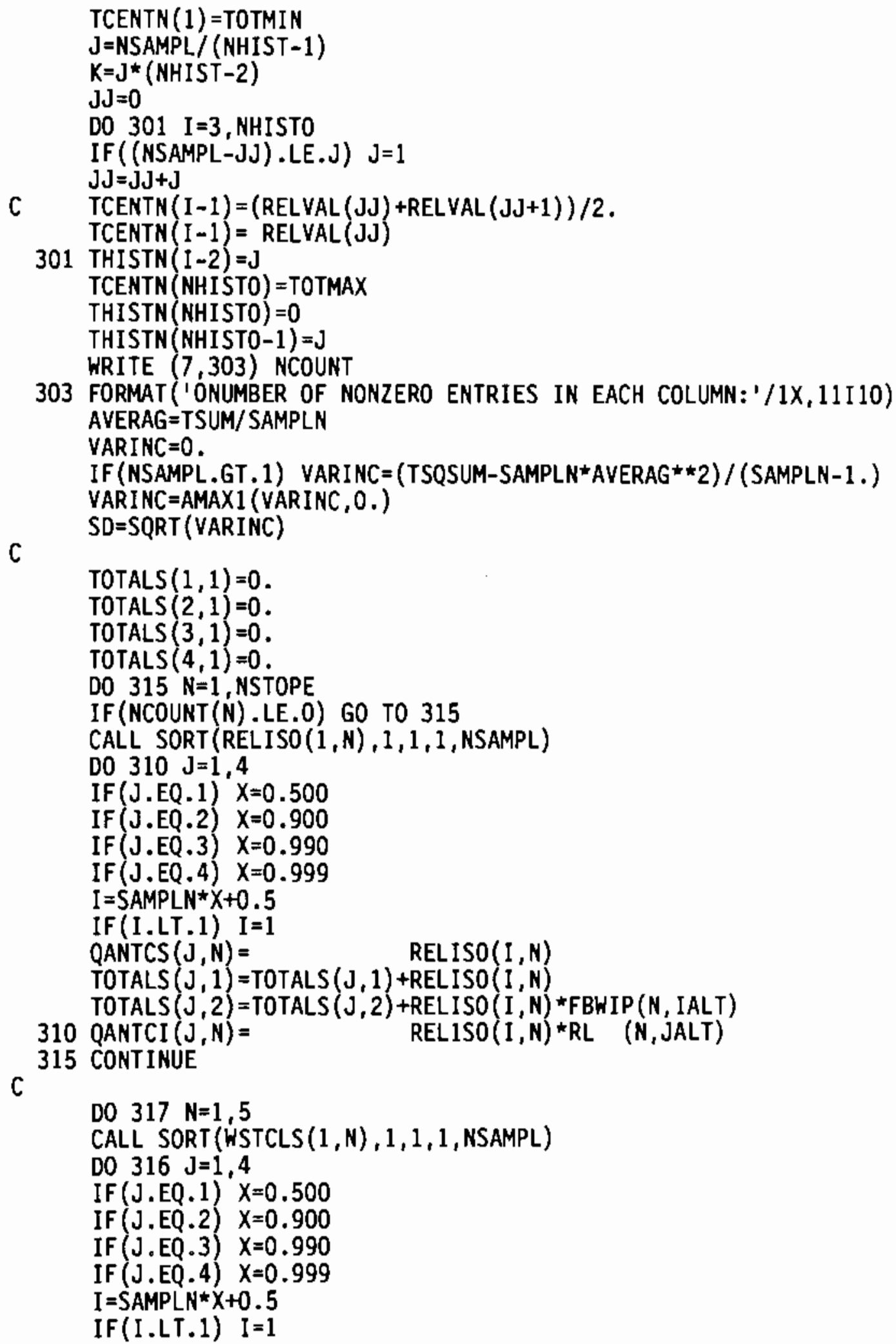




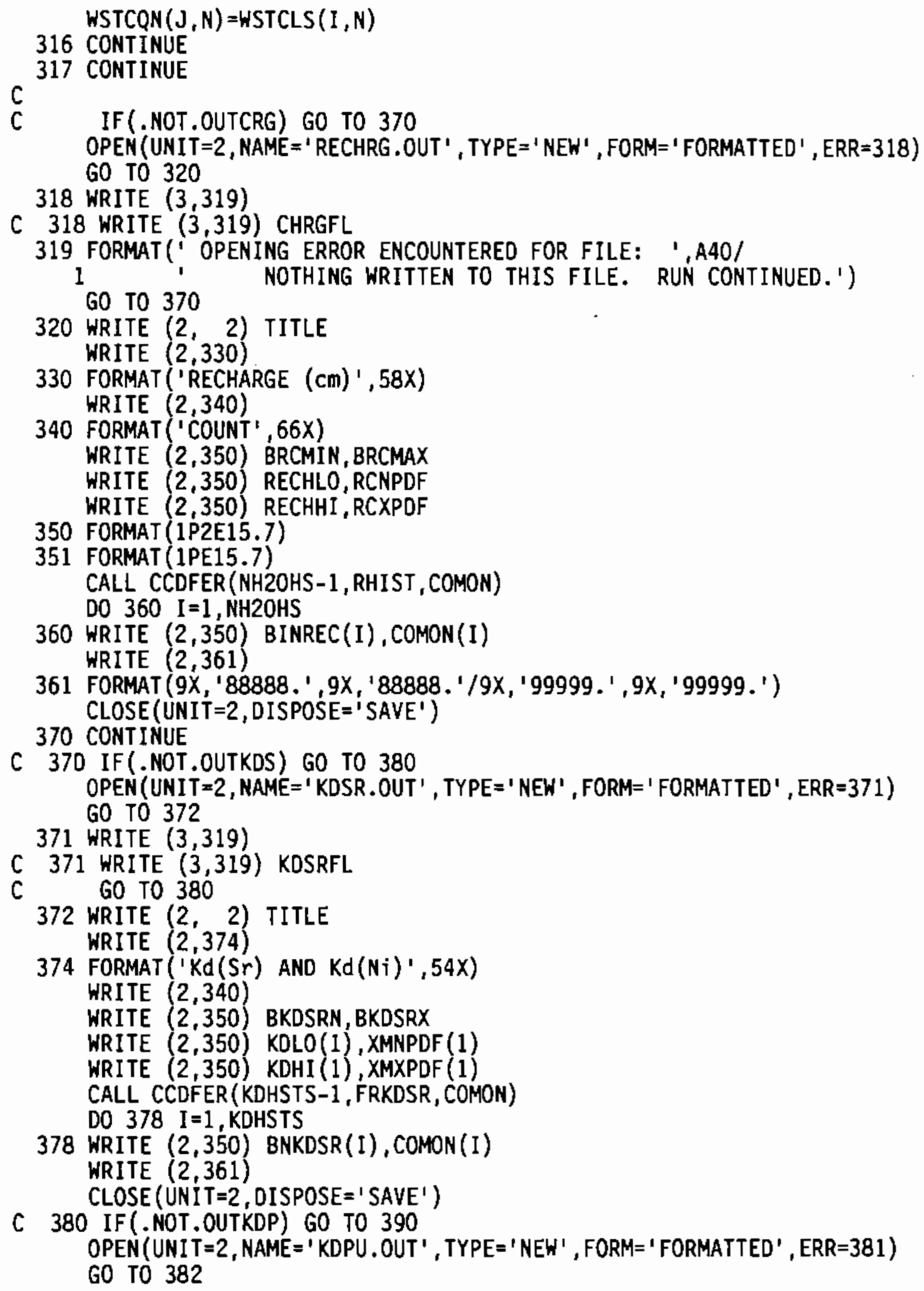




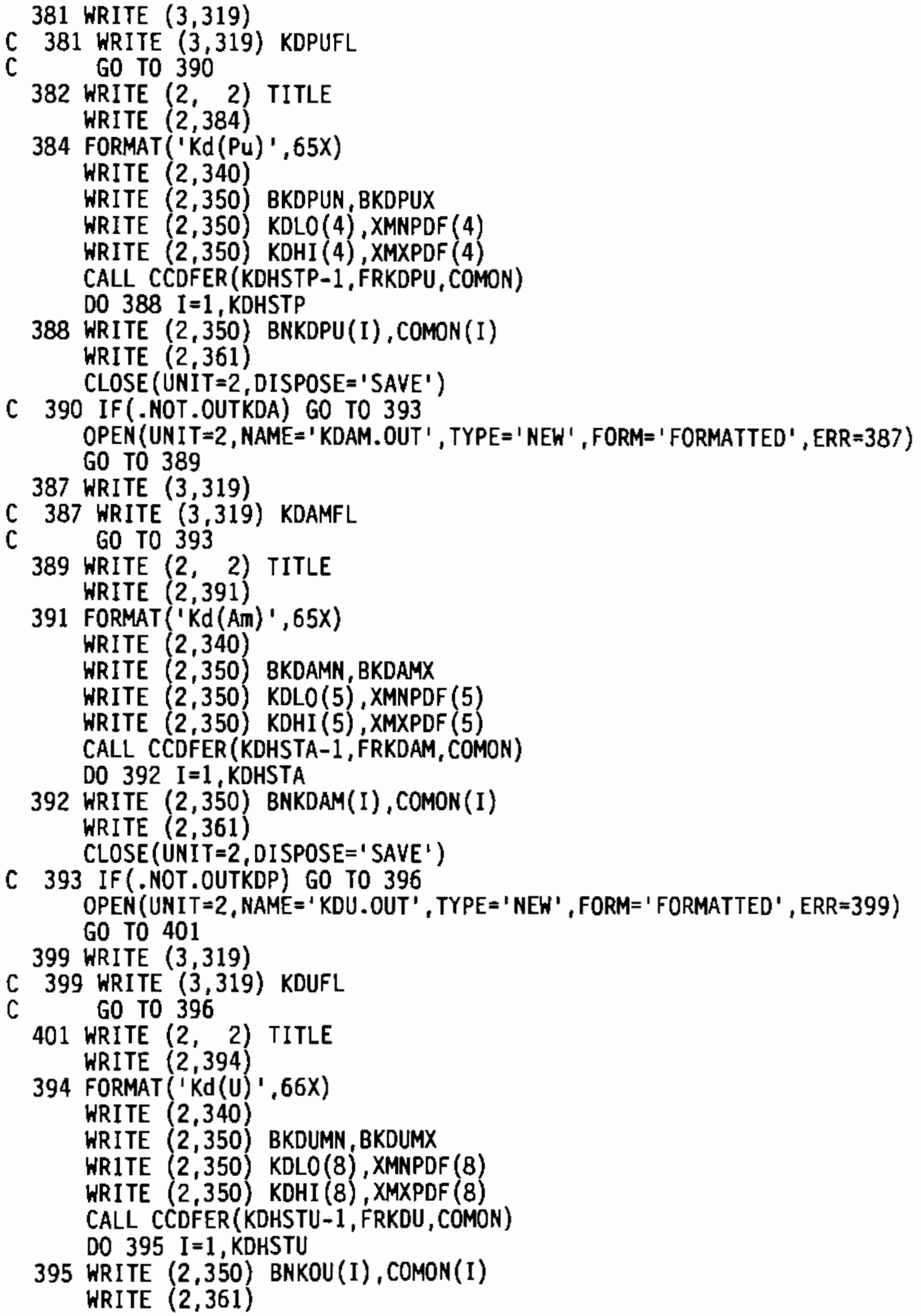




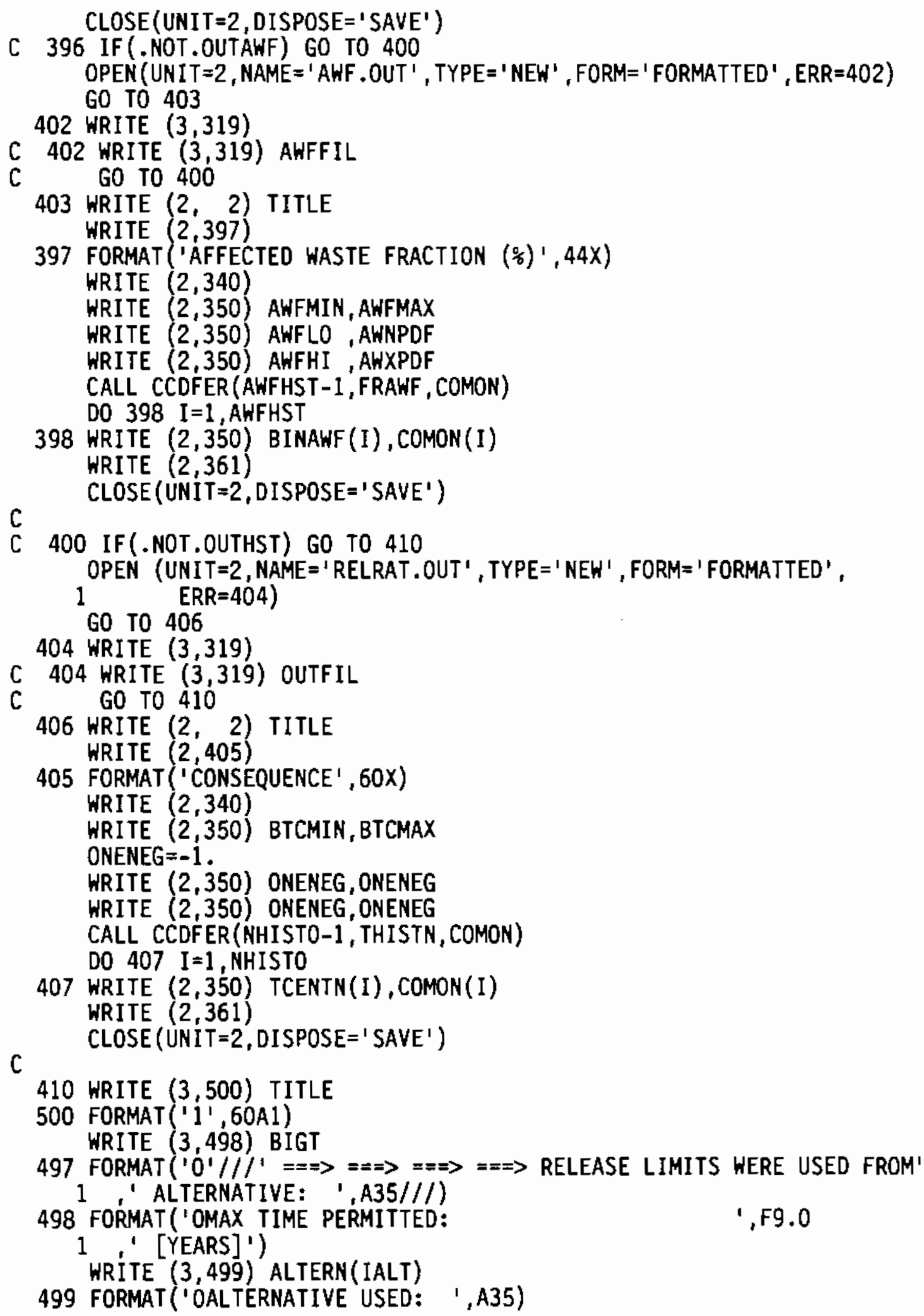




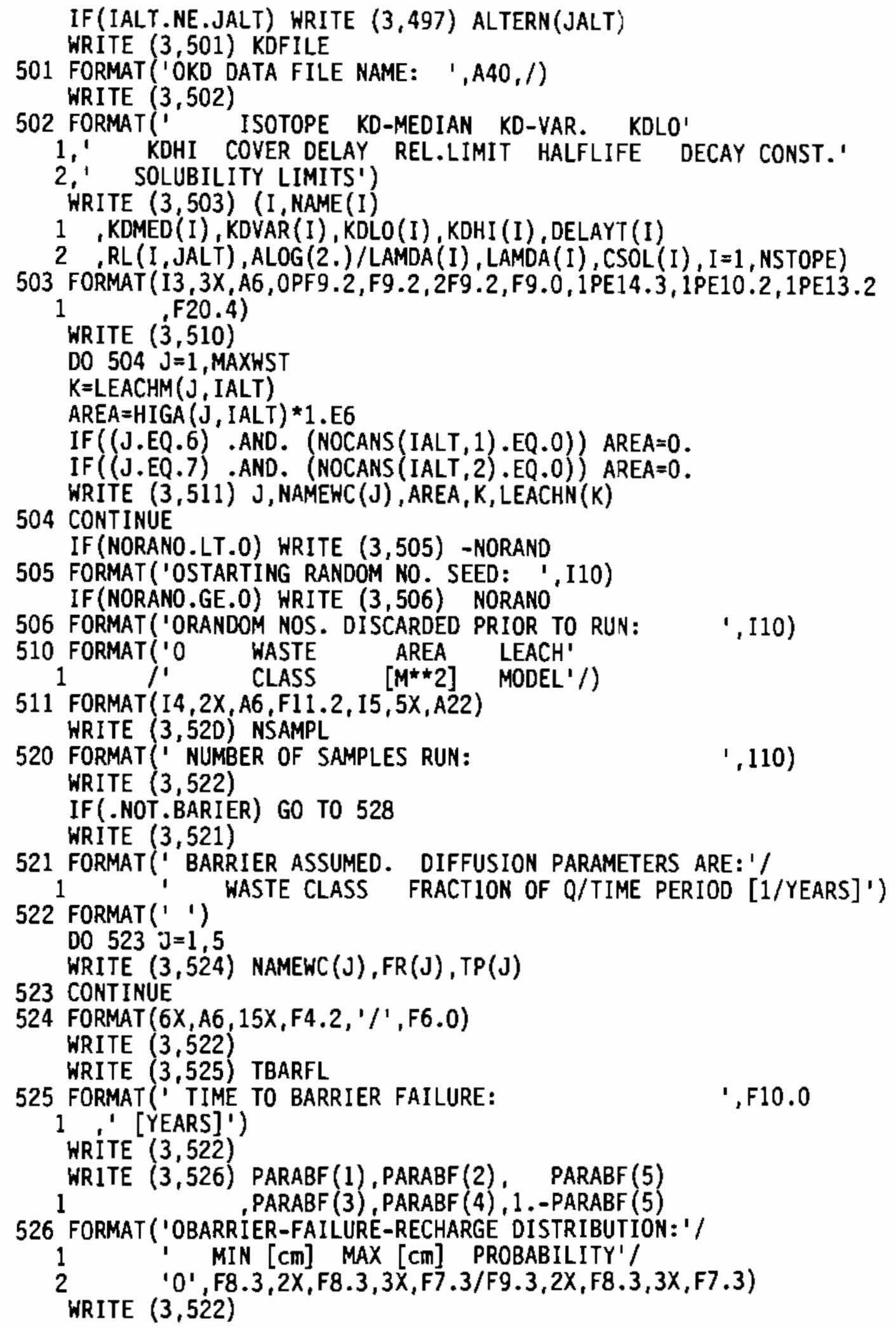




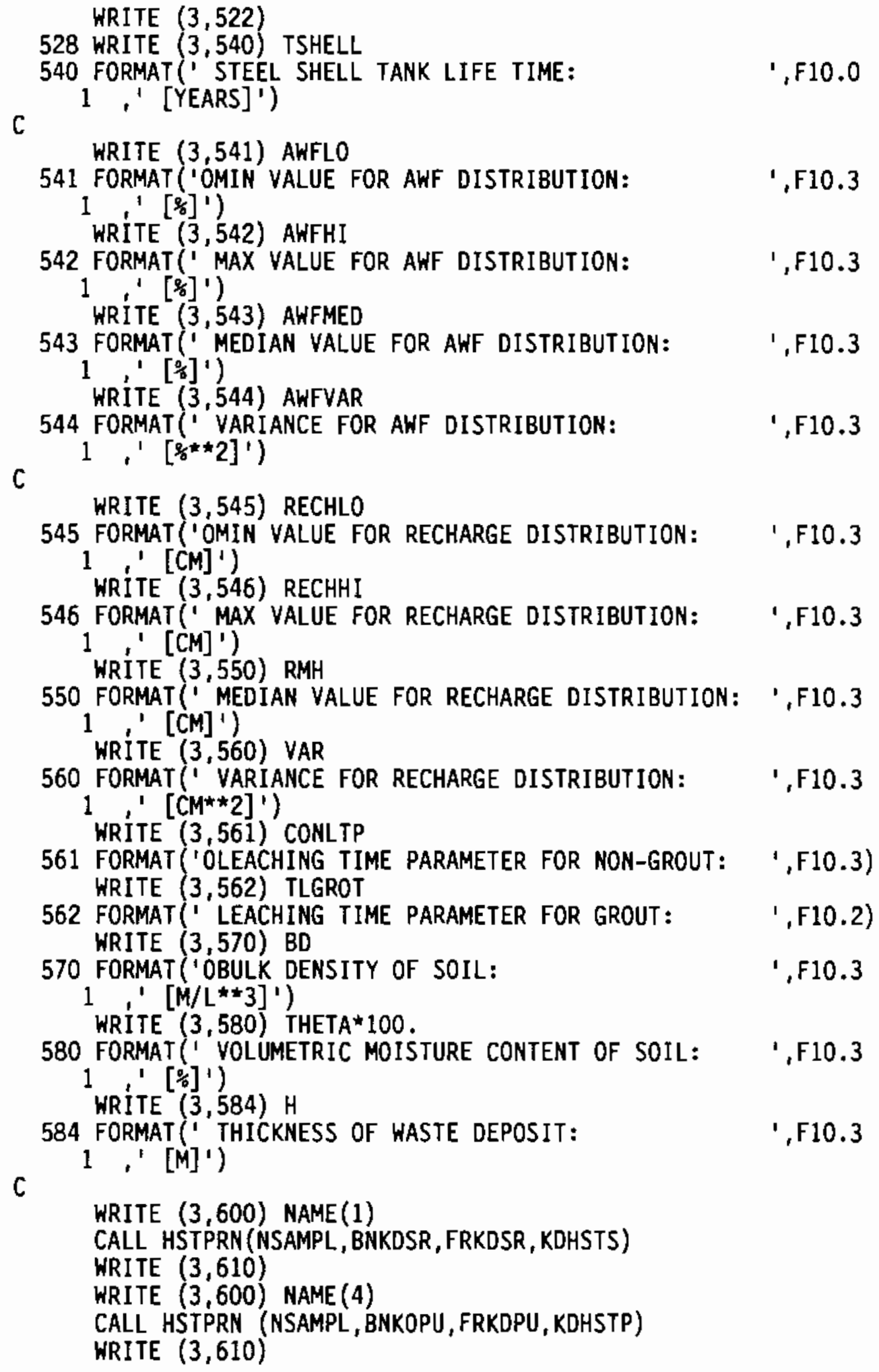


WRITE $(3,600)$ NAME (5)

CALL HSTPRN (NSAMPL, BNKDAM, FRKDAM, KDHSTA)

WRITE $(3,610)$

WRITE $(3,600)$ NAME $(8)$

CALL HSTPRN (NSAMPL, BNKDU, FRKDU, KDHSTU)

WRITE $(3,620)$

CALL HSTPRN (NSAMPL, BINREC, RHIST, NH2OHS)

WRITE $(3,610)$

IF(.NOT.BARIER ) GO TO 585

WRITE $(3,618)$

CALL HSTPRN(NSAMPL, BINRBF, RBFHST, NH2OBF)

WRITE $(3,610)$

585 IF (AWFVAR.LE.0.) GO TO 586

WRITE $(3,622)$

CALL HSTPRN (NSAMPL, BINAWF, FRAWF, AWFHST)

C

WRITE $(3,610)$

586 WRITE $(3,581)$

581 FORMAT ('OSTAN.DEV. AND CORRELATION MATRIX FOR: $\mathrm{Kd}(\mathrm{Sr}), \mathrm{Kd}(\mathrm{Pu})$ '

1 ,' $\mathrm{Kd}(\mathrm{Am}), \mathrm{Kd}(\mathrm{U})$, recharge,barr.fail-rechrg, and affected '

2 ' '-waste-fraction'//)

D0 $582 I=1,7$

WRITE $(3,583)$ I, $\operatorname{SDN}(I),(\operatorname{SSQ}(I, J), J=1, I)$

582 CONTINUE

583 FORMAT (I3, F14.4,3X,7F12.4)

WRITE $(3,610)$

C

WRITE $(3,627)$ TITLE

627 FORMAT ('IFINAL STATISTICS FOR A CALCULATED RELEASE-RATIO',

1

WRITE $(3,590)$ AVERAG, SD, TOTMIN, TOTMAX

590 FORMAT ('OMEAN $=1,1$ PE15.7/' S.D. $=1$, E15.7

$1 /{ }^{\prime}$ MIN $=$ ', E15.7/' MAX =',E15.7)

WRITE (3,591) RELVAL(I50), RELVAL(I90), RELVAL(I99), RELVAL (I999)

591 FORMAT ('OQUANTILE VALUES OF RELEASE-RATIO CONSEQUENCE' $/ /$

$1 \quad 50-$ TH $=$ ', 1PE15.7/

$2 \quad 190-\mathrm{TH}=1$, E15.7/

$3+99-\mathrm{TH}=1$, E15.7/

4 ' 99.9-TH $=1, E 15.7$ )

IF(NPCTIL.LE.0) GO TO 589

DO $588 \quad I=1$, NPCTIL

$\mathrm{J}=$ SAMPLN $*$ PERCEN $(\mathrm{I}) / 100 .+0.5$

IF (J.LT.1) J=1

WRITE $(3,587)$ PERCEN (1), RELVAL (J)

587 FORMAT (' $O$ ' , F3.1, ' - TH $=$ ', 1PE15.7)

588 CONTINUE

589 WRITE $(3,592)$

592 FORMAT ('OSTATISTICS FOR THOSE ISOTOPES REACHING THE BIOSPHERE'/

$\begin{array}{llll}1 & 10 N \text { ISOTOPE NUMBER MEAN S.D. } \\ 2 & \text { 'MAXIMUM' } /) & & \end{array}$ 


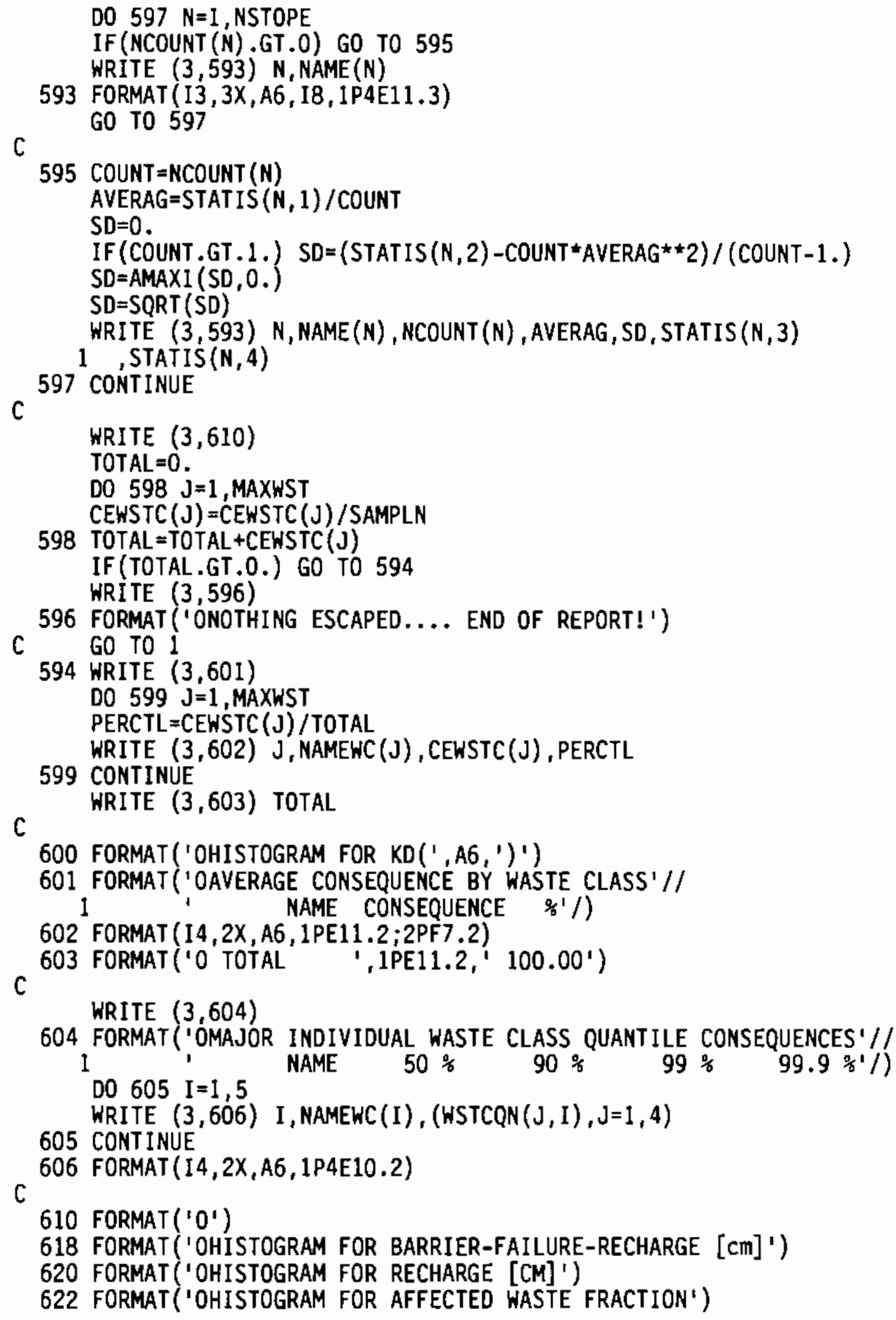




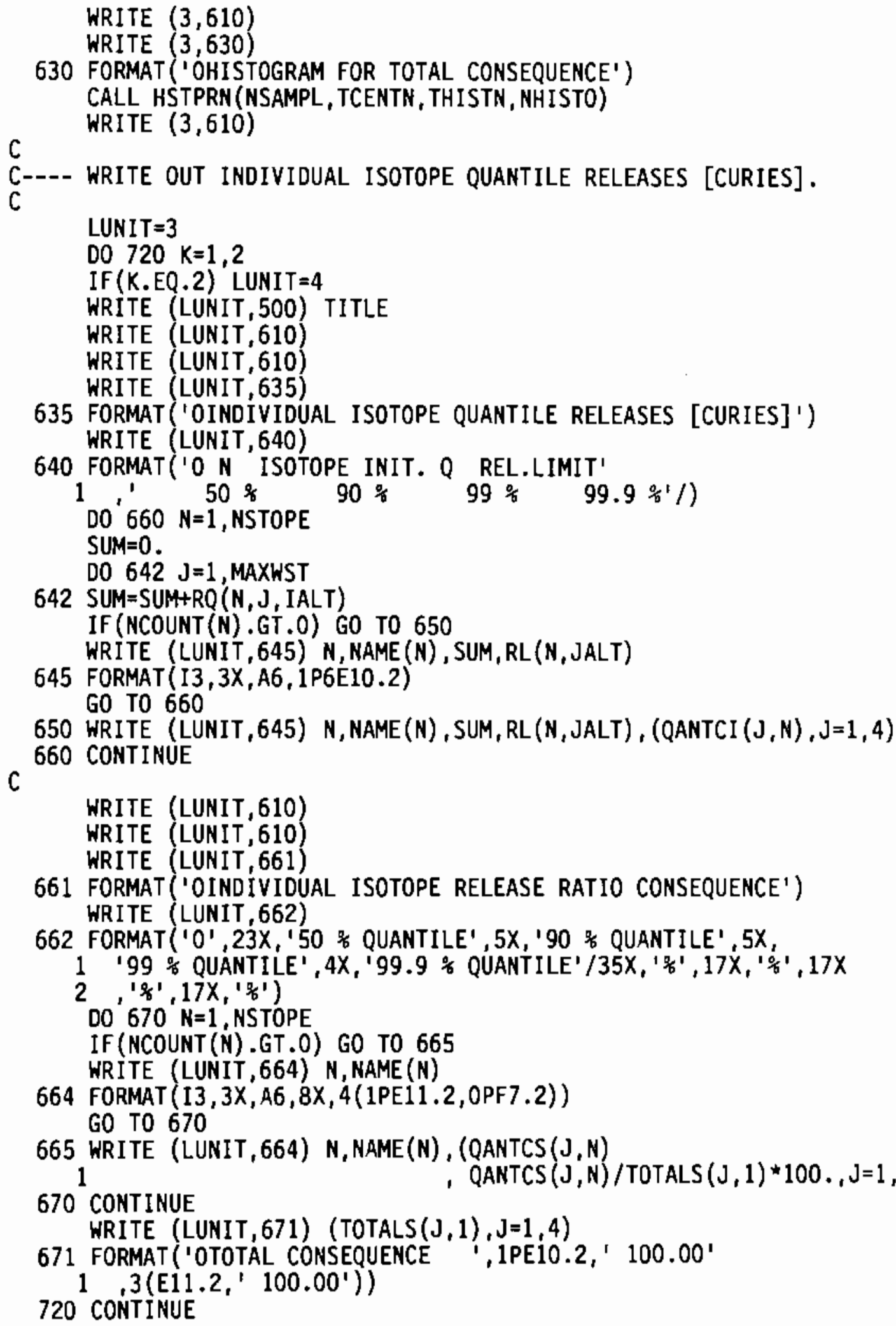




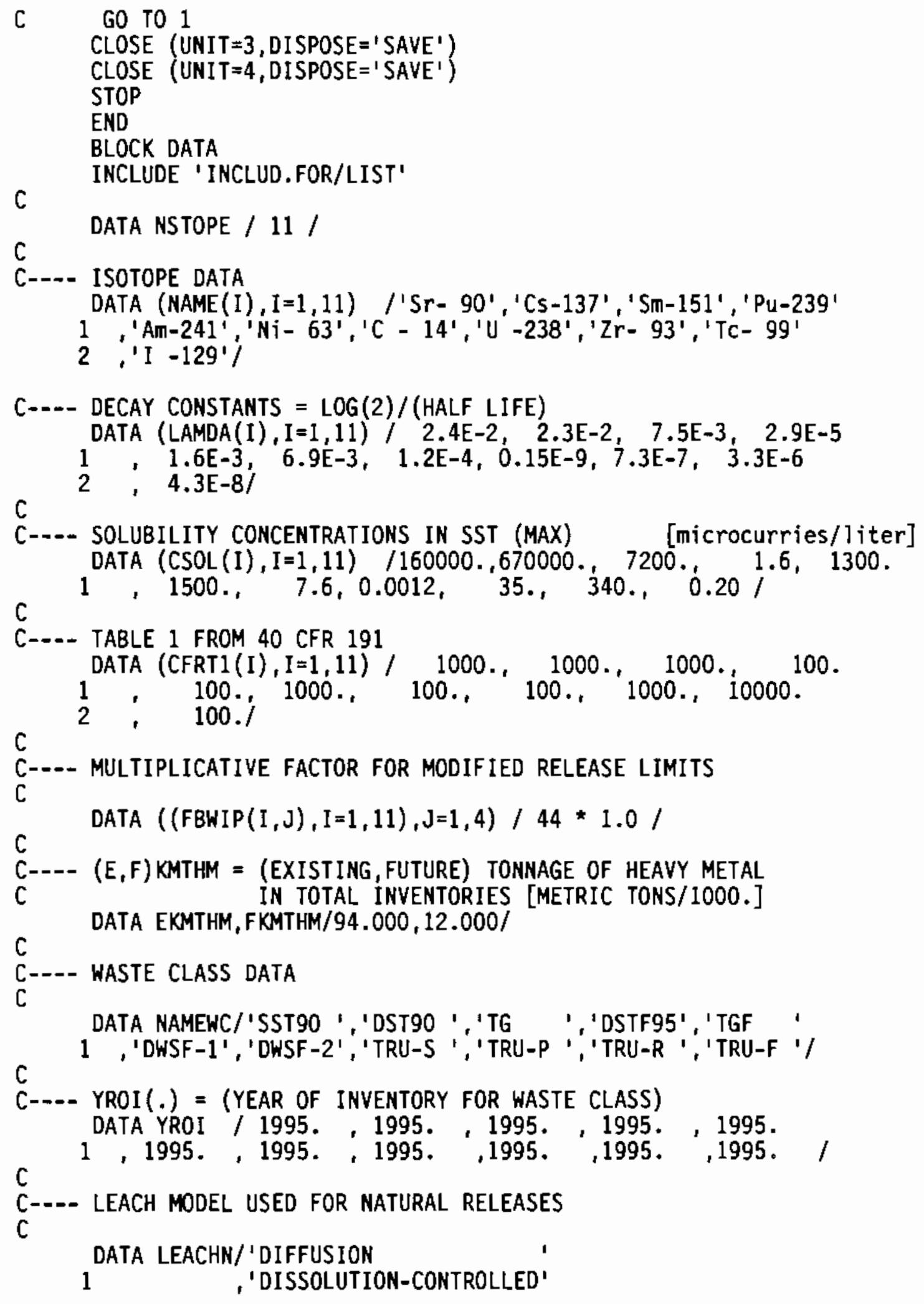




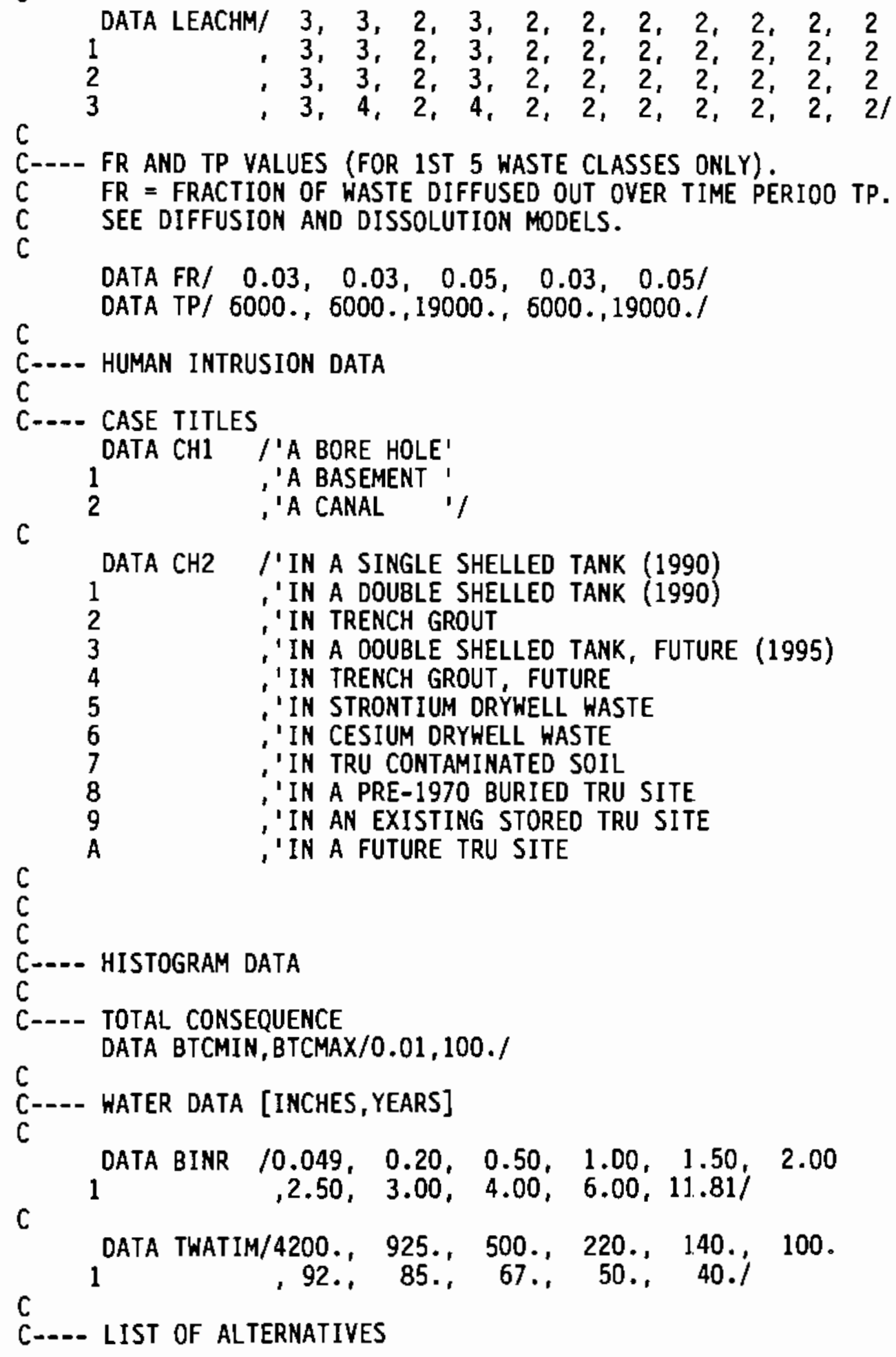




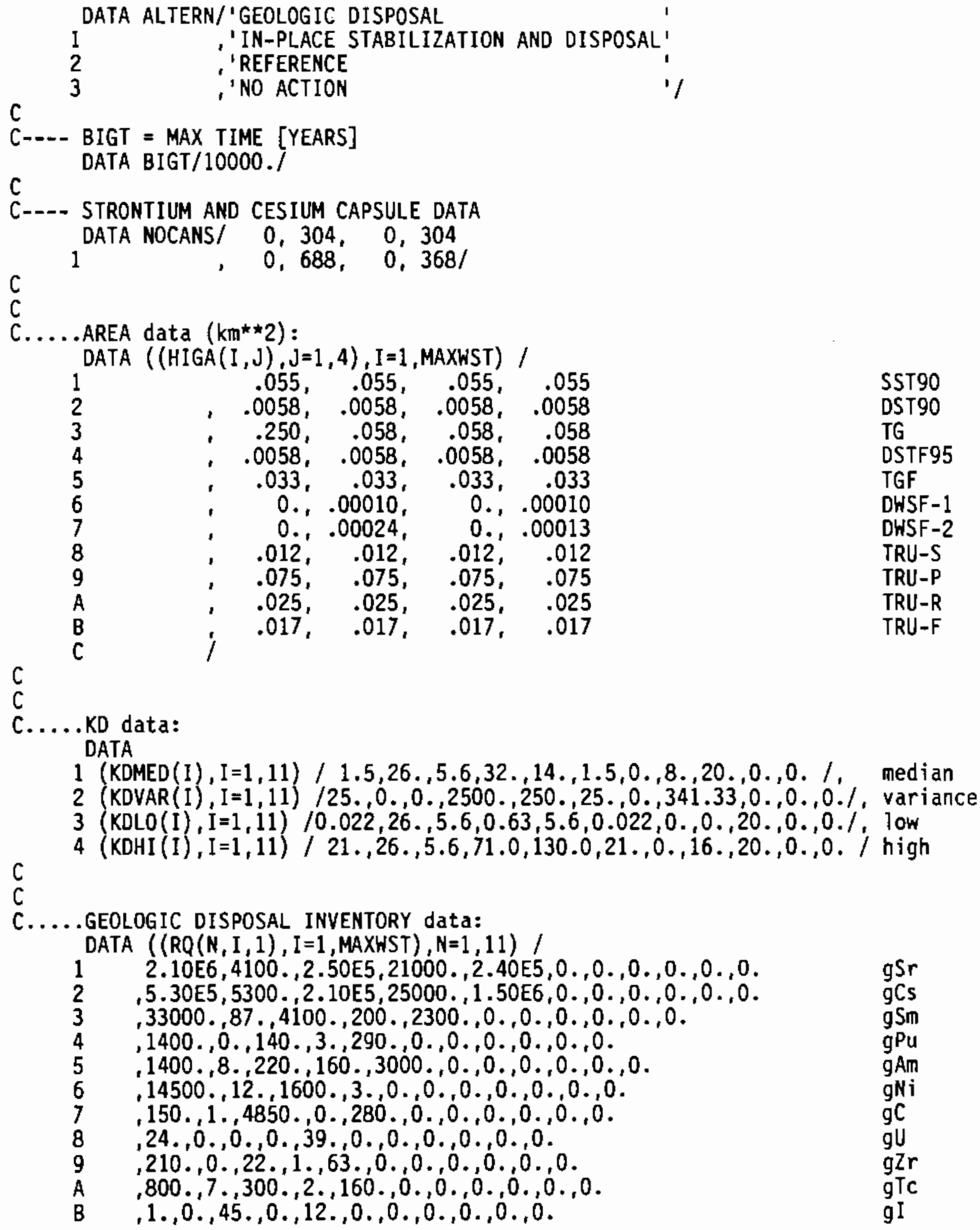




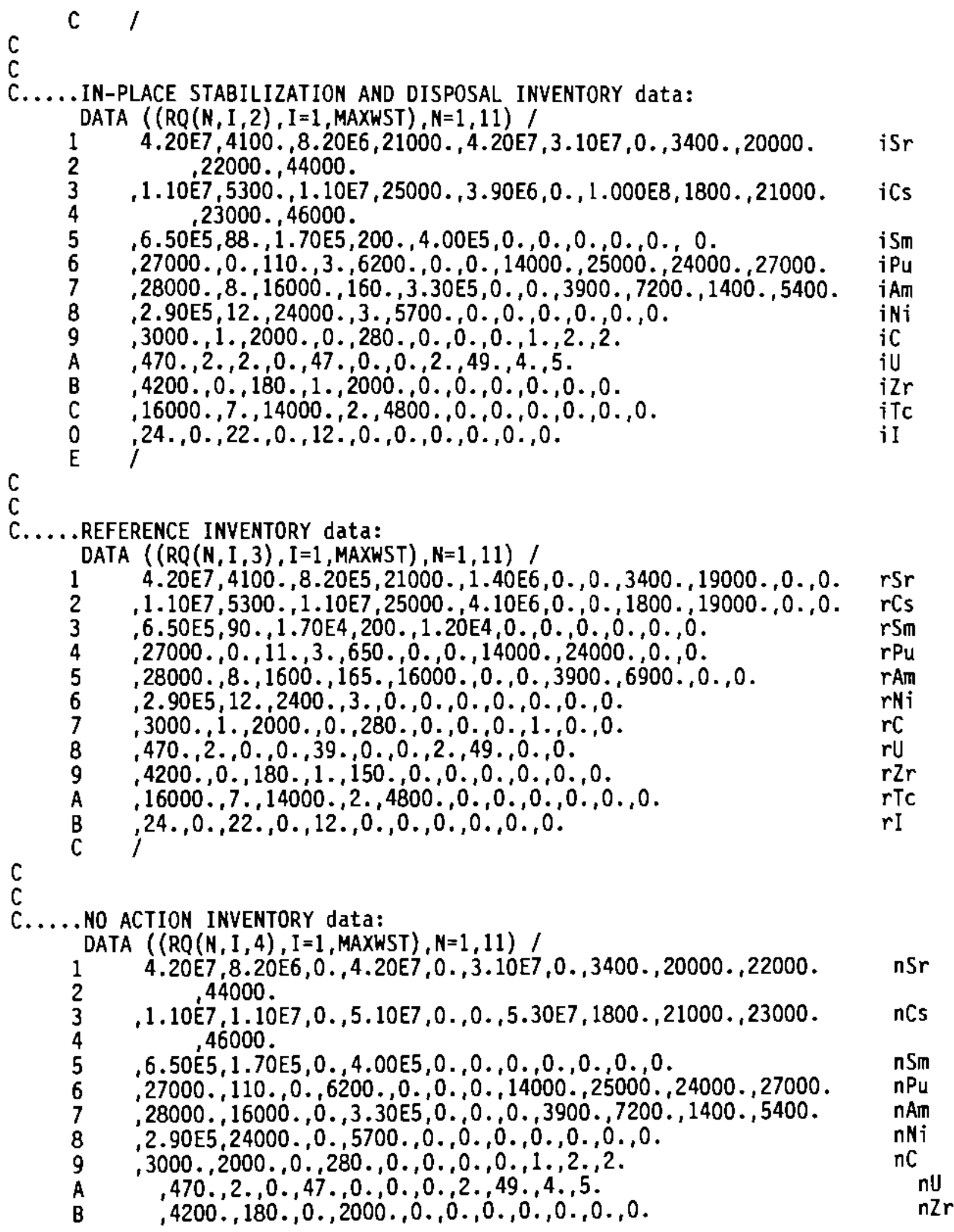




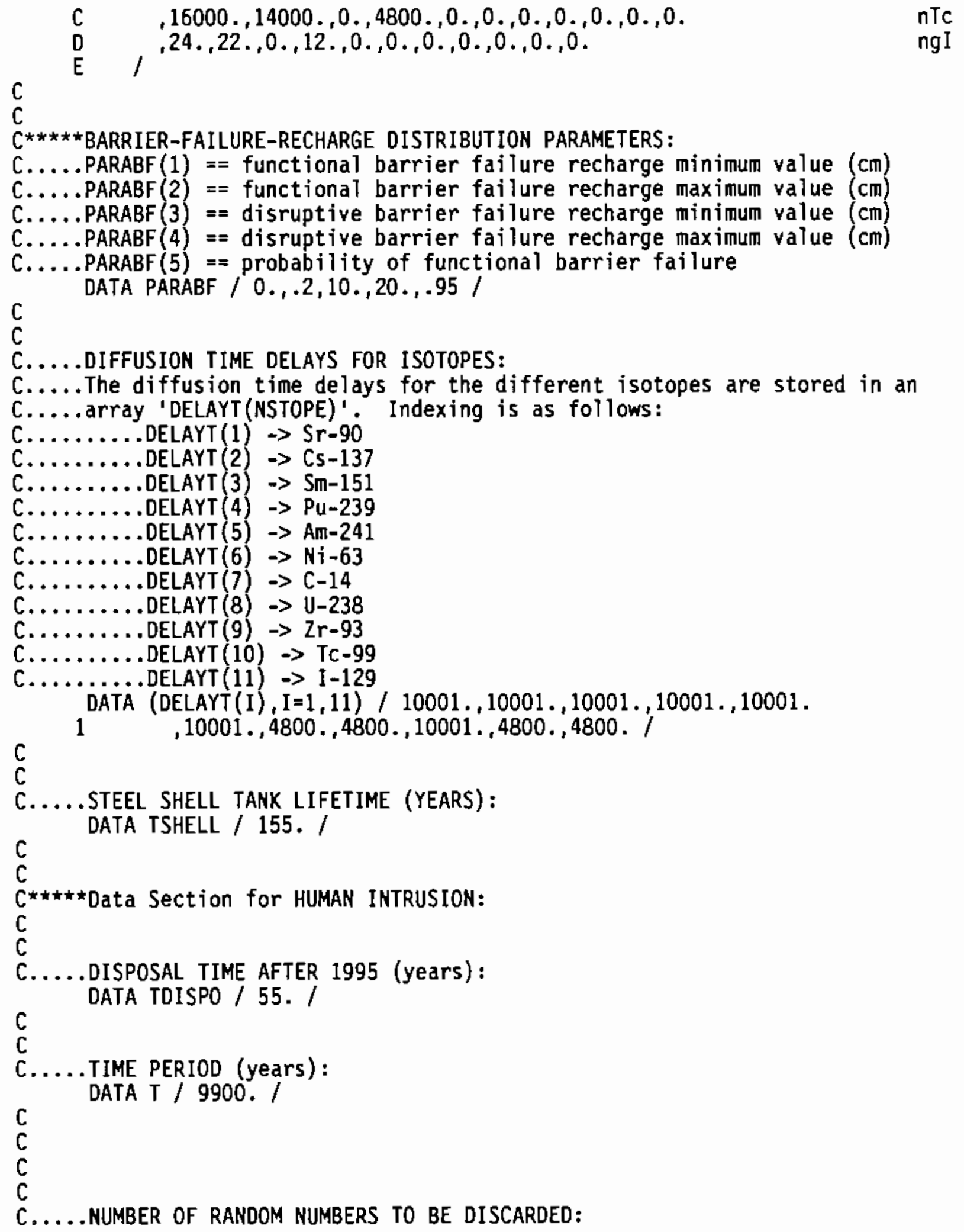




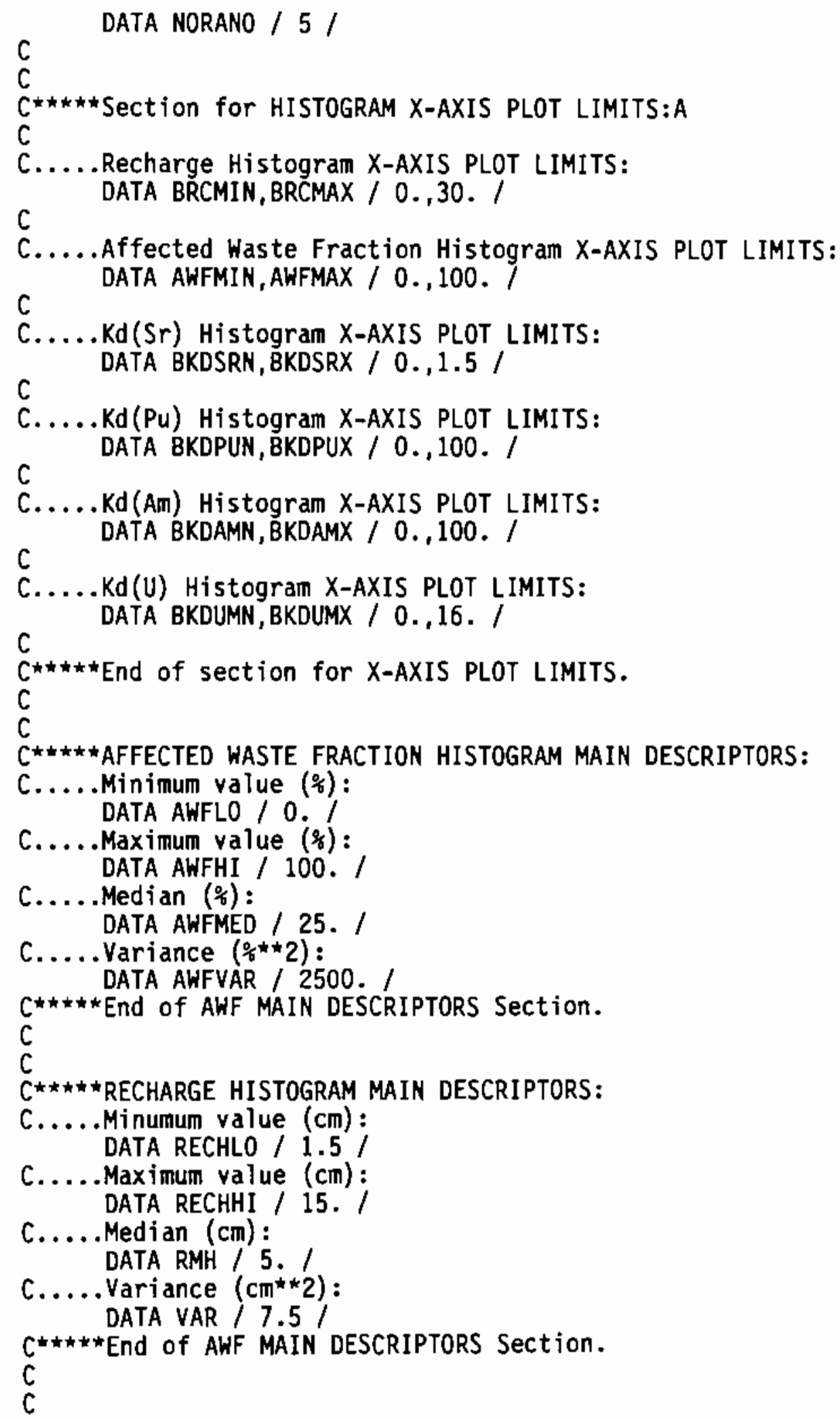




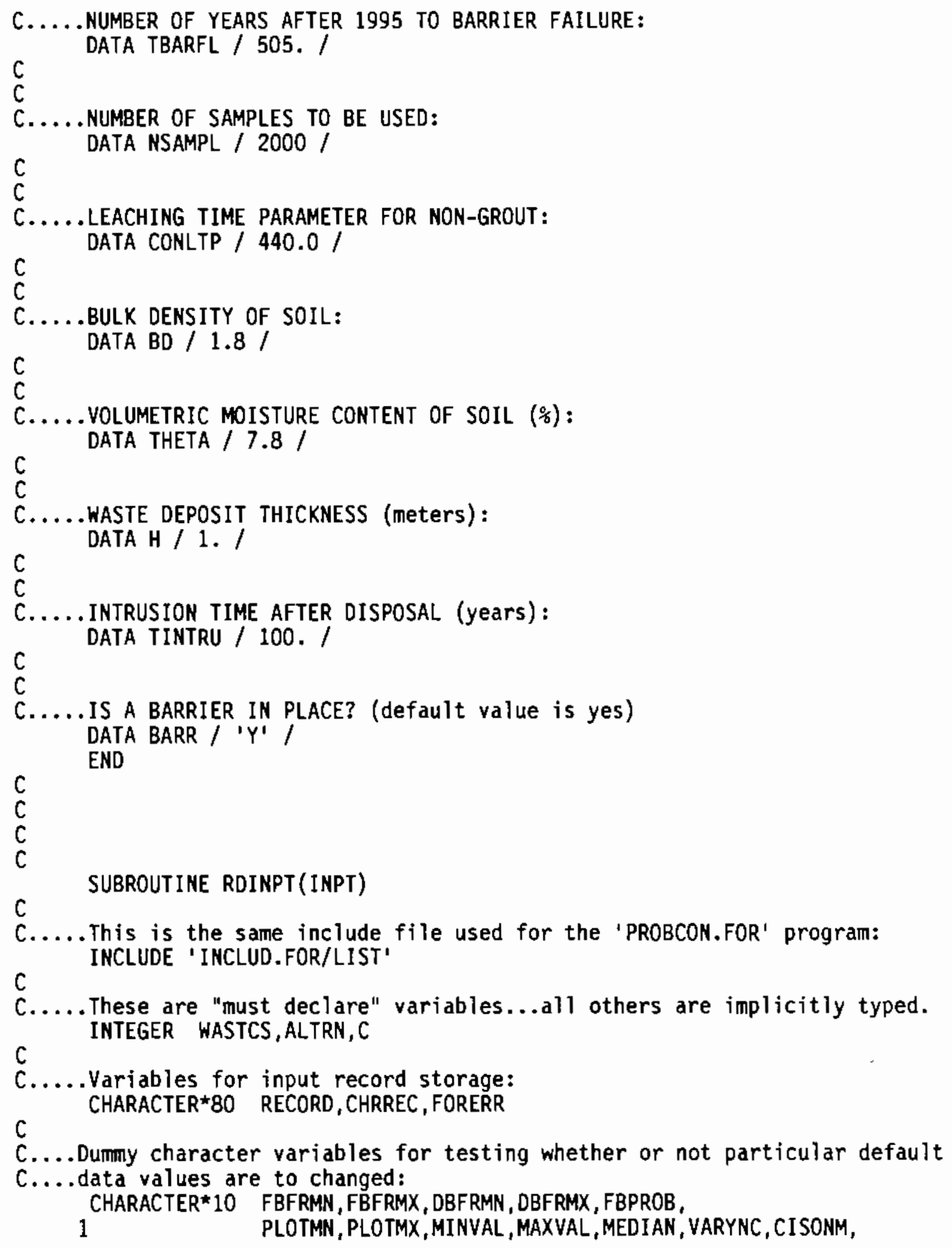




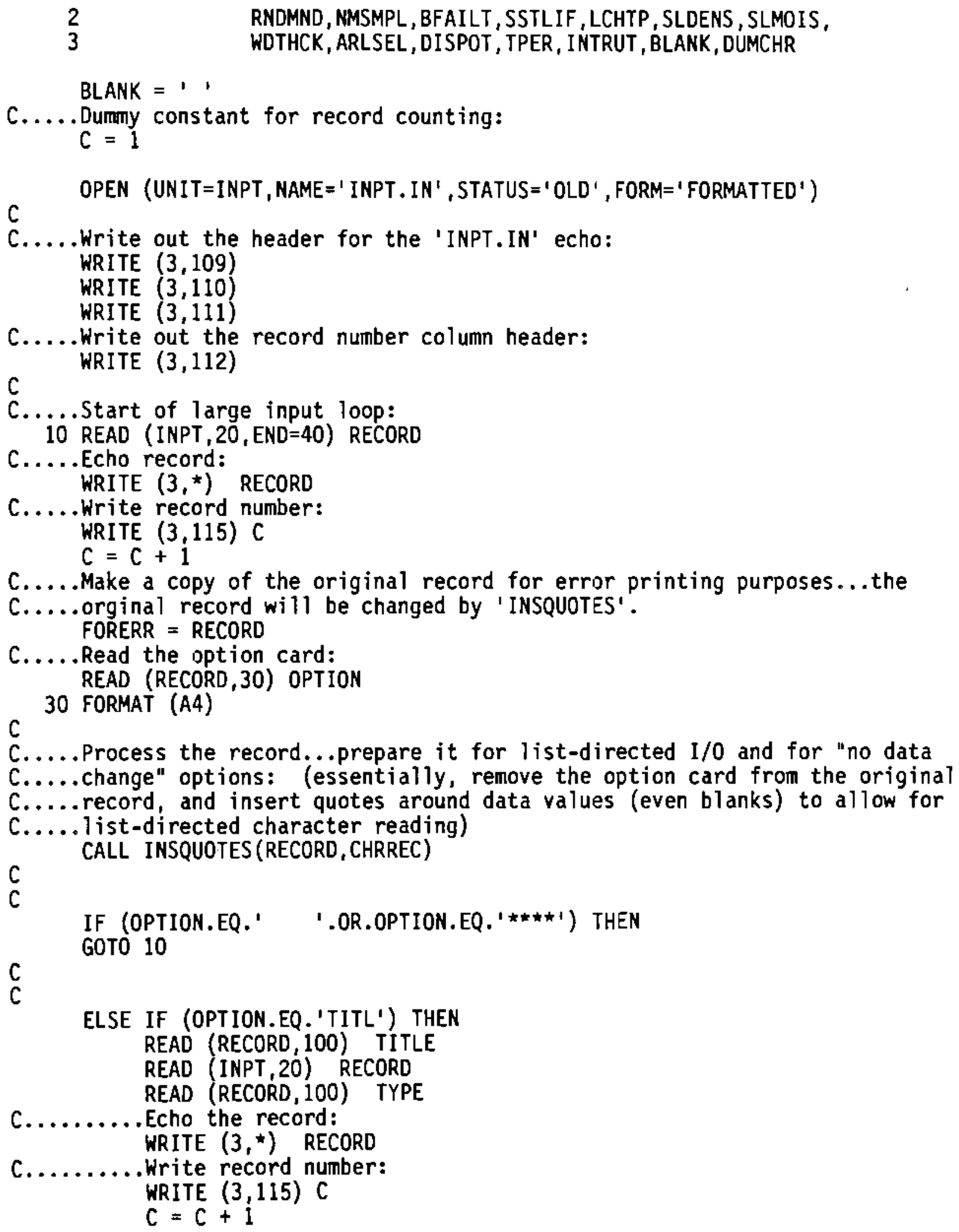




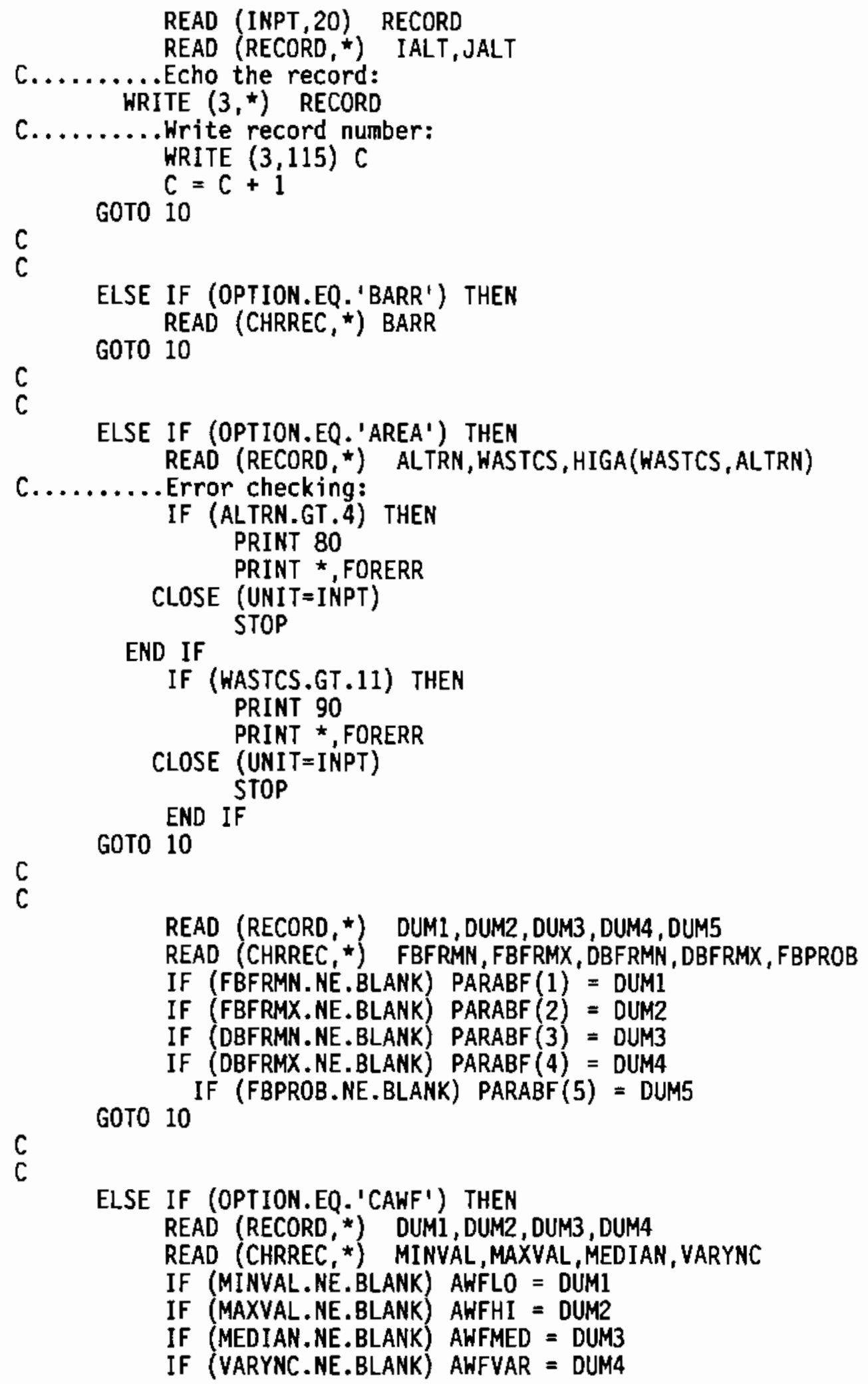




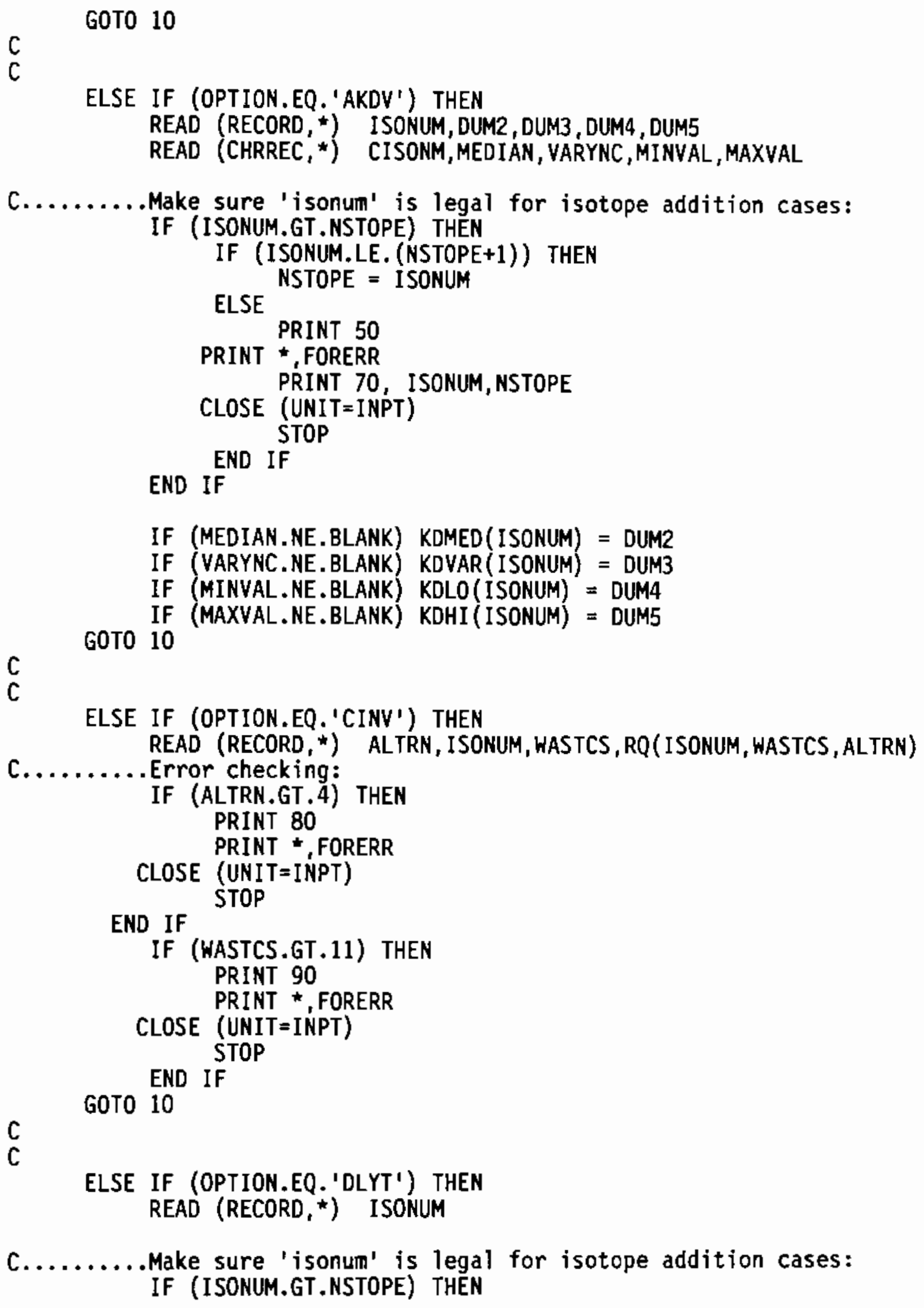




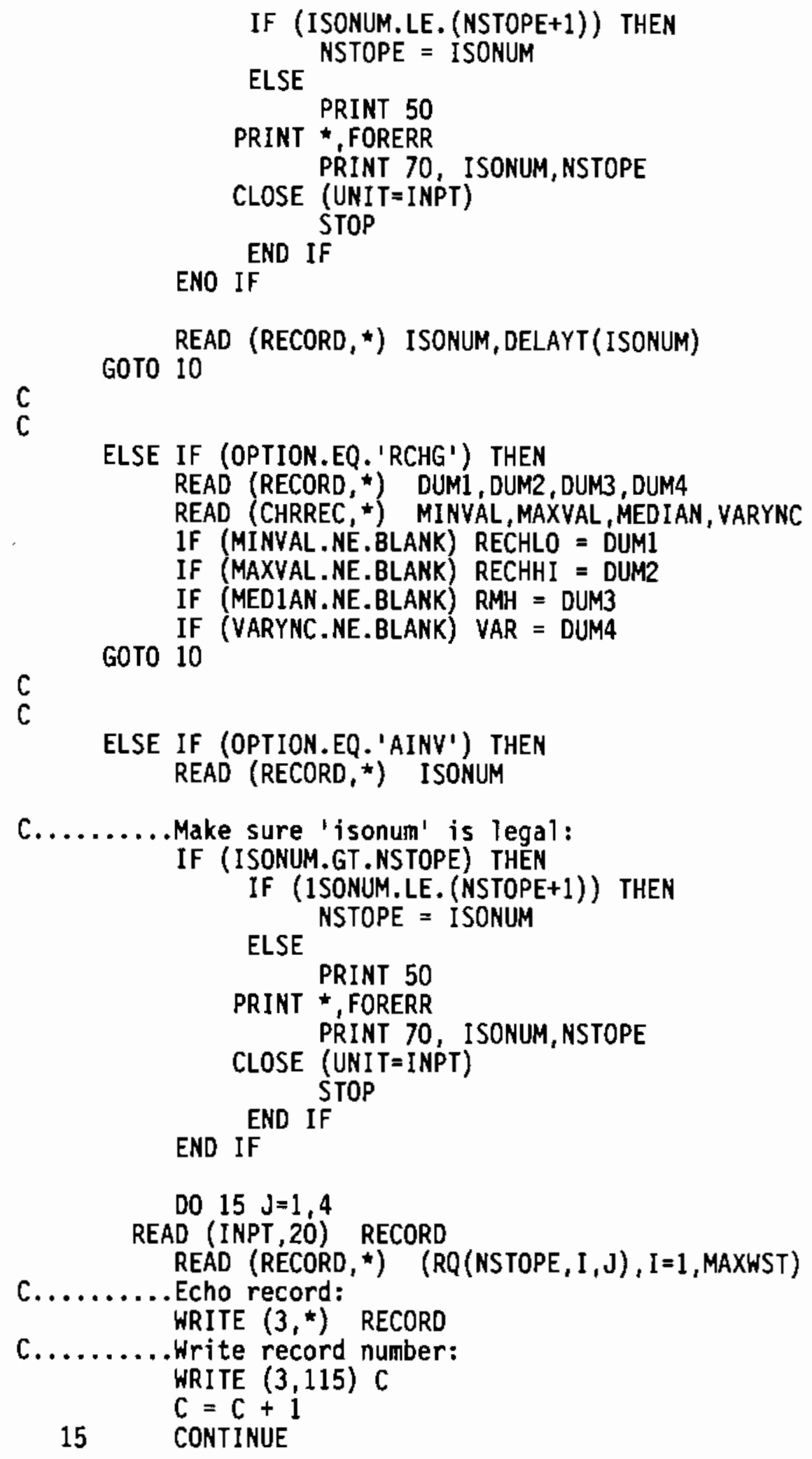




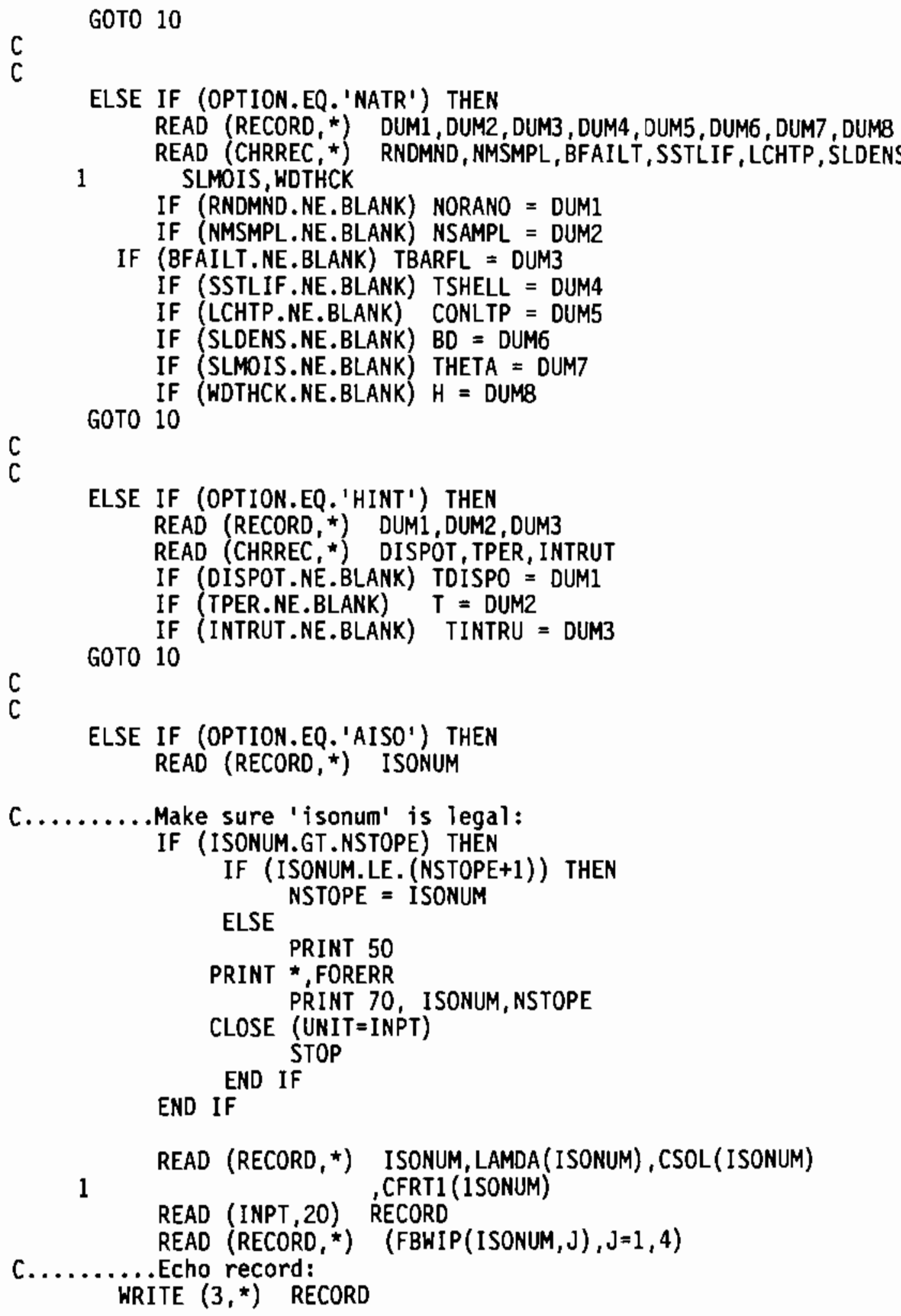




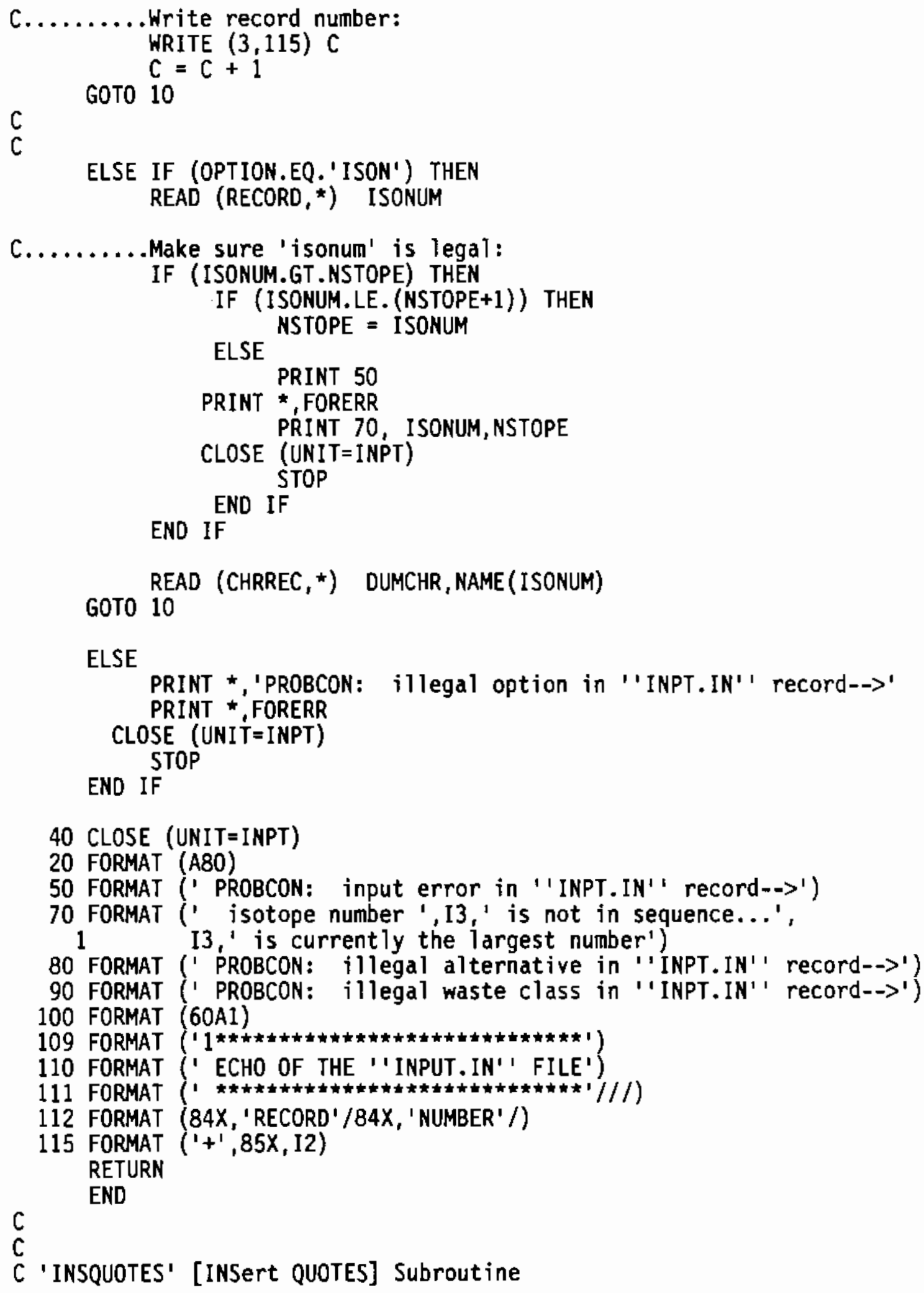


C Coded by Tu-Cuong(Clark) H. Nguyen on June 17, 1987

$\mathrm{C}$

* This subroutine accepts as arguments a character variable (80 chars long)

" holding the entry string to be "quoted" 'ENTRY' and a character variable (also

* 80 chars long) 'QENTRY' to hold the newly "quoted" string. 'ENTRY' must have

* the form

$\star$

* cards arg1, arg2, arg3, arg4,...

*

* where 'card' is the input option indicator, and the arguments are data values

* (which can be blanks for some options). The commas between arguments are

* required, but the arguments may be spaced as desired. For example, the

* following is legal:

$\star$

$$
\star
$$

+

C

* The 'card' is removed from 'ENTRY' and a comma is appended to it (in case the

* Tast argument is a blank), preparing it for a REAL variable READ. When

* 'INSQUOTES' returns control to the calling program, 'QENTRY' will contain the

* information from 'ENTRY' adjusted so that it can be read into character

* variables, i.e. quotes will be inserted in the appropriate places. For

* example, 'ENTRY' will contain the following after 'INSQUOTES' has been

* called with the examples above:

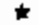

* arg1 ,arg2 ,arg3 ,arg4,

$\star$

* Note that 'cards' is removed and a comma has been appended. 'QENTRY' will

* contain the following:

เ

* 'arg1', ' $\arg 2 ', \cdot \arg 31, ' \arg 4 '$

เ

C

* Variable Identification:

*

* AFTGSN $==$ position in 'ENTRY' after the ' $>$ ' sign

* COMLOC = $=$ position of a comma in a string

* CONCAT $=$ = char variable to hold the initial string in 'NENTRY' to be

* concatenated to 'QENTRY'

* ENTRY == char variable holding the string to be "quoted"

* LSNCHR $==$ position of the last character before blanks in 'NENTRY'

* LSQCHR =e position of the last character before blanks in 'QENTRY'

* NENTRY = = char variable holding the reduced form of 'ENTRY'....it's necessary

* since 'ENTRY' must not be changed

* NXTLOC == position of the character after a comma in a string

* PRELOC == position of the character before a comma in a string

"QENTRY == char variable for manufacture of a newly "quoted" 'ENTRY' 
$c$
$c$
$c$

SUBROUTINE INSQUOTES (ENTRY, QENTRY)

INTEGER COMLOC, PRELOC, NXTLOC, LSOCHR, LSNCHR, AFTGSN

CHARACTER ${ }^{\star} 0$ ENTRY, NENTRY, QENTRY, CONCAT

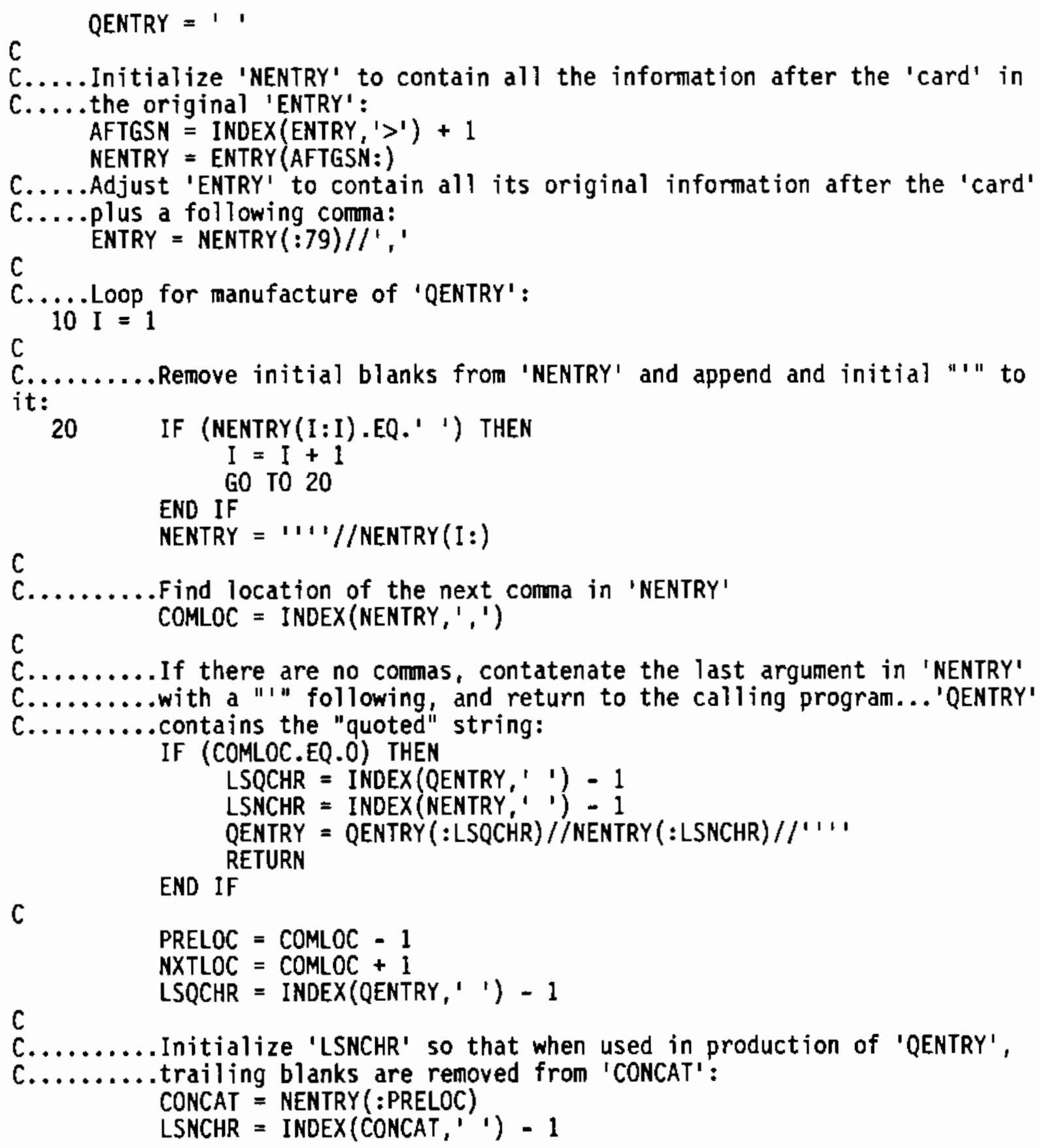




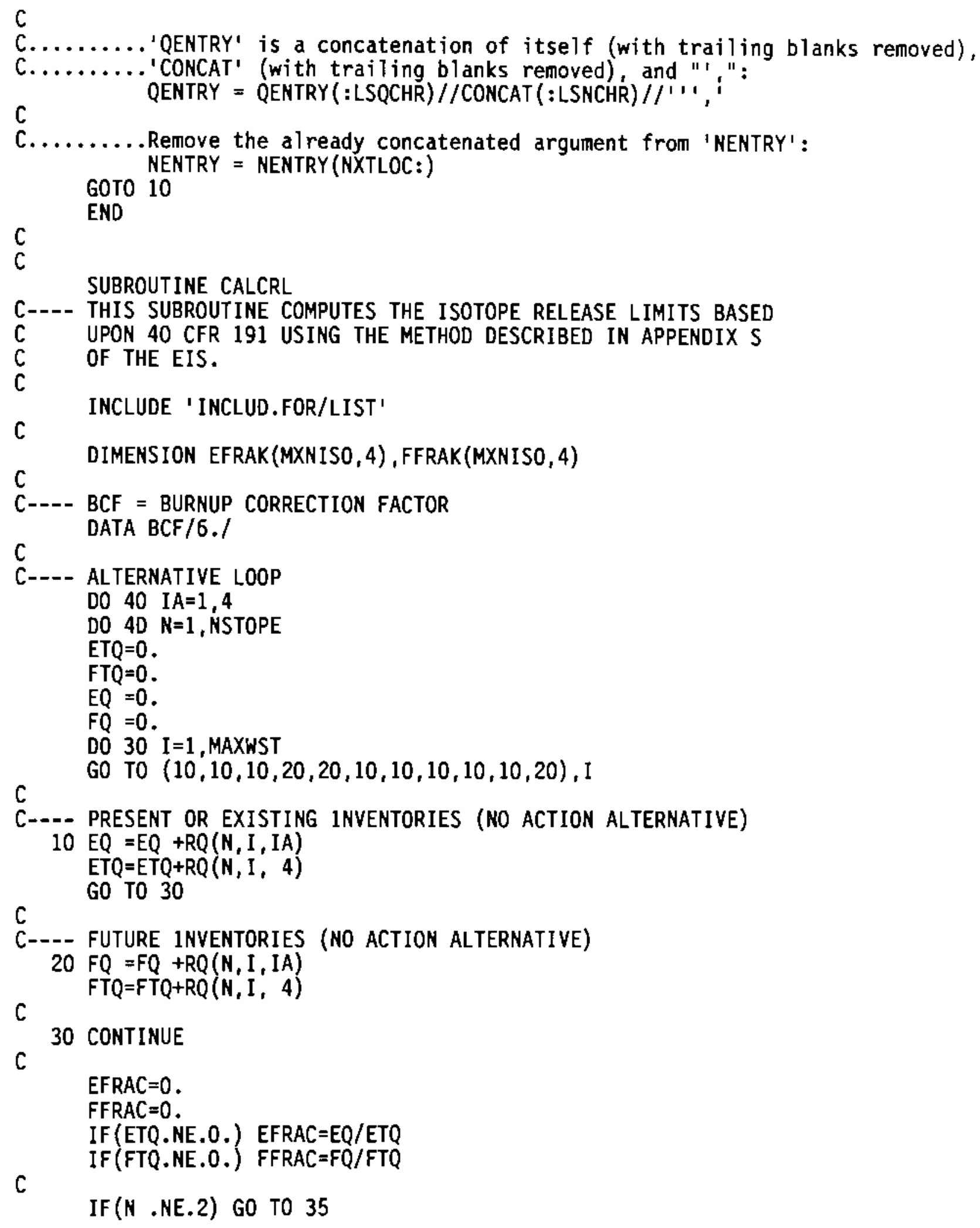




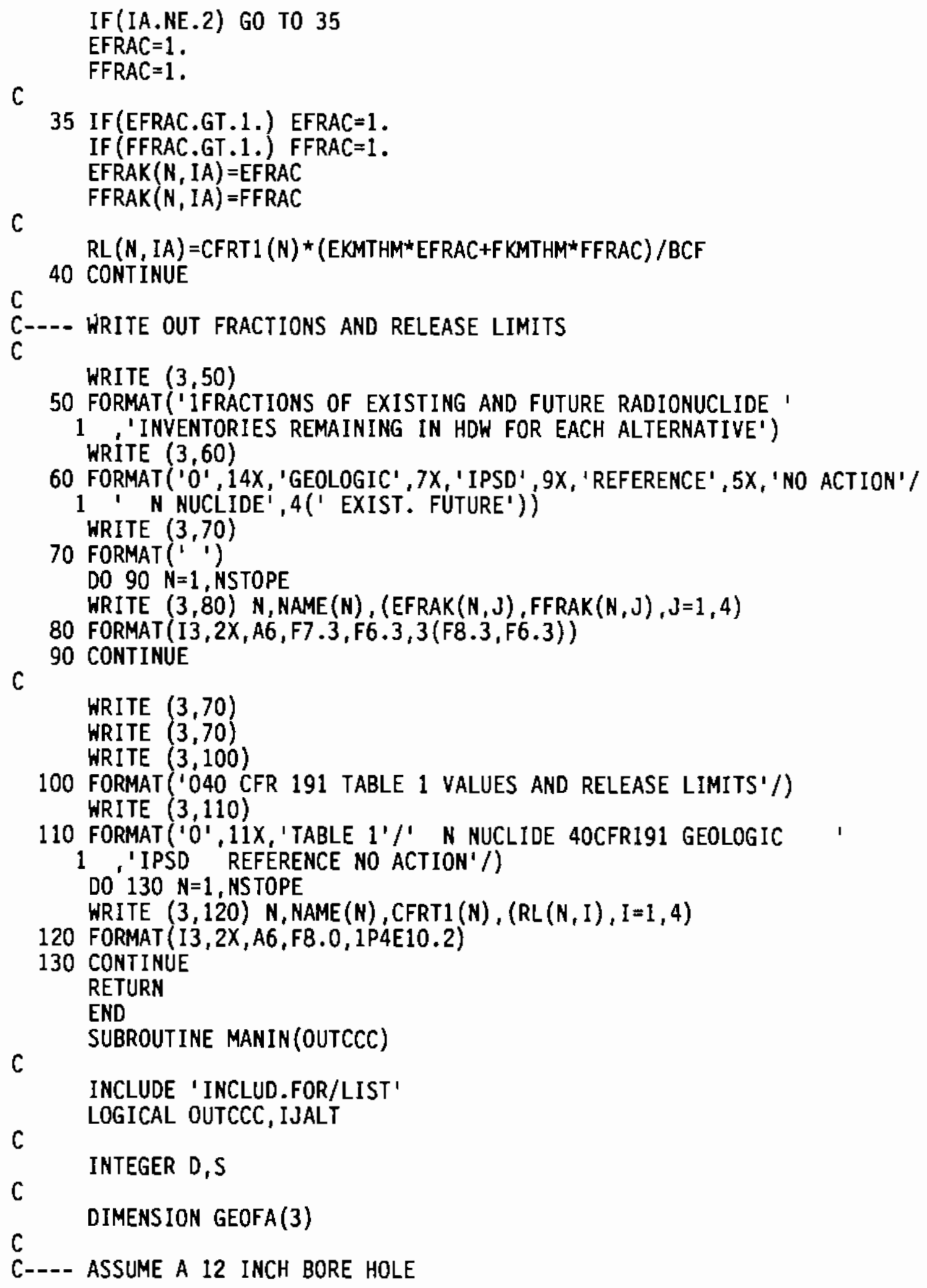




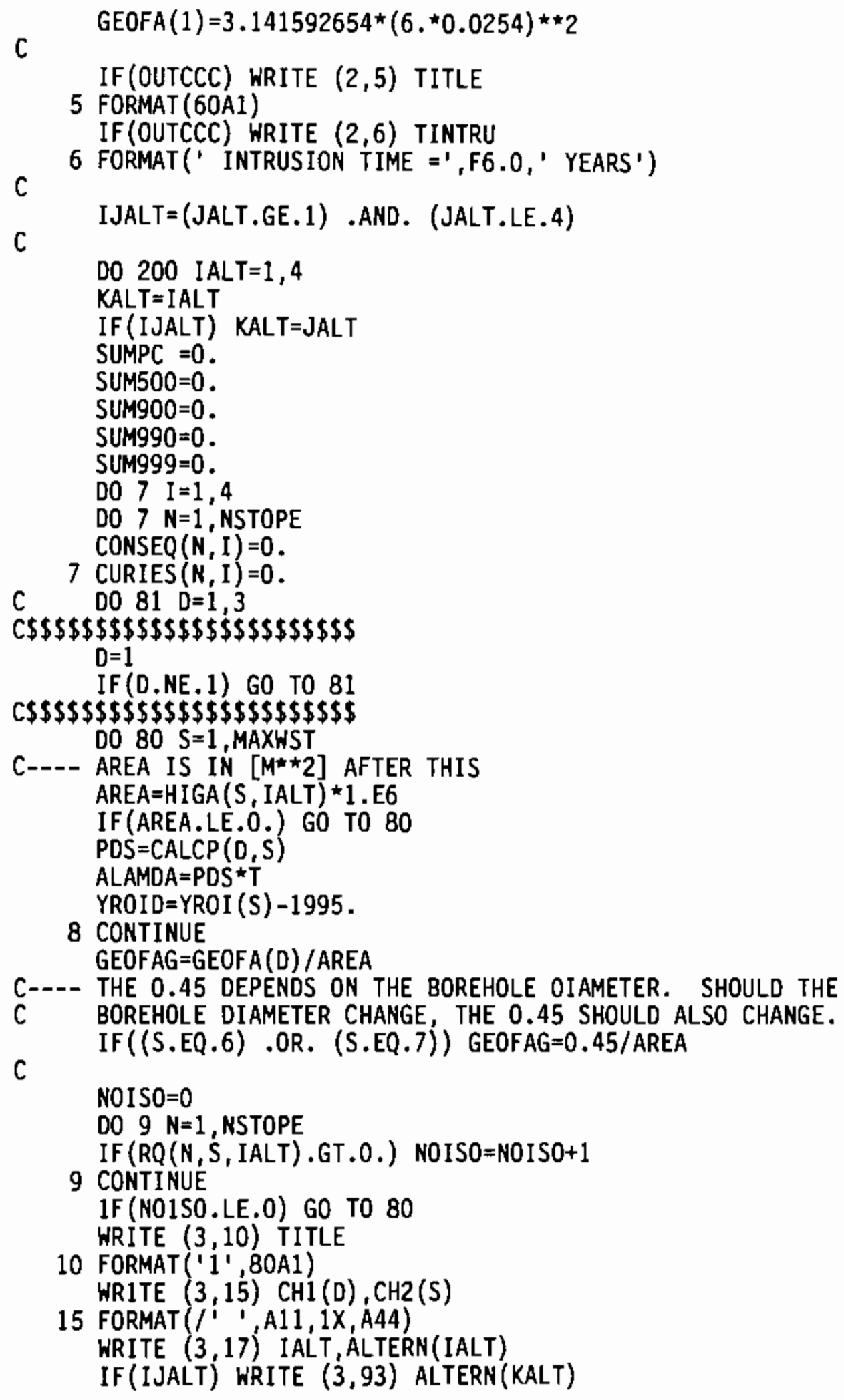




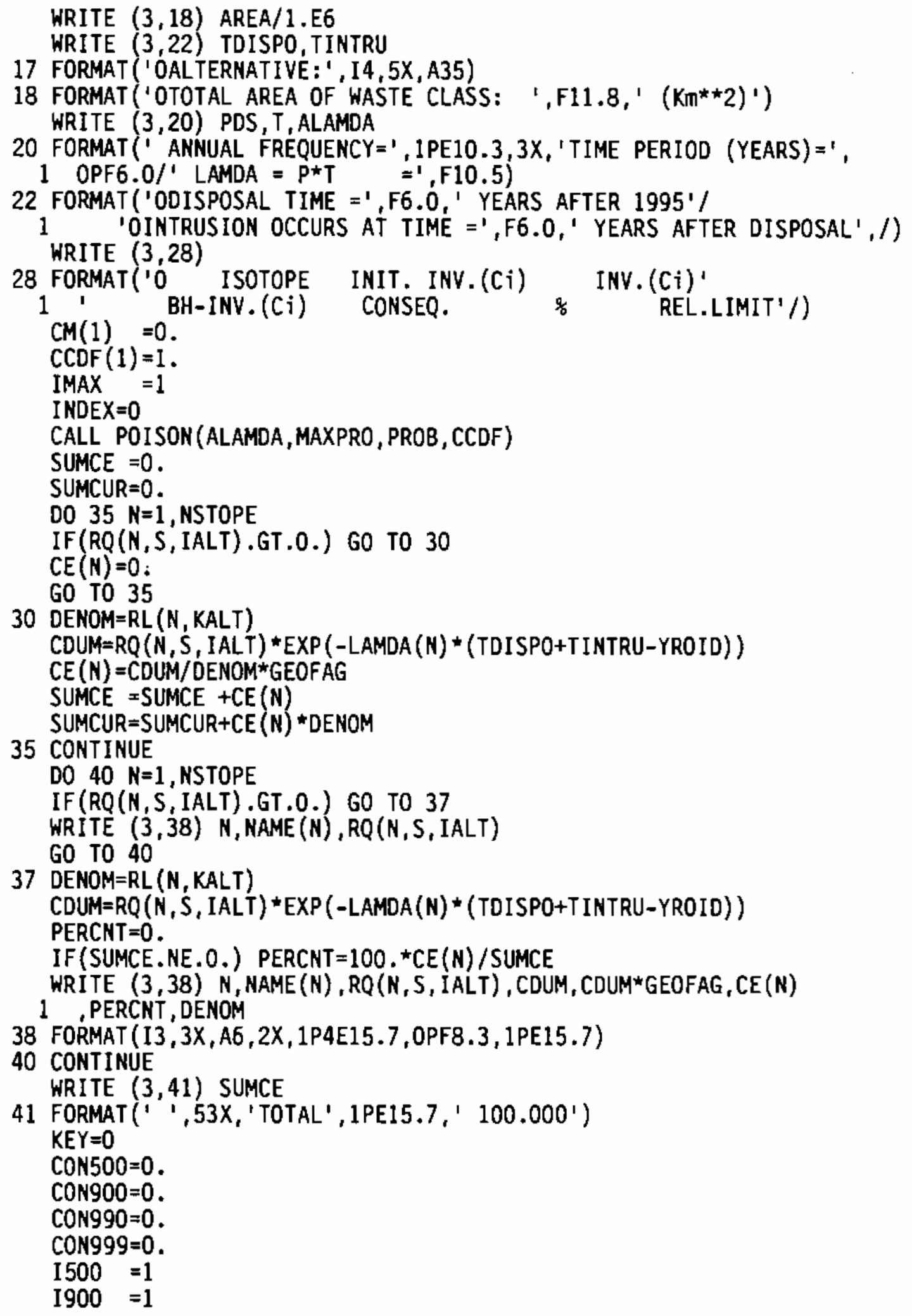




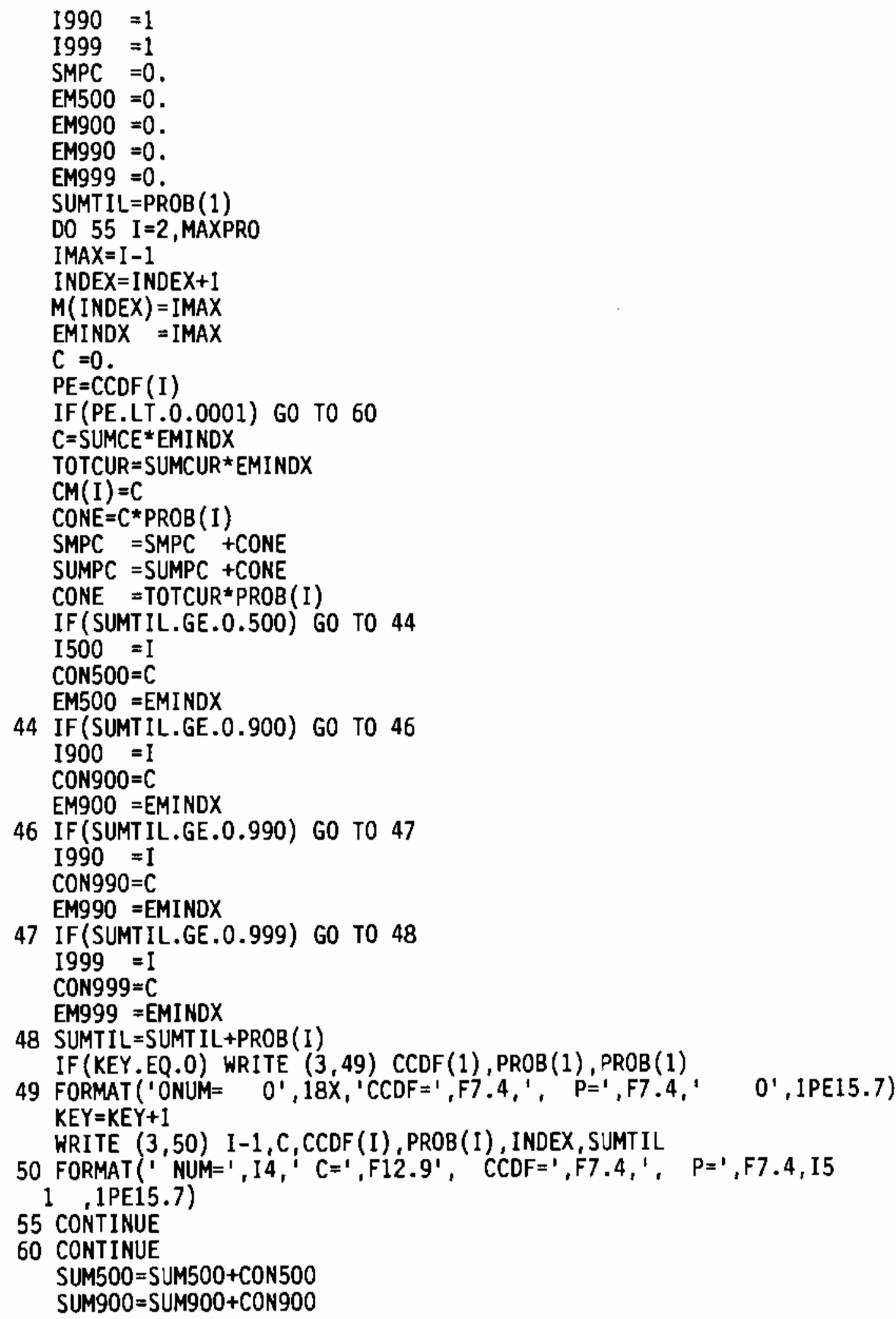


SUM $990=$ SUM990+CON990

SUM999 $=$ SUM999 + CON999

WRITE $(3,88)$

WRITE $(3,53)$

53 FORMAT('OSUMMARY'//' ISOTOPE RELEASES (Ci) '//

1 ISOTOPE $50 \%$-TILE $90 \%$-TILE $99 \%$-TILE'

2 ' $99.9 \%-$ TILE'$\left.^{\prime} /\right)$

54 FORMAT('OCONSEQUENCE ' , 1PE14.7,3E15.7)

51 FORMAT ( 'OCONSEQUENCE 35 ', 1PE14.7,3E15.7)

$0058 N=1$, NSTOPE

IF ((EM500+EM900+EM990+EM999) .EQ. O.) GO TO 56

IF (CE (N) .GT.0.) GO TO 57

56 WRITE $(3,38) \mathrm{N}, \operatorname{NAME}(\mathrm{N})$

GO TO 58

57 CEN=CE $(N)$

VCL500 $=$ CEN $*$ EM500

$\checkmark C L 900=C E N * E M 900$

$V C L 990=$ CEN ${ }^{\star}$ EM990

$V C L 999=$ CEN*EM999

VAL500 $=R L(N, K A L T) * V C L 500$

VAL $900=R L(N, K A L T) * V C L 900$

$V A L 990=R L(N, K A L T) * V C L 990$

$V A L 999=R L(N, K A L T) * V C L 999$

$\operatorname{CONSEQ}(N, 1)=\operatorname{CONSEQ}(N, 1)+V C L 500$

CONSEQ $(N, 2)=\operatorname{CONSEQ}(N, 2)+V C L 900$

$\operatorname{CONSEQ}(N, 3)=\operatorname{CONSEQ}(N, 3)+V \operatorname{VL} 990$

CONSEQ $(N, 4)=\operatorname{CONSEQ}(N, 4)+V C L 999$

$\operatorname{CURIES}(N, 1)=\operatorname{CURIES}(N, 1)+V A L 500$

$\operatorname{CURIES}(N, 2)=\operatorname{CURIES}(N, 2)+V A L 900$

CURIES $(N, 3)=$ CURIES $(N, 3)+V A L 990$

CURIES $(N, 4)=$ CURIES $(N, 4)+V A L 999$

WRITE $(3,38)$ N, NAME $(N)$, VAL500, VAL 900, VAL 990 , VAL 999

58 CONTINUE

WRITE $(3,54)$ CON500, ,CON900, CON990, CON999

WRITE $(3,51)$ CON500*35. , CON900*35., CON990*35. , CON999*35.

WRITE $(3,88)$

WRITE $(3,89)$ SMPC

IF (IMAX.LT.2 ) GO TO 80

IF (.NOT.OUTCCC) GO TO 80

WRITE $(2,59)$ IALT, ALTERN(IALT)

59 FORMAT $(I 5,5 X, A 35)$

WRITE $(2,61) \mathrm{CH} 1(0), \mathrm{CH} 2(\mathrm{~S})$

61 FORMAT (A11,1X,A44)

WRITE $(2,62)$

WRITE $(2,63)$

62 FORMAT ('CONSEQUENCE, $C$ ')

C

63 FORMAT ('PROBABILITY OF CONSEQUENCE $\Rightarrow\left(C^{\prime}\right.$ )

WRITE $(2,76)$ IMAX

76 FORMAT(I5) 


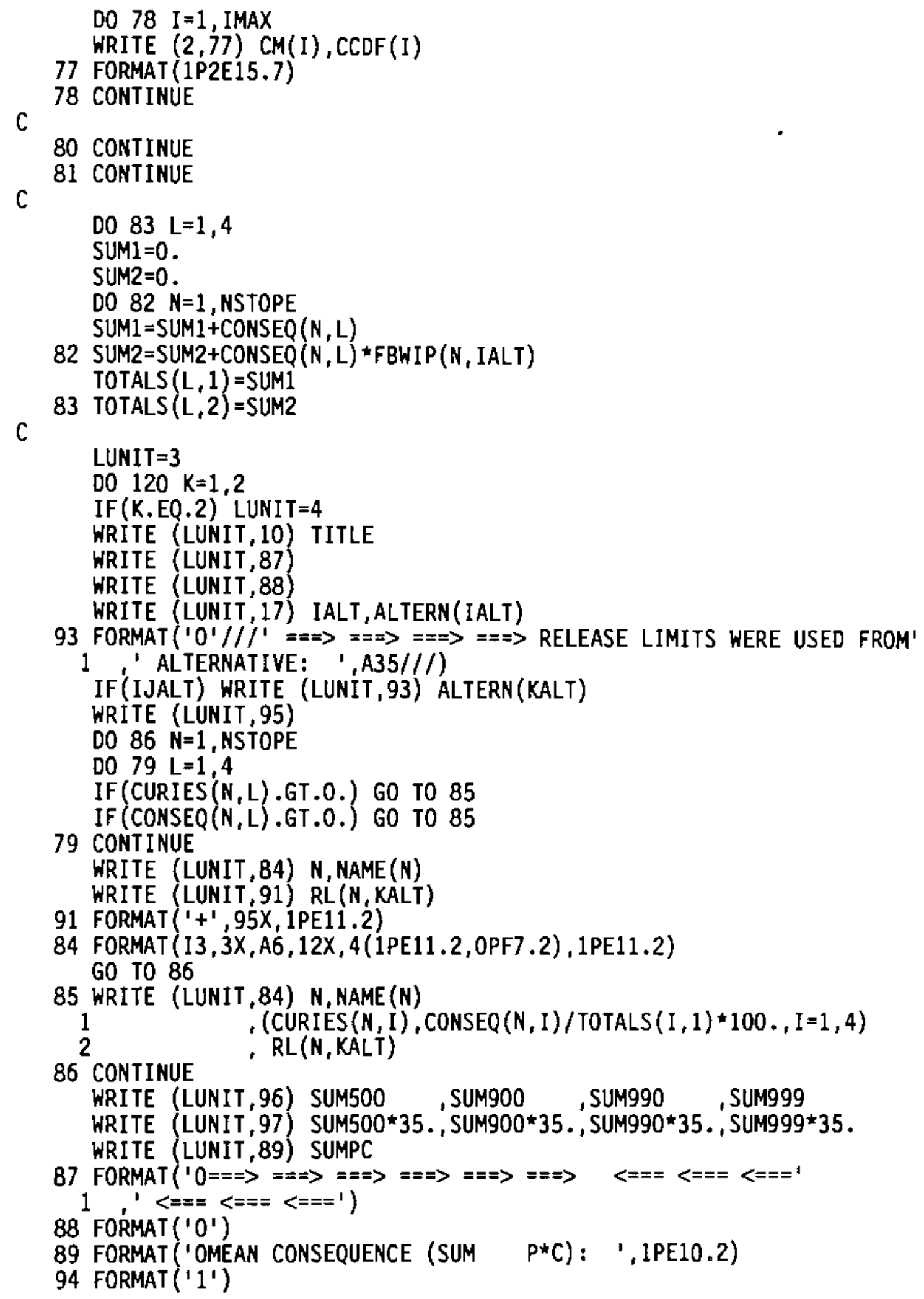




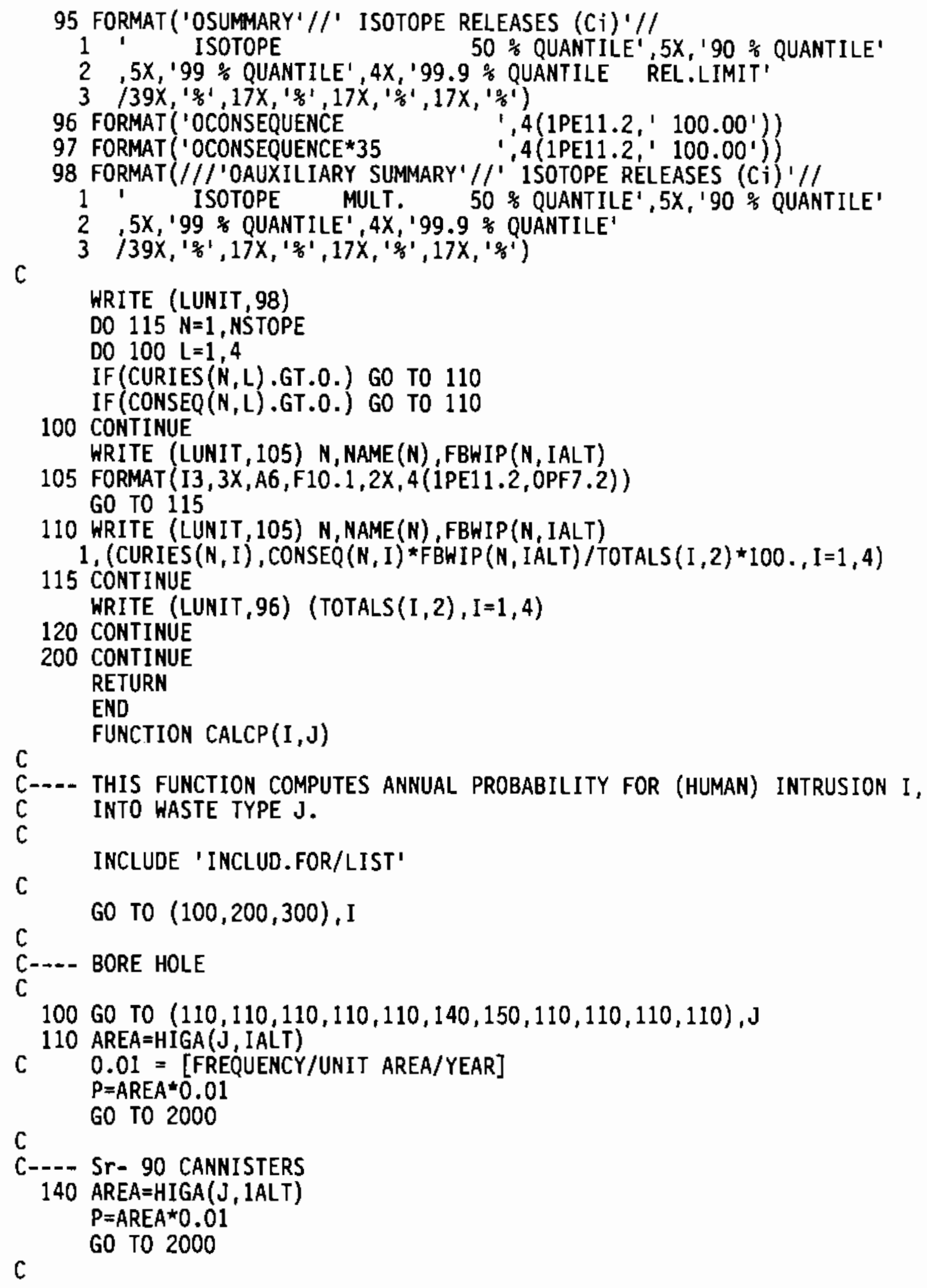




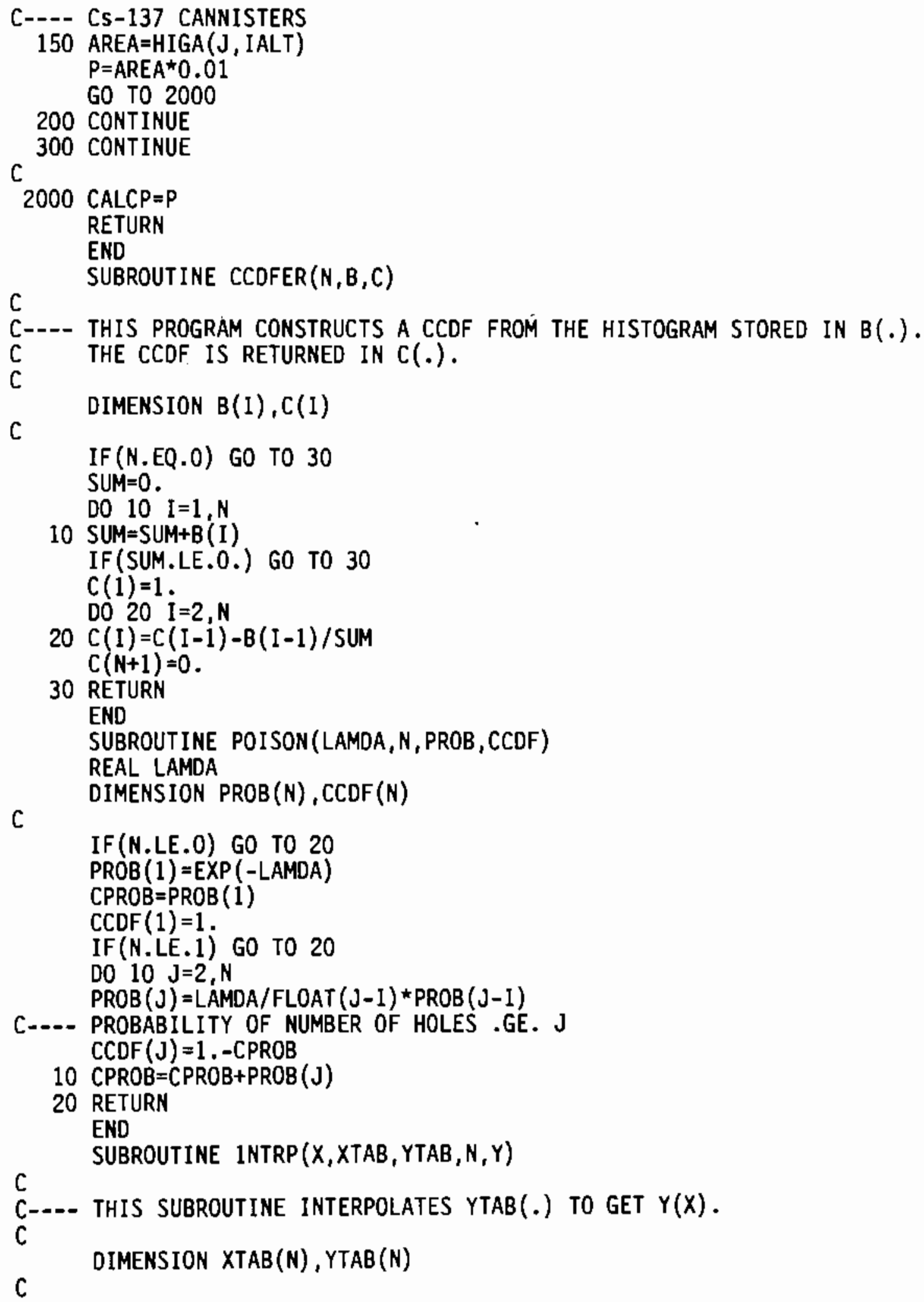




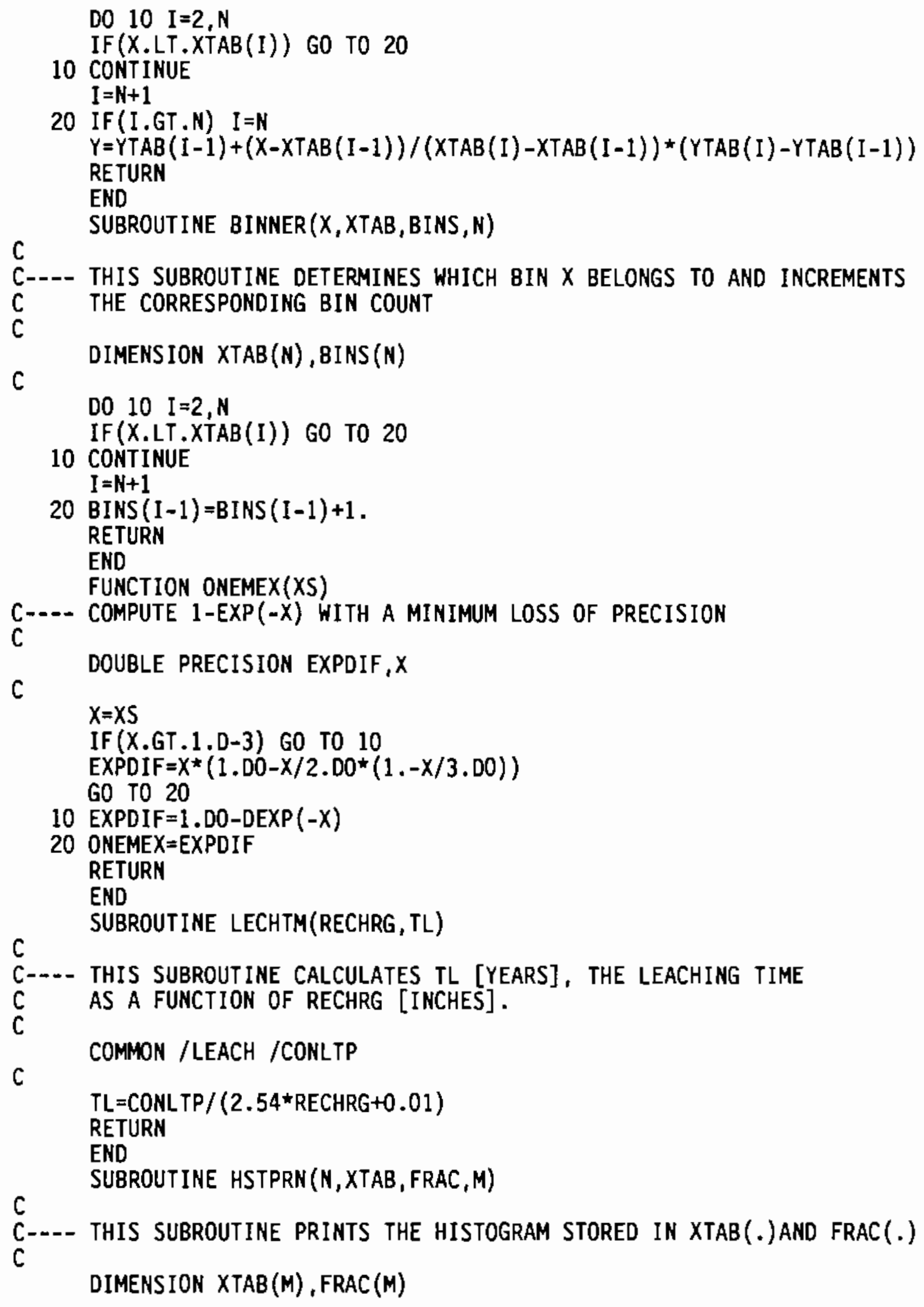




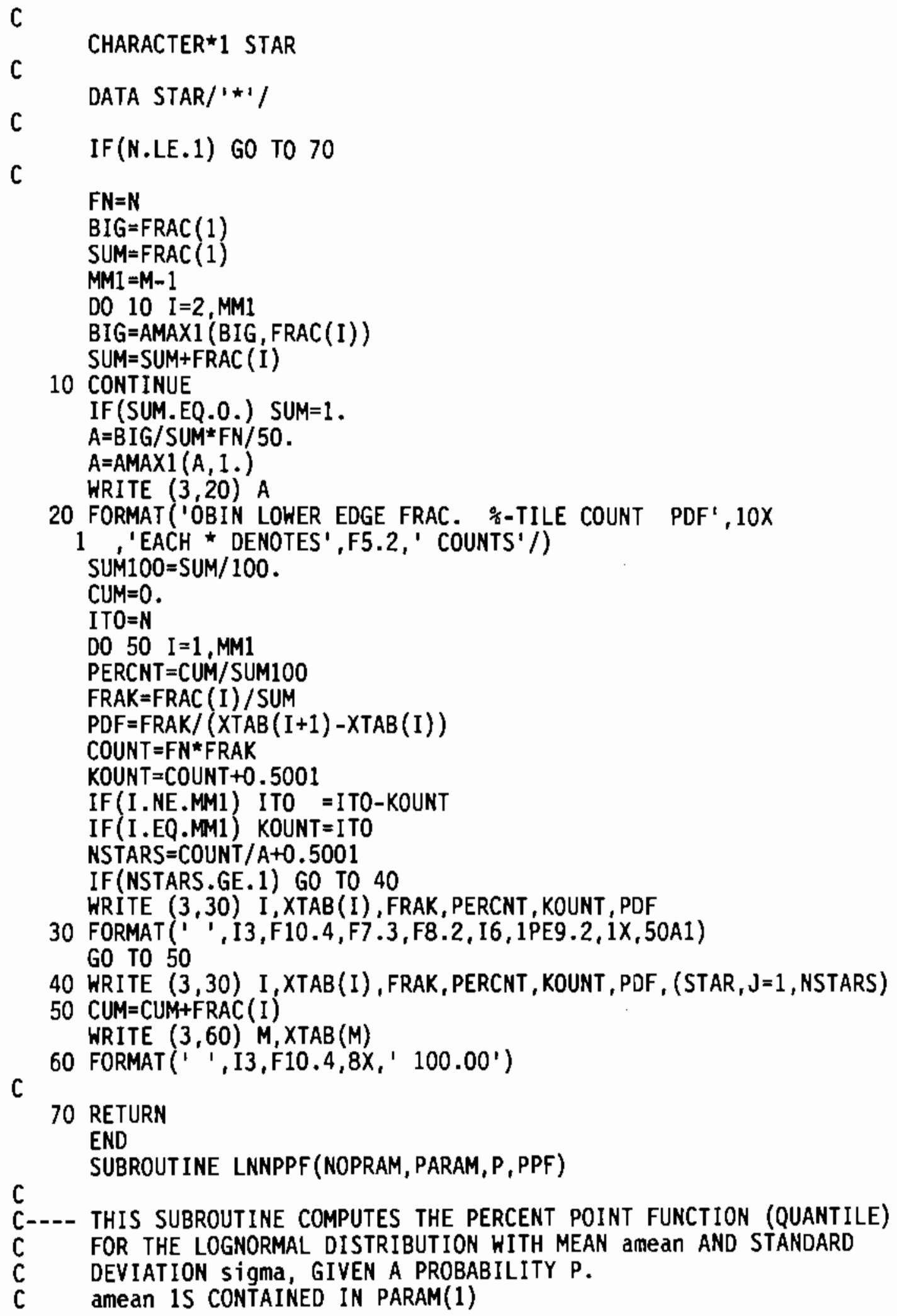




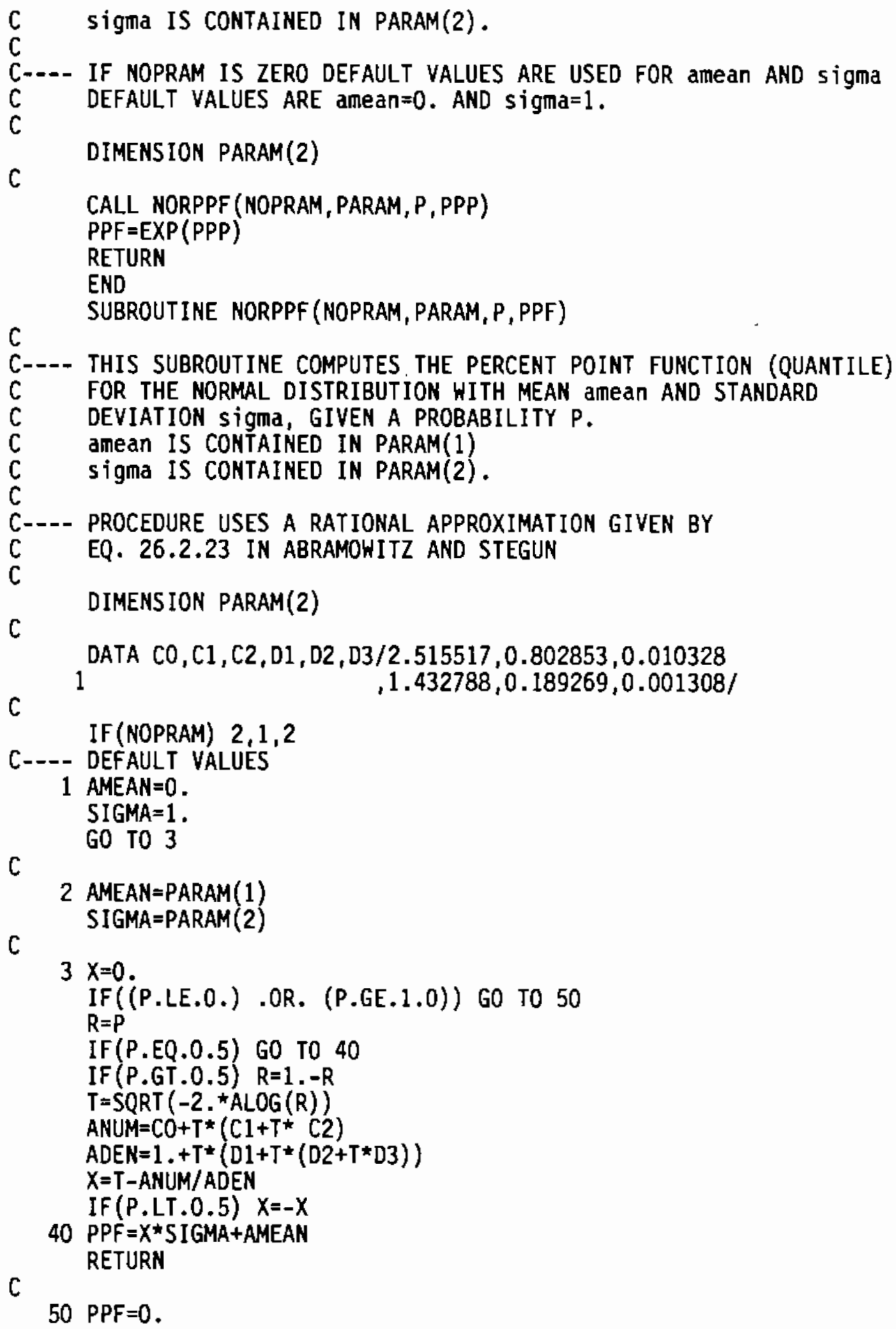


RETURN

END

SUBROUTINE MAKBIN (NOPRAM, PARAM, XMIN, XMAX, N, BINS)

C-..- THIS SUBROUTINE DETERMINES $N-1$ BIN BOUNDARIES BETWEEN

C XMIN AND XMAX, SUCH THAT EACH OF THE N-1 BINS HAS EQUAL

C PROBABILITY ASSOCIATED WITH IT. THE UNDERLYING DISTRIBUTION IS

C LOGNORMAL.

C

C

DIMENSION PARAM(2), BINS(N)

LOGICAL NONEO

$\mathrm{C}$

C--- NOPRAM .EQ. $0 \Rightarrow X$ IS UNIFORMLY DISTRIBUTED BETWEEN XMIN AND XMAX

$C \quad$.EQ. $5 \Rightarrow X$ IS DISTRIBUTED BETWEEN XMIN AND XMAX AS TWO

$C \quad$ DISTINCT UNIFORM DISTRIBUTIONS.

C ANY OTHER VALUE $=\Rightarrow X$ IS LOGNORMALLY DISTRIBUTED BETWEEN XMIN AND XMAX

$\mathrm{C}$

IF (NOPRAM.EQ.5) GO TO 30

C

NONEO $=$ NOPRAM. NE.O

IF (NONEO) GO TO 3

PHIGH $=$ XMAX

PLOW $=$ XMIN

C

GO TO 6

3 PLOW $=0$.

IF (XMIN.LE.0.) GO TO 5

$X L O W=A L O G(X M I N)$

CALL NORCUM(NOPRAM, PARAM, XLOW ,PLOW )

5 XHIGH=ALOG (XMAX)

CALL NORCUM(NOPRAM, PARAM, XHIGH, PHIGH)

6 BINS(1) =XMIN

IF (N.LE.2) GO TO 20

$N M 1=N-1$

DELTAP $=($ PHIGH - PLOW $) /$ FLOAT $($ NM1 $)$

DO $10 \quad I=2, N M 1$

C

$\mathrm{P}=\mathrm{PLOW+FLOAT}(\mathrm{I}-1)$ *DELTAP

IF (NONEO) GO TO 8

$P P F=P$

GO TO 10

C

8 CALL LNNPPF (NOPRAM, PARAM, P,PPF)

10 BINS (I) $=$ PPF

20 BINS $(N)=X M A X$

25 RETURN

C

C-.-- TWO UNIFORM DISTRIBUTIONS

C

$30 \mathrm{NN}=\operatorname{PARAM}(5) \star F L O A T(N)+0.5$ 
IF (NN.LT.2) $\quad \mathrm{NN}=2$

$M M=N-N N$

IF (MM.LT.2) MM=2

$N N=N-M M$

$\operatorname{BINS}(1)=X M I N$

PLOW $=$ XMIN

PHIGH=PARAM (2)

IF (PLOW.GE.PHIGH) GO TO 45

IF (NN . LE.2 ) GO TO 45

$N M 1=N N-1$

DELTAP $=($ PHIGH-PLOW $) / F L O A T$ (NM1)

DO $40 \quad I=2$, NM1

40 BINS (I) $=$ PLOW+FLOAT $(I-1) \star D E L T A P$

$\operatorname{BINS}(N N)=\operatorname{PARAM}(2)$

$45 \mathrm{I}=\mathrm{NN}+1$

IF (I.GT.N) GO TO 25

$\operatorname{BINS}(\mathrm{I})=\operatorname{PARAM}(3)$

PLOW =PARAM (3)

PHIGH $=X M A X$

IF (PLOW.LT.PHIGH) GO TO 60

50 IF (MM .LE.2 ) GO TO 60

$N M 1=M M-1$

DELTAP $=($ PHIGH-PLOW $) /$ FLOAT $($ NM1 $)$

DO $55 \mathrm{~J}=2$, NM1

$\mathrm{I}=\mathrm{I}+1$

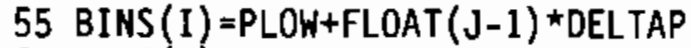

60 BINS $(N)=X M A X$

GO TO 25

END

SUBROUTINE NORCUM(NOPRAM, PARAM, $X, P$ )

C.--- CORCUM COMPUTES THE CUMULATIVE (-INFINITY, $X$ ) PROBABILITY

C P FOR THE NORMAL DISTRIBUTION WITH MEAN amean AND STANTARD

C DEVIATION sigma. amean AND sigma ARE CONTAINED IN PARAM(1) AND

C PARAM(2) RESPECTIVELY.

C

C--.- IF NOPRAM IS ZERO THEN THE DEFAULT VALUES FOR amean AND sigma

C ARE USED. THAT IS PARAM(1) $=0$. AND PARAM $(2)=1$.

C

C---- PROCEDURE USES A POWER SERIES EXPANSION FOR 0. LE. Z .LE. 1

C GIVEN BY EQ. 7.1.6 IN ABRAMOWITZ AND STEGUN. FOR Z .GT. 1

C THE CONTINUED FRACTION EXPANSION IN EQ. 7.1.14 IN

- C ABRAMONITZ AND STEgUn IS USED.

c

C-..- PROGRAMMED AND CHECKED BY AR(TONY) OLSEN

C DATE: OCTOBER 2, 1978

$\because \quad$ C MODIFIED BY CA OSTER

DIMENSION PARAM(2)

C 


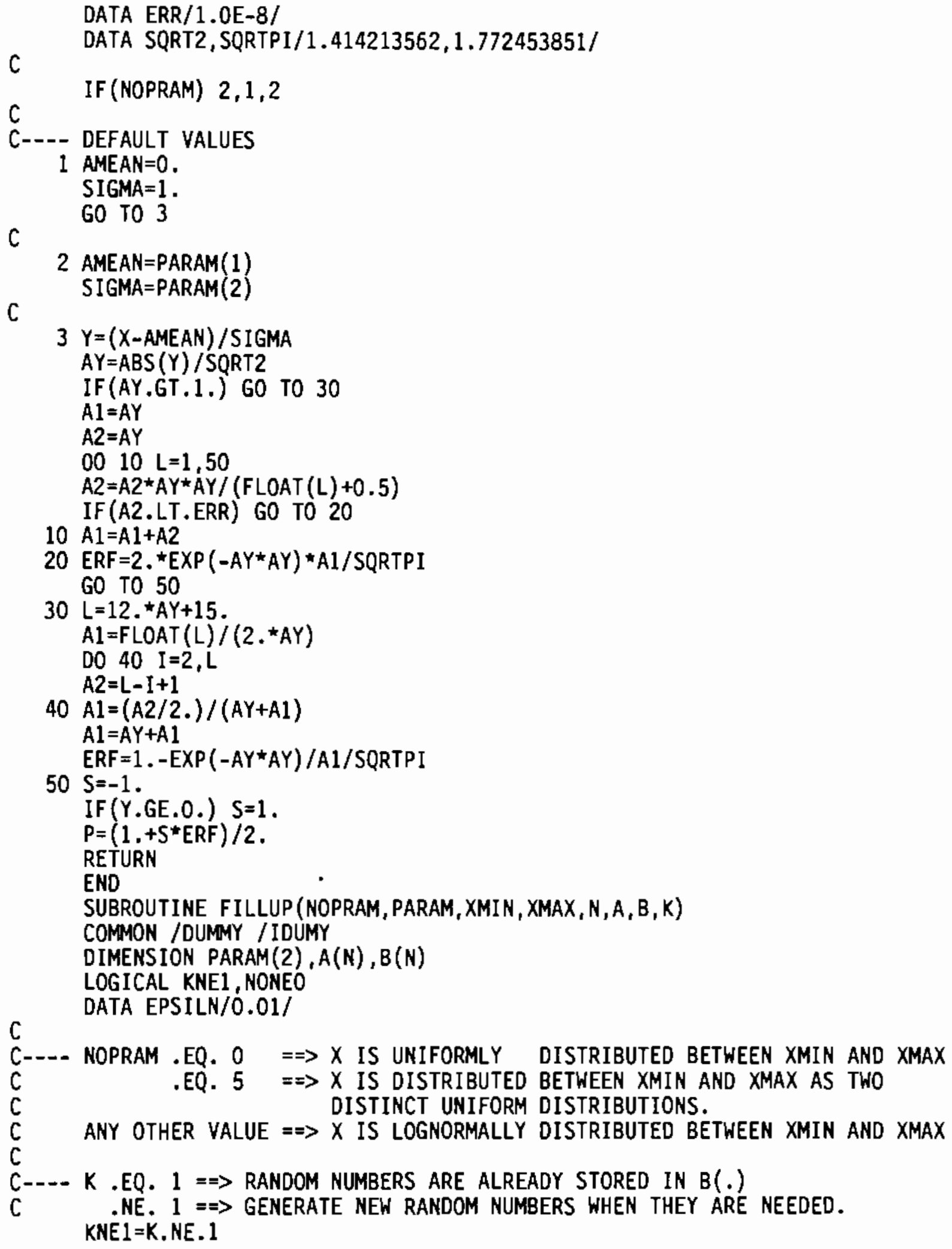


C

IF (NOPRAM.EQ.5) GO TO 50

NONEO $=$ NOPRAM. NE . 0

C

IF (NONEO) GO TO 3

$P L O=X M I N$

$\mathrm{PHI}=\mathrm{XMAX}$

GO TO 7

C

$3 \mathrm{PLO}=0$.

IF (XMIN.LE.0.) GO TO 5

$X L O=A L O G(X M I N)$

CALL NORCUM(NOPRAM, PARAM, XLO, PLO)

$5 X \mathrm{XHI}=A \mathrm{LOG}$ (XMAX)

CALL NORCUM(NOPRAM, PARAM, XHI, PHI)

$7 \mathrm{DX}=(\mathrm{PHI}-\mathrm{PLO}) / \mathrm{FLOAT}(\mathrm{N}-1)$

$10 \mathrm{~A}(\mathrm{I})=-1$.

$E N=N$

D0 $40 \quad I=1, N$

$X=P L O+F L O A T(I-1) * D X$

IF (NONEO) GO TO 14

$\mathrm{PPF}=\mathrm{X}$

C

GO TO 16

C

14 CALL LNNPPF (NOPRAM, PARAM, $X, P P F$ )

$16 X I=B(I)$

IF (KNEI) XI =RAN (IDUMY)

$\mathrm{IX}=\mathrm{EN} \mathrm{XII}^{+}+.5$

IF (IX.LT.1) IX $X=N$

20 IF (IX.GT.N) IX=1

IF (A(IX).LT.0.) G0 TO 30

$\mathrm{IX}=\mathrm{IX}+1$

GO TO 20

$30 \mathrm{~A}(\mathrm{IX})=\mathrm{PPF}$

40 CONTINUE

45 RETURN

C

C---- TWO UNIFORM DISTRIBUTIONS

C

$50 \mathrm{NN}=\operatorname{PARAM}(5) \star F L O A T(N)+0.5$

$N N=\operatorname{MAXO}(2, N N)$

$N N=M I N O(N-1, N N)$

PLOL =AMAX1 (XMIN, PARAM(1))

PHIL =PARAM (2)

$D X L=($ PHIL-PLOL $) / F L O A T(N N-1)$

PLOR $=$ PARAM $(3)$

PHIR=AMIN1 $(X M A X$, PARAM $(4))$

DXR $=($ PHIR-PLOR $) / F L O A T(N-N N-1)$ 


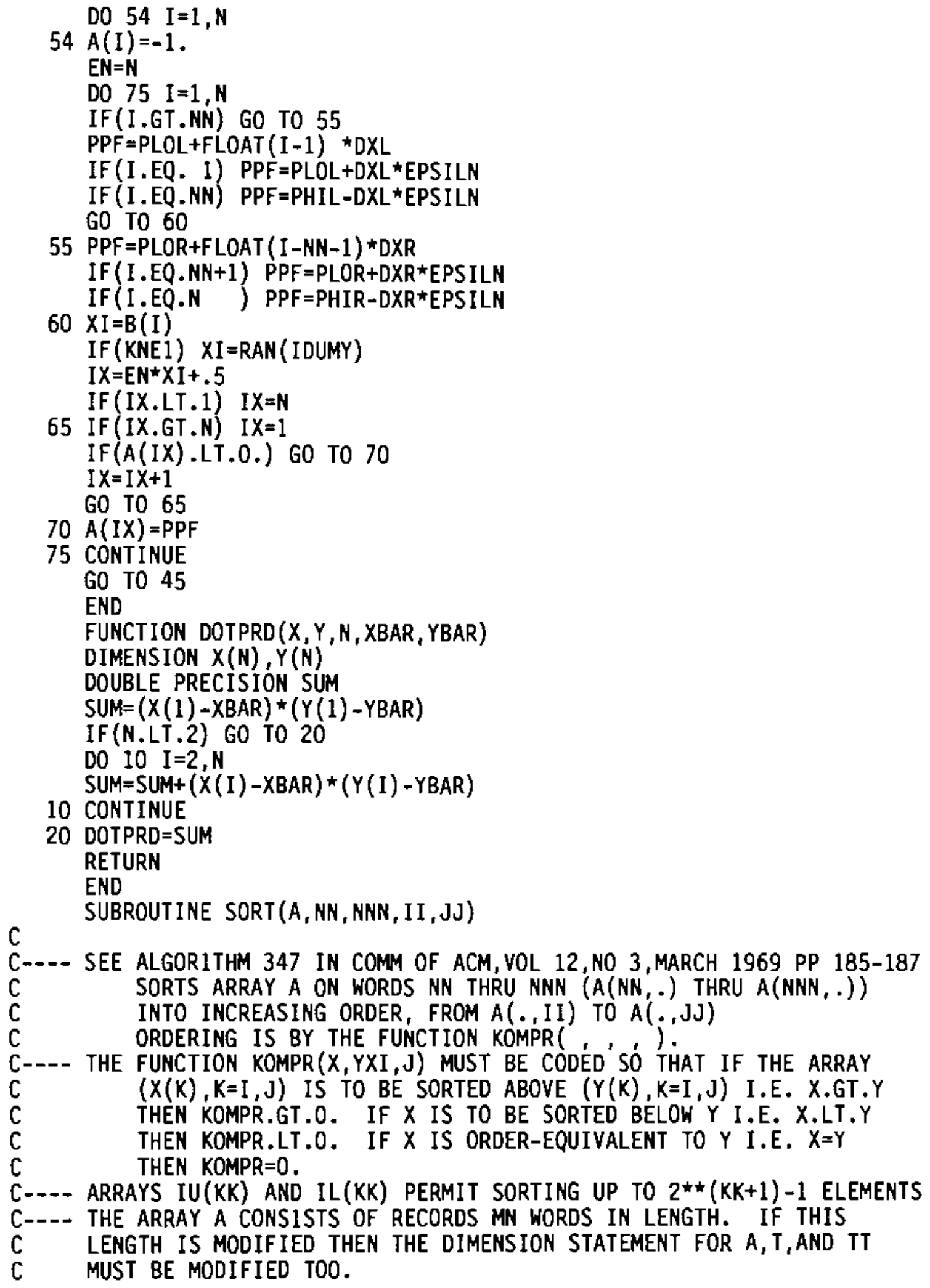




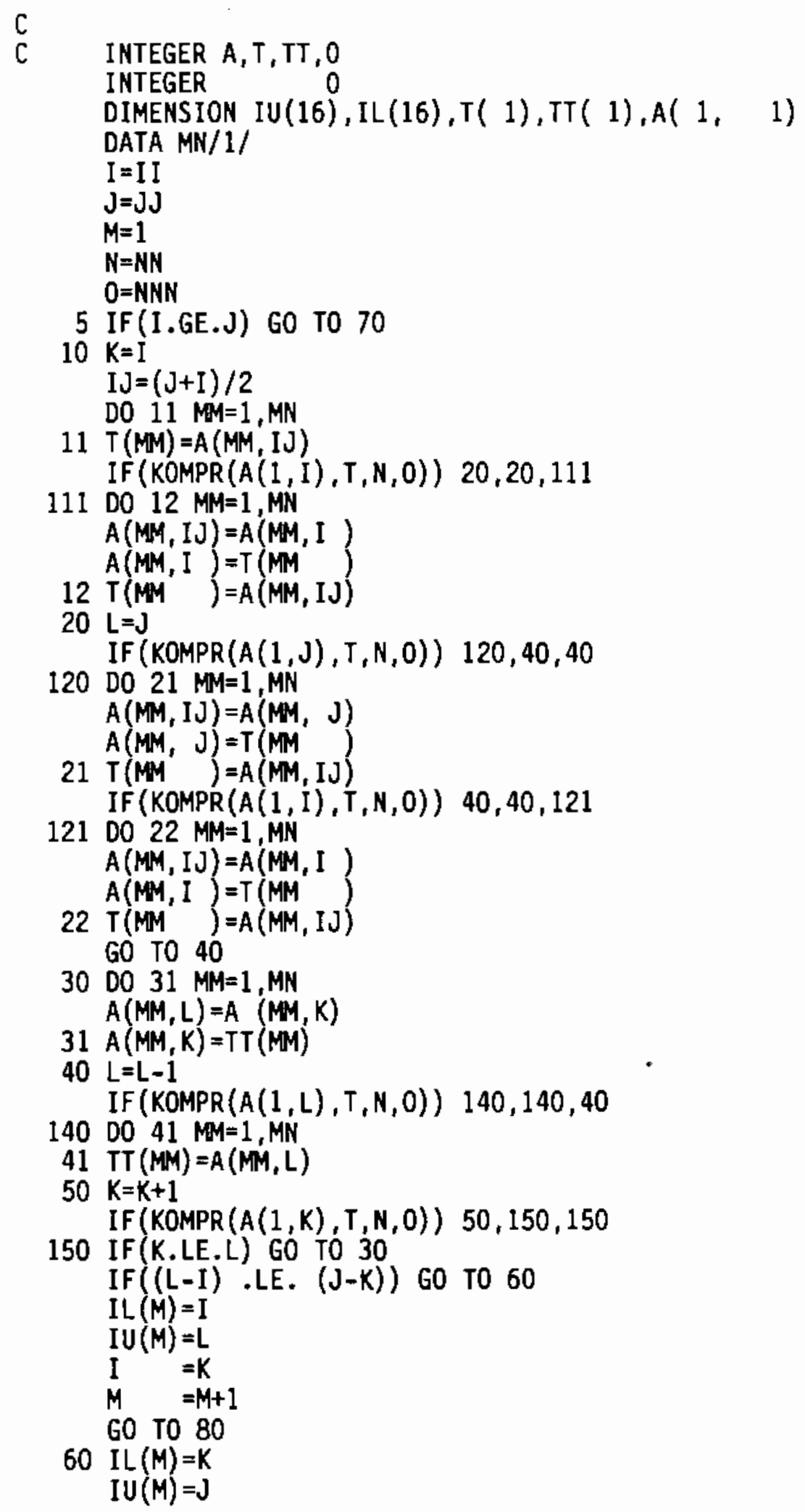




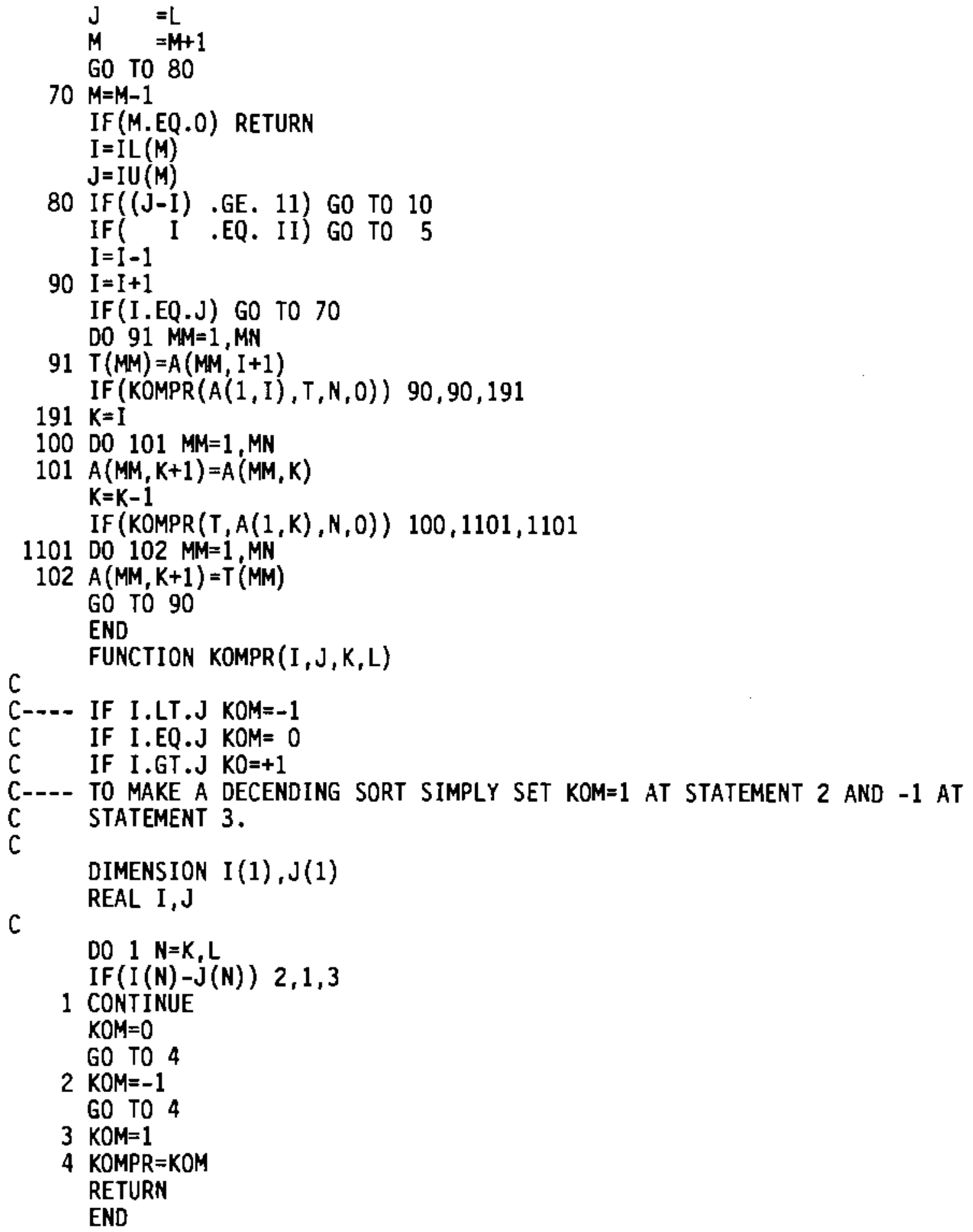


APPENDIX D

CMCCDF CODE LISTING 


\section{APPENDIX D}

\section{CMCCDF CODE LISTING}

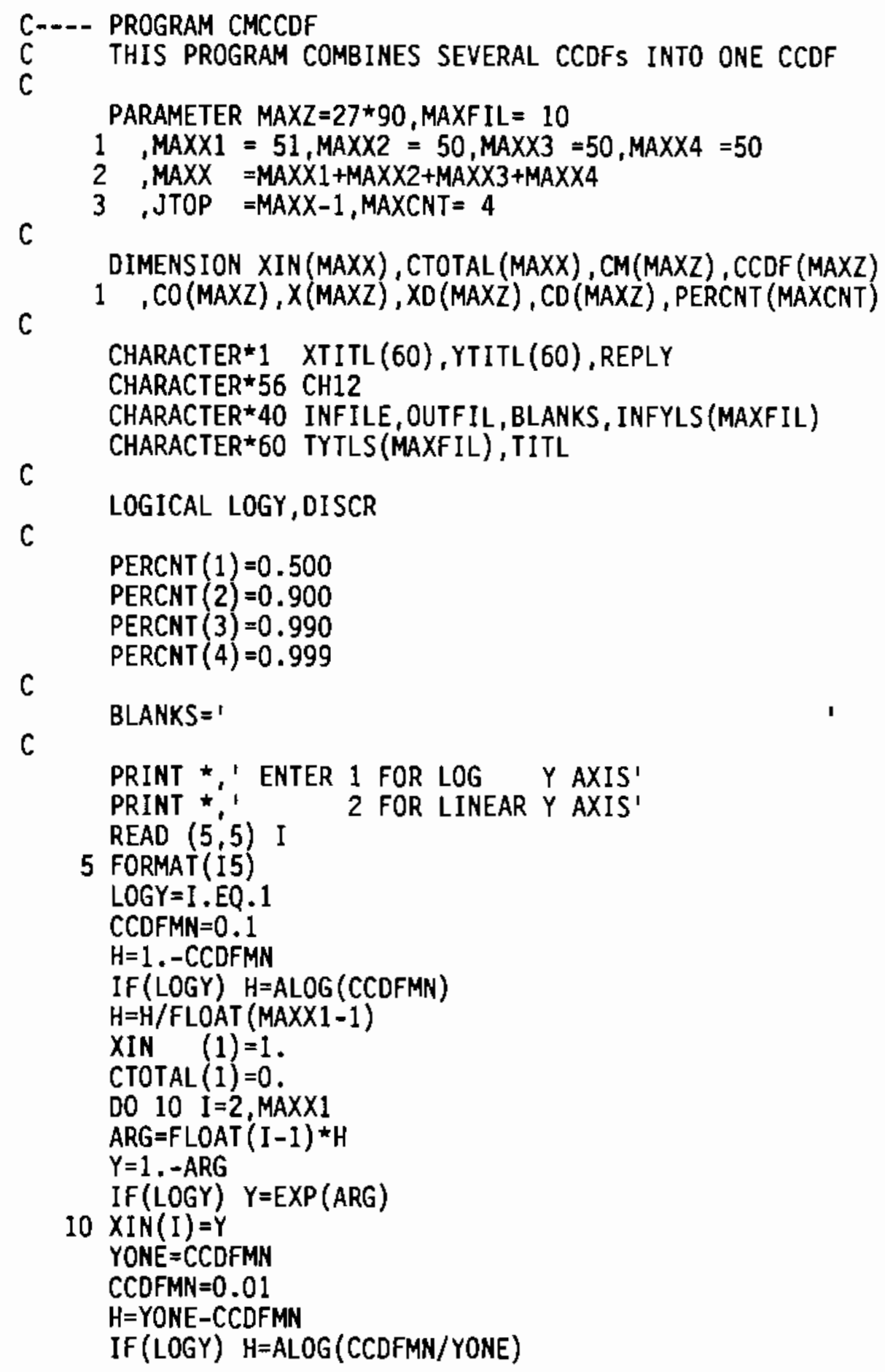




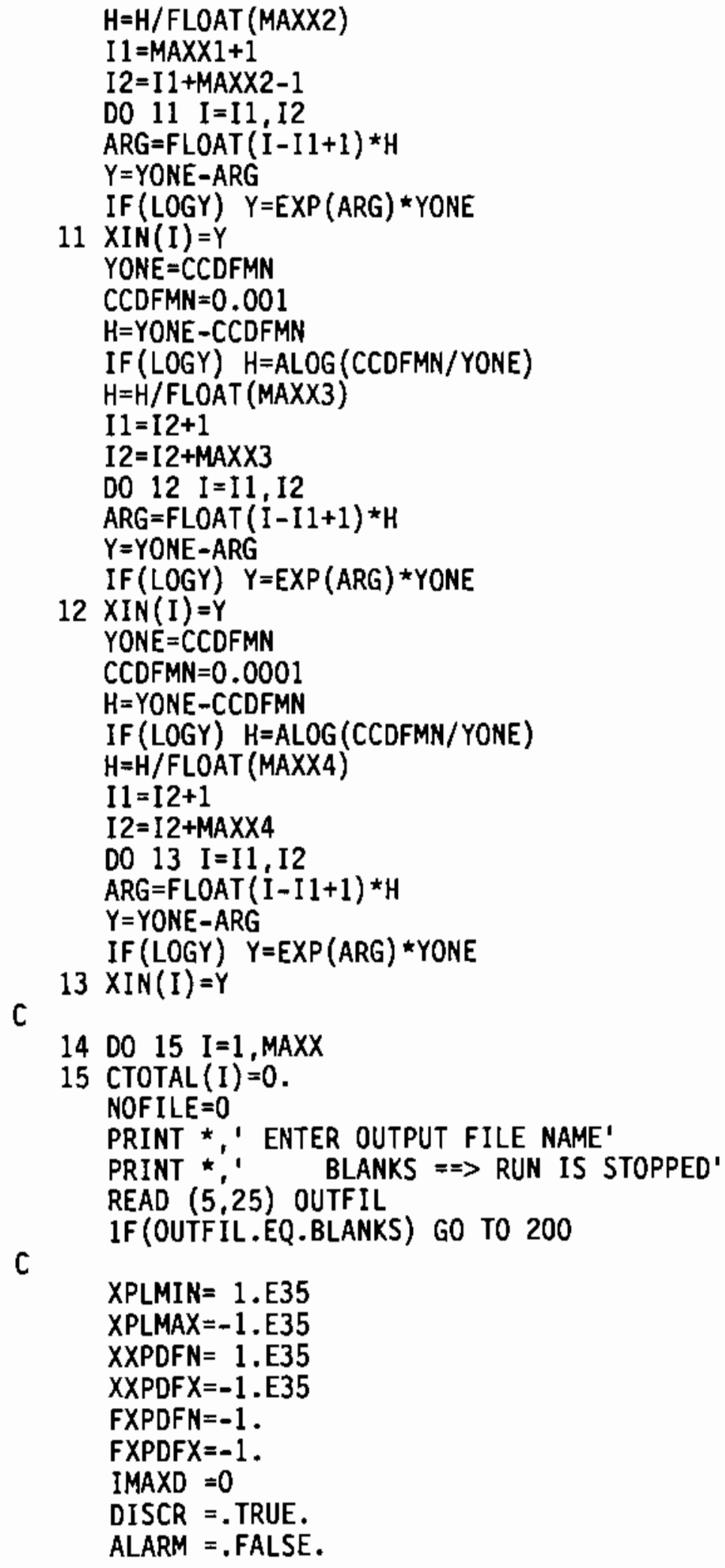


C

20 PRINT * , ENTER INPUT FILE NAME'

PRINT *,' BLANKS $=\Rightarrow$ WRITE OUTPUT FILE AND STOP'

READ $(5,25)$ INFILE

25 FORMAT (A40)

IF(INFILE.EQ.BLANKS) GO TO 110

$\mathrm{C}$

OPEN (UNIT=2, NAME=INFILE, TYPE= ' OLD' ', FORM= ' FORMATTED ')

READ $(2,31)$ TITL

32 FORMAT (60A1)

31 FORMAT(A60)

NOF ILE $=$ NOFILE+1

INFYLS (NOFILE) = INF ILE

C

TYTLS (NOFILE) $=$ TITL

$\begin{array}{ll}\text { READ }(2,32) & \text { XTITL } \\ \text { READ }(2,32) & \text { YTITL } \\ \text { READ }(2,75) & \text { XPLMI, XPLMA } \\ \text { READ }(2,75) & \text { XNPDF, FNPDF } \\ \text { READ }(2,75) & \text { XXPDF, FXPDF }\end{array}$

IF (XNPDF.NE. -1.) XXPDFN=AMIN1 (XXPDFN, XNPDF)

IF (FNPDF.NE. -1.) FXPDFN=AMAX1 (FXPDFN, FNPDF)

IF (XXPDF . NE. -1.) XXPDFX=AMAX1 (XXPDFX, XXPDF)

IF (FXPDF.NE. -1.) FXPDFX=AMAX1 (FXPDFX, FXPDF)

IMAX $=0$

DO 7D $I=1$, MAXZ

READ $(2,75, E N D=76) \times(I), C O(I)$

IF ((X(I).EQ.88888.) .AND. (CO(I) .EQ.88888.)) GO TO 76

75 FORMAT (2E15.7)

70 IMAX $=$ I

76 DO $74 \quad I=1, M A X Z$

READ $(2,75, E N D=73)$ XDI, CDI

IF ((XDI.EQ.99999.) .AND. (CDI.EQ.99999.)) GO TO 73

IF (IMAXD.GE.MAXZ) GO TO 73

IMAXD $=I M A X D+1$

$X D(\operatorname{IMAXD})=X D I$

CD $($ IMAXD $)=C D I$

74 CONTINUE

73 CLOSE (UNIT=2, DISPOSE='SAVE')

XPLMIN=AMIN1 (XPLMIN, XPLMI)

XPLMAX=AMAXI (XPLMAX, XPLMA)

MAXDI = IMAXD

C --- CONSTRUCT WORKING CCDF FOR INPUT CCDF

IF (IMAX.LE.O) GO TO 105

SUMC $=0$.

DO $77 I=2, I M A X$

77 SUMC $=\operatorname{SUMC}+(X(I)-X(I-1)) *(C O(I-1)+C O(I))$

SUMC=SUMC $/ 2$. 


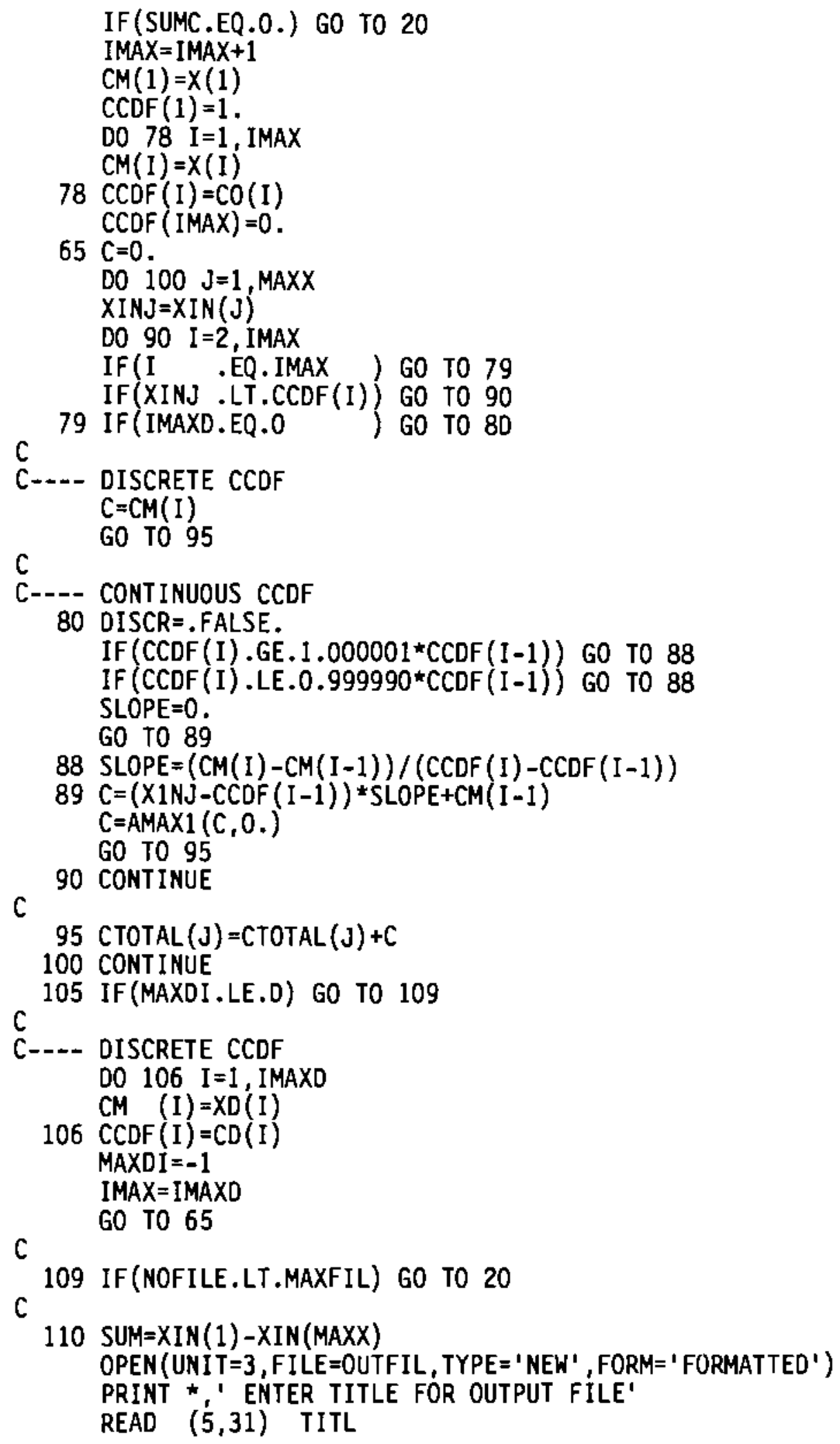




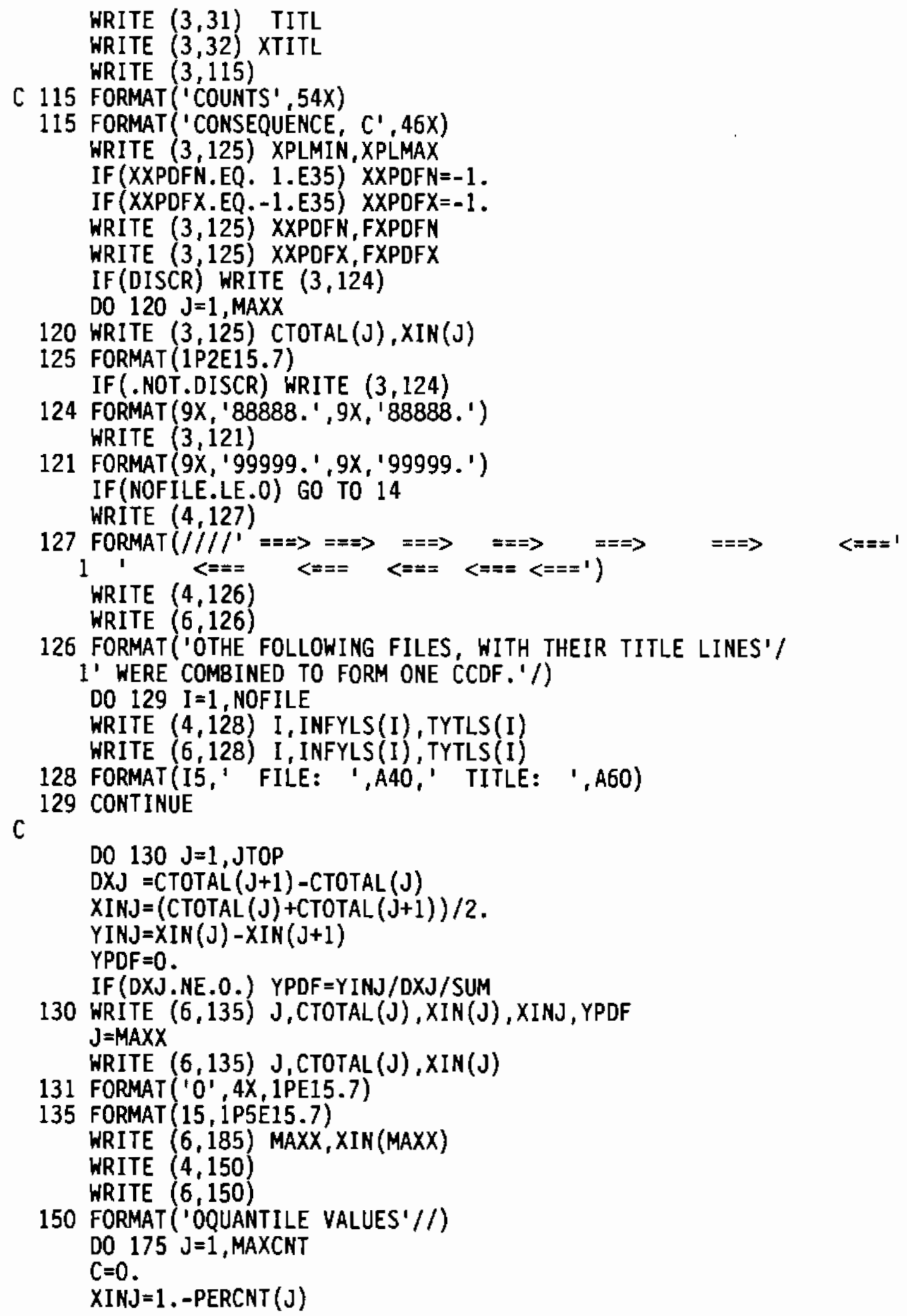




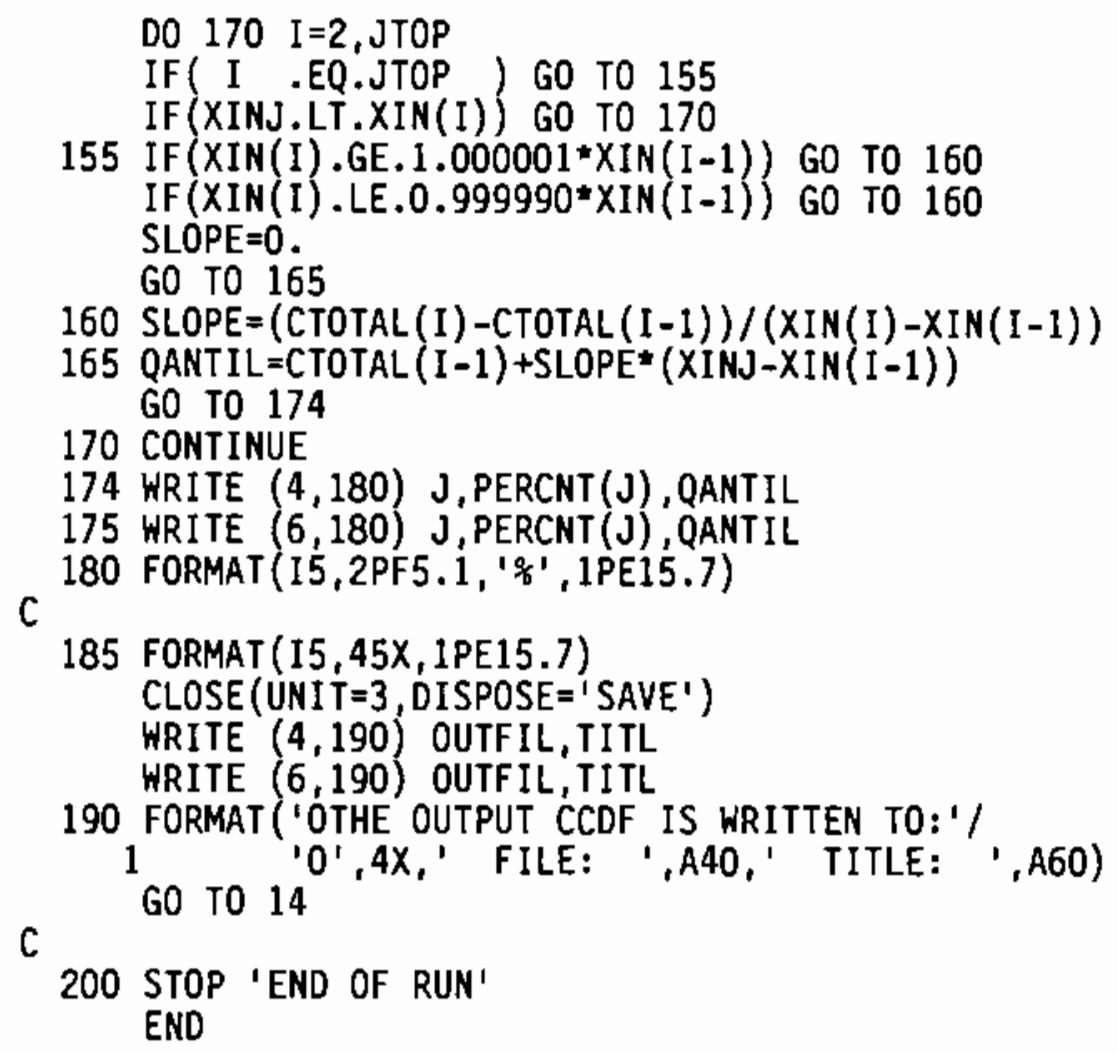


APPENDIX E

COMHUM CODE LISTING 


\section{APPENDIX E}

\section{COMHUM CODE LISTING}

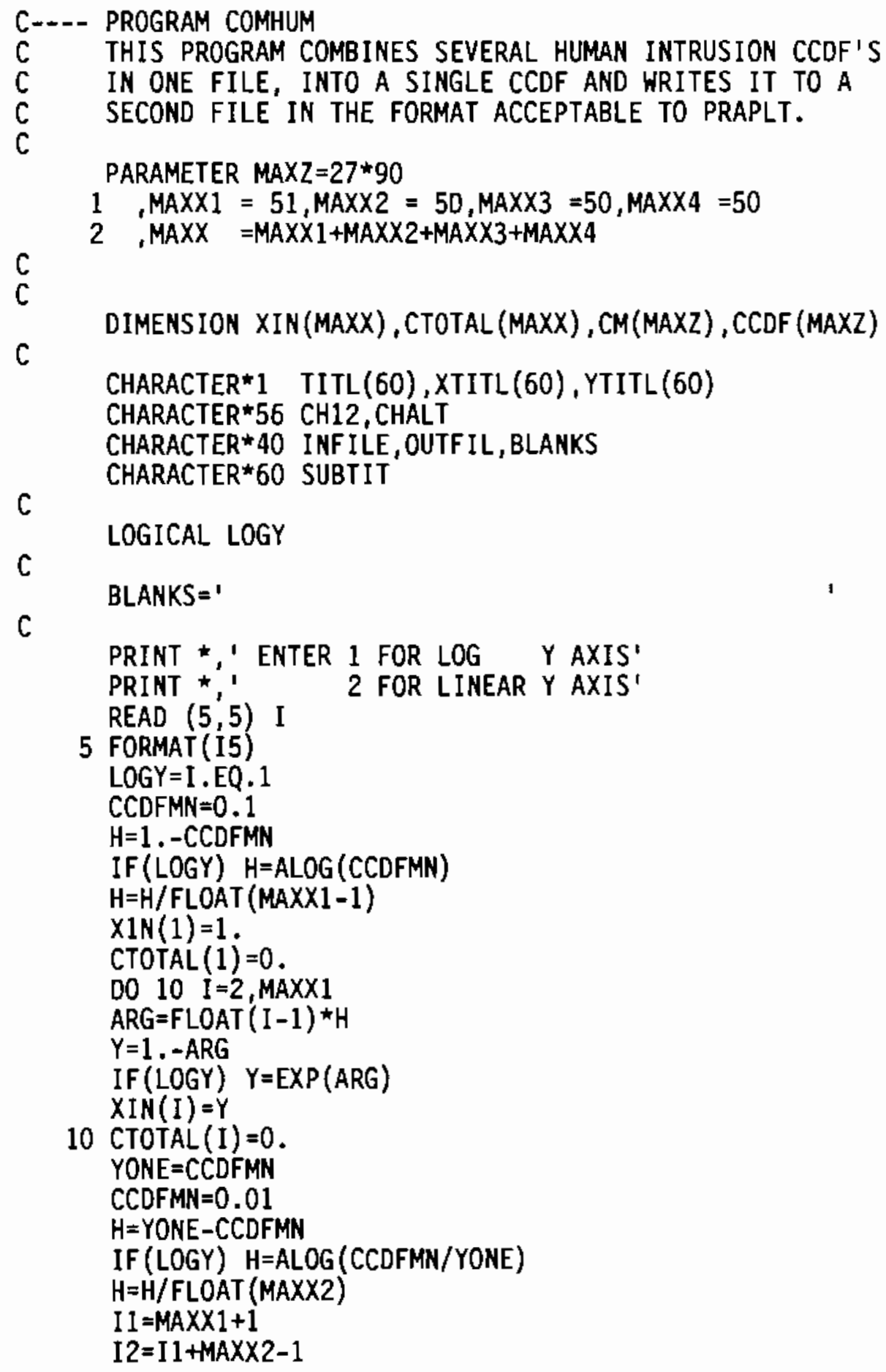




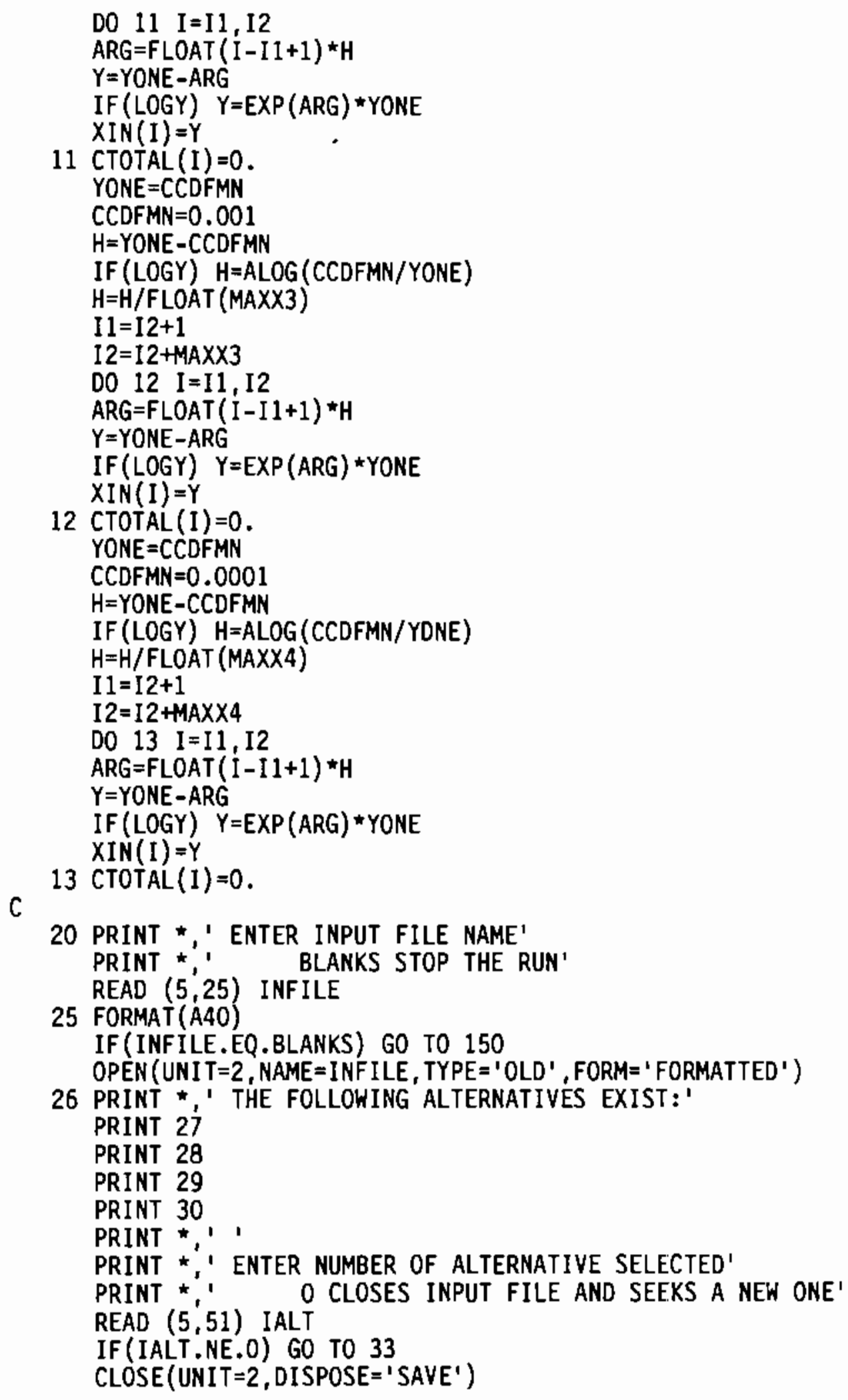


GO TO 20

27 FORMAT (' 1. GEOLOGIC DISPOSAL')

28 FORMAT (' 2. IN-PLACE STABILIZATION AND DISPOSAL')

29 FORMAT (' 3. REFERENCE')

C

30 FORMAT (' 4. NO ACTION')

33 REWIND 2

PRINT *' 'ENTER OUTPUT FILE NAME'

READ $(5,25)$ OUTFIL

C

OPEN (UNI T=3, NAME = OUTF IL, TYPE=' NEW' , FORM= ' FORMATTED' $)$

$\therefore \quad \mathrm{C}$

READ (2,32) TITL

32 FORMAT (60A1)

31 FORMAT (A60)

WRITE $(6,35)$ INF ILE, OUTFIL, TITL

35 FORMAT ('IPROGRAM COMHUM USED TO COMBINE THE CCDFS ON FILE: 1 ,A40 $/$ THE OUTPUT FILE HISTOGRAM IS ON FILE:

$2, \mathrm{A40} / /$, ',60A1)

READ $(2,31)$ SUBTIT

WRITE $(6,36)$ SUBTIT

36 FORMAT (' 0 ', A60)

WRITE $(6,37)$

37 FORMAT('OALTERNATIVE CHOSEN: ')

IF (IALT.EQ.1) WRITE $(6,27)$

IF (IALT.EQ.2) WRITE $(6,28)$

IF (IALT.EQ.3) WRITE $(6,29)$

C

IF (IALT.EQ.4) WRITE $(6,30)$

$c$

D0 $40 \quad I=1, \operatorname{MAXX}$

40 CTOTAL $(I)=0$.

NOPROC $=0$

50 READ $(2,51$, END $=110)$ JALT, CHALT

51 FORMAT $(15,5 X, A 35)$

READ $(2,55) \quad \mathrm{CH} 12$

55 FORMAT (A56)

WRITE $(6,60) \quad \mathrm{CH} 12$

60 FORMAT (' 0 ', A56)

READ $(2,32)$ XTITL

READ $(2,32)$ YTITL

READ $(2,65)$ IMAX

65 FORMAT(I5)

DO 70 I =1, IMAX

70 READ $(2,75)$ CM(I), CCDF (I)

75 FORMAT (2E15.7)

IF (JALT.NE.IALT) GO TO 50

NOPROC $=$ NOPROC +1

$C=0$.

DO $100 \mathrm{~J}=1, \operatorname{MAXX}$

$X I N J=X I N(J)$ 


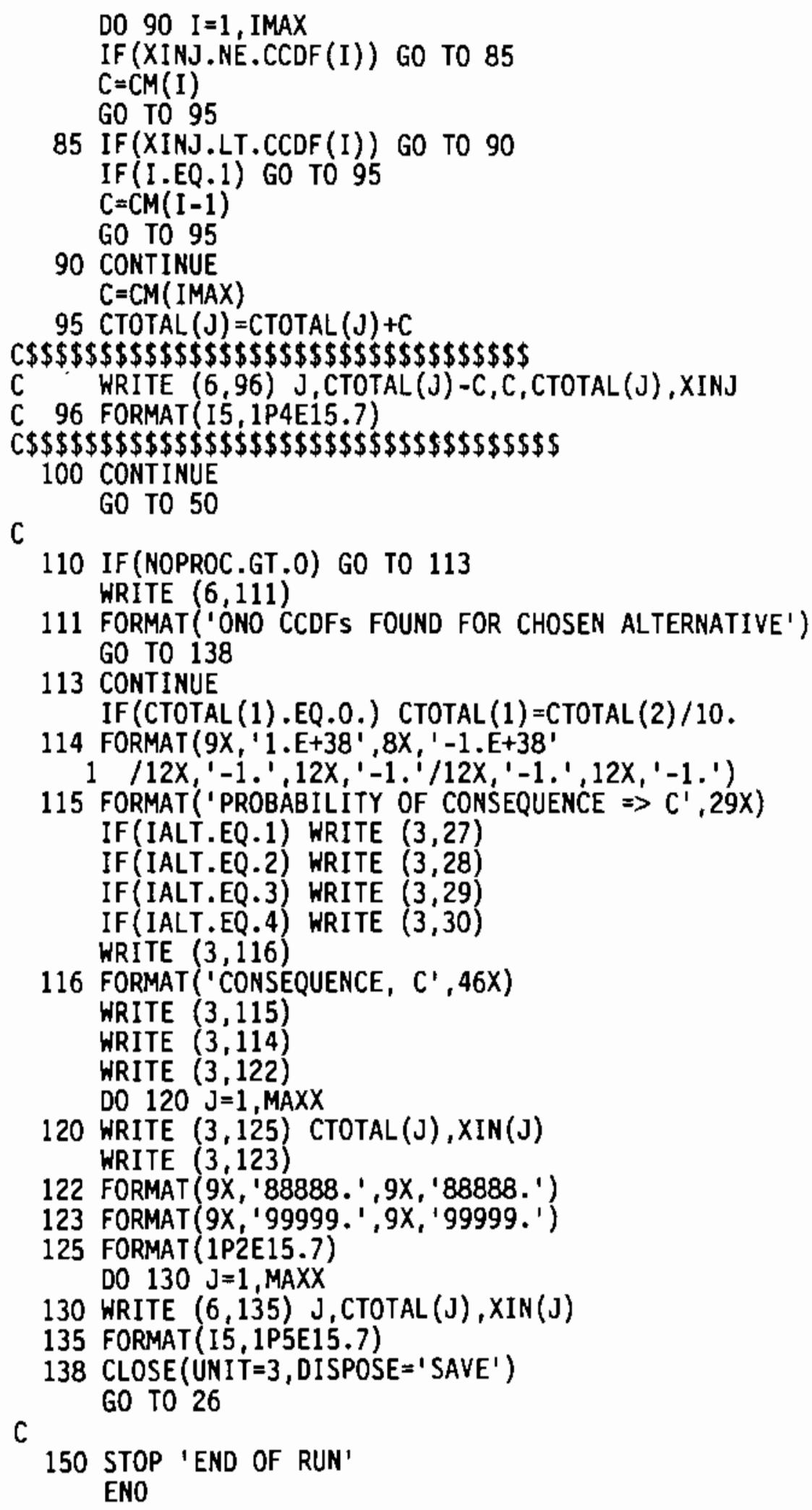


APPENDIX $F$

PRAPLT CODE LISTING 


\section{APPENDIX $F$}

PRAPLT CODE LISTING

C...- PRAPLT IS A PROGRAM TO PLOT PRA HISTOGRAMS AS pdf'S OR CCDF'S

C PARAMETER MAXXY $=27 * 90$, MAXXY4 $=$ MAXXY +4

DIMENSION X(MAXXY4,4), Y(MAXXY4,4),XTAB (MAXXY4,4), YTAB(MAXXY4,4)

C 1 ,XPLOT (MAXXY4), YPLOT (MAXXY4)

DIMENSION NOX (4), NOY (4), NO(4), NOH(4)

1 ,XPLMIN (4), XPLMAX (4), FXPDFX (4),XPL (2), YPL(2)

C

2 ,FXPDFN(4), SLLX(5), SLLY (5), XXPDFN (4), XXPDFX (4)

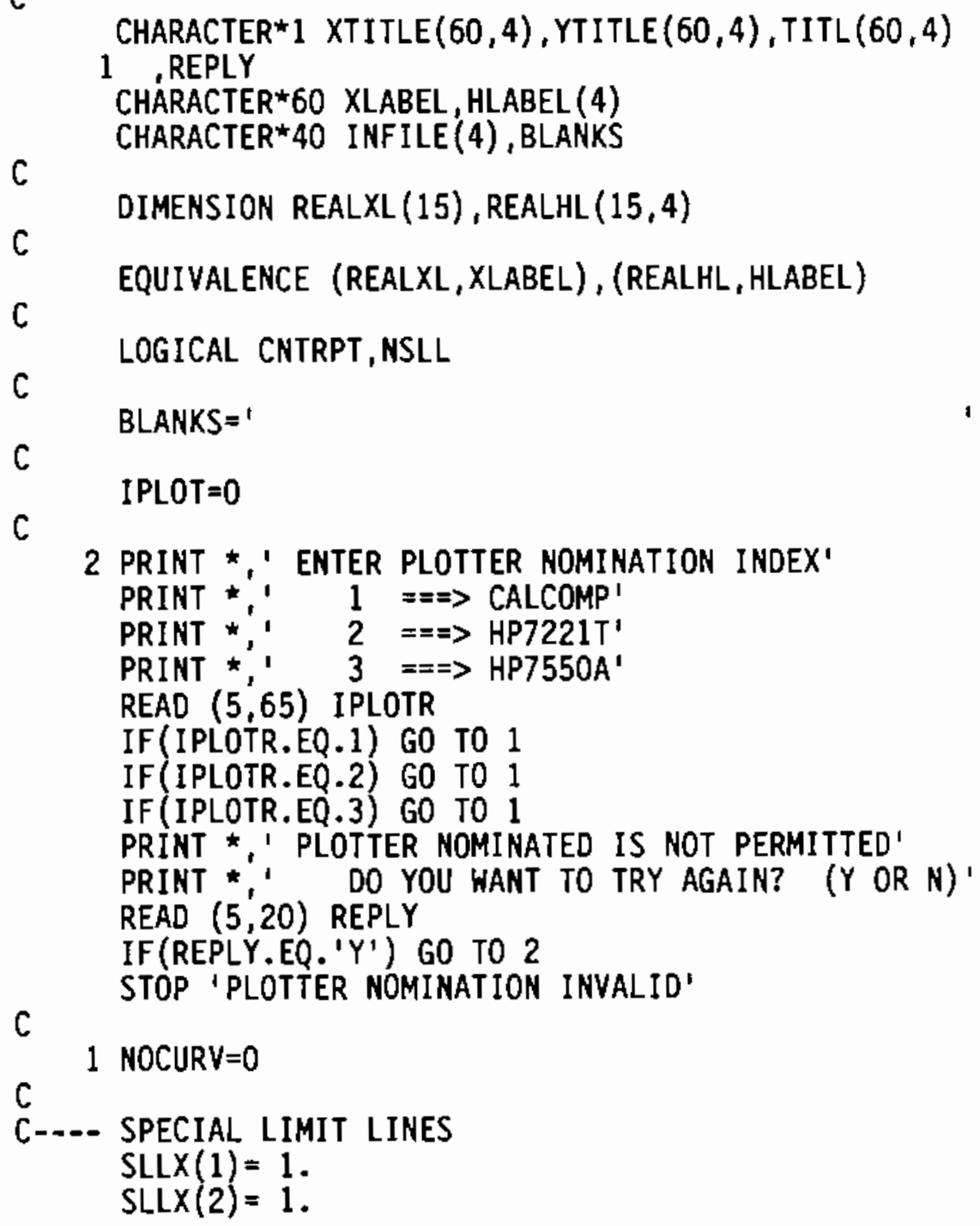




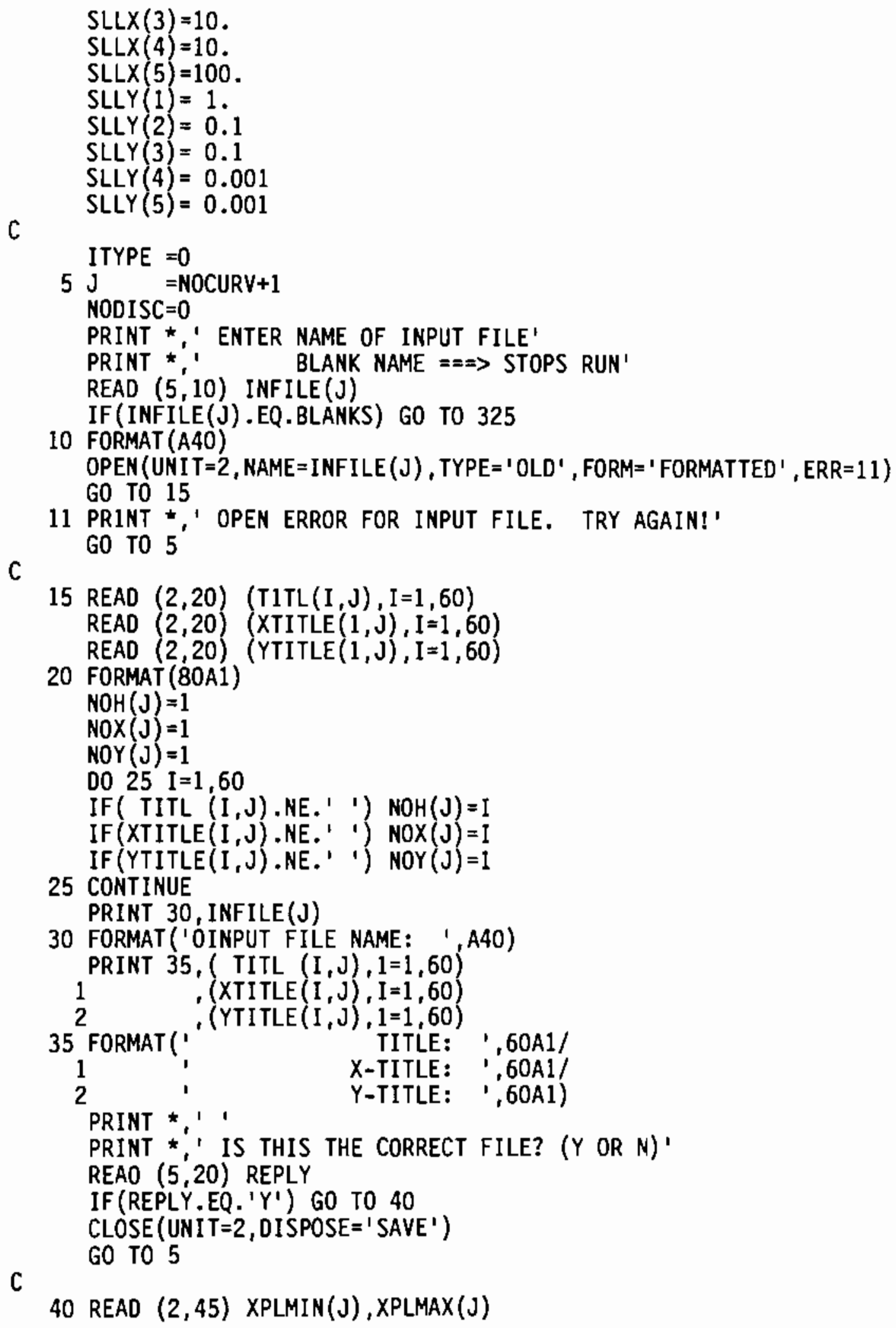

$40 \operatorname{READ}(2,45) \operatorname{XPLMin}(\mathrm{J}), \operatorname{XPLMAX}(\mathrm{J})$ 


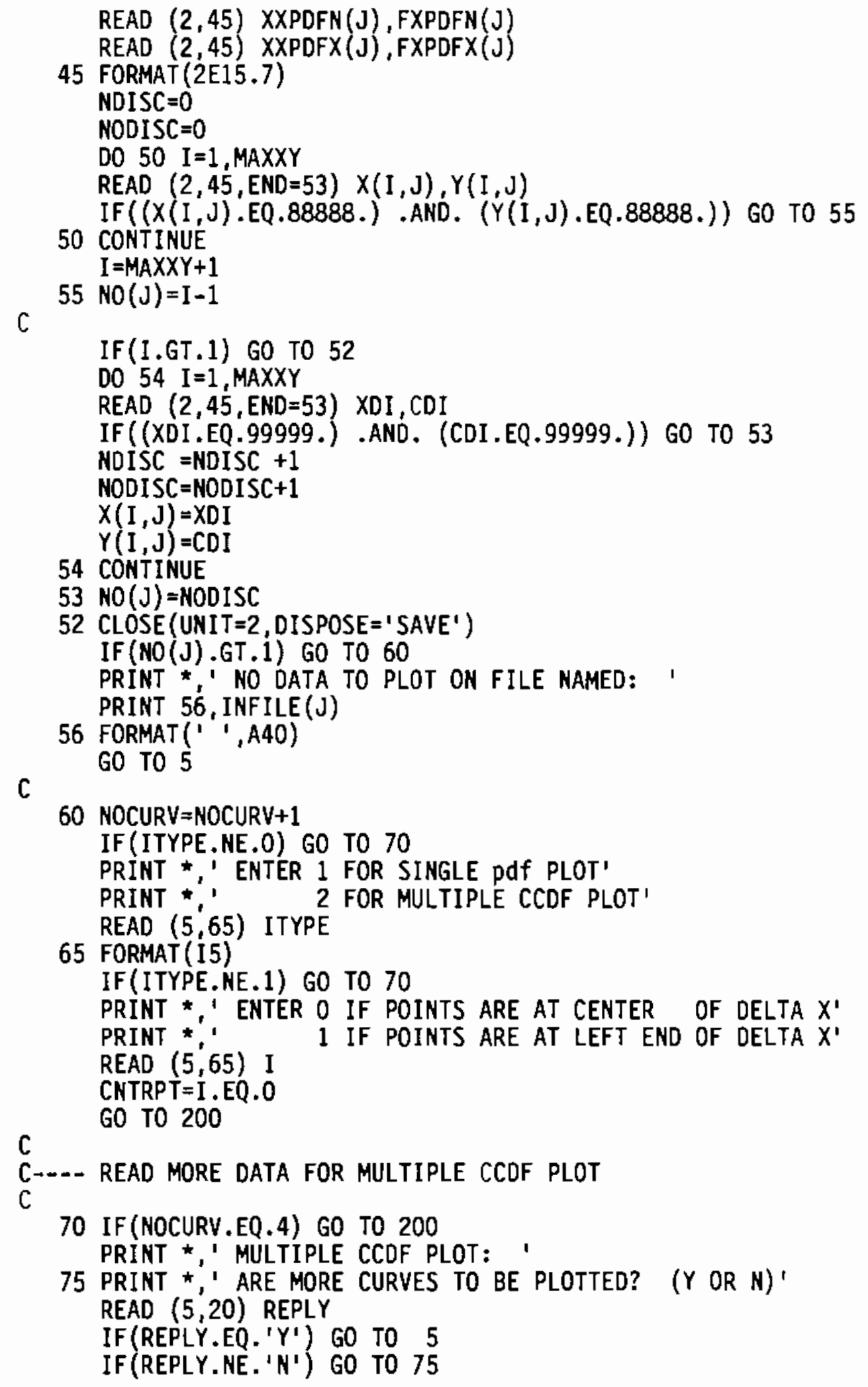




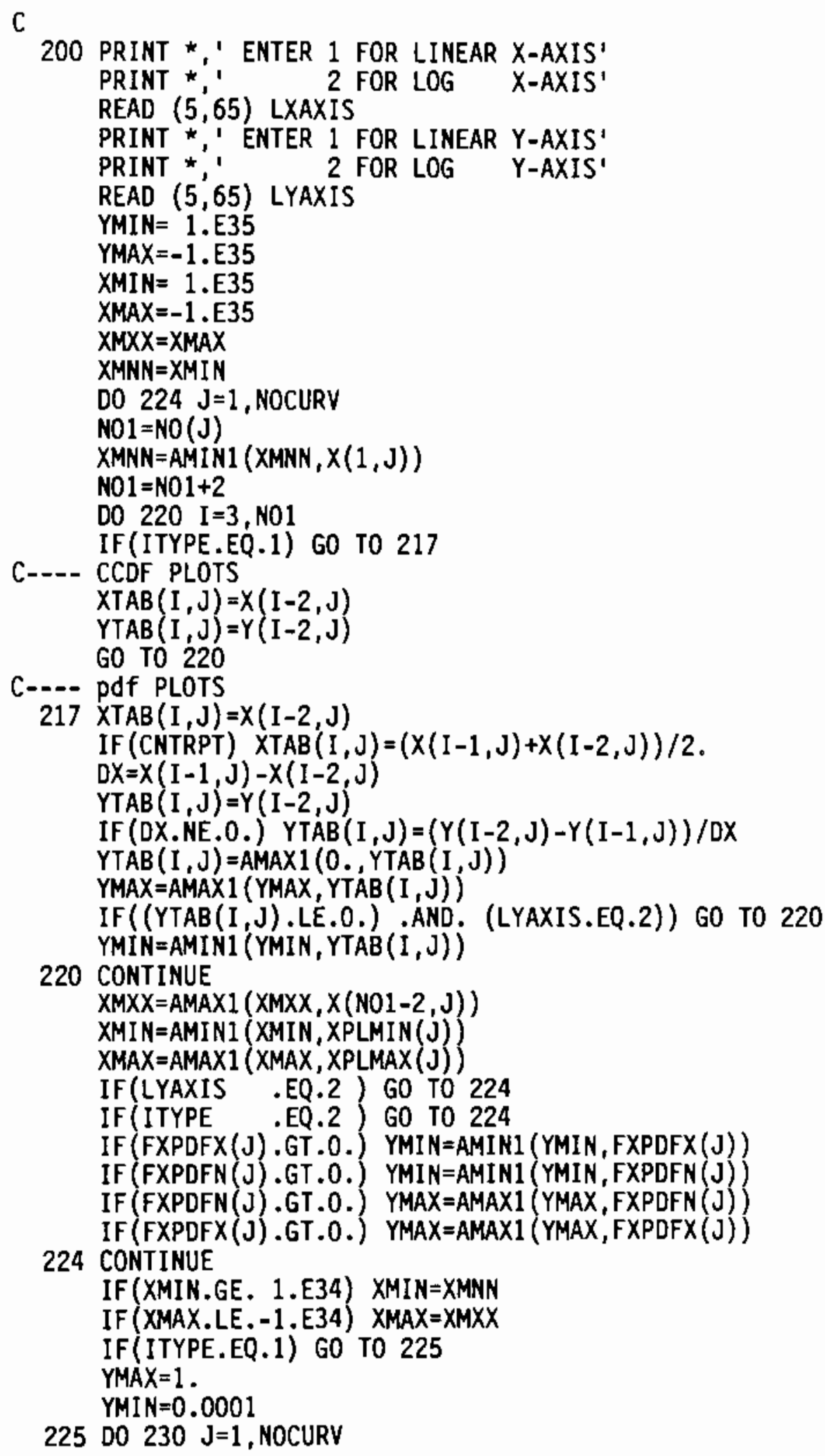




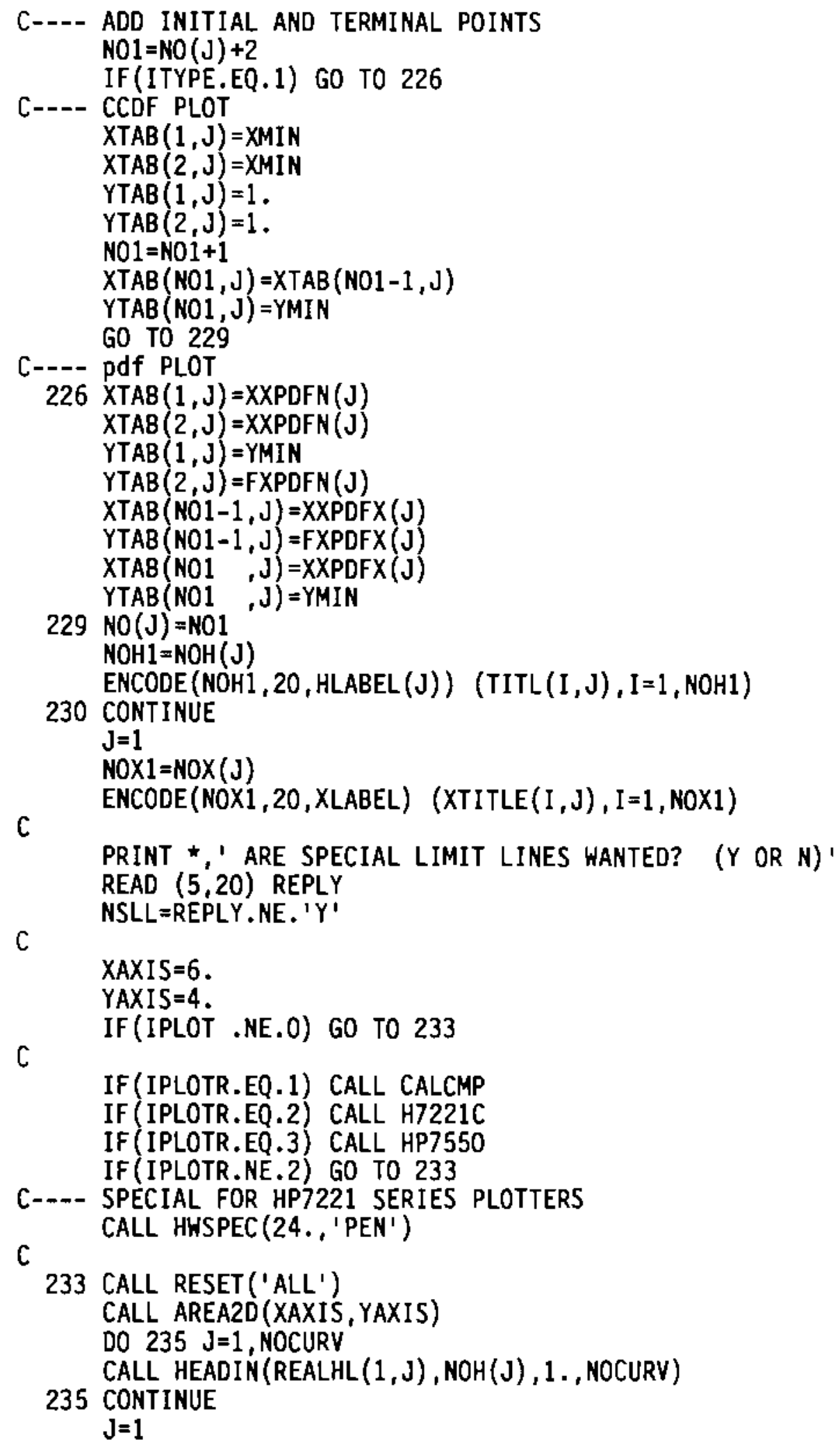


IF (ITYPE. EQ.2) GO TO 238

CALL XNAME(REALXL, NOX1)

CALL YNAME('pdf\$',100)

GO TO 240

238 CALL XNAME ('RELEASE RATIO CONSEQUENCE, C \$',100)

CALL YNAME('PROBABILITY OF CONSEQUENCE $\Rightarrow C \$ 1,100)$

C

240 IF (LXAXIS.NE.2) GO TO 255

C--.- LOG X-AXIS

CALL ALGPLT (XMIN, XMAX, XAXIS, ORGX,XCYCLE)

IF(LYAXIS.NE.2) GO TO 250

C

C---- LOG X-AXIS AND LOG Y-AXIS

CALL ALGPLT (YMIN, YMAX, YAXIS, ORGY, YCYCLE)

CALL LOGLOG (ORGX, XCYCLE, ORGY, YCYCLE)

c

GO TO 270

C---- LOG X-AXIS AND LINEAR Y-AXIS

250 CALL AXSPLT (YMIN, YMAX, YAXIS, ORGY, YSTEP, YAXISL)

CALL XLOG (ORGX, XCYCLE, ORGY, YSTEP)

$\mathrm{C}$ GO TO 270

C--.- LINEAR X-AXIS

255 CALL AXSPLT (XMIN, XMAX, XAXIS, ORGX, XSTEP, XAXISL) IF (LYAXIS.NE.2) GO TO 260

C

C-.-- LINEAR X-AXIS AND LOG Y-AXIS

CALL ALGPLT (YMIN, YMAX, YAXIS, ORGY, YCYCLE)

CALL YLOG (ORGX, XSTEP, ORGY, YCYCLE)

GO TO 270

C

C---- LINEAR X-AXIS AND LINEAR Y-AXIS

260 CALL AXSPLT (YMIN, YMAX, YAXIS, ORGY, YSTEP, YAXISL) $X A X I S M=0 R G X+X S T E P \star X A X I S L$ YAXISM $=0 R G Y+Y S T E P * Y A X I S L$

C

CALL GRAF (ORGX, XSTEP, XAXISM, ORGY, YSTEP, YAXISM)

270 IF(ITYPE.EQ.2) GO TO 280

$\mathrm{NOI}=\mathrm{NO}(1)$

DO $275 \mathrm{I}=1$, N01

$X P L O T(I)=X T A B(I, 1)$

275 CONTINUE

YPLOT (I) =YTAB (I, 1)

$\mathrm{II}=\mathrm{NO} 1+1$

XPLOT (II $)=X P L O T(I I-1)$

YPLOT (II) $=$ YMIN

IF (NDISC.NE.0) GO TO 276

C CALL MARXER(15)

CALL CURVE(XPLOT, YPLOT I II,0)

GO TO 300 


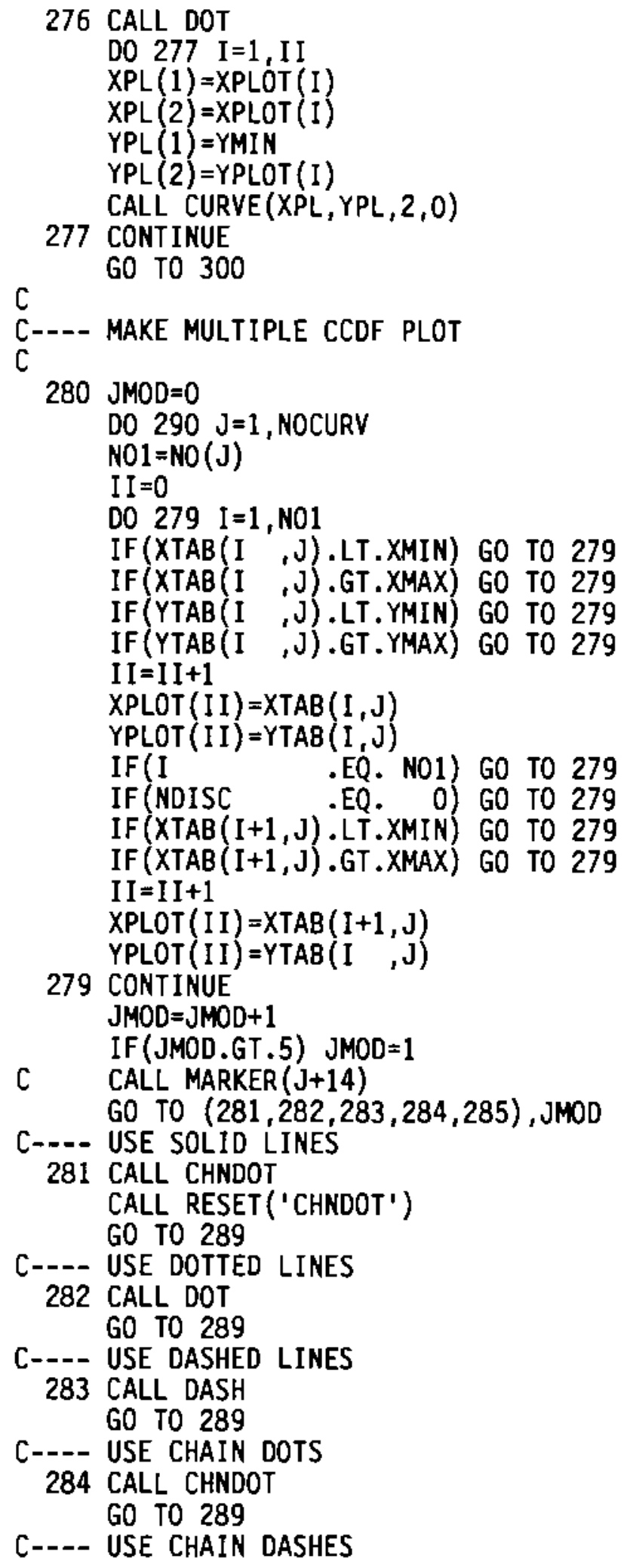




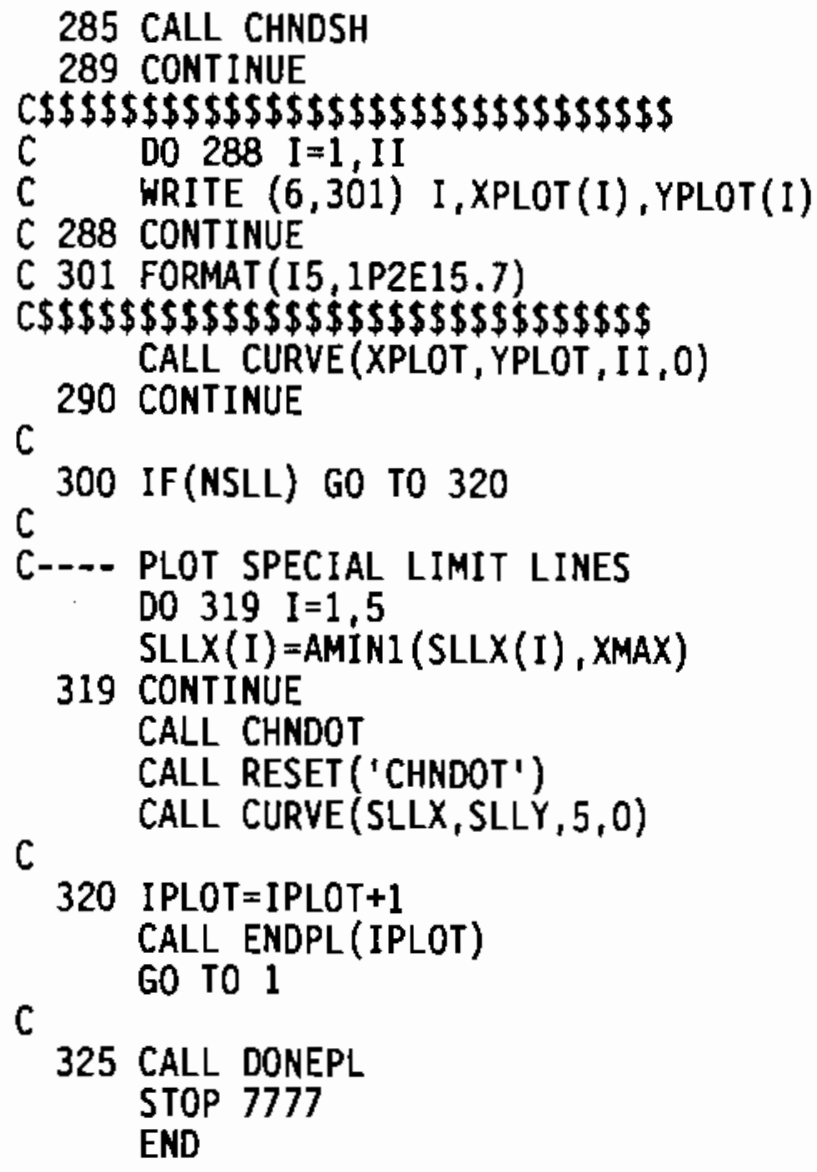


APPENDIX G

W8CCDF CODE LISTING 
APPENDIX G

W8CCDF CODE LISTING

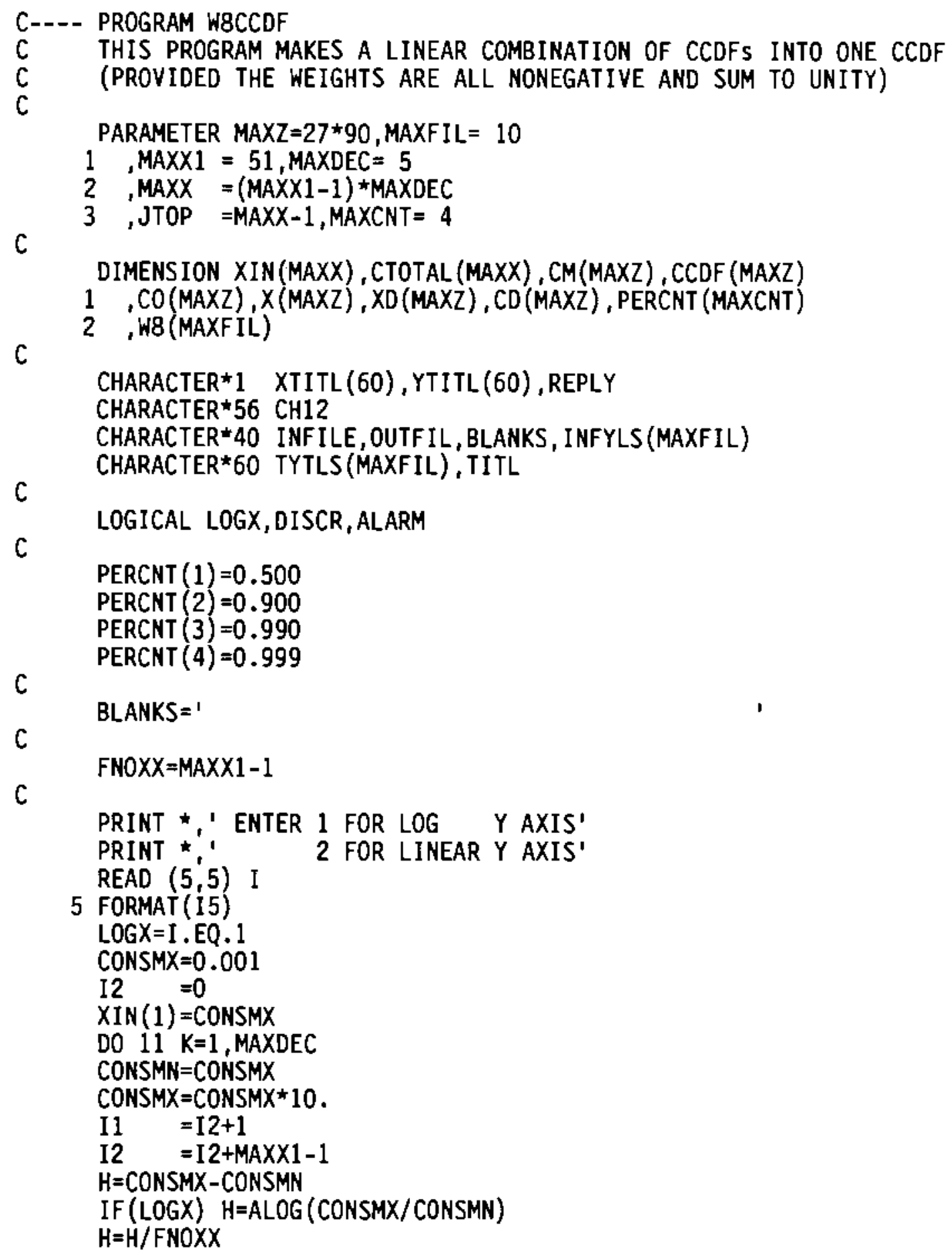




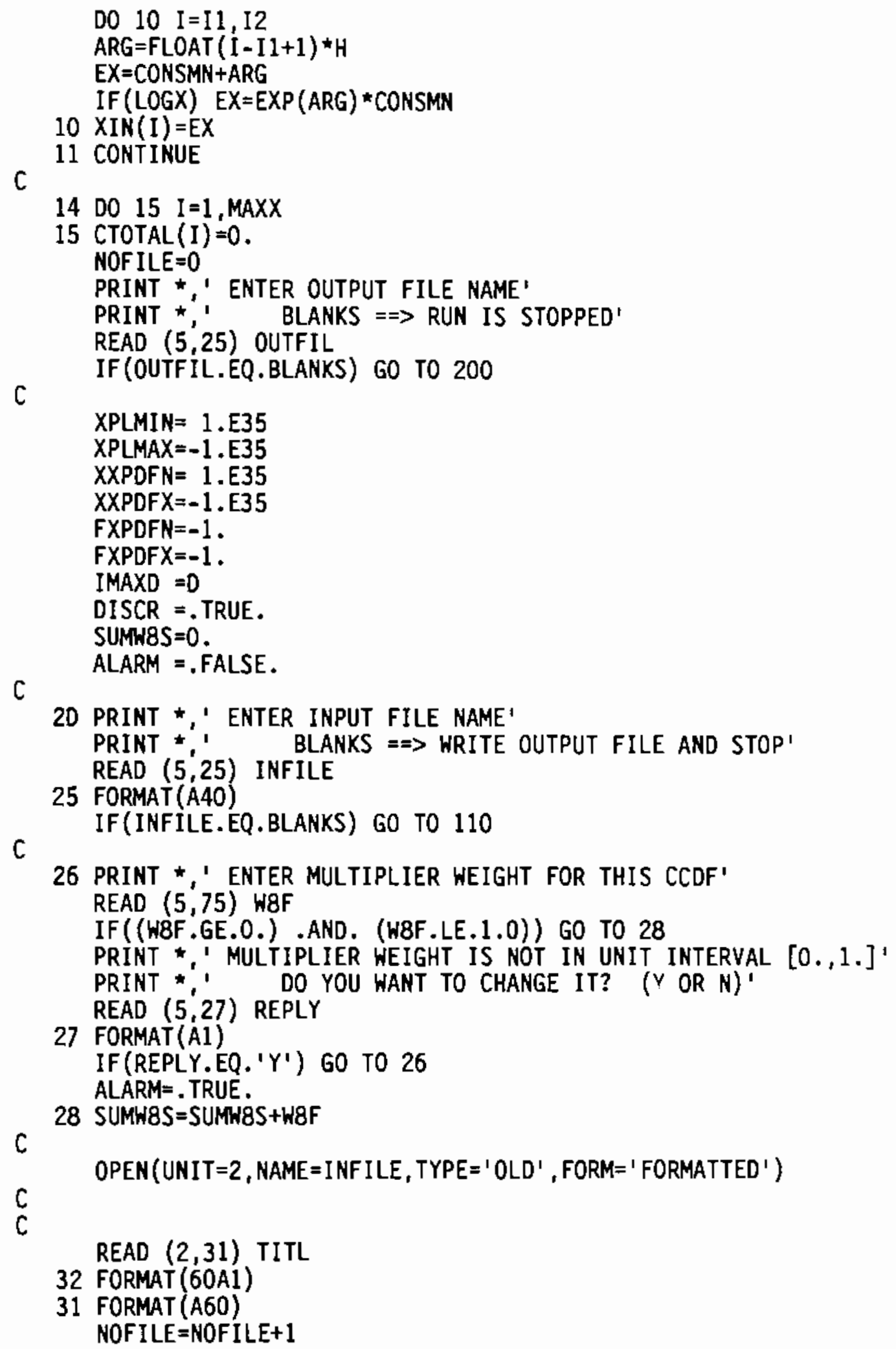




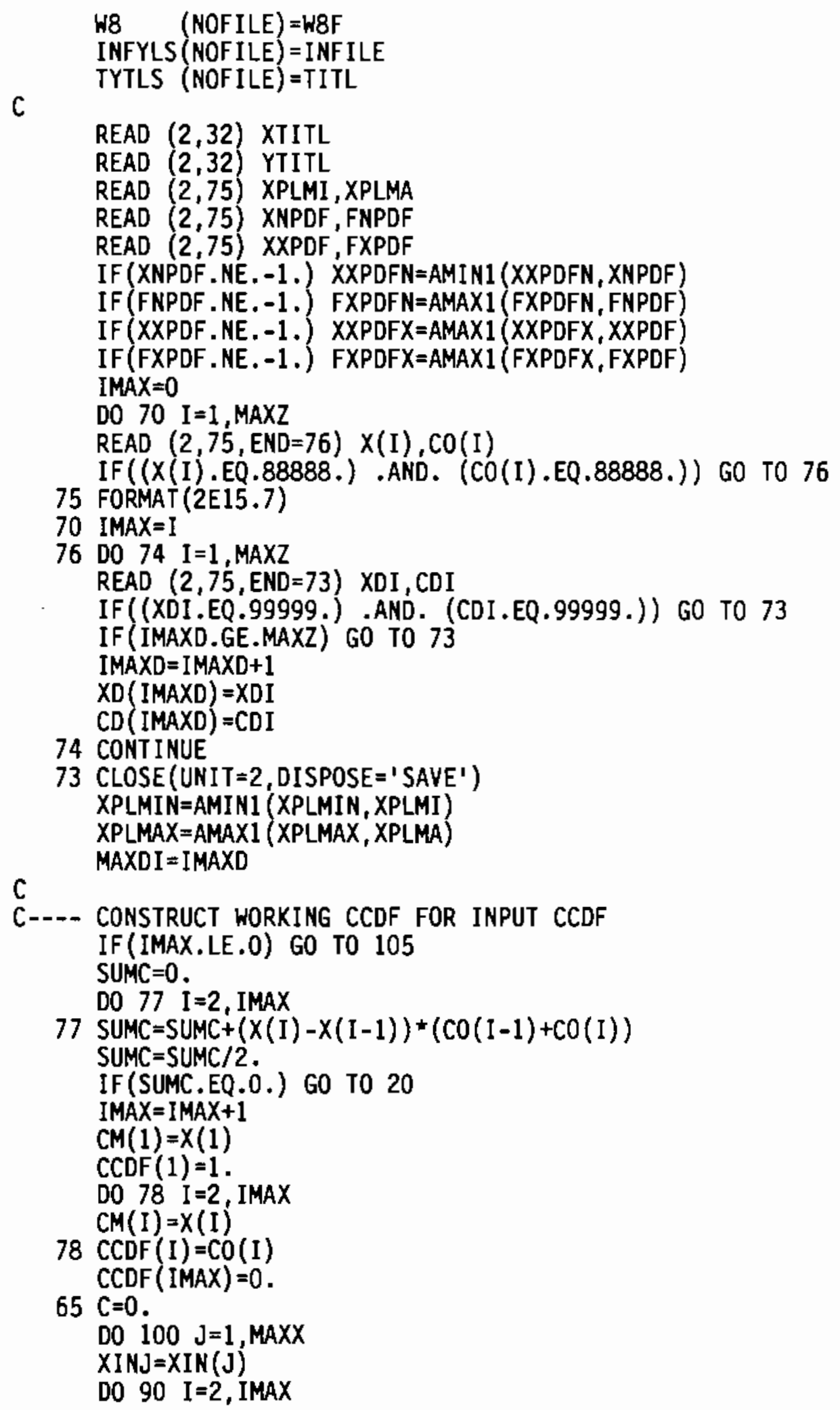




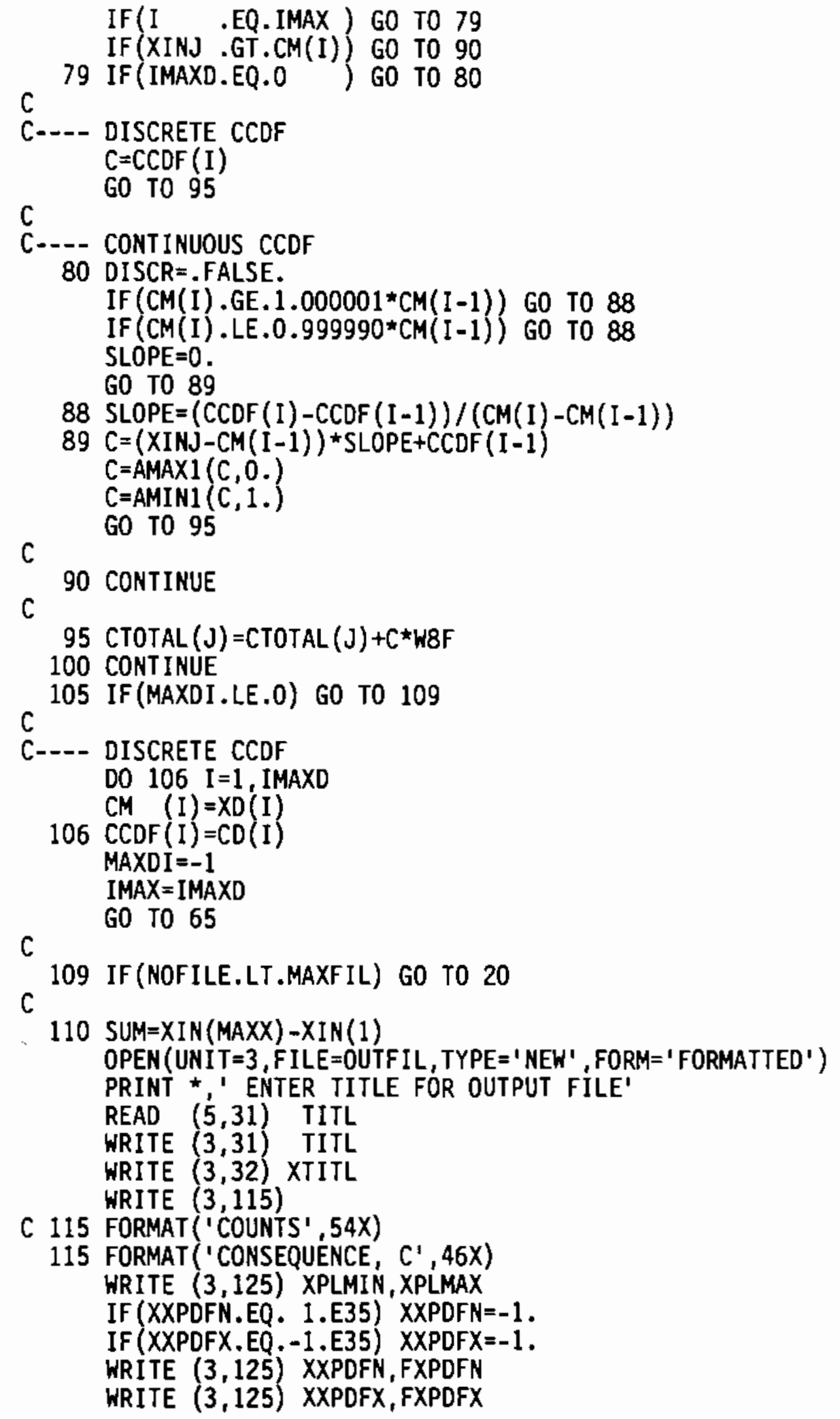


IF (DISCR) WRITE $(3,124)$

DO $120 \mathrm{~J}=1$, MAXX

120 WRITE $(3,125) \times \operatorname{XIN}(\mathrm{J}), \operatorname{CTOTAL}(\mathrm{J})$

125 FORMAT (1P2E15.7)

IF (.NOT.DISCR) WRITE $(3,124)$

124 FORMAT (9X, '88888.' ', 9X, ' 88888. ' $\left.^{\prime}\right)$

WRITE $(3,121)$

121 FORMAT (9X,' 99999. ' , 9X, ' $99999 . '$ ')

IF (NOF ILE. LE.0) GO TO 14

WRITE $(4,127)$

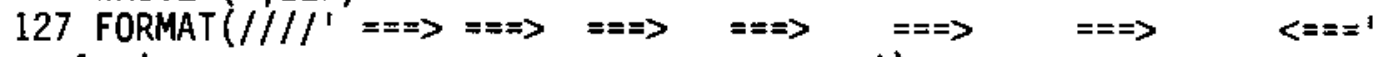

1

WRITE $(4,126)$

WRITE $(6,126)$

126 FORMAT('OTHE FOLLOWING FILES, WITH THEIR TITLE LINES' /

1 ' WERE COMBINED TO FORM ONE CCDF. ' $/$ )

DO $129 I=1$, NOF ILE

WRITE $(4,128)$ I, INFYLS (I), TYTLS(I)

WRITE $(6,128)$ I, INFYLS (I), TYTLS (I)

128 FORMAT (15,' FILE: ',A40,' TITLE: ',A60)

C

129 CONTINUE

WRITE $(4,140)$

WRITE $(6,140)$

140 FORMAT ('OMULTIPLIER WEIGHTS ARE: ' $/ /$ )

DO $141 I=1$, NOF ILE

WRITE $(4,142)$ I, W8(I)

141 WRITE $(6,142)$ I, W8(I)

142 FORMAT (I5, F10.6)

WRITE $(4,143)$ SUMW8S

WRITE $(6,143)$ SUMW8S

143 FORMAT ('

-

IF ((SUMW8S.LE.0.) .OR. (SUMW8S.GT.1.)) ALARM= . TRUE.

IF(ALARM) WRITE $(4,144)$

IF (ALARM) WRITE $(6,144)$

144 FORMAT (' $0 * \star \star * * * \star * \star \star *$ ONE OR MORE MULTIPLIER WEIGHT IS OUTSIDE'

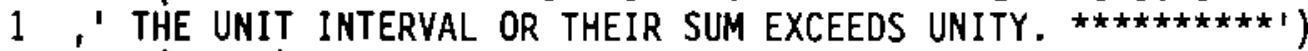
WRITE $(4,145)$

WRITE $(6,145)$

145 FORMAT (' 0 ')

DO $130 \mathrm{~J}=1, \mathrm{JTOP}$

$\operatorname{DXJ}=X \operatorname{IN}(J+1)-X \operatorname{IN}(\mathrm{J})$

$X I N J=(X I N \quad(J)+X I N \quad(J+1)) / 2$.

$Y \operatorname{INJ}=\operatorname{CTOTAL}(\mathrm{J})-\operatorname{CTOTAL}(\mathrm{J}+1)$

$Y P D F=0$.

IF (DXJ.NE.0.) YPDF=YINJ/DXJ/SUM

130 WRITE $(6,135) \mathrm{J}, X I N(\mathrm{~J}), \mathrm{CTOTAL}(\mathrm{J}), X I N J, Y P D F$

$J=\operatorname{MAXX}$

WRITE $(6,135) \mathrm{J}, X I N(\mathrm{~J}), \operatorname{CTOTAL}(\mathrm{J})$

131 FORMAT (' 0 ' , 4X, 1PE15.7) 


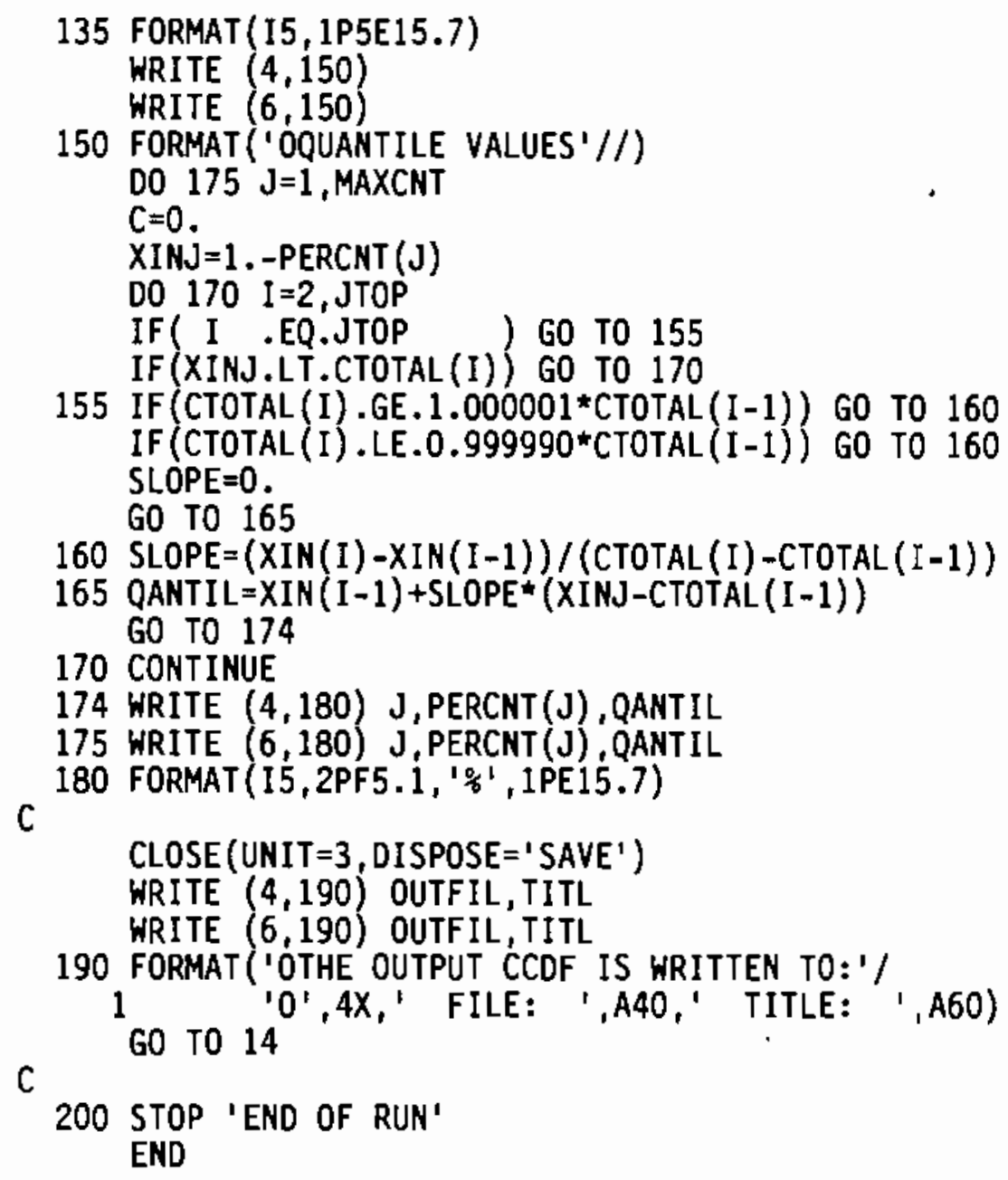




\section{APPENDIX $\mathrm{H}$}

W8PLOT CODE LISTING 
APPENDIX H

\section{WBPLOT CODE LISTING}

C-..- WBPLOT IS A PROGRAM TO PLOT PRA HISTOGRAMS AS Pdf'S OR CCDF'S

C--.-WBPLOT IS BASICALLY THE PRAPLOT PROGRAM EXCEPT FOR 7 ADDITIONAL LINES

C-.--WBPLOT GRAPHICS ARE GEARED FOR SCALES OF THE COMPOSITE CCDF \& EPA STAND.

C

PARAMETER MAXXY $=27 \star 90$, MAXXY4=MAXXY +4

DIMENSION X(MAXXY4,4), Y (MAXXY4,4), XTAB (MAXXY4,4), YTAB (MAXXY4,4)

C

1 ,XPLOT (MAXXY4), YPLOT (MAXXY4)

DIMENSION NOX(4), NOY (4), NO(4), NOH (4)

1 ,XPLMIN (4), XPLMAX (4), FXPDFX (4), XPL (2), YPL (2)

C

2 , $\operatorname{XPDFN}(4), \operatorname{SLLX}(5), \operatorname{SLLY}(5), X X P D F N(4), X X P D F X(4)$

CHARACTER*1 XTITLE $(60,4), \operatorname{YTITLE}(60,4), \operatorname{TITL}(60,4)$

1 , REPLY

CHARACTER *60 XLABEL, HLABEL (4)

C

CHARACTER 40 INFILE (4), BLANKS

C

DIMENSION REALXL(15), REALHL $(15,4)$

C

EQUIVALENCE (REALXL, XLABEL), (REALHL, HLABEL)

C

LOGICAL CNTRPT, NSLL

c

$$
\text { BLANKS }=1
$$

IPLOT $=0$

C

2 PRINT *,' ENTER PLOTTER NOMINATION INDEX'

PRINT * $\quad 1==>$ CALCOMP'

PRINT *, $2==\Rightarrow$ HP7221T'

PRINT *', $3==>$ HP7550A'

READ $(5,65)$ IPLOTR

IF (IPLOTR.EQ.1) GO TO 1

IF (IPLOTR.EQ.2) GO TO 1

IF (IPLOTR.EQ.3) GO TO I

PRINT * ' PLOTTER NOMINATED IS NOT PERMITTED'

PRINT *' DO YOU WANT TO TRY AGAIN? (Y OR N) '

READ $(5,20)$ REPLY

IF (REPLY.EQ.' 'Y') GO TO 2

C

STOP 'PLOTTER NOMINATION INVALID'

1 NOCURV $=0$

C

C...- SPECIAL LIMIT LINES 


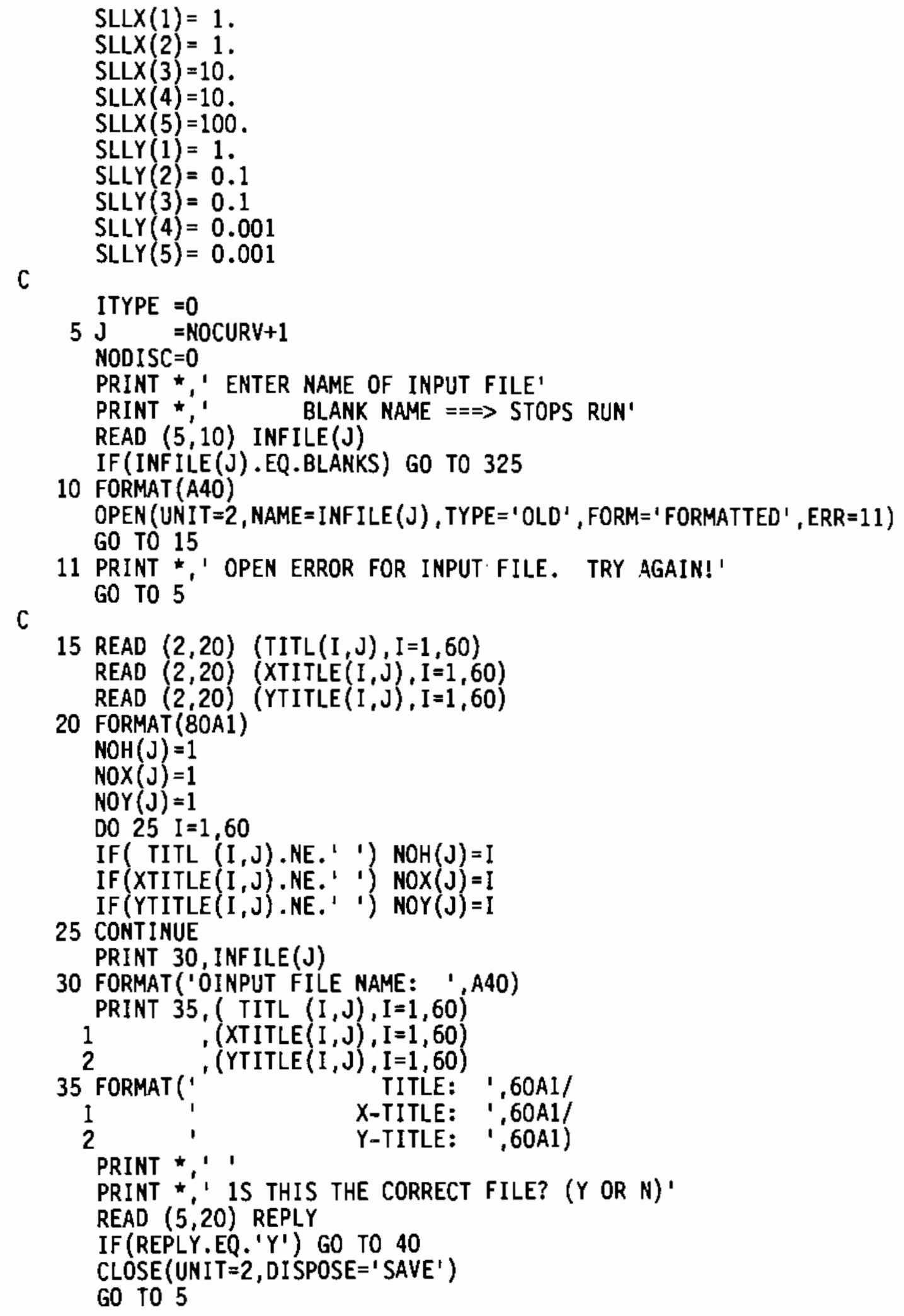


C

$40 \operatorname{READ}(2,45)$ XPLMIN $(J), X P L M A X(J)$

READ $(2,45)$ XXPDFN $(J), F X P D F N(J)$

READ $(2,45)$ XXPDFX $(J), F X P D F X(J)$

45 FORMAT (2E15.7)

NDISC $=0$

NODISC $=0$

DO $50 \quad I=1, \operatorname{MAXXY}$

$\operatorname{READ}(2,45, E N D=53) \quad X(I, J), Y(I, J)$

50 CONTINUE

IF $((X(I, J), E Q .88888$.$) .AND. (Y (I, J) . E Q .88888)$.$) GO TO 55$

C $I=M A X X Y+1$

$55 N O(J)=I-1$

IF(I.GT.1) GO TO 52

DO $54 I=1$, MAXXY

$\operatorname{READ}(2,45, E N D=53) \quad X D I, C D I$

IF ((XDI.EQ.99999.) .AND. (CDI.EQ.99999.)) GO TO 53

NDISC $=$ NDISC +1

NODISC $=$ NODISC +1

$X(I, J)=X D I$

$Y(I, J)=C D I$

54 CONTINUE

$53 \mathrm{NO}(\mathrm{J})=$ NODISC

52 CLOSE (UNIT $=2$, DISPOSE $=$ ' SAVE')

IF(NO(J).GT.1) GO TO 60

PRINT *,' NO DATA TO PLOT ON FILE NAMED: '

PRINT 56, INFILE (J)

56 FORMAT $\left({ }^{\prime}\right.$, , A40)

C

GO TO 5

60 NOCURV=NOCURV+1

IF(ITYPE.NE.0) GO TO 70

PRINT *,' ENTER 1 FOR SINGLE pdf PLOT'

PRINT *', 2 FOR MULTIPLE CCDF PLOT'

READ $(5,65)$ ITYPE

65 FORMAT (I5)

IF (ITYPE.NE.1) G0 TO 70

PRINT * ' ENTER 0 IF POINTS ARE AT CENTER OF DELTA $X^{\prime}$

PRINT *', 1 IF POINTS ARE AT LEFT END OF DELTA $x^{\prime}$

$\operatorname{READ}(5,65)$ I

CNTRPT $=$ I.EQ.D

C GO TO 200

C--- READ MORE DATA FOR MULTIPLE CCDF PLOT

C

70 IF (NOCURV.EQ.4) GO TO 200

PRINT * ' MULTIPLE CCDF PLOT: '

75 PRINT *', ARE MORE CURVES TO BE PLOTTEO? (Y OR N)' READ $(5,20)$ REPLY 


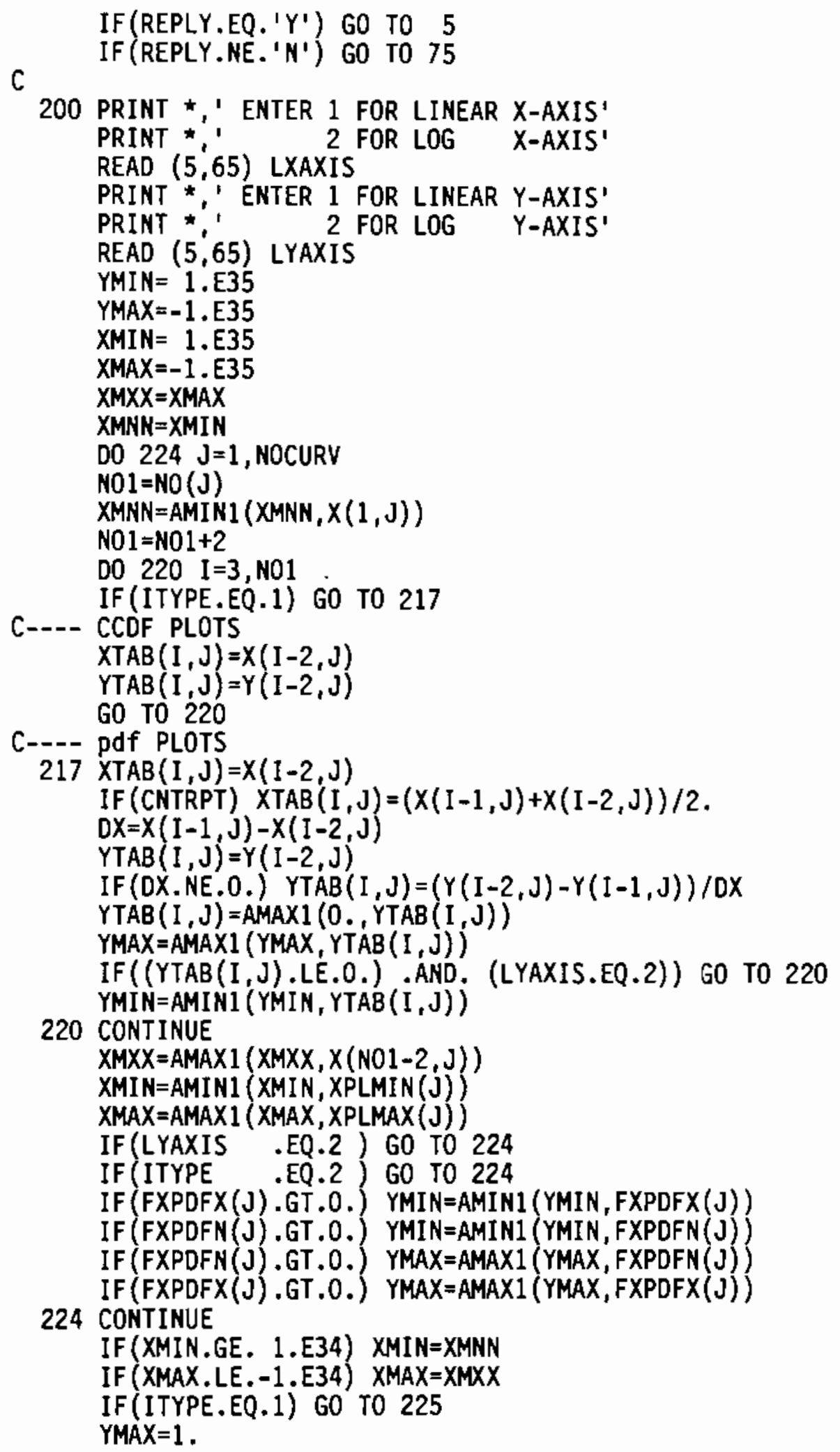

224 CONTINUE

IF (XMIN.GE. 1.E34) XMIN=XMNN IF (XMAX.LE. -1.E34) XMAX $=X M X X$ IF(ITYPE.EQ.1) GO TO 225 $Y M A X=1$. 


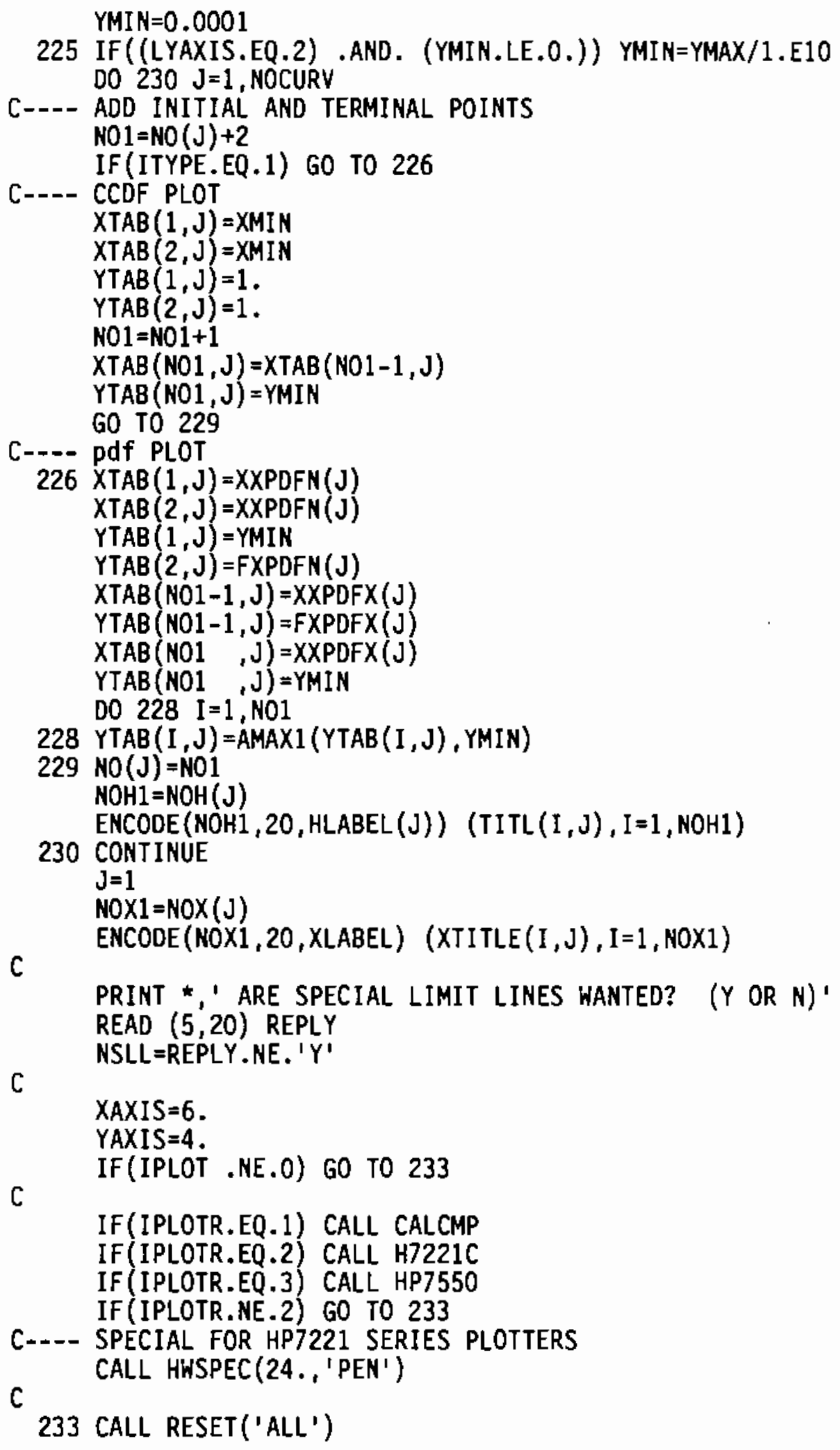




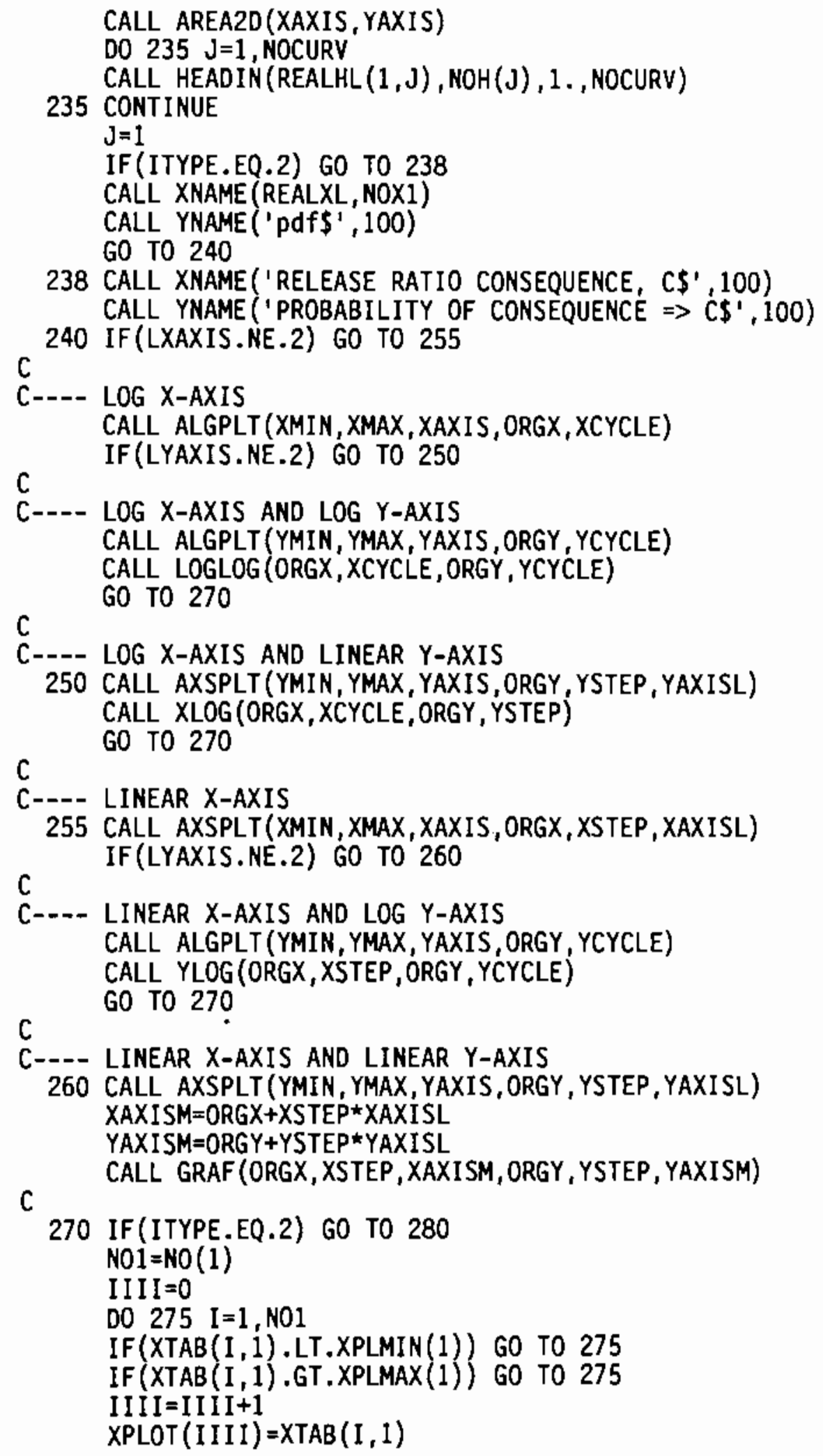




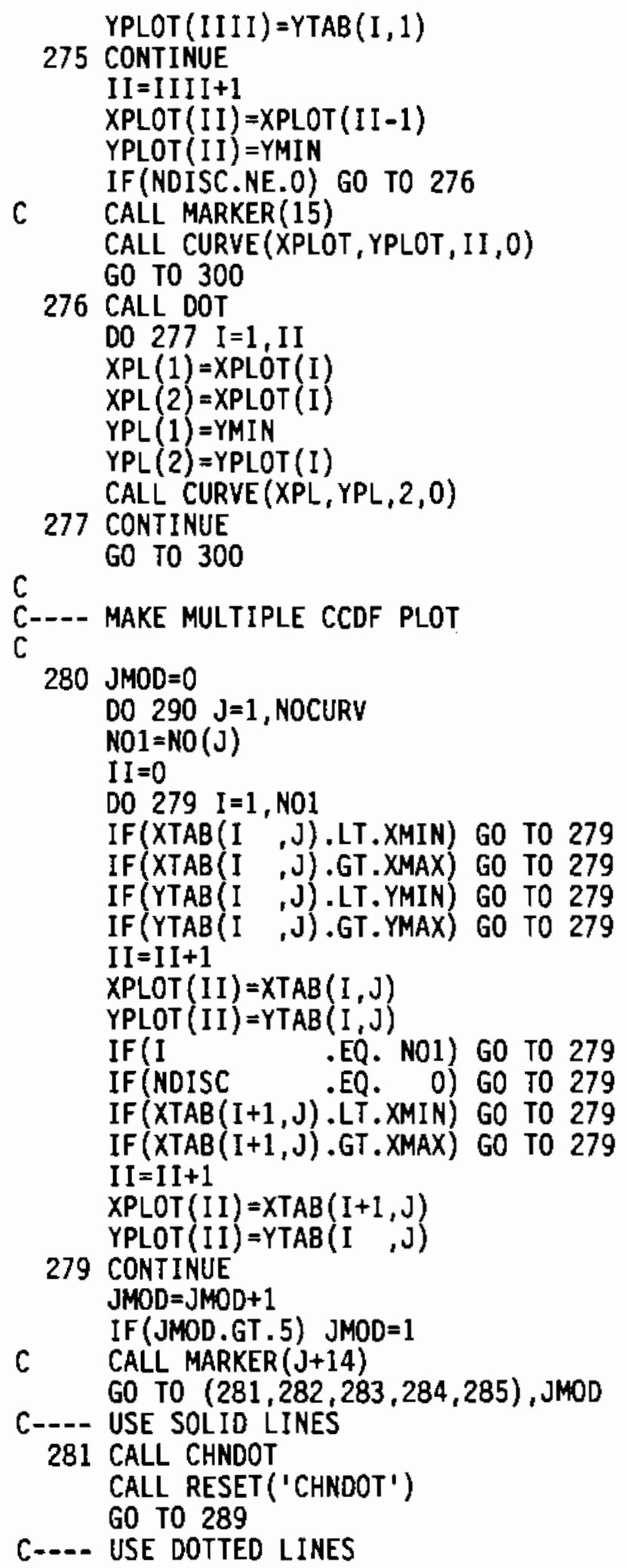




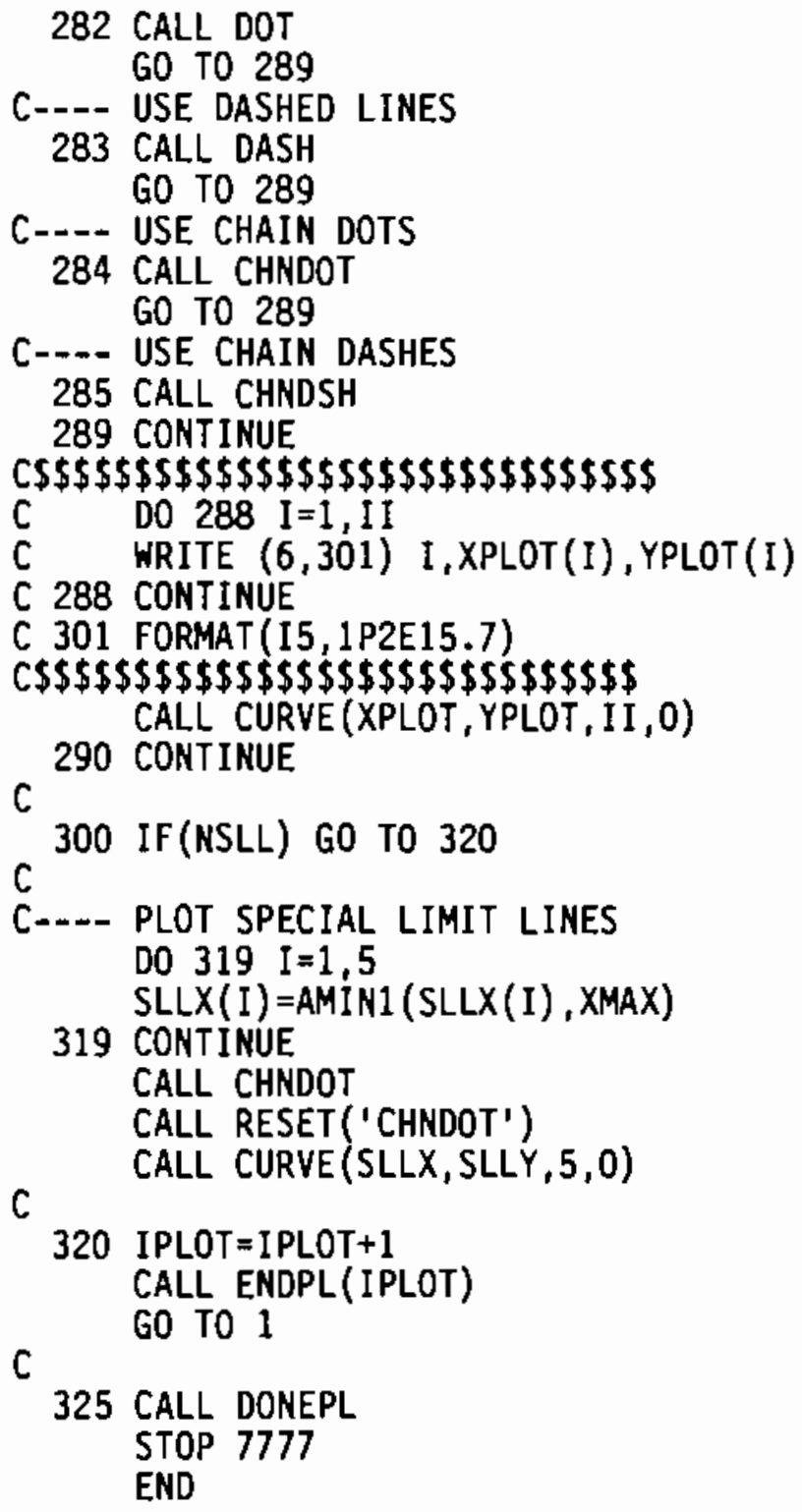


PNL -6656

UC-70

\section{DISTRIBUTION}

No. of

Copies

OFFSITE

10 DOE/Office of Scientific and Technical Information

\section{Blazek}

Oregon Dept. of Energy

102 Labor \& Industries BIdg.

Salem, OR 97310

Or. H. Brewer

Office of Nuclear Waste Management

Department of Ecology

MS; PV/11

Olympia, WA 98504
No. of

Copies

\section{ONSITE}

3 DOE Richland Operations Office

R. L. Skaggs

S. L. Stein

W. L. Templeton

Publishing Coordination (2)

Technical Report Files (5)

P. K. Clark (2)

R. E. Gerton

8 Westinghouse Hanford Company

M. R. Adams

C. Defigh-Price

C. J. Geier

M. T. Jansky

R. E. Lerch

H. E. McGuire

S. A. Wiegman

D. E. Wood

25 Pacific Northwest Laboratory

M. S. Hanson

B. A. Napier

I. C. Nelson (2)

T. H. Nguyen

M. G. Piepho (10) 
!

更

-

:

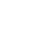

